\title{
DIAGNÓSTICO Y REMOCIÓN DE CONTAMINANTES EMERGENTES EN AGUAS SUPERFICIALES Y CLOACALES
}

\author{
Tesis de Doctorado \\ NASLY YANID DELGADO ESPINOSA \\ Presentada ante la Facultad de Ingeniería de la \\ Universidad Nacional de La Plata \\ como requisito para la obtención del grado académico de
}

\section{DOCTOR EN INGENIERÍA}

Dirección de tesis:

Director: Ing. Agustín Fernando Navarro

Director: Dr. Alberto Luis Capparelli

Co-director: Dr. Gustavo Antonio Peñuela

Jurados de tesis:

Dra: Noemi Zaritzky

Dr: Adrían Razzitte

Dr: Edgardo Contreras

Fecha de la defensa oral y pública: 14 de marzo de 2019 


\section{UNIVERSIDAD NACIONAL DE LA PLATA \\ FACULTAD DE INGENIERÍA DOCTORADO EN INGENIERÍA}

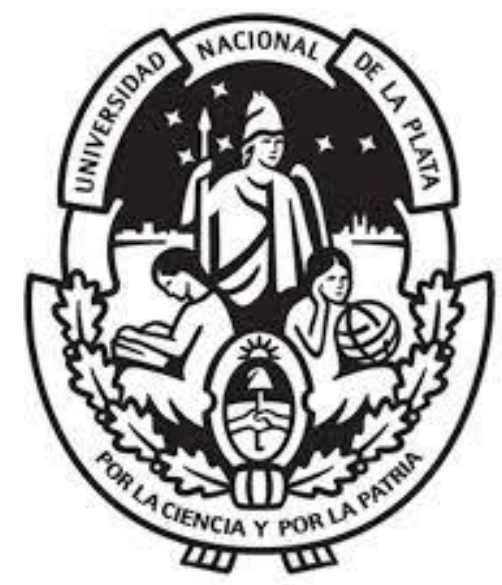

"DIAGNÓSTICO Y REMOCIÓN DE CONTAMINANTES EMERGENTES EN AGUAS SUPERFICIALES Y CLOACALES"

TESIS DOCTORAL

Presentada por:

Ing. Nasly Delgado Espinosa

Dirigida por:

Director: Ing. Agustín Fernando Navarro

Director: Dr. Alberto Luis Capparelli

Co-director: Dr. Gustavo Antonio Peñuela

La Plata, 14-marzo-2019 
El presente trabajo de tesis se desarrolló en el Centro de Investigaciones del Medio Ambiente, CIM, Departamento de Química, Facultad de Ciencias Exactas, y en el Laboratorio de Ingeniería Química, Departamento de Ingeniería Química, Facultad de Ingeniería, Universidad Nacional de La Plata, bajo la dirección del Ing. Agustín Fernando Navarro y el Prof. Dr. Alberto Luis Capparelli, y la co-dirección del Dr. Gustavo Peñuela. 


\section{AGRADECIMIENTOS}

El presente trabajo está dedicado a la memoria de la Dra. Alicia Estela Ronco, quién se desempeñó como mi directora de tesis y de beca doctoral, siendo una guía para la realización del mismo de manera activa y entusiasta, con alto compromiso y conocimiento hasta su desaparición física. Me brindó la posibilidad de cumplir con una meta tan importante en mi vida, por abrirme las puertas de su grupo de trabajo y de su vida. De igual forma agradezco al Dr. Damián Marino, mi director de beca doctoral, quien conjuntamente con la Dra. Alicia Estela Ronco, me brindaron su confianza, sin conocerme, desde un inicio y trabajaron hombro a hombro conmigo para acceder a las Becas de Doctorado Latinoamericanas otorgadas por el Conicet, y a partir de su otorgamiento me encaminaron y apoyaron hasta lograr este sueño de entrar en el mundo de la investigación.

A mis directores de doctorado Agustín Fernando Navarro y Alberto Luis Capparelli y a mi co-director Gustavo Antonio Peñuela por confiar en mí, por guiarme, por su paciencia, por estar siempre pendientes y brindarme siempre su apoyo, conocimientos y motivación durante estos años de trabajo.

Al Consejo Nacional de Investigaciones Científicas y Técnicas (CONICET) por la beca otorgada que hizo posible la realización de este trabajo de tesis doctoral.

A la Universidad Nacional de La Plata (UNLP) por facilitar el ámbito y financiamiento para el desarrollo de las actividades experimentales.

Al Centro de Investigaciones del Medio Ambiente (CIM) y al Departamento de Ingeniería Química de la UNLP, por brindarme lugar de trabajo.

En el CIM agradezco de manera especial al Licenciado Tomás MacLoughlin y a la estudiante Marianela Ramos por su acompañamiento y apoyo durante las tareas del diagnóstico en Argentina.

En la Universidad del Cauca (Colombia) agradezco de manera especial al profesor Juan Carlos Casas y a sus estudiantes Lizeth Bermeo y Daniel Alejandro López por su acompañamiento y apoyo durante mi pasantía en el grupo GCISA, realizada en el 
período 01/10/2017 - 01/04/2018 como parte de los compromisos establecidos en el plan de trabajo aprobado por el CONICET.

En la Universidad de Antioquía (Colombia) agradezco al equipo técnico del Grupo de Diagnóstico y Control de la Contaminación - GDCON por su disposición para la determinación analítica de los compuestos evaluados en este estudio durante mi pasantía en este país.

A todos mis compañeros de trabajo, los actuales y los que estuvieron, por la buena predisposición, por su acompañamiento, por las charlas y porque todos de alguna $\mathrm{u}$ otra forma colaboraron para que este trabajo fuera posible.

A mis padres, Nora y Lorenzo, y a mis hermanos Yesni, Jhon, Zuly, Norida y Fabio, por incentivarme y apoyarme a continuar con mis estudios y por estar siempre presentes, ayudándome en todo momento brindándome su amor incondicional.

A Andrés, mi novio, amigo y compañero; a su familia y a mis amigos, por su cariño y por los innumerables momentos bellos compartidos.

A todos los que de algún modo colaboraron directa o indirectamente para que pudiera concretar mi tesis doctoral. 
ESQUEMA GENERAL DE LA TESIS

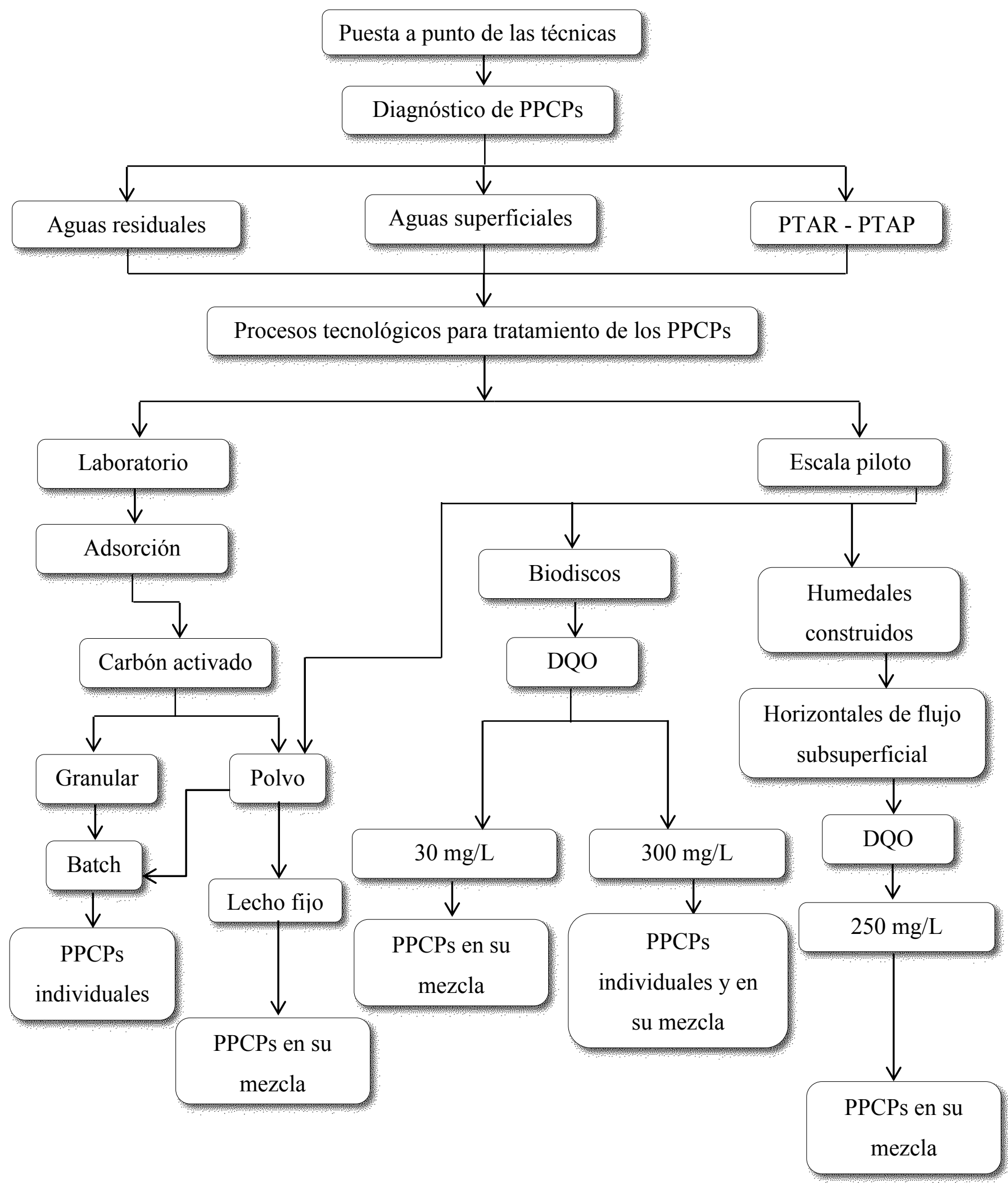




\section{RESUMEN}

Los contaminantes emergentes detectados en los cursos de aguas por actividades antrópicas son una preocupación constante para la biota acuática y la salud humana, ya que pueden provocar efectos adversos, incluso en concentraciones traza. Los tratamientos de aguas residuales actuales no son eficientes para eliminar muchos de estos compuestos; además no están regulados en ninguna normativa. Por lo tanto, en este estudio se monitorearon dos fármacos: carbamazepina (Cbz) y sildenafil (Sil), y un producto de cuidado personal: metilparabeno $(\mathrm{Mp})$, representativos de los cuerpos de agua superficiales de Argentina y Colombia. Fue evidente la presencia de los tres compuestos en los diferentes sitios muestreados, con concentraciones de Cbz, Sil y Mp entre $0,04 \mu \mathrm{g} / \mathrm{L}-11 \mu \mathrm{g} / \mathrm{L} ; 0,44 \mu \mathrm{g} / \mathrm{L}-2,64 \mu \mathrm{g} / \mathrm{L} ;$ y $0,03 \mu \mathrm{g} / \mathrm{L}-7,24 \mu \mathrm{g} / \mathrm{L}$, respectivamente. Consecuentemente, se estudiaron diferentes técnicas para remover estos contaminantes. Inicialmente se evaluaron dos tratamientos biológicos a escala piloto, los contactores biológicos rotativos (CBR) y los humedales construidos o artificiales. Con ambas tecnologías se obtuvieron eficiencias de eliminación superiores al $90 \%$ para el Mp, al igual que para la materia orgánica. El Sil presentó remociones inferiores al 10\% en los CBR, pero superiores al $90 \%$ en los humedales. La Cbz fue recalcitrante ante ambos tratamientos. Luego, como tecnologías alternativas, se estudiaron el carbón activado granular (CAG) y el carbón en polvo (CAP). En los estudios de laboratorio en batch se determinó que el CAP presentaba mayor velocidad y capacidad de adsorción que el CAG, con valores promedio de $0,21 / \mathrm{h}$ y $300 \mathrm{mg} / \mathrm{g}$, respectivamente, alcanzando remociones superiores al 90\% en menos de 8 h de contacto. Para el CAG fueron de 0,02 $1 / \mathrm{h}$ y $150 \mathrm{mg} / \mathrm{g}$, respectivamente, con remociones inferiores al $10 \%$. Se diseñó una columna en lecho fijo a escala de laboratorio con CAP, trabajando con $1 \mathrm{~g}$ del mismo a una velocidad superficial de 1,1 cm/min. Se logró remover más del $90 \%$ de Sil durante 25 días de funcionamiento en continuo, pero se alcanzó la saturación con la Cbz, determinándose remociones superiores al $50 \%$ en menos de 12 días. En la columna a escala piloto, que trabajó con $40 \mathrm{~g}$ de CAP y una velocidad de $0,4 \mathrm{~cm} / \mathrm{min}$, se obtuvieron remociones superiores al $90 \%$ para ambos fármacos durante 3 meses de operación. Éste el primer diseño reportado para columnas de lecho fijo con CAP. Se concluye que implementar y combinar tecnologías alternativas, contribuye a reducir la magnitud de los efectos adversos que provocan los CE sobre los recursos hídricos, la biota acuática y la salud humana. 


\section{TABLA DE CONTENIDO}

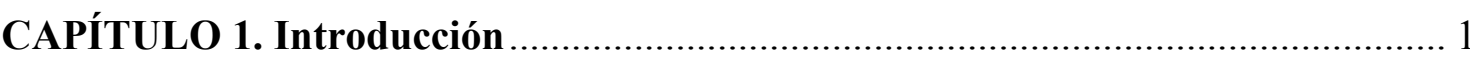

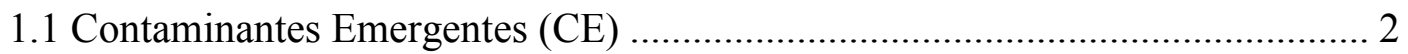

1.2 Contaminantes emergentes en las aguas residuales domésticas ....................... 4

1.3 Tecnologías para la remoción de contaminantes emergentes............................ 8

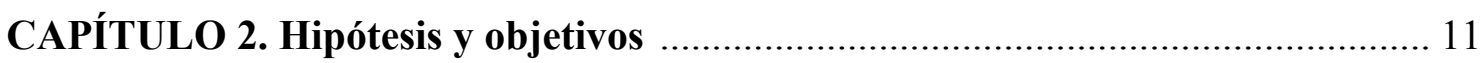

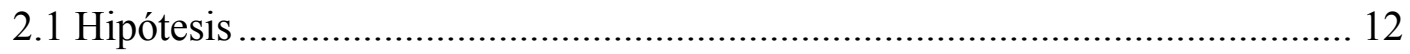

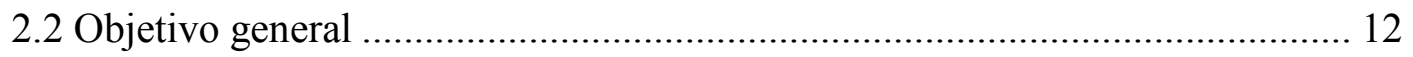

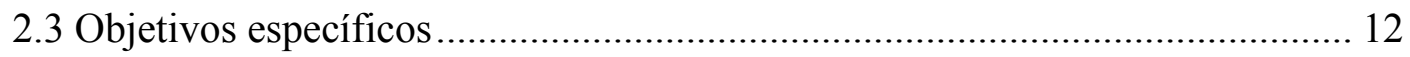

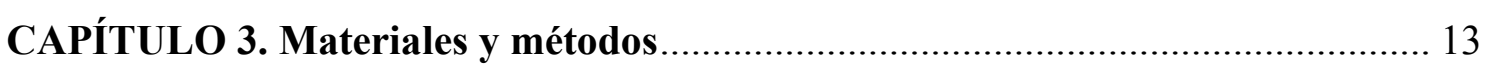

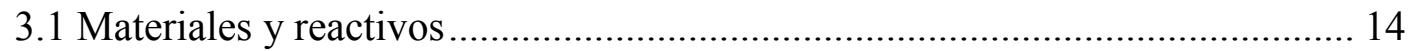

3.2 Diagnóstico de los fármacos y productos de cuidado personal ....................... 17

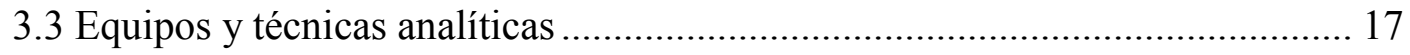

3.4 Determinación de los parámetros fisicoquímicos.......................................... 23

3.5 Diseños experimentales a escala de laboratorio y a escala piloto .................... 24

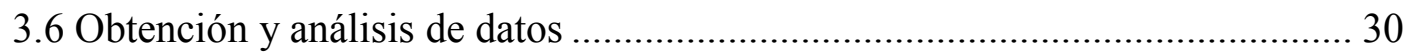

CAPÍTULO 4. Diagnóstico de contaminantes emergentes en aguas residuales y

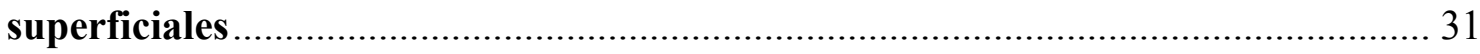

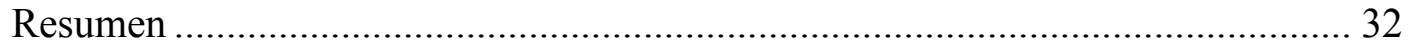

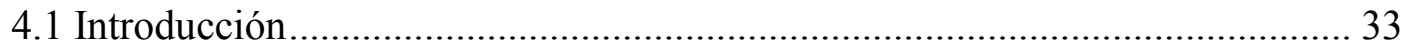

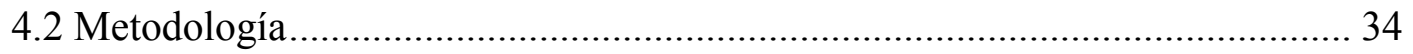

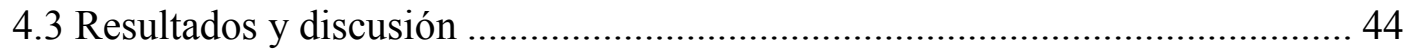

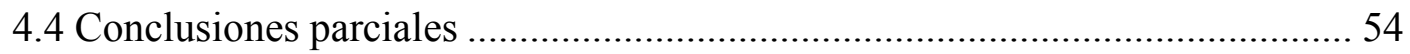

CAPÍTULO 5. Contactores biológicos rotativos para remoción de fármacos y

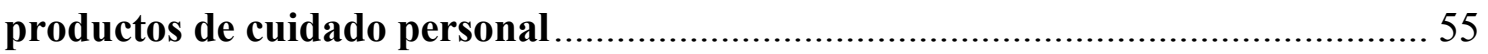

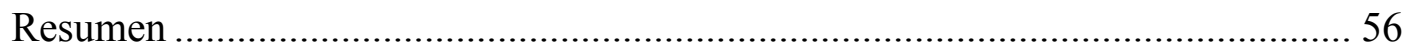

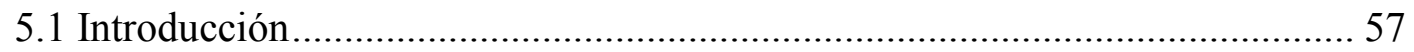

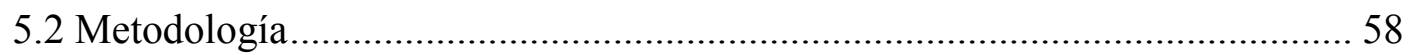

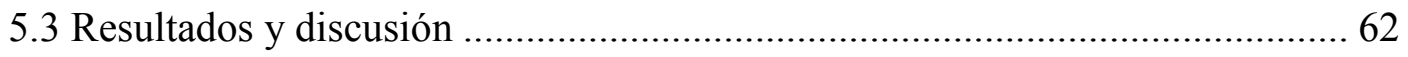


5.4 Conclusiones parciales 77

CAPÍTULO 6. Humedales construidos para remoción de fármacos y productos de cuidado personal 78

Resumen 79

6.1 Introducción 80

6.2 Metodología 81

6.3 Resultados y discusión 85

6.4 Conclusiones parciales 105

CAPÍTULO 7. Carbón activado granular para remoción de contaminantes emergentes: experimentos en batch

Resumen 108

7.1 Introducción 109

7.2 Metodología 110

7.3 Resultados y discusión 112

7.4 Conclusiones parciales 124

7.5 Anexo 126

CAPÍTULO 8. Carbón activado en polvo para remoción de compuestos farmacéuticos: experimentos en batch

Resumen

8.1 Introducción

8.2 Metodología. 134

8.3 Resultados y discusión 136

8.4 Conclusiones parciales 153

CAPÍTULO 9. Remoción de compuestos farmacéuticos en columnas con carbón activado en polvo

Resumen

9.1 Introducción

9.2 Metodología

9.3 Resultados y discusión 160

9.4 Conclusiones parciales 183 


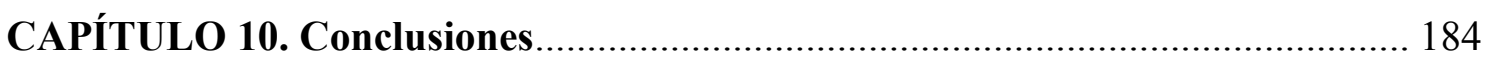

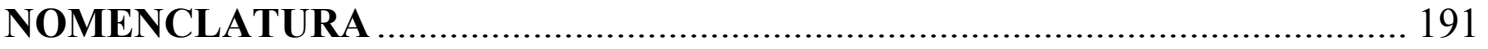

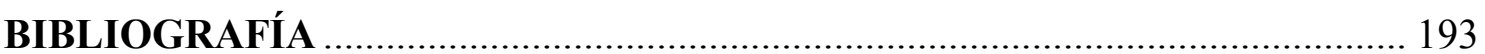




\section{CAPÍTULO 1}

\section{INTRODUCCIÓN}

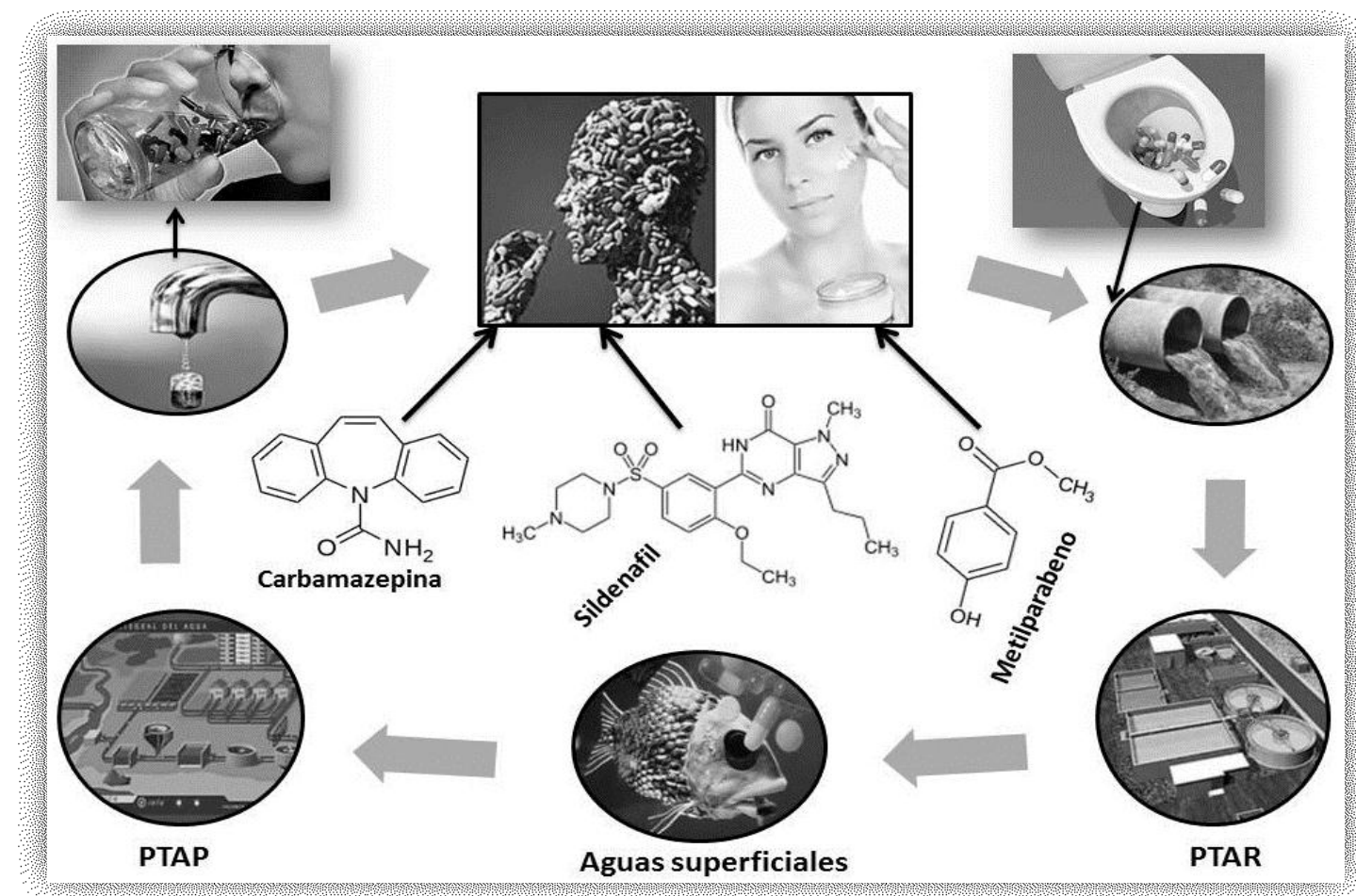




\subsection{Contaminantes Emergentes (CE)}

El agua es un recurso indispensable para los seres vivos. Sin embargo, ha sufrido un alarmante deterioro debido al vertimiento y eliminación de contaminantes de forma incontrolada. Las aguas residuales son una de las principales vías de ingreso de contaminantes en el ambiente. Durante décadas, toneladas de sustancias biológicamente activas han sido vertidas, sin reparar en las posibles consecuencias, llevando a la aparición de compuestos "no deseables" y tóxicos para los ecosistemas (Bondia, 2014; Mayorquín, 2011). Al problema de la contaminación, que comenzó a hacerse notable ya a principios del siglo XIX, cabe añadir la falta de implementación de tecnologías de tratamiento adecuadas. En América Latina el 70\% de las aguas residuales vuelven a los ríos sin ser tratadas. En países como Argentina y Colombia menos del 20\% de las aguas residuales reciben un tratamiento previo antes de su descarga (Yee-Batista, 2013). Las medidas legislativas que se han ido adoptando progresivamente para evitar la contaminación de los cuerpos de agua y los riesgos que se derivan de ello, han contribuido a atenuar parcialmente esta situación.

En las últimas décadas, gracias a las nuevas y más avanzadas técnicas analíticas, se ha alcanzado la detección de compuestos en concentraciones extremadamente bajas en matrices complejas. Muchos estudios han mostrado la presencia de una amplia gama de compuestos químicos, observados repetidamente en el medio acuoso en todo el mundo. A este conjunto de contaminantes, se los reconoce como “Contaminantes Emergentes". Este término, generalmente se utiliza para referirse a compuestos de distinto origen y naturaleza química. La característica de estos grupos de contaminantes es que no necesitan ser persistentes en el ambiente para causar efectos negativos, puesto que sus altas velocidades de transformación/remoción se pueden compensar por su introducción continua en los cuerpos de agua (Ferreira et al., 2016; Rivera-Utrilla et al., 2013). Los CE comprenden una gran cantidad de compuestos, como biocidas, productos farmacéuticos y de cuidado personal, fragancias, plastificantes, hormonas, retardantes de llama, nanopartículas, compuestos de perfluoroalquilo, parafinas cloradas, siloxanos, toxinas de algas y varios oligoelementos, incluyendo tierras raras y radio nucleídos, etc. Estos son solo algunos ejemplos de una larga lista de posibles CE. También se incluye en la lista, la síntesis de nuevos compuestos químicos o cambios en el uso y disposición de los productos 
químicos ya existentes, que se utilizan diariamente para diversos fines y que no están incluidos en el monitoreo actual de programas de tratamiento de aguas. La mayoría de estos compuestos no están regulados en muchos países, o se están sometiendo a un proceso de regularización (Desrosiers, 2014). Recientemente, amplios estudios han demostrado la presencia de contaminantes emergentes en aguas subterráneas, aguas superficiales, aguas pluviales, aguas residuales y hasta en el agua potable (Desrosiers, 2014; Mohamed and Paleologos, 2018; Stackelberg et al., 2004). Las principales fuentes de introducción de $\mathrm{CE}$ en el ambiente acuático son las plantas de tratamiento de aguas residuales urbanas e industriales, así como la descarga directa de las aguas residuales (Dimpe and Nomngongo, 2016).

Diferentes investigaciones han reportado sobre las fuentes, diagnóstico, comportamiento ambiental y destino de los contaminantes emergentes, sin embargo, se pueden generar comportamientos inesperados de estos $\mathrm{CE}$ en el medio acuático debido a sus propiedades fisicoquímicas y la complejidad de las matrices ambientales (Gavrilescu et al., 2015). En este caso, su detección y eliminación se vuelve difícil, aunque es un problema importante, ya que la presencia de los $\mathrm{CE}$ pone en riesgo la reutilización de las aguas residuales tratadas, así como la sustentabilidad del ciclo del agua.

Existen estudios que demuestran que las plantas de tratamiento de aguas residuales convencionales (PTAR) y las plantas potabilizadoras (PTAP) no están siendo eficientes para remover una gran cantidad de CE (Petrović et al., 2003; Rosal et al., 2010). Para alcanzar una solución exitosa frente al problema de los CE se deben generar enfoques altamente interdisciplinario, capaces de estudiar su comportamiento en el ambiente, así como generar estudios básicos y tecnológicos para una remoción eficiente de las aguas residuales. Su aparición en los cuerpos de agua ha sido reconocida recientemente como un área de creciente preocupación, debido a que se han relacionado con impactos ecológicos, incluso en concentraciones traza. Además, su vertimiento puede aumentar la presencia de microorganismos resistentes a este tipo de contaminantes (Haman et al., 2015; Kolpin et al., 2004; Ma et al., 2017; Xagoraraki and Kuo, 2008). 


\subsection{Contaminantes emergentes en las aguas residuales domésticas}

Las aguas residuales domésticas son una de las principales fuentes de introducción y dispersión de CE en el ambiente acuático. Los CE más comúnmente detectados en este tipo de aguas incluyen plastificantes, agentes tensioactivos, productos farmacéuticos, drogas de abuso, hormonas, compuestos para el cuidado personal y edulcorantes. Dentro de este subconjunto de contaminantes, los fármacos y productos de cuidado personal han presentado gran interés por los organismos públicos, investigadores y entes reguladores, debido a que son sustancias potencialmente activas para los organismos acuáticos, como para los seres humanos (Jung et al., 2015).

El consumo de fármacos a nivel mundial alcanza varios cientos de toneladas por año y conocer con precisión qué cantidad es la que circula en el sistema depende directamente del tipo de acceso (controlado o no controlado) que tiene la población a dichos productos. En general, las cifras de producción exactas no han sido publicadas en la literatura. Sin embargo, las cantidades de productos farmacéuticos prescritos por los médicos se pueden evaluar de multiplicar la cantidad de dosis diaria con el número de dosis diarias prescritas por año. En Alemania, por ejemplo, para el año 1998 se había prescrito hasta aproximadamente 100 toneladas de fármacos (Ternes, 1998), cifra que puede aumentar dramáticamente cuando se consideran medicamentos que se pueden comprar sin receta médica. Debido a este alto nivel de consumo y al rápido crecimiento poblacional, se pueden esperar concentraciones detectables de fármacos y sus metabolitos en las aguas residuales. Las moléculas farmacéuticas identificadas en el ambiente también pertenecen a varias clases de fármacos para humanos, como analgésicos, antibióticos, betabloqueantes, anticonvulsivos, reguladores de lípidos, agentes anticancerígenos y hormonas (Deblonde et al., 2011).

La industria farmacéutica usa la denominación de Ingredientes Farmacéuticos Activos para describir productos que son farmacológicamente activos, resistentes a la degradación, altamente persistentes en medio acuoso y potencialmente capaces de producir eventos adversos en organismos acuáticos y con un impacto negativo en la salud humana. Por lo tanto, la contaminación producida por estos compuestos en las aguas superficiales y subterráneas ha sido reconocida por muchos países como un 
problema ambiental, estableciéndose un campo de investigación conocido como Fármacos en el Ambiente.

La aparición de los fármacos en los cuerpos de agua se debe a que su metabolización en los seres humanos no siempre es completa, y por lo tanto, gran parte se excretan en distintos grados. Además, los compuestos farmacéuticos vertidos en el sanitario después de su fecha de caducidad es también una fuente importante en el aumento de su concentración en las aguas residuales (Deblonde et al., 2011). Algunos de estos compuestos pueden persistir en el ambiente por más de un año, y otros, como por ejemplo la carbamazepina, pueden persistir durante varios años y volverse biológicamente activa por acumulación (Rivera-Utrilla et al., 2013).

Otros compuestos que se vierten a los cuerpos de agua a través de las aguas residuales son los productos de cuidado personal, los cuales son lavados en los desagües domésticos después de su uso, lo que lleva a la aparición de niveles elevados de ingredientes tales como agentes antimicrobianos, fragancias sintéticas, plastificantes, agentes tensioactivos y agentes de protección solar (Hijosa-Valsero et al., 2016; Lin and Li, 2016). Estos productos se diferencian de los fármacos porque pueden ser introducidos directamente al ambiente en grandes concentraciones (Bolong et al., 2009; Petrović et al., 2003; Yang et al., 2017).

Algunos países de Europa y América del Norte han llevado a cabo una amplia investigación sobre el comportamiento, el destino y la evaluación de tecnologías alternativas para la remoción de los fármacos y productos de cuidado personal (PPCPs). Sin embargo, en América Latina, estos estudios han comenzado hace muy poco tiempo, con informes limitados (Roberts et al., 2016). Por lo tanto, teniendo en cuenta las diferencias en el clima, la hidrología, la demografía de la población y las estadísticas de uso de los PPCPs, se hace necesario recoger datos regionales, para generar información confiable y desarrollar tecnologías de tratamiento eficientes (Ma et al., 2017).

Algunos estudios en Argentina y Colombia han demostrado la presencia de los PPCPs en las aguas superficiales, entre los más comúnmente detectados se encuentran dos fármacos: carbamazepina (Cbz) y sildenafil (Sil) (Elorriaga et al., 2013a) y un producto de cuidado personal: metilparabeno (Mp) (Gracia-Lor et al., 2012). Teniendo en cuenta esta información, la presente investigación se enfoca en el estudio de 
diferentes tecnologías alternativas para remover estos tres contaminantes modelos (Cbz, Sil, Mp) de las aguas residuales domésticas.

\subsubsection{Carbamazepina (Cbz)}

La carbamazepina, descubierta a principios de la década de 1960 por W Scindler en los laboratorios Geigy en Suiza, es un importante medicamento que se usa principalmente para el tratamiento de la epilepsia, reconocida como la segunda enfermedad más frecuente del sistema central neuronal. La Cbz también se usa como una droga estabilizadora del estado de ánimo y para el tratamiento de otros trastornos cerebrales, como el comportamiento bipolar, una enfermedad grave que afecta al 1,2\% de los adultos. La prescripción anual de Cbz en Alemania es de aproximadamente 80 toneladas por año (Ternes, 1998), esta cifra aún es desconocida en los países de América Latina. Se ha demostrado que los antiepilépticos están asociados con un mayor riesgo de anomalías congénitas en los hijos de mujeres que usan el fármaco durante el embarazo lo que genera preocupación sobre la contaminación del agua potable por este compuesto (Webb et al., 2003). La ingesta de Cbz por el agua potable en Alemania se evalúa en $30 \mathrm{ng} / \mathrm{L}$ (Webb et al., 2003). La concentración máxima de Cbz informada en Canadá en el agua potable fue de $35 \mathrm{ng} / \mathrm{L}$, y de aproximadamente 258 ng/L en los Estados Unidos (Jones et al., 2007). En América Latina se desconoce este dato, pero se han reportado concentraciones entre 100-1000 ng/L en los efluentes de las aguas residuales (Zhang and Geiben, 2010).

\subsubsection{Sildenafil (Sil)}

El sildenafil, comercializado comúnmente bajo la marca Viagra, Revatio y otros, es un fármaco utilizado para tratar la disfunción eréctil y la hipertensión arterial pulmonar. El medicamento actúa suprimiendo la enzima que controla el flujo sanguíneo, permitiendo que los vasos se relajen y se ensanchen. En el caso de los atletas, el aumento del gasto cardíaco y el transporte más eficiente de sangre oxigenada a los músculos puede mejorar su resistencia. Por esa razón, se recomendó que este compuesto figure como sustancia dopante (Nieto et al., 2010). Su presencia continua en las aguas superficiales se puede deber a que la cantidad consumida de drogas estimulantes generalmente es más alta que las cantidades legalmente prescritas. En el Reino Unido se prescribieron 512 kg de sildenafil en el año 2012 (Petrie et al., 2015). En Europa se detectó contaminación de las aguas residuales con Sil, estando 
presente en el $100 \%$ de las muestras de agua analizadas en concentraciones máximas de 176 ng/L (Baker and Kasprzyk-Hordern, 2011). En aguas superficiales de Argentina se han reportado concentraciones de Sil de hasta 380ng/L(Elorriaga et al., 2013a); su presencia también ha sido detectada en los músculos de peces autóctonos del Río Uruguay a la altura de Villa Paranacito, en concentraciones de hasta $56 \mu \mathrm{g} / \mathrm{Kg}$ (Rojo, 2016).

\subsubsection{Metilparabeno (Mp)}

El metilparabeno es un químico antiséptico de uso frecuente en productos para el cuidado personal, también suele utilizarse en la industria alimentaria como aditivo conservante y como plastificante en la industria farmacéutica (Fan and Wang, 2012). Este compuesto contiene un éster metílico y un grupo hidroxilo fenólico $(\mathrm{Ph}-\mathrm{OH})$, que es estructuralmente similar al $17 \backslash$ beta-estradiol natural. Esta estructura puede ser responsable de la actividad estrogénica en el cáncer de mama, aunque estudios previos han sugerido que el Mp desempeña un papel como disruptor endocrino (Haman et al., 2015). Los primeros resultados que demuestran su presencia en el agua se publicaron en 1.996 , pero, solo a mediados de la década de 2.000 , se pudieron obtener datos concretos sobre su distribución y concentración en entornos acuáticos (Haman et al., 2015). El Mp es uno de los parabenos más abundantes en las aguas residuales, con concentraciones reportadas de hasta $20.000 \mathrm{ng} / \mathrm{L}$ (Li et al., 2015a). En tejido muscular de peces se han detectado concentraciones máximas de $3450 \mathrm{ng} / \mathrm{g}$ (Bratkowska et al., 2011). En aguas superficiales de Colombia se han detectado concentraciones máximas de 537 ng/L (Gracia-Lor et al., 2012).

Las tecnologías reparadas hasta el momento para remover CE son escasas, y la mayoría de los estudios evaluados se llevn a cabo a escala de laboratorio (Gavrilescu et al., 2015; Mashayekh-Salehi and Moussavi, 2016; Tejeda et al., 2017). Por lo tanto, se hace necesario investigar procesos alternativos, tanto a escala de laboratorio como a escala piloto, capaces de remover compuestos químicos como la Cbz, el Sil y el Mp, con el fin de eliminar los $\mathrm{CE}$ en la fuente y evitar efectos negativos sobre la biota acuática. 


\subsection{Tecnologías para la remoción de contaminantes emergentes}

La recuperación de las aguas residuales municipales es una solución prometedora para superar la presión creciente sobre los recursos hídricos, pero también puede tener un riesgo potencial para la salud, debido a los efectos tóxicos que pueden generar los CE, si no se realizan tratamientos adecuados (Rodriguez et al., 2016). Las principales prioridades para el tratamiento de las aguas residuales son la calidad del efluente, el costo y la eficiencia energética (Hassard et al., 2015). Las plantas de tratamiento actuales están diseñadas para eliminar la materia orgánica y ciertos tipos de contaminantes, especialmente los que se especifican en las normas oficiales. Sin embargo, para la remoción de CE se requiere de tratamientos avanzados para una incorporación segura de las aguas residuales al ambiente. Se han estudiado varias opciones que incluyen sistemas con tratamientos físico-químicos, procesos de oxidación avanzada, procesos biológicos, tratamientos combinados, etc. Los procesos de radiación UV o de cloración generalmente se utilizan con fines de desinfección en los sistemas de tratamiento, aunque en las últimas décadas se los está considerando como una técnica posible para la remoción de los CE (Abdel, 2013; Desrosiers, 2014; Li et al., 2015c). Sin embargo, investigaciones han demostrado que éstas técnicas pueden generar subproductos a partir de la interacción de los reactivos con los compuestos objetivo, cuya toxicidad residual puede resultar mayor que los compuestos originales (Desrosiers, 2014). Por ejemplo, en la oxidación con cloro y la radiación UV de la Cbz se ha detectado la acridina como subproducto, un compuesto que es más tóxico que la propia $\mathrm{Cbz}$ (Gauthier, 2008).

Por su parte, la biorremediación se ha considerado como una tecnología atractiva, que da como resultado la transformación completa de compuestos orgánicos a productos finales inocuos como el $\mathrm{CO}_{2} \mathrm{y}$ el $\mathrm{H}_{2} \mathrm{O}$. Además, se considera un medio económico y respetuoso con el ambiente (Ferreira et al., 2016; Vasiliadou et al., 2014). Dentro de estas tecnologías, los procesos biológicos simples, como los humedales artificiales o los contactores biológicos rotativos (biodiscos), requieren ser investigados para evaluar su eficiencia en la remoción de PPCPs por su potencial eliminación a bajo costo. Así mismo, los procesos de adsorción resultan prometedores a la hora de eliminar CE. 


\subsubsection{Contactores biológicos rotativos (CBR)}

Los CBR, conocidos comúnmente como "Biodiscos", se instalaron por primera vez en Alemania Occidental en la década de 1960 y luego se introdujeron en otros países como el Reino Unido y los Estados Unidos de América. En el año 2003 se investigaron algunos aspectos en el diseño de los CBR (Patwardhan, 2003), y solo hasta el año 2008 se destacaron algunos parámetros del proceso relacionados con su eficiencia de remoción (Cortez et al., 2008). Su uso se ha extendido principalmente para el tratamiento de la materia orgánica disuelta o coloidal, y más recientemente para la investigación en áreas tales como la eliminación mejorada de fósforo biológico y la desnitrificación (Cabije et al., 2009), la creciente evidencia sugiere que los consorcios bacterianos desarrollados en los RBC pueden ofrecer soluciones atractivas para la eliminación de contaminantes específicos, como ciertas moléculas aromáticas, incluidos hidrocarburos, metales pesados, productos farmacéuticos y de cuidado personal (Hassard et al., 2015). Su eficiencia para remover PPCPs no ha sido muy estudiada, por lo tanto realizar investigaciones para evaluar su eficiencia de eliminación de los $\mathrm{CE}$, resultan de gran interés para entender el funcionamiento a más profundidad y los potenciales beneficios que esta tecnología puede ofrecer en el tratamiento de las aguas residuales.

\subsubsection{Humedales construidos (artificiales)}

Los humedales artificiales son sistemas que han sido diseñados y construidos para embalsar el agua o los biosólidos bajo diferentes condiciones operativas, y que aprovechan distintos procesos naturales asociados a la vegetación, suelos y los consorcios microbianos. Comúnmente se los usa para tratar la materia orgánica, los nutrientes, vertidos líquidos industriales, estabilización de biosólidos e infiltraciones agrícolas y forestales de tipo difusas, entre otras (Scholz and Lee, 2005; Sundaravadivel and Vigneswaran, 2001). Los humedales fueron desarrollados en Europa hace aproximadamente veinte años, donde siguen operando con éxito (Cooper, 1999).

Estos sistemas son un tratamiento alternativo al que pueden ser sometidos los contaminantes emergentes, que pueden permitir su remoción por efecto de la biodegradación y de la absorción en las plantas (Li et al., 2014). En estudios recientes se han encontrado eficiencias de remoción inferiores al 20\% para Cbz (Tejeda et al., 
2017); mientras que contaminantes emergentes como el Sil y el Mp aún no han sido estudiados. Esta tecnología ha sido poco implementada en América Latina, además resulta interesante conocer el funcionamiento de estos sistemas con plantas típicas de las zonas de estudio, de igual forma, evaluar su eficiencia de remoción cuando se tienen policultivos, los cuales pueden generar una comunidad diversa de microorganismos, que pueden favorecer la eficiencia de remoción de los PPCPs.

\subsubsection{Tecnologías de adsorción}

La adsorción es un proceso de transferencia de masa, en el cual un compuesto en fase líquida o gaseosa es retenido en una superficie. $\mathrm{Su}$ uso, con madera carbonizada, para limpiar el agua data a aproximadamente $2000 \mathrm{aC}$ (Scholz, 2006). Se han estudiado varios materiales adsorbentes para la remoción de contaminantes orgánicos, sin embargo, el carbón activado presenta la mayor atención entre los investigadores (Álvarez-Torrellas, 2017; Rivera-Utrilla et al., 2013).

Diversos estudios han evaluado su eficiencia para remover CE mediante ensayos en batch en laboratorio, alcanzando remociones de hasta el $50 \%$ con carbón activado granular (Bellver et al., 2017; Mashayekh-Salehi and Moussavi, 2016). Aunque en algunos estudios sugieren que el CAP puede presentar un mayor potencial en la remoción de estos contaminantes, y que se pueden alcanzar eficiencias de hasta un 90\% (Schäfer et al., 2003). Sin embargo, el carbón activado en polvo no ha sido muy utilizado para el tratamiento de aguas residuales debido a la complejidad que presenta en su manejo.

Son muchos los estudios que investigan la parte básica de la adsorción de los PPCPs sobre diferentes materiales, pero su potencial utilización a escala industrial aún no se ha aplicado debido a que faltan datos confiables, la influencia de las variables operativas, parámetros relacionados con la cinética de adsorción y los problemas de diseño del reactor (Bellver et al., 2017; Rivera-Utrilla et al., 2013). 


\section{CAPÍTULO 2}

\section{HIPÓTESIS Y OBJETIVOS}

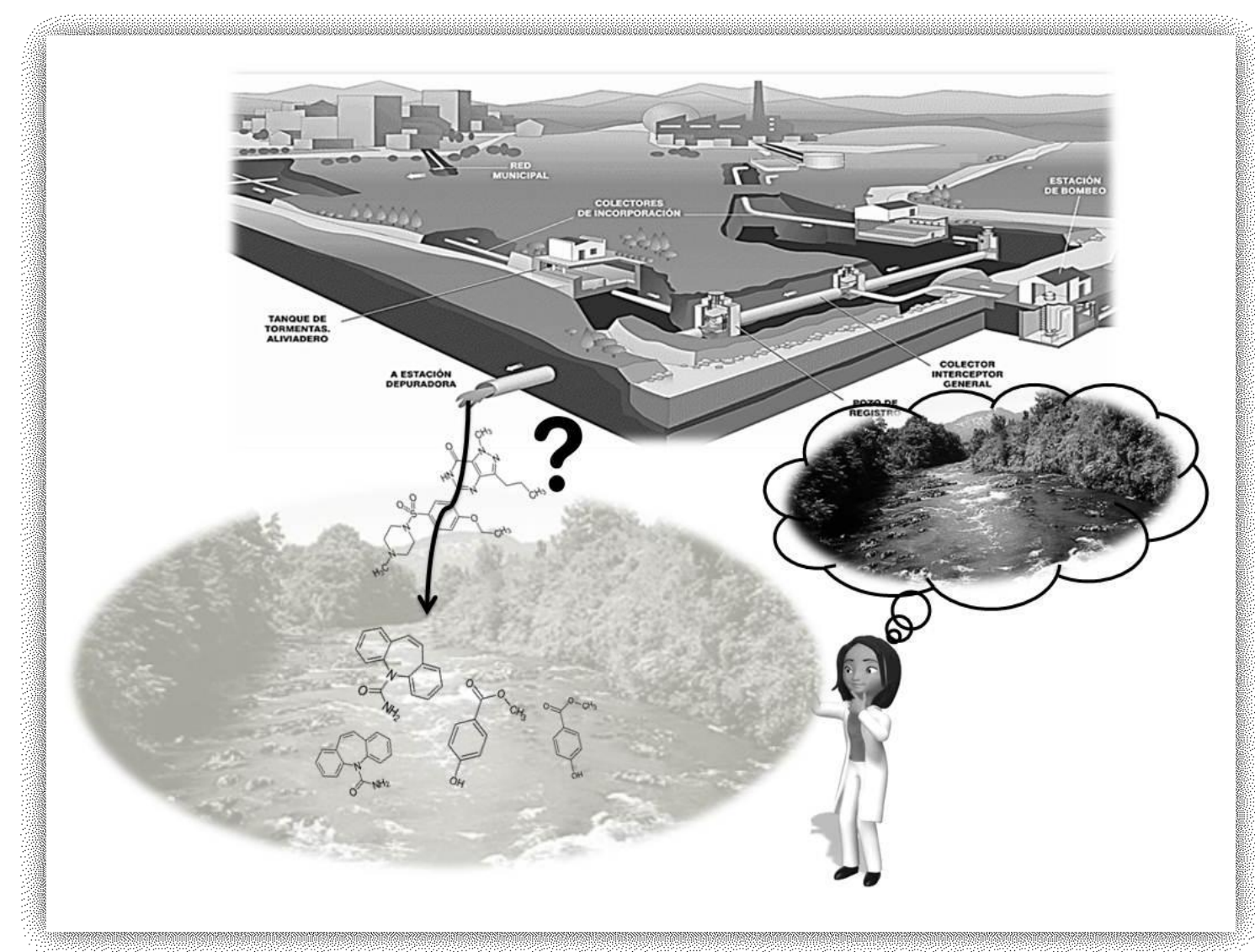




\subsection{Hipótesis}

Teniendo en cuenta la escala del problema ambiental en Argentina y en Colombia, las escasas tecnologías estudiadas e instaladas para la remoción de contaminantes emergentes de origen farmacéutico y de cuidado personal, se propone como hipótesis que los métodos alternativos de tratamientos, como procesos biológicos y fisicoquímicos, permiten alcanzar mejores eficiencias de remoción de los PPCPs en las aguas residuales, generando herramientas de intervención en la mejora de la calidad de agua.

\subsection{Objetivo general}

Evaluar la eficiencia y potencialidad de algunos tratamientos fisicoquímicos y biológicos en la remoción de contaminantes emergentes en aguas residuales domésticas en sitios de interés de Argentina y Colombia.

\subsection{Objetivos específicos}

Determinar los niveles de concentración de contaminantes emergentes (compuestos representativos de origen farmacéutico y productos de higiene personal) presentes en aguas superficiales y residuales en las zonas de estudio.

> Analizar y comparar la eficiencia de remoción por diferentes métodos alternativos de tratamiento a escala de laboratorio y piloto de un grupo representativo de contaminantes emergentes detectados en aguas residuales de Argentina y Colombia.

Seleccionar las tecnologías más adecuadas para el propósito de remoción de estos contaminantes y estudiar alternativas para su potencial aplicación a escala real. 


\section{CAPÍTULO 3}

\section{MATERIALES Y MÉTODOS}

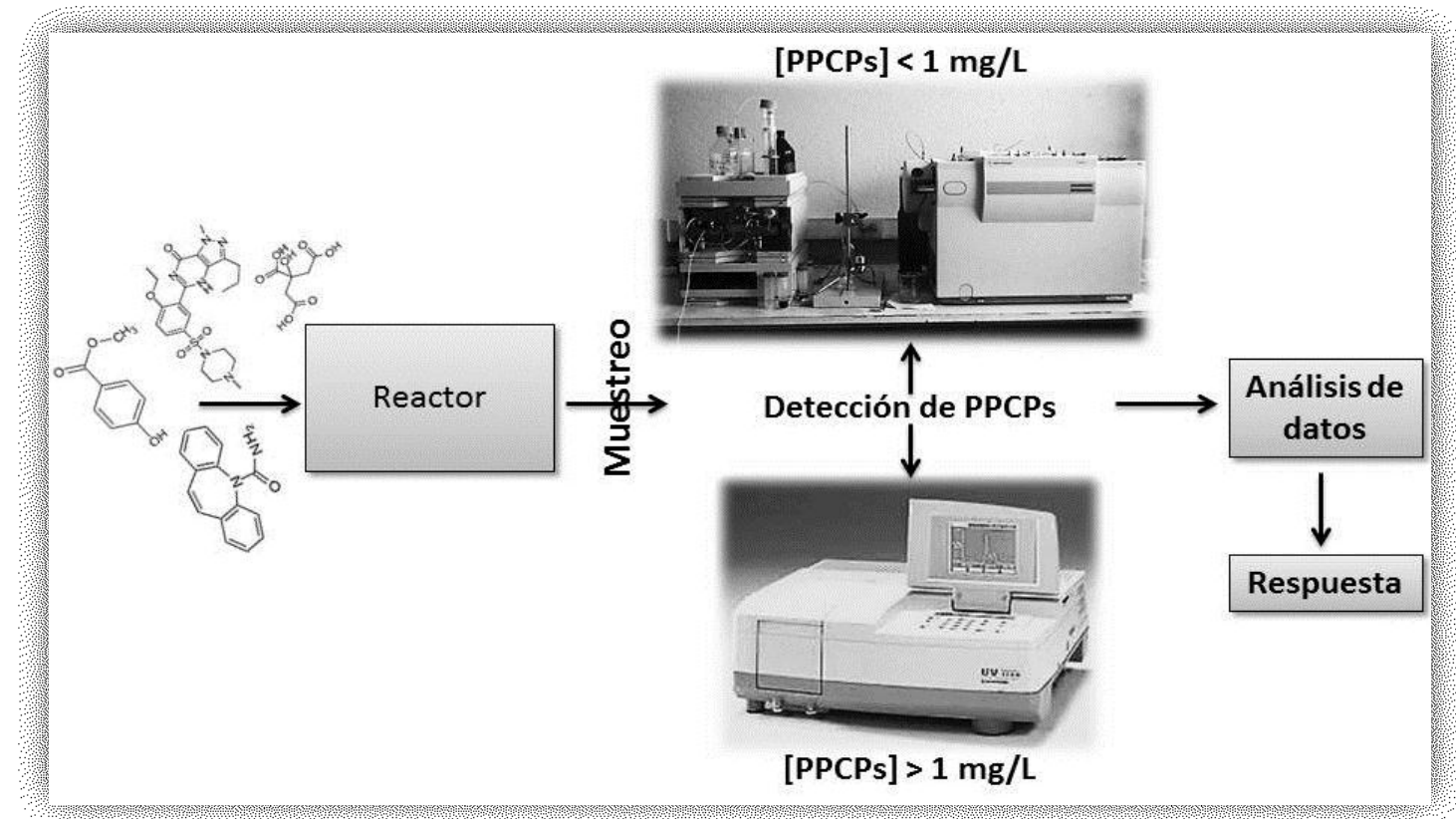


Por sus objetivos generales, de carácter interdisciplinario, este trabajo se realizó en el ámbito de la Universidad Nacional de La Plata (UNLP- Argentina), y colaboraciones de la Universidad de Antioquia (U de A - Colombia) y de la Universidad del Cauca (Unicauca - Colombia). Los aspectos generales de las actividades encaradas en las distintas instituciones se describen a continuación.

El desarrollo del trabajo experimental y analítico de la presente tesis se realizó en las instalaciones del Centro de Investigaciones del Medio Ambiente (CIM), de la Facultad de Ciencias Exactas, y en el Departamento de Ingeniería Química, de la Facultad de Ingeniería de la UNLP. El CIM, mediante el proyecto PICT 2014-0919 " Flujo de nutrientes, distribución de contaminantes, impactos ambientales de actividades productivas y alternativas de mitigación en el sistema de humedales del Delta del Paraná -Delta Entrerriano-" suministró la infraestructura, servicios, materiales y equipamientos necesarios para el diagnóstico, la cuantificación, la determinación analítica y los estudios bases para evaluación de los contaminantes emergentes; y para la caracterización fisicoquímica del agua a tratar. El departamento de Ingeniería Química facilitó el acceso a la infraestructura, servicios y materiales necesarios para el desarrollo de las pruebas de remoción de contaminantes emergentes en sistemas a escala piloto. Tanto en el CIM como en el Departamento de Ingeniería Química se realizaron los estudios concernientes a las tecnologías de adsorción y la evaluación de contactores biológicos rotativos.

En el marco de una beca Latinoamericana de CONICET, con compromiso del país colaborador de realizar allí tareas experimentales, en el Grupo de Diagnóstico y Control de la Contaminación (GDCON-UdeA) y el Grupo de Ciencia e Ingeniería en Sistemas Ambientales (GCISA-Unicauca) se realizó una pasantía por seis meses, en donde se puso a nuestra disposición todos los elementos técnicos, de infraestructura y experiencia local para evaluar el diagnóstico de contaminantes emergentes en aguas superficiales y residuales en este país, y para estudiar su eficiencia de remoción en humedales construidos a escala piloto.

\subsection{Materiales y reactivos}

Se utilizó material de vidrio borosilicato (matraces, vasos de precipitado, pipetas, balones aforados), pipetas automáticas de P10, P100 y P1000, planchas de agitación, sonicadores, centrifugas, vortex, balanzas granatarias y analíticas. 
Los solventes utilizados para el análisis por HPLC-MS fueron: ácido fórmico 88\% pro-análisis (Cicarelli Laboratorios), metanol calidad HPLC (J.T. Baker), acetonitrilo calidad HPLC (J.T. Baker) y agua nano pura, de generación propia.

Los reactivos utilizados para la determinación de la DQO fueron: biftalato de potasio, sulfato de plata, sulfato de mercurio, dicromato de potasio y ácido sulfúrico, grado analítico.

\subsubsection{Fármacos y productos de cuidado personal}

Los compuestos químicos seleccionados como contaminantes emergentes fueron dos fármacos: carbamazepina y sildenafil, y un producto de cuidado personal: metilparabeno, de calidad farmacopea (Parafarm de droguería Saporiti Argentina). Estos compuestos fueron elegidos como contaminantes modelo debido a su presencia en muestras de efluentes cloacales y/o aguas superficiales de Argentina y Colombia (Elorriaga et al., 2013a; Gracia-Lor et al., 2012), y a su amplia prescripción en los países de estudio. Se prepararon soluciones stock de $10 \mathrm{mg} / \mathrm{L}$ en agua destilada; y en metanol de $1.000 \mathrm{mg} / \mathrm{L}$ y $5.000 \mathrm{mg} / \mathrm{L}$ para experimentos de calibración y dilución. En la Tabla 3.1 se muestran las principales características fisicoquímicas de los tres compuestos evaluados.

\subsubsection{Agua residual sintética}

Teniendo en cuanta que una de las principales fuentes de contaminación del ambiente acuático con compuestos farmacéuticos y de cuidado personal (PPCPs) son las aguas residuales domésticas, se preparó un agua residual sintética cuyas características respetan las modificaciones de la Norma ISO 11733 indicadas en la Tabla 3.2 (Ho and Sung, 2010). La misma se preparó en agua declorinada mediante la adición de los reactivos que se muestran en dicha Tabla para obtener una carga orgánica de aproximadamente $200 \mathrm{mg} / \mathrm{L}$. Con el fin de lograr una solución homogénea, cada reactivo fue disuelto de forma individual en aproximadamente 100 $\mathrm{mL}$ de agua declorinada antes de ser mezclados en el volumen final de trabajo. Esta solución acuosa se agitó vigorosamente antes de alimentar los sistemas de tratamiento. 
Tabla 3.1 Propiedades fisicoquímicas contaminantes emergentes seleccionados.

\begin{tabular}{|c|c|c|c|}
\hline Propiedades* & Carbamazepina & Sildenafil & Metilparabeno \\
\hline \multicolumn{4}{|l|}{ Estructura molecular } \\
\hline Estructura química & $\mathrm{C} 15 \mathrm{H} 12 \mathrm{~N} 2 \mathrm{O}$ & $\mathrm{C} 28 \mathrm{H} 38 \mathrm{~N} 6 \mathrm{O} 11 \mathrm{~S}$ & $\mathrm{C} 8 \mathrm{H} 8 \mathrm{O} 3$ \\
\hline Número CAS & $298-46-4$ & 171599-3-0 & $99-76-3$ \\
\hline Peso molar (g/mol) & 236,09 & 666,70 & 152,05 \\
\hline $\mathrm{Ws}(\mathrm{mg} / \mathrm{L})$ a $25^{\circ} \mathrm{C}$ & 18 & 3.500 & 2.500 \\
\hline $\mathrm{pKa}$ & $<2,3 ;>13.9$ & $4 ; 5,5 ; 8,8$ & 8,4 \\
\hline $\log K_{\text {ow }}$ & 2,45 & 2,75 & 1,96 \\
\hline $\log \mathrm{K}_{\mathrm{oc}}$ & 2,7 & 3,5 & 2,4 \\
\hline $\mathrm{H}(\mathrm{atm} \mathrm{m} / \mathrm{mol})$ & $1,08 \times 10^{-7}$ & $7,2 \times 10^{-21}$ & $2,23 \times 10^{-9}$ \\
\hline \multicolumn{4}{|c|}{ Cálculos con el programa Hiperchem } \\
\hline$\overline{\log \mathrm{K}_{\mathrm{ow}}}$ & 1,95 & 0,78 & 1,49 \\
\hline Área superficial $\left(\AA^{2}\right)$ & 300,13 & 694,53 & 313,16 \\
\hline Volumen de la molécula $\left(\AA^{3}\right)$ & 686,2 & $1.303,37$ & 488,48 \\
\hline
\end{tabular}

*Abreviaciones: CAS, Número de registro del Chemical Abstracts Service; Ws, solubilidad en agua; $\mathrm{pKa}$, logaritmo negativo de la constante de ionización de un ácido; $\log \mathrm{K}_{\mathrm{ow}}$, coeficiente de reparto octanol-agua; $\log \mathrm{K}_{\mathrm{oc}}$, coeficiente de reparto agua-carbono orgánico del suelo; $\mathrm{H}$, constante de Henry.

Los valores de las propiedades fisicoquímicas se tomaron principalmente de la base de datos del National Center for Biotechnology Information. PubChem Compound Database; CID=7456, https://pubchem.ncbi.nlm.nih.gov/compound/7456 (accessed Mar. 4, 2018).

Tabla 3.2 Componentes del agua residual sintética según la ISO 11733 modificada

\begin{tabular}{lc}
\hline Compuesto & Cantidad $(\mathrm{mg} / \mathrm{L})$ \\
\hline Leche en polvo sin grasa & 135 \\
Almidón soluble & 65 \\
Acetato de sodio & 40 \\
Extracto de levadura & 10 \\
Cloruro de amonio & 38 \\
Urea & 21,5 \\
Fosfato de potasio monobásico & 22 \\
\hline
\end{tabular}




\subsection{Diagnóstico de los fármacos y productos de cuidado personal}

Para el análisis de los PPCPs se seleccionaron sitios de recolección de aguas superficiales y cloacales en Argentina y en Colombia. Las áreas estudiadas en Argentina incluyeron zonas urbanizadas de la región pampeana (Provincias de Buenos Aires y Entre Ríos); y en Colombia se estudiaron cuerpos de agua de los departamentos del Cauca y del Valle del Cauca. Además se evaluaron los afluentes y efluentes de una planta potabilizadora (Puerto Mallarino) y de una planta de tratamiento de aguas residuales (Cañaveralejo).

\subsection{Equipos y técnicas analíticas}

\subsubsection{Extracción de fase sólida (SPE)}

Los análisis químicos para la detección de los PPCPs en matrices ambientales se realizaron principalmente sobre la fracción soluble, para ello las muestras de agua se filtraron por membranas de nylon de $47 \mathrm{~mm}$ de diámetro y 0,45 micrómetros de tamaño de poro, se adicionaron con $\mathrm{NaN}_{3}$ al $0,01 \%$ e inmediatamente llevadas al laboratorio, donde se mantuvieron a $4^{\circ} \mathrm{C}$ para su análisis dentro de las siguientes 24 horas. La extracción en fase sólida (SPE) se llevó a cabo usando cartuchos de C18, marca Waters ${ }^{\circledR}$ tipo Oasis HLB, los cuales se acondicionaron con $5 \mathrm{~mL}$ de metanol y $5 \mathrm{~mL}$ de agua nanopura. El mismo volumen de muestra se diluyó en agua nanopura (100 mL) y dicha solución fue circulada por los cartuchos SPE, lavando posteriormente con $5 \mathrm{~mL}$ de agua nanopura, y pasaje de aire por $30 \mathrm{~min}$ hasta sequedad. Luego los compuestos de interés se desorbieron con $5 \mathrm{~mL}$ metanol, este procedimiento fue tomado de Elorriaga et al., (2013a). Los extractos se llevaron a sequedad bajo corriente de nitrógeno y se resuspendieron en $0,50 \mathrm{ml}$ metanol/agua nanopura (1:1). Las cuantificaciones de los compuestos seleccionados, en las muestras ambientales y de ensayos, se analizaron utilizando un HPLC-MS equipado con una fuente de ionización electrospray (ESI), apernando en modo positivo, para ello se utilizó nitrógeno para nebulización de la muestra y también como gas de colisión. En conjunto con las muestras se evaluaron mediante el método de sobreagregado a campo, y sobre extractos de laboratorio, los efectos matriz y de recuperación de los compuestos estudiados, permitiendo obtener resultados confiables (Taylor, 2005). 
Los filtros que contenían el material particulado se evaluaron para determinar la concentración de la Cbz y el Mp sobre el material en suspensión. Para determinar su concentración sobre el sedimento se tomaron muestras compuestas de los primeros 5 cm del fondo de cada cuerpo de agua muestreado, dada su baja profundidad. El procedimiento analítico para estas matrices se explica en detalle en el trabajo realizado por Ramos, 2018.

\subsubsection{Extracción de los PPCPs del material vegetal}

La determinación de los fármacos en el material vegetal (Capítulo 5) se realizó mediante la técnica validada por el Grupo de Diagnóstico y Control de la Contaminación (GDCON) de la Universidad de Antioquía - Colombia. Para ello se trituró y se homogenizó cada planta muestreada por separado. Se pesaron $2 \mathrm{~g}$ de muestra homogeneizada colocadas en un tubo de polipropileno de $50 \mathrm{~mL}$. A continuación, se añadieron $15 \mathrm{~mL}$ de ácido acético al $1 \%(\mathrm{v} / \mathrm{v})$ en acetonitrilo junto con 6 g de $\mathrm{MgSO}_{4}$ anhidro y 1,5 g de acetato de sodio anhidro. Los tubos cerrados se agitaron manualmente durante 1 minuto y se centrifugaron durante $5 \mathrm{~min}$ a $5.000 \mathrm{rpm}$. Se transfirió $1 \mathrm{~mL}$ de sobrenadante a un tubo de polipropileno de $2 \mathrm{~mL}$ que contenía $150 \mathrm{mg}$ de $\mathrm{MgSO} 4-$ anhidro, $50 \mathrm{mg}$ de amina primaria-secundaria y $50 \mathrm{mg}$ de negro de carbón grafitado para la limpieza. El extracto se agitó manualmente durante 1 minuto y se centrifugó durante 5 minutos a $5.000 \mathrm{rpm}$. Se transfirió una alícuota del extracto $(\approx 0,5 \mathrm{~mL})$ a viales, se secó bajo corriente de nitrógeno y finalmente se resuspendió en el mismo volumen de n-hexano.

\subsubsection{Determinación de los PPCPs}

Para la detección de los PPCPs en aguas superficiales y residuales, y para evaluar la capacidad de su remoción mediante diferentes tratamientos, que comprenden en este estudio procesos biológicos: como humedales construidos y contactores biológicos rotativos, y procesos físico-químicos: como sistemas de adsorción sobre carbón activado, se utilizaron dos técnicas analíticas principales: cromatografía líquida acoplada a masas y espectrofotometría ultravioleta-visible. 


\subsubsection{Espectrofotometría ultravioleta-visible}

Para el monitoreo de los PPCPs en concentraciones iniciales mayores a $1 \mathrm{mg} / \mathrm{L}$ y cuando se encontraban de forma individual en las soluciones acuosas, se utilizó un espectrofotómetro UV/Vis marca Shimadzu 1203. Las longitudes de onda de trabajo fueron $285 \mathrm{~nm}$ para Cbz, $291 \mathrm{~nm}$ para Sil y $256 \mathrm{~nm}$ para Mp. Los límites de cuantificación y detección para Cbz, Sil y Mp fueron: 200, 500 y $100 \mu \mathrm{g} / \mathrm{L}$, y 60, 150 y $30 \mu \mathrm{g} / \mathrm{L}$, respectivamente. Teniendo en cuenta que las concentraciones de trabajo alcanzaron los $40 \mathrm{mg} / \mathrm{L}$, fue necesario realizar diluciones de las soluciones remanentes, ya que la sensibilidad de absorbancia (A) del equipo llega hasta 2A; y este valor se sobrepasaba principalmente en las soluciones de Mp en concentraciones iniciales superiores a $15 \mathrm{mg} / \mathrm{L}$.

La curva de calibración para la técnica espectrofotométrica se efectuó a partir de soluciones estándares con diferentes concentraciones: 1, 5, 10 y $15 \mathrm{mg} / \mathrm{L}$ para Mp y $5,10,15,20,25,30,35$ y 40 para Cbz y Sil. Además el análisis estadístico de los datos obtenidos fue realizado por regresión lineal, a fin de establecer la relación concentración inyectada vs la respuesta del equipo, con un nivel de significancia de 0,05 para la prueba realizada. El mismo procedimiento se llevó a cabo cada vez que se realizaba una réplica de los experimentos.

A modo de ejemplo, en la Figura 3.1 se presentan las curvas de regresión lineal de cada uno de los compuestos estudiados, las cuales fueron utilizadas para la determinación de los PPCPs en los experimentos de adsorción con carbón activado granular, con concentraciones iniciales superiores a $5 \mathrm{mg} / \mathrm{L}$ de cada PPCPs evaluados de forma individual. En el Capítulo 7 se presenta más detalladamente los estudios realizados. Los coeficientes de correlación para las curvas de regresión lineal estuvieron por encima de 0,999 , con un $\mathrm{p}$-valor $<0,001$, en todos los casos evaluados. Las ecuaciones de las curvas para Cbz, Sil y Mp fueron: $\mathrm{Abs}=0,029+0,047 \mathrm{C}$; $\mathrm{Abs}=$ $0,000+0,020 \mathrm{C} ; \mathrm{Abs}=0,012+0,098 \mathrm{C}$, respectivamente. Las siglas Abs y C representan la absorbancia y la concentración de los PPCPs $(\mathrm{mg} / \mathrm{L})$, respectivamente. 


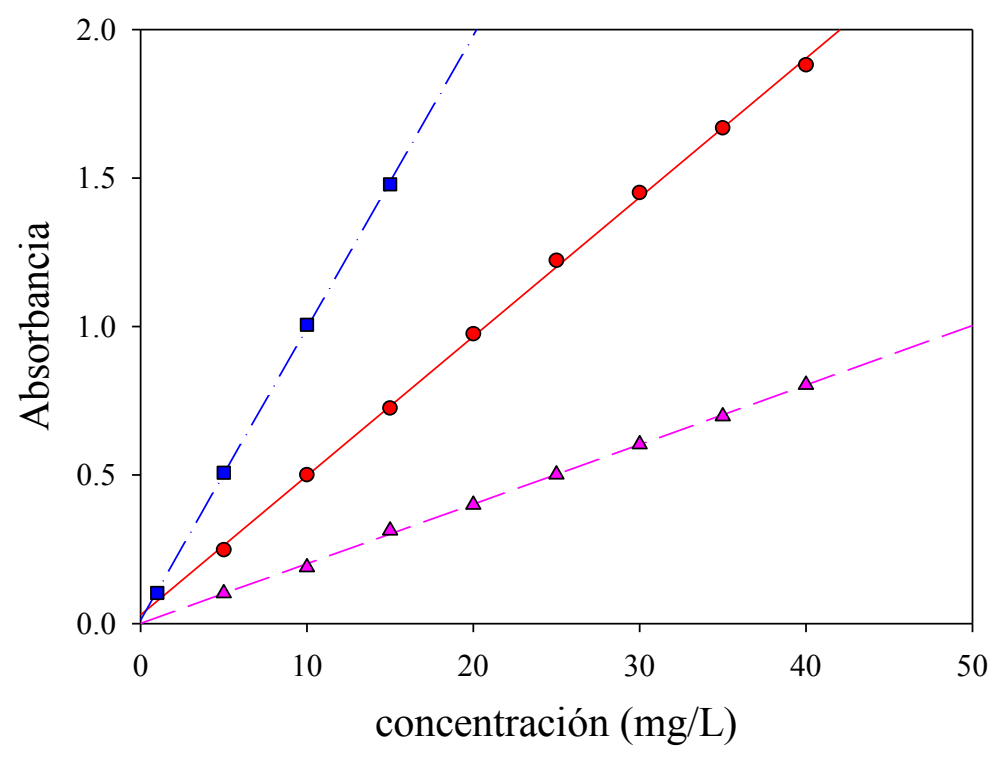

Figura 3.1 Curvas de regresión lineal a partir de soluciones estándares de 1, 5, 10 y $15 \mathrm{mg} / \mathrm{L}$ para $\mathrm{Mp}(\mathbf{\square})$ y $5,10,15,20,25,30,35$ y $40 \mathrm{mg} / \mathrm{L}$ para $\mathrm{Cbz}(\bullet)$ y Sil $(\Delta)$, evaluadas por espectrofotometría UV/VIS.

\subsubsection{Cromatografía líquida acoplada a espectrometría de masas}

En el ambiente, y a consecuencia de su interacción con matrices acuosas complejas, las concentraciones de los PPCPs pueden hallarse en niveles traza. Como consecuencia se requieren procesos analíticos confiables y precisos para su determinación. El uso de sistemas de cromatografía líquida (HPLC) acoplada a espectrometría de masas (MS), y el uso de análisis cualitativos y cuantitativos con diferentes detectores ha sido la mejor opción para su determinación. La espectrometría de masas (MS) presenta altas ventajas de selectividad, especificidad y sensibilidad para analizar los PPCPs; ésta es la razón por la cual HPLC-MS se ha convertido en una herramienta indispensable en la investigación de este tipo de compuestos en matrices ambientales (Arrubla et al., 2016).

El monitoreo de los PPCPs en las aguas superficiales y residuales, así como su análisis en los efluentes de los sistemas de tratamiento biológicos y físico-químicos, fueron determinados en el laboratorio mediante el análisis por comatografía HPLCMS, utilizando un equipo Agilent modelo 1100, acoplado a un espectrómetro de masas Agilent modelo VL, con una columna de carbono 18, marca Waters ${ }^{\circledR}$, modelo XSELECT-CSH, con fuente de ionización electro-spray (ESI) en modo del ión 
selectivo (SIM) positivo para cada compuesto. Se utilizó acido fórmico al $0,1 \%$ y metanol de pureza al 99.9\%, como solventes para la fase móvil. Cada ion característico fue seleccionado de acuerdo con lo planteado por Elorriaga et al. (2013a) previa caracterización en modo de barrido (SCAN) en las mismas condiciones cromatográficas de estudio.

La identificación de los PPCPs se realizó en base al ion de cuantificación y los tiempos de retención obtenidos para cada uno. Los iones de determinación más representativos fueron $\mathrm{m} / \mathrm{z}=237$ para Cbz, $\mathrm{m} / \mathrm{z}=475$ para Sil y $\mathrm{m} / \mathrm{z}=51$ para Mp. Los iones hijos para Cbz, Sil y Mp fueron $\mathrm{m} / \mathrm{z}=194, \mathrm{~m} / \mathrm{z}=303$ y m/z $=136$, respectivamente. La cuantificación se realizó en base a la determinación del área bajo la curva, mediante integración de los picos cromatográficos y curva de calibración externa. En la Figura 3.2 se presenta un ejemplo del cromatograma obtenido por HPLC-MS para determinar la eficiencia de remoción alcanzada en un sistema de biodiscos para el Mp (ver el análisis detallado en el Capítulo 6), con dos estándares de la curva de calibración.

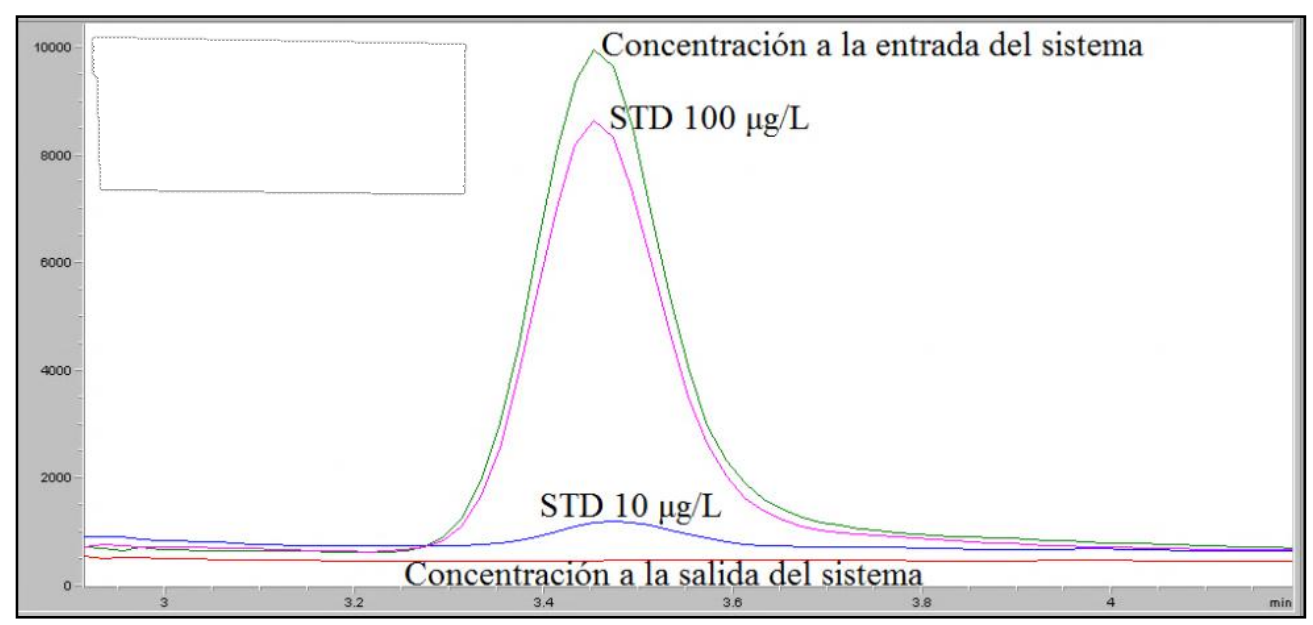

Figura 3.2 Ejemplo del cromatograma obtenido por HPLC-MS para determinar la eficiencia de remoción del $\mathrm{Mp}$ en un Contactor biológico rotativo $(\mathrm{STD}=$ estándar $)$.

Las curvas de calibración se construyeron correlacionando los valores de concentraciones de los estándares (concentración nominal = 1, 5, 7, 10, 100 y 1000 $\mu \mathrm{g} / \mathrm{L}$ ), y las áreas respectivas de los mismos. Las soluciones fueron preparadas con agua nanopura, a partir de una solución stock de $1.000 \mathrm{mg} / \mathrm{L}$ en metanol. La respuesta 
lineal observada permitió, en cada caso, calcular la pendiente y el coeficiente de correlación utilizando el programa Excel y Sigma Plot. La linealidad se determinó a partir del mejor coeficiente de correlación obtenido. El límite de cuantificación se determinó utilizando la ecuación $\mathrm{LC}=10 *$ [menor estándar] / (señal/ruido), y el límite de detección como $\mathrm{LD}=\mathrm{LC} / 3,3$; de acuerdo al criterio establecido por SANTE 11945/2015. Los límites de cuantificación y detección fueron $0,50 \mu \mathrm{g} / \mathrm{L}$ y $0,15 \mu \mathrm{g} / \mathrm{L}$ para la Cbz; 2,29 $\mu \mathrm{g} / \mathrm{L}$ y $0,69 \mu \mathrm{g} / \mathrm{L}$ para el Sil; y $5,0 \mu \mathrm{g} / \mathrm{L}$ y $1,5 \mu \mathrm{g} / \mathrm{L}$ para el Mp, respectivamente.

Se inyectó un estándar cada 7 muestras leídas en el HPLC-MS para verificar la calibración del equipo. Para lecturas superiores a 40 muestras, se leyeron 3 curvas de calibración, una al inicio, otra intermedia y otra al final. A modo de ejemplo, en la Figura 3.3 se presentan las curvas de regresión lineal de cada uno de los compuestos estudiados, tomadas de los experimentos de adsorción con carbón activado polvo, en los cuales se estudiaron concentraciones iniciales similares a las encontradas en el ambiente acuatico, como se explica más adelante, en los Capítulos 8 y 9. Los coeficientes de correlación estuvieron por encima de 0,999, con un p-valor $<0,001$ para cada curva evaluada. Las ecuaciones de las curvas para Cbz, Sil y Mp fueron: Área $=2167,6+2863,6^{*} \mathrm{C}$; Área $=105,49+1682,1^{*} \mathrm{C}$; Área $=1459,9+544,91^{*} \mathrm{C}$, respectivamente. La sigla $\mathrm{C}$ representa la concentración de los PPCPs en $\mu \mathrm{g} / \mathrm{L}$.

Las muestras extraídas de los sistemas de tratamiento para evaluación de la concentración de los PPCPs fueron mantenidas a $-20{ }^{\circ} \mathrm{C}$ y filtradas por filtros de nylon de 0,45 $\mu \mathrm{m}$ de tamaño de poro, antes de ser inyectadas en el HPLC-MS. Las inyecciones de las muestras se realizaron de las menos concentradas a las más concentradas.

Para los respectivos picos cromatográficos demasiado pequeños o no detectables, las concentraciones de los PPCPs se reemplazaban por la mitad del límite de detección (LD). La mitad del límite de cuantificación (LC) se utilizó si se detectaron picos, pero el software del instrumento no calculó un valor explícito (Kahl et al., 2017). 


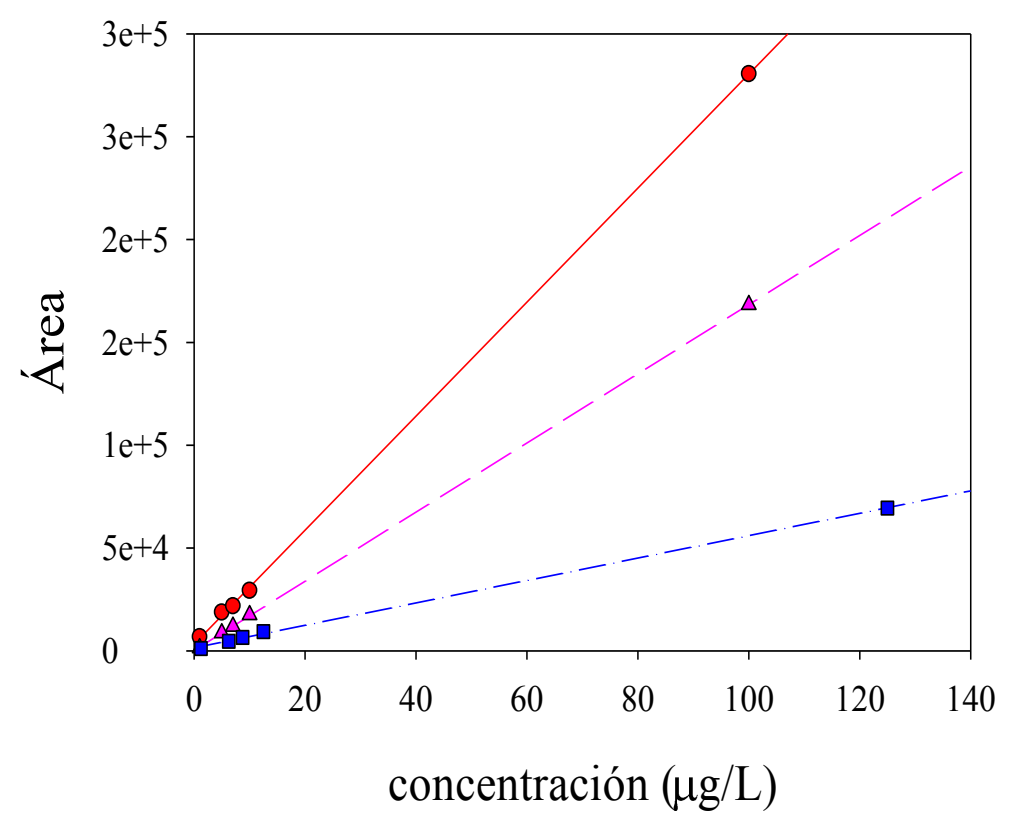

Figura 3.3 Curvas de regresión lineal evaluadas por HPLCMS, para estándares de 1, 5, 7, 10 y $100 \mu \mathrm{g} / \mathrm{L}$ de $\mathrm{Cbz}(\bullet)$, Sil ( $\triangle$ ) у $\operatorname{Mp}(\boldsymbol{\square})$.

\subsection{Determinación de los parámetros fisicoquímicos}

Para determinar la calidad del agua afluente y efluente en cada uno de los sistemas de tratamiento a escala piloto se midió in situ el oxígeno disuelto, el pH, la conductividad y la temperatura, utilizando analizadores multiparamétricos WA2017SD y HI98194 Hanna. Para determinar la carga orgánica del agua afluente y efluente de cada sistema evaluado, se tomaron muestras de $50 \mathrm{~mL}$ y se midieron como demanda química de oxigeno (DQO). Cada determinación de la DQO se realizó en el laboratorio por triplicado mediante el método de reflujo cerrado, establecido en el Standard Methods (APHA, 1998). Se utilizó el mismo principio de análisis de regresión lineal descrito en el apartado anterior para la determinación de la carga orgánica, construyendo las curvas de calibración con las soluciones estándar. En este caso, se utilizó una solución de biftalato de potasio de $500 \mathrm{mg} / \mathrm{L}$ para preparar los estándares de las curvas de calibración. Los estándares de calibración para bajas concentraciones fueron $0,5,20,50$, y $100 \mathrm{mg} / \mathrm{L}$ y para concentraciones mayores fueron 0, 100, 200, 400 y $500 \mathrm{mg} / \mathrm{L}$. Las Curvas de calibración se indican en la Figura 3.4. Las ecuaciones de las curvas para las soluciones fueron: $\mathrm{Abs}=0,0011-0,0016 \mathrm{C}$ para concentraciones $\mathrm{C}<100 \mathrm{mg} / \mathrm{L}$ y Abs $=-0,0008+0,0003^{*} \mathrm{C}$ para $100<\mathrm{C}<500$. 
En estas ecuaciones, Abs representa la absorbancia y C la concentración de la DQO $(\mathrm{mg} / \mathrm{L})$. Los coeficientes de correlación estuvieron por encima de 0,999 y el p-valor $<$ 0,001 para cada curva evaluada. Se utilizó un espectrofotómetro UV/Vis marca Shimadzu 1203 para las lecturas de absorbancia, con longitudes de onda de $600 \mathrm{~nm}$ y $420 \mathrm{~nm}$ para las soluciones de altas y bajas concentraciones, respectivamente. El límite de cuantificación de la técnica fue $5 \mathrm{mg} / \mathrm{L}$.
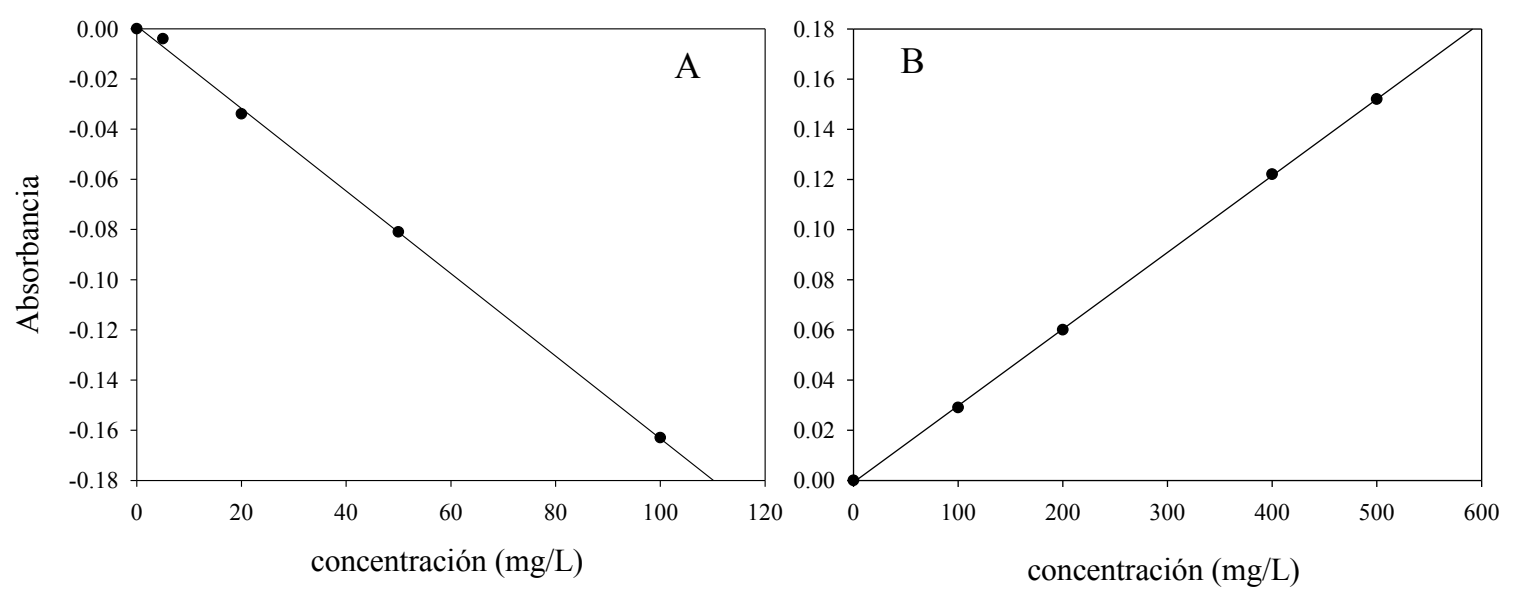

Figura 3.4 Curvas de calibración para la determinación de la carga orgánica medida como DQO, con estándares de (A) bajas concentraciones: 0, 5, 20, 50, y $100 \mathrm{mg} / \mathrm{L}$ y (B) altas concentraciones: 0, 100, 200, 400 y $500 \mathrm{mg} / \mathrm{L}$, con longitudes de onda de $420 \mathrm{~nm}$ y $600 \mathrm{~nm}$, respectivamente.

\subsection{Diseños experimentales a escala de laboratorio y a escala piloto}

Se analizaron las capacidades de remoción de carbamazepina, sildenafil y metilparabeno en diferentes sistemas (1) a escala de laboratorio, (2) escala piloto, en distintas matrices acuosas. Se prestó atención especial a las soluciones que simulaban aguas residuales domésticas, con el fin de que en su momento puedan utilizarse como base para su aplicación en sistemas a escala real.

Los reactores evaluados como sistemas de biodegradación fueron: contactores biológicos rotativos y humedales construidos; y como métodos fisicoquímicos: La adsorción sobre carbón activado granular y carbón activado en polvo.

El seguimiento del sistema se efectuó en el afluente y el efluente, con toma de muestras de acuerdo a los tiempos de retención hidráulica. Los principales parámetros medidos para determinar la calidad de las aguas fueron $\mathrm{pH}$, temperatura, oxígeno 
disuelto, conductividad eléctrica y DQO. Además se tomaron muestras para evaluar las concentraciones de los PPCPs presentes, las cuales que se mantuvieron a $-20^{\circ} \mathrm{C}$ hasta el momento de su análisis.

A continuación se hace una breve descripción de los sistemas utilizados para la remoción de los PPCPs, los cuales se estudian detalladamente en los Capítulos 5, 6, 7, 8 у 9.

\subsubsection{Contactor biológico rotativo (CBR)}

Los contactores biológicos rotativos, comúnmente conocidos como "biodiscos", son procesos de tratamiento biológico secundario de las aguas residuales. Su diseño consiste en un medio formado por una serie de discos corrugados, montados sobre un eje horizontal que gira lentamente, mientras aproximadamente el $40 \%$ de la superficie del medio está sumergida en el agua residual contenida en un tanque (Scholz, 2006). Inmediatamente después de iniciar su funcionamiento, los microorganismos presentes en el agua comienzan a adherirse al medio en movimiento y a multiplicarse. Después de un corto periodo de tiempo se forma una delgada biopelícula que cubre los discos. Al girar, los discos llevan al exterior a los microorganismos y a una fina capa de agua que los rodea, poniéndolos en contacto con el aire, de donde toman el oxígeno. Este oxígeno, parte es usado por los organismos presentes en la biomasa para eliminar la materia orgánica del agua residual, y el resto es mezclado con el agua a tratar, manteniendo una concentración de oxígeno disuelto en el medio acuoso. Las fuerzas cortantes ejercidas sobre la biopelícula al pasar a través del agua residual desprenden el exceso de biomasa del medio al seno del líquido, manteniendo un espesor de biomasa uniforme. La acción de mezcla de los discos deja los sólidos desprendidos en suspensión siendo arrastrados al exterior por el flujo de agua tratada, llevándolos al decantador donde son separados (Scholz, 2006).

El aspecto de la biopelícula es sustancialmente diferente a la de los lechos bacterianos, en estos es gelatinosa y exteriormente uniforme, mientras que en los CBR es compacta y exteriormente rugosa, ofreciendo así una mayor superficie activa. Este crecimiento se desarrollará en espesor y longitud mientras las fuerzas de rozamiento hidráulico se lo permitan. El movimiento giratorio de los discos provoca asimismo, una fuerte turbulencia en la interface agua-biomasa que facilita la distribución uniforme del sustrato y del oxígeno disuelto a toda la biomasa. El conjunto de la 
unidad del CBR se comporta como un reactor de flujo pistón, mientras que cada etapa del mismo actúa como un reactor de mezcla completa en donde existe un equilibrio dinámico entre la velocidad del crecimiento de la biomasa y la velocidad de desprendimiento del exceso de ella. Así, el agua atraviesa las sucesivas etapas produciéndose un progresivo aumento del grado de depuración de los contaminantes (Reyilla, 1993).

Teniendo en cuenta las bondades que presenta esta tecnología, en el presente trabajo se eligió un reactor de biodiscos a escala piloto, similar a los encontrados a escala real, para investigar su eficiencia en la remoción de los PPCPs. El reactor constaba de veinte discos de acrílico de superficie rugosa, para la adherencia del biofilm, girando a una velocidad de $1.5 \mathrm{rpm}$ y contenidos en una pileta de 20L de capacidad. El caudal de trabajo fue de $70 \mathrm{~mL} / \mathrm{min}$, el cual se llevaba desde el tanque de alimentación hasta el reactor mediante una bomba peristáltica de caudales variables. En la Figura 5.1 se muestra una foto y un esquema del sistema utilizado.

El desarrollo de esta experiencia se llevó a cabo en las instalaciones del Departamento de Ingeniería química, en la Facultad de Ingeniería, de la UNLP. Las técnicas analíticas para determinar la calidad del agua tratada se realizaron en el laboratorio del Centro de Investigaciones del Medio Ambiente (CIM) de la Facultad de Ciencias Exactas, de la UNLP. El diseño y evaluación de ésta técnica se presenta más detalladamente en el Capítulo 5.

\subsubsection{Humedales construidos}

Los humedales artificiales son sistemas acuáticos que han sido diseñados y construidos en procesos naturales al aire libre, los cuales involucran la vegetación de las zonas húmedas, los suelos y la inoculación de microorganismos asociados para ayudar en la remoción de contaminantes de las aguas residuales. Están diseñados para aprovechar muchos de los procesos que ocurren en los ambientes naturales, pero lo hacen en un entorno más controlado. Mediante estos sistemas se busca aprovechar los procesos físicos, químicos y biológicos que se presentan al interactuar el agua, el medio filtrante, las macrófitas, los microorganismos y la atmósfera; con lo que se imitan las condiciones ecológicas y la capacidad de depuración encontradas en un humedal natural (Heike Hoffmann, 2011). En el tratamiento de las aguas residuales, los humedales construidos cumplen las siguientes funciones: fijar físicamente algunos 
contaminantes a través de la absorción en la superficie del lecho y las plantas; utilizar y transformar los elementos orgánicos e inorgánicos, por intermedio de las plantas macrófitas y de los microorganismos que están adheridos al sustrato; logrando niveles de tratamiento con un bajo consumo de energía y poco mantenimiento. Estos mecanismos hacen que estos sistemas sean técnica y económicamente factibles para tratar varios tipos de aguas (López, 2014).

Teniendo en cuenta que este tipo de sistemas presentan una gran interacción entre los elementos que los componen, en el presente trabajo se estudiaron cuatro humedales artificiales de flujo horizontal subsuperficial para evaluar su eficiencia en la remoción de los PPCPs. Dos de los reactores se dejaron sin plantar, mientras que los otros dos se plantaron con macrófitas emergentes propias de la zona de estudio, en policultivo. El flujo de trabajo fue de $15 \mathrm{~mL} / \mathrm{min}$, y se desarrolló el método del frasco de Mariotte para alimentar cada reactor. En la Figura 6.1 se muestra una foto y un esquema del sistema utilizado.

El desarrollo de esta experiencia se llevó a cabo en las instalaciones del Centro de Estudios Vegetales y Diversidad Asociada La Rejoya, en colaboración con del Grupo de Investigación de Ciencia e Ingeniería en Sistemas Ambientales -GCISATSEJK- de la Universidad del Cauca - Colombia. En el Capítulo 6 se detalla el diseño de los sistemas y la metodología de trabajo.

\subsubsection{Estudios y tecnologías de adsorción}

La adsorción es un fenómeno superficial con una importante capacidad para la eliminación de contaminantes orgánicos e inorgánicos. Cuando una solución que contiene un soluto adsorbible entra en contacto con un sólido con una estructura superficial altamente porosa, las fuerzas intermoleculares líquido-sólidas de atracción provocan que algunas de las moléculas del soluto de la solución se concentren o depositen en la superficie sólida. El soluto retenido (en la superficie sólida) en los procesos de adsorción se denomina adsorbato, mientras que el sólido sobre el que se retiene se denomina adsorbente. Esta acumulación superficial de adsorbato en el adsorbente se denomina adsorción (Mohamed and Paleologos, 2018). La adsorción sólido-líquido es más compleja que la adsorción sólido-gas, puesto que las fuerzas de interacción no son sólo adsorbente-adsorbato, sino que también intervienen fuerzas de interacción adsorbente-disolvente y adsorbato-disolvente. Este hecho motiva que la 
afinidad de un adsorbente por un adsorbato no dependa solamente de la naturaleza de las interacciones entre ambos, sino también de la naturaleza del disolvente en el que el adsorbato se encuentra disuelto (Asenjo, 2014).

Para evaluar la eficiencia de adsorción de un contaminante sobre un material adsorbente, en primer lugar se deben realizar experimentos de adsorción en batch, en laboratorio. En este caso, se desea un contacto eficaz entre el adsorbente y el adsorbato durante un periodo de tiempo. Esto permite que la concentración de adsorbato en solución alcance el equilibrio con el adsorbente (Álvarez-Torrellas, 2017; Reyilla, 1993). El equilibrio de adsorción suele expresarse como la cantidad de soluto adsorbido por unidad de masa de adsorbente, en función de la concentración de soluto en la disolución. Las representaciones gráficas de estas distribuciones cuando son realizadas a temperatura constante reciben el nombre de isotermas de adsorción (Eric Lichtfouse, 2013).

Se pueden utilizar uno o más modelos de isoterma de adsorción para describir la interacción entre el adsorbente y de moléculas de adsorbato presentes en la fase líquida. La idoneidad, el denominado grado "favorable" de un modelo de isoterma al sistema de adsorción se verifica a menudo a partir de la forma generada en el gráfico isotérmico. La forma isotérmica proporciona información sobre la naturaleza de la interacción entre el soluto y la superficie. En el sistema de adsorción, el rendimiento de diferentes adsorbentes se evalúa siempre a partir de su máxima capacidad de adsorción que puede obtenerse a partir de la isoterma de adsorción ajustada. La información de capacidad también permite la selección del adsorbente más apropiado para una aplicación de adsorción particular (Asenjo, 2014; Eric Lichtfouse, 2013).

Existen diversos modelos teóricos para la descripción de las isotermas de adsorción, que difieren entre sí en las hipótesis de partida y en el número de parámetros característicos de cada uno de ellos (Worch, 2012). Entre las ecuaciones más utilizadas se encuentran los modelos de Langmuir y Freundlich, estos son modelos típicos representantes del grupo de isotermas de dos parámetros. Por otro lado, para poder comprender mejor la interacción adsorbato-adsorbente y el comportamiento de adsorción, los modelos que implican más de dos parámetros son necesarios para interpretar los datos. Es muy frecuente que los investigadores hagan estudios de comparación entre una serie de isotermas de dos parámetros y de tres parámetros al describir los datos de equilibrio, porque en algunos casos podría ser 
necesario más de un modelo para explicar el mecanismo de adsorción. Entre las isotermas de tres parámetros de uso común para la predicción de datos experimentales de adsorción se encuentran la isoterma de Lagmuir-Freundlich y la isoterma de Redlich-Peterson.

De igual forma, el conocimiento de la cinética de cualquier proceso de adsorción es crucial para diseñar un proceso de separación a escala industrial, así como la determinación de las condiciones óptimas de operación, la velocidad de adsorción de adsorbato $\mathrm{y}$, finalmente, tiempo para la especificación de equilibrio (Mashayekh-Salehi and Moussavi, 2016). El progreso temporal del proceso de adsorción se denomina cinética de adsorción. Un adsorbente excelente debe poseer no sólo una alta capacidad de adsorción, sino también una velocidad de adsorción rápida. Por lo tanto, los estudios cinéticos que implican la investigación de la velocidad de adsorción son cruciales para determinar los tiempos de contacto requeridos en los sistemas. De hecho, también se realizan estudios cinéticos para identificar factores que afectan al proceso de adsorción, conduciendo a un sistema de adsorción optimizado (Eric Lichtfouse, 2013). En la bibliografía existen numerosos modelos ampliamente utilizados para describir la cinética de los procesos de adsorción, algunos de los cuales se destacan por su sencillez en la aplicación y su fácil interpretación. El modelo de Lagergren (seudo primer orden), el modelo cinético de seudo-segundo-orden y el modelo de la difusión intrapartícula son los modelos cinéticos comúnmente aplicados entre los investigadores.

Con el fin de determinar el mejor material adsorbente para la remoción de los PPCPs seleccionados, y realizar el diseño de una columna de adsorción eficiente, en el presente trabajo se evaluaron inicialmente en laboratorio la cinética y equilibrio de adsorción de dos tipos de carbón activado, carbón activado granular y carbón activado en polvo, mediante ensayos en batch por triplicado, en matraces erlenmeyer de 100 $\mathrm{mL}$, en contacto con $50 \mathrm{~mL}$ de solución acuosa, $5 \mathrm{mg}$ de cada carbón activado y concentraciones de los PPCPs en un rango entre 5 a $40 \mathrm{mg} / \mathrm{L}$. Se utilizó un agitador Arcano, modelo SHZ-88, para agitar las soluciones acuosas. Las concentraciones remanentes de las soluciones fueron monitoreadas en un espectrofotómetro UV/Vis. La velocidad de adsorción de los PPCPs también se evaluó en contacto con diferentes soluciones acuosas, en concentraciones iniciales similares a las encontradas en las aguas superficiales $(\approx 0,2 \mathrm{mg} / \mathrm{L})$, y determinadas mediante HPLC-MS. 
Luego de los ensayos en batch se diseñó una columna de adsorción en lecho fijo a escala de laboratorio, para ser llevada posteriormente a escala piloto. Para los experimentos de laboratorio se utilizó una columna en polipropileno de $20 \mathrm{~cm}$ de largo y $2 \mathrm{~cm}$ de diámetro, la cual se alimentó con una bomba peristáltica Masterflex ${ }^{\circledR}$, a un caudal de 6,5 $\mathrm{mL} / \mathrm{min}$. El lecho de adsorción estaba compuesto por una mezcla de carbón activado en polvo y arena, en relación 1:50.

En los experimentos a escala piloto se trabajó con una columna de $110 \mathrm{~cm}$ de alto y un diámetro de $10 \mathrm{~cm}$, y con la misma mezcla del material adsorbente evaluado en la columna de laboratorio. En la columna a escala piloto se utilizó una bomba peristáltica de caudales variables para llevar un caudal de alimentación de aproximadamente $30 \mathrm{~mL} / \mathrm{min}$. Los modelos matemáticos utilizados para predecir la capacidad y la velocidad de adsorción de los PPCPs en las columnas de lecho fijo fueron: el modelo de Bohart-Adams, el modelo de Thomas, el modelo de YoonNelson, y el modelo de dosis-respuesta modificado.

El desarrollo de estas experiencias a se llevó a cabo en las instalaciones del laboratorio del el Centro de Investigaciones del Medio Ambiente (CIM) de la Facultad de Ciencias Exactas, en la UNLP. Detalles de estas experiencias se presentan en los Capítulos 7, 8 y 9 .

\subsection{Obtención y análisis de datos}

La interpretación de resultados experimentales tuvo en cuenta: a) las concentraciones de los compuestos farmacéuticos y el producto de cuidado personal, características de las aguas superficiales y aguas cloacales (para el caso de estudios de campo); b) las concentraciones de los PPCPs antes y después de someterlos al tratamientos en los diferentes sistemas a escala de laboratorio y a escala piloto; c) la aplicación de métodos estadísticos multivariados de los resultados experimentales de ensayos de laboratorio, a escala piloto y estudios de campo, procesando las variables medidas con programas estadísticos para el análisis de datos (XLStat, R-project, Statistica, Sigma Plot). 


\section{CAPÍTULO 4}

\section{DIAGNÓSTICO DE CONTAMINANTES EMERGENTES EN AGUAS RESIDUALES Y SUPERFICIALES}

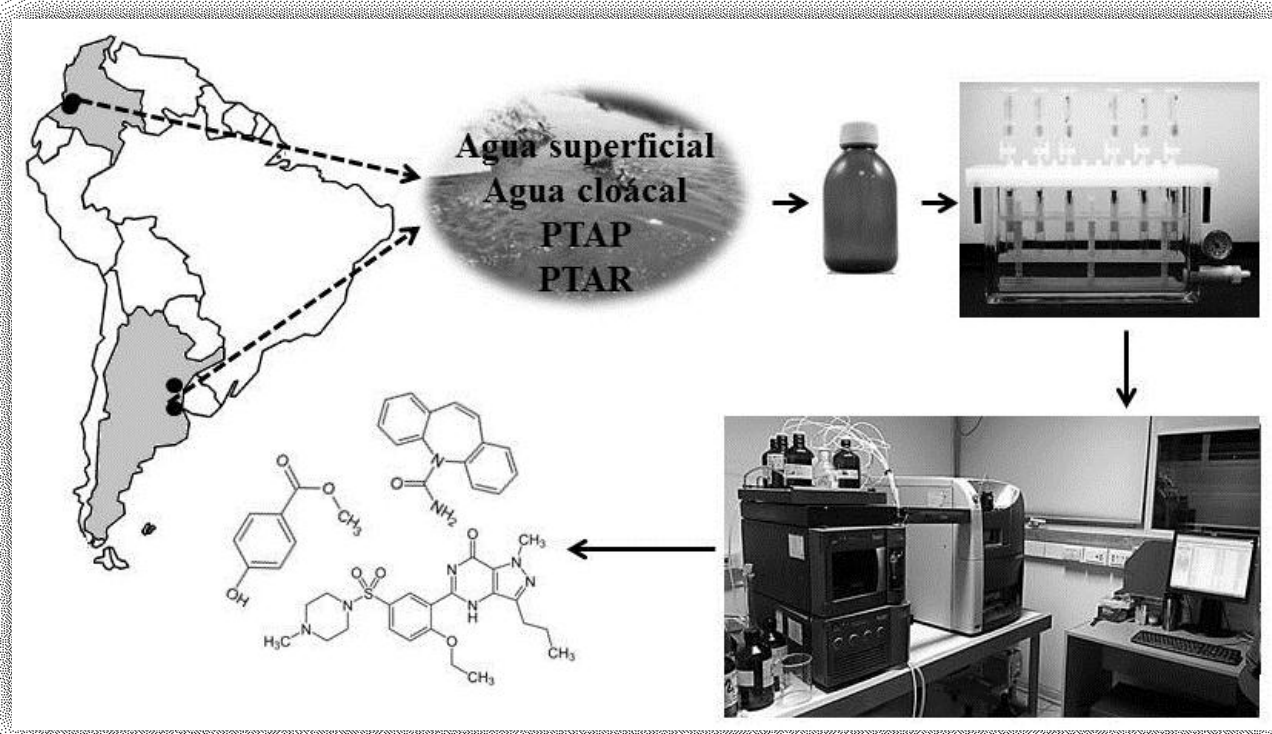




\section{Resumen}

Un número significativo de contaminantes emergentes resultantes de la contaminación puntual y difusa está presente en el ambiente acuático. Estos son productos químicos que no se monitorean comúnmente pero que tienen el potencial de causar efectos adversos para la salud humana y ecológica. Su aparición y comportamiento en las aguas residuales, superficiales, en las plantas de tratamiento de agua residual y en las potabilizadoras, son cuestiones claves para la reutilización de los recursos hídricos, teniendo en cuenta que en países como Argentina y Colombia es frecuente potabilizar la misma agua donde se viertes las aguas residuales urbanas. Por lo tanto, en este trabajo se estudiaron tres contaminantes modelos: la Carbamazepina (Cbz), el sildenfil (Sil) y el metilparabeno (Mp). El Mp fue el compuesto con mayor concentración y más comúnmente detectado en los diferentes sitios de estudio en Argentina, con un valor máximo de $0,5 \mu \mathrm{g} / \mathrm{L}$, mientras que para la $\mathrm{Cbz}$ fue de 0,09 $\mu \mathrm{g} / \mathrm{L}$, con principal presencia en la cloaca del Río de La Plata. Por el contrario, en los sitios muestreados en Colombia, principalmente sobre el río Molino, la Cbz presentó la mayor concentración, con un valor de $10,66 \mu \mathrm{g} / \mathrm{L}$, seguido del Mp $(7,24 \mu \mathrm{g} / \mathrm{L})$ y el Sil $(2,64 \mu \mathrm{g} / \mathrm{L})$. Las mayores concentraciones detectadas en Colombia se relacionaron con el mayor flujo de aguas residuales vertidas sobre los pequeños caudales de los ríos. Además se determinó que los compuestos presentan mayor afinidad sobre la fracción soluble de los cuerpos de agua. 


\subsection{Introducción}

La contaminación creciente de los sistemas de agua dulce está generando un deterioro importante de los recursos hídricos (Archer et al., 2017b). En las últimas décadas, a este proceso se está sumando la contaminación resultante de los contaminantes emergentes (CE), lo que ha generado numerosos estudios de investigación básica como tecnológica para disminuir su impacto en el ambiente (Arrubla et al., 2016).

Algunos autores han sugerido que hasta 6 millones de productos farmacéuticos y de cuidado personal (PPCPs) están disponibles comercialmente en todo el mundo, y su uso está creciendo de 3\% a 4\% en peso por año (Cizmas et al., 2015; Ebele et al., 2017). Estos compuestos solo se eliminan levemente en las plantas de tratamiento de aguas residuales (PTAR) y luego ingresan al medio acuático (Bu et al., 2013). Muchos han sido reportados como compuestos ambientales persistentes, bioactivos, bioacumulativos y disruptores endocrinos (Cruz and Barceló, 2015; Hontela and Habibi, 2013; Niemuth and Klaper, 2015). Su concentración ambiental varía de una región a otra y según la estación del año. Además, su destino ambiental depende las propiedades fisicoquímicas, como el coeficiente de partición octanol-agua (Kow), la velocidad de degradación y el coeficiente de partición sedimento-agua (Koc), así como otras características relacionadas con su liberación, caudal o el tipo de PPCPs, también determinan su destino (Montes-Grajales et al., 2017).

Sin embargo, la información disponible no es suficiente para evaluar el destino, transporte y mecanismos de reacción/interacción en el ambiente, para evaluar su riesgo sobre los ecosistemas y la salud humana (Mottaleb et al., 2015). Además, al no existir regulaciones relacionadas con el control de este tipo de contaminantes emergentes no siempre es posible una metodología de monitoreo regular, asociado a su vez con el alto costo analítico de estos procedimientos (Mottaleb et al., 2015).

Esta situación se ha ido revirtiendo en Europa, Norte América y Asia, donde durante los últimos 20 años se ha generado un volumen importante de información sobre la presencia y concentración de los $\mathrm{CE}$ en efluentes cloacales, aguas superficiales y plantas de tratamiento. Las concentraciones ambientales típicas para los PPCPs están en el rango de $1.800-4.000 \mathrm{ng} / \mathrm{L}$ en aguas superficiales y $39.000-$ $56.000 \mathrm{ng} / \mathrm{L}$ en efluentes de PTAR (Zenobio et al., 2015).Comparativamente, la 
información disponible para América del Sur todavía es muy limitada (Valdés et al., 2015). Entre los compuestos farmacéuticos monitoreados en Argentina se encuentra la carbamazepina, con niveles de detección máximos de $0,63 \mu \mathrm{g} / \mathrm{L}$ en las descargas de aguas residuales (Elorriaga et al., 2013b); mientras que en Colombia se tiene información de algunos productos de cuidado personal, como el metilparabeno, con concentraciones máximas de $0,537 \mu \mathrm{g} / \mathrm{L}$ en reservorios de agua (Aristizabal et al., 2017).

Argentina y Colombia tienen muchos ecosistemas acuáticos que proporcionan agua para el consumo humano, siendo este el caso del Río La Plata en Argentina y el río Cauca en Colombia. Ambos cursos de agua reciben grandes volúmenes de aguas residuales urbanas con distintos grados de tratamiento. Por esta razón, es importante monitorear la calidad del agua, específicamente para aquellos PPCPs utilizados en aplicaciones humanas y hogares con el fin de tener mejor conocimiento de su presencia en las fuentes de agua.

\subsection{Metodología}

\subsubsection{Fármacos y productos de cuidado personal estudiados}

Se seleccionaron tres tipos de contaminantes emergentes representativos de los cuerpos de agua en Argentina y Colombia (Aristizabal et al., 2017; Elorriaga et al., 2013b). Entre ellos, la carbamazepina (Cbz) y el sildenafil (Sil) se eligieron del grupo de los fármacos, mientras que el metilparabeno $(\mathrm{Mp})$ se seleccionó dentro de los productos de cuidado personal. Además, teniendo en cuenta que la Cbz y la Cafeina (Caf) se las considera como marcadores antropogénicos (Clara et al., 2004), también se evaluó la Caf con el fin de determinar si se mantenía la proporcionalidad de los resultados obtenidos comparados con los reportados anteriormente por Elorriga et. al (2013). Las características de cada compuesto se presentan en el Capítulo 3.

\subsubsection{Sitios de muestreo}

Los sitios muestreados en Argentina y Colombia se eligieron sobre la base de la experiencia previa. En estas áreas se han realizado estudios sistemáticos para determinar otros contaminantes y a la vez constatar la influencia de las distintas poblaciones asentadas en las cercanías de los cuerpos de agua elegidos. 
Los sitios muestreados corresponden a sectores de diferentes niveles de población, que varían de 10.000 a 2.500.000 habitantes, como se muestra en la Tabla 4.1. La influencia de las descargas de efluentes en los cuerpos de agua varió en cada sitio. Las muestras de Argentina se tomaron en noviembre del 2017, mientras que las de Colombia se tomaron en el mismo mes, pero en el 2018.

Se estudiaron once muestras de aguas superficiales de ríos y arroyos en las provincias de Buenos Aires y Entre Ríos, en Argentina. En Colombia se evaluaron doce muestras de aguas superficiales, y de afluentes y efluentes de una planta potabilizadora (PTAP) y una de tratamiento de aguas residuales (PTAR), en los departamentos del Cauca y Valle del Cauca.

\subsubsection{Puntos de muestreo en Argentina}

En la provincia de Buenos Aires se muestrearon el Arroyo Carnaval y el punto de descarga cloacal en la ciudad de la Plata, al Río de La Plata en un radio de $100 \mathrm{~m}$, mientras que en la provincia de Entre Ríos se tomaron muestras del Río Gualeguay y el Arroyo Cala, en el marco del proyecto de investigación vigente PICT 2014-0919.

Conforme a los antecedentes del grupo de trabajo CIM, en cual se tiene un banco de datos para la Cbz y el Sil, generados por Elorriaga et al., (2013a; 2013b), se seleccionaron cinco puntos de muestreo en el Arroyo Carnaval, el cual tiene una longitud de $14.5 \mathrm{~km}$ y una profundidad promedio de $0,8 \mathrm{~m}$, y muestra alta turbidez y baja velocidad de corriente. Su caudal en la unión con el Arroyo Martín es de 208 $\mathrm{m}^{3} / \mathrm{s}$. Un punto inicial se ubicó cerca de la Laguna García, donde nace el arroyo Carnaval (CH1), mientras que los otros cuatro se muestrearon, a $220 \mathrm{~m}$ antes $(\mathrm{CH} 2)$ y sobre las rutas 448 (CH3), la $178(\mathrm{CH} 4)$ y la $146(\mathrm{CH} 5)$, todas ellas en cercanías al cordón hortícola Platense, como se ve en la Figura 4.1. Estos puntos de muestreo se seleccionaron con el fin determinar el alcance ambiental para los PPCPs que tiene el uso de camiones atmosféricos, para el fertilizado de cultivos, sobre las aguas superficiales.

El Río de La Plata se muestreo a la salida de la cloaca, donde se encuentra el agua residual con el Río y comienza su dilución (CL1). Este punto recibe la mayoría de las descargas de la ciudad de La Plata, en la que se encuentran 176175 viviendas conectadas a la red de alcantarillado. Un segundo y tercer punto se tomaron dentro del 
caño maestro de la cloaca (CL2) y en un canal lateral, cercano al mismo (CL3). En la provincia de Entre Ríos se muestreo un punto inicial sobre el Arroyo Cala, en cercanías al municipio de Rosario del Tala (RDT), el cual desemboca sobre el Río Gualeguay. Dos puntos más se muestrearon sobre el Río Gualeguay, el primero se ubicó en el camping Paso de Alonso (PA), antes del municipio de Gualeguay, y el segundo en el camping Dos Banderas (2B), ubicado después del mismo municipio, como se muestra en la Figura 4.1. La distancia recorrida por el Arroyo Cala hasta el camping Paso de Alonso, donde desemboca al Río Gualeguay es de aproximadamente $160 \mathrm{~km}$. El agua de red también se muestreó en la ciudad de La Plata. Estos sitios se seleccionaron con el fin de determinar el impacto que tienen los vertimientos directos de agua residuales sobre los cuerpos de agua.

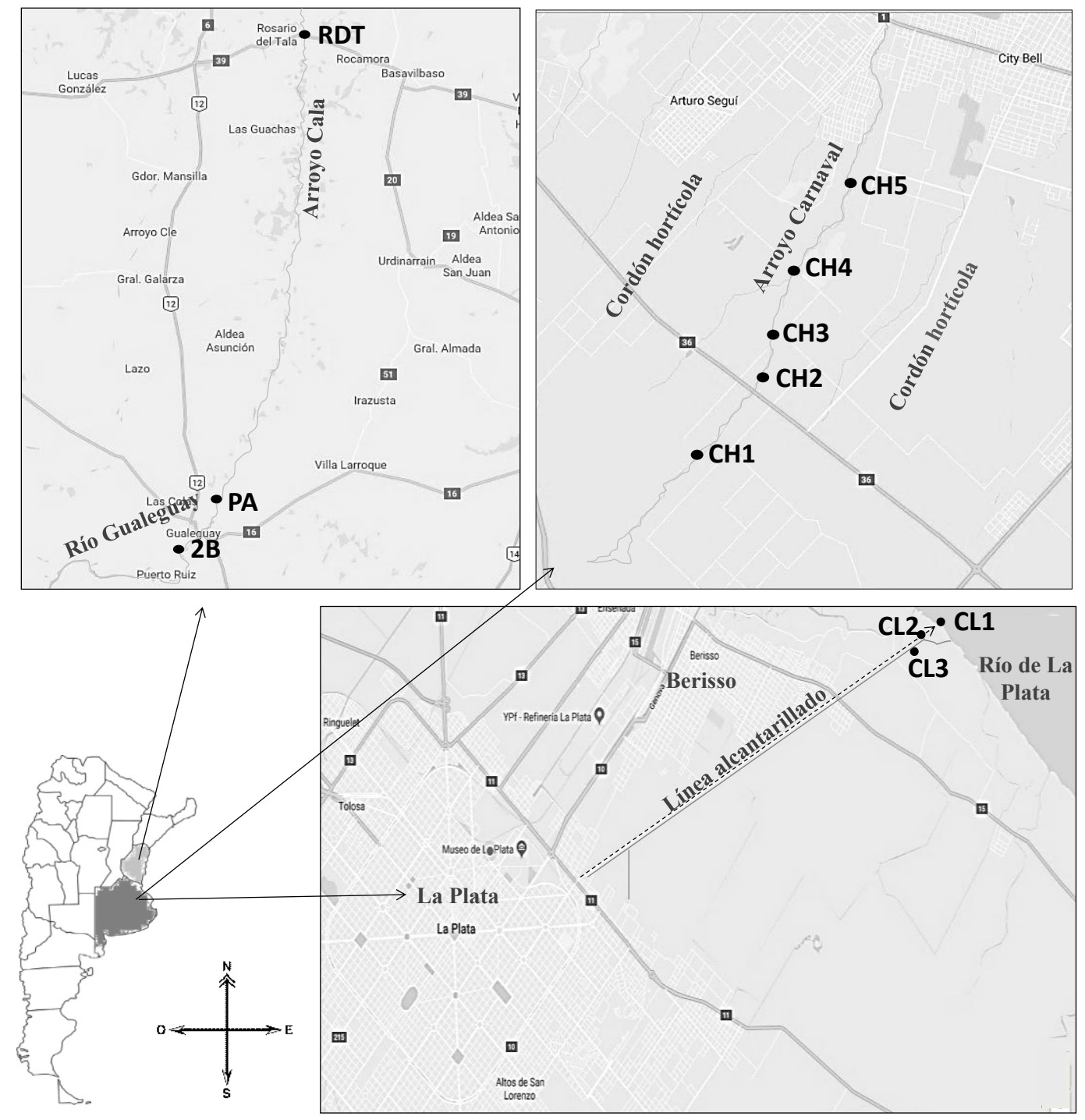

Figura 4.1 Sitios de muestreo para el diagnóstico de carbamazepina y metilparabeno en las provincias de Buenos aires y Entre Ríos - Argentina. 


\subsubsection{Puntos de muestreo en Colombia}

Se eligieron sitios ubicados en el suroccidente de este país, en el Departamento Cauca y en el Valle del Cauca, realizándose muestreos en las ciudades capitales de Popayán y Santiago de Cali, respectivamente, ya que se no se tiene información referente para estos contaminantes.

Popayán se encuentra localizado en el valle de Pubenza, entre la Cordillera Occidental y Central al suroccidente del país. Su extensión territorial es de $512 \mathrm{~km}^{2}$, su altitud media es de $1760 \mathrm{~m}$ sobre el nivel del mar, su precipitación media anual de $1.941 \mathrm{~mm}$, su temperatura promedio de $14 / 19^{\circ} \mathrm{C}$ y distancia aproximada de $600 \mathrm{~km}$ a Bogotá, capital de Colombia. La ciudad es atravesada por el Río Cauca, por más de 10 $\mathrm{km}$ de urbe alcanzando a tener $40 \mathrm{~m}$ de ancho en promedio. Este río es el segundo más importante de Colombia, nace en este departamento y desemboca en el río Magdalena, en el departamento de Bolivar, contando con una longitud de $1350 \mathrm{~km}$, un caudal medio de $3000 \mathrm{~m}^{3} / \mathrm{s}$ y $63300 \mathrm{~km}^{2}$ de superficie de la cuenca. También entran en la ciudad los ríos Molino, Piedras, Vinagre, Negro, Ejido, Blanco, Hondo, Saté, Palacé Clarete y Pisojé, además de cerca de 50 quebradas.

En esta ciudad las tareas de muestreo se enfocaron sobre tres puntos clave, ubicados en los ríos Cauca, Molino y Ejido. Estos dos últimos desembocan en el río Cauca, y cuentan con un caudal medio de aproximadamente $1 \mathrm{~m}^{3} / \mathrm{s}$ y una longitud aproximada de $25 \mathrm{~km}$ y $1 \mathrm{~km}$, respectivamente. Un kilómetro después de cada descarga también se muestreó para determinar la dilución de los compuestos. Estos puntos se seleccionaron con ayuda de la empresa de acueducto y alcantarillado de la misma ciudad. El vertido del Hospital Universitario San José se eligió para la toma de muestras de agua residual hospitalaria (HSJ), ubicada en la caja de inspección sobre la calle $10 \mathrm{~N}$ con Río Molino, siendo éste el hospital más grande de Popayán. Las muestras de las aguas residuales urbanas de la parte norte se tomaron sobre el Río Molino ubicado en la Aeronáutica Civil (Ae) y a $1 \mathrm{~km}$ después $\left(\mathrm{Ae}_{+1 \mathrm{~km}}\right)$, sobre el cauce del mismo río, en el barrio La Isla. Las descargas de la parte céntrica de la ciudad se muestrearon sobre el Río Ejido en barrio José Ilario López, en la calle 14 con $12(\mathrm{JL})$, y a $1 \mathrm{~km}$ después sobre el puente del barrio Minuto de Dios $\left(\mathrm{JL}_{+1 \mathrm{~km}}\right)$. Los vertimientos de la parte sur se muestrearon sobre el Río Cauca, ubicado en barrio Lomas de Granada ( $\mathrm{Lg}$ ), y su dilución fue evaluada $1 \mathrm{~km}$ después $\left(\operatorname{Lg}_{+1 \mathrm{~km}}\right)$, en cercanías a la vereda Julumito, como se ve en la Figura 4.2. Estos puntos recogen la 
mayoría de las aguas residuales de Popayán. El punto muestreado en $\operatorname{Lg}_{+1 \mathrm{~km}}$, recibe todas las descargas de la Ciudad, como se puede ver en la Figura 4.2.

Los sitios de muestreo en la Ciudad de Santiago de Cali, en el departamento del Valle del Cauca, se seleccionaron de acuerdo a estudios realizados previamente por el Grupo de Investigación en Ingeniería Sísmica, Eólica, Geotécnica y Estructural de la Universidad del Valle. Los puntos de muestreo se enfocaron en el cauce del Río Cauca, el cual es la principal fuente de abastecimiento de la ciudad capital del departamento del Valle del Cauca (Santiago de Cali). Se muestrearon dos puntos sobre el mismo río, antes de llegar al reservorio inicial de la planta potabilizadora de Puerto Mallarino (PTAP). Estos sitios se ubicaron sobre el puente de Hormiguero (PH) y sobre el Canal colector sur (CS), como se muestra en la Figura 4.2. Este canal recoge las aguas residuales de cerca de 200.000 personas del suroriente de la ciudad y vierte sus aguas, sin tratamiento, al río Cauca (Espinel and Valencia, 2007). El Río Cauca tiene un recorrido de aproximadamente $190 \mathrm{~km}$ desde el último punto muestreado en Popayán $\left(\operatorname{Lg}_{+1 \mathrm{~km}}\right)$, hasta el primer punto muestreado en el departamento del valle del Cauca, sobre el Puente Hormiguero. Además se tomaron muestras del reservorio inicial (PPA) y del agua tratada de la planta potabilizadora, que abastece el 60\% de la ciudad. El afluente (EDA) y el efluente (EDE) de la planta de tratamiento de aguas residuales (PTAR) de Cañaveralejo también se muestrearon (a estos tratamientos también se los conoce como estaciones depuradoras). Finalmente se evaluó un último punto sobre el Río Cauca, ubicado en el Puente Paso del Comercio (PC), a 2,5 km después de la descarga de la PTAR. 


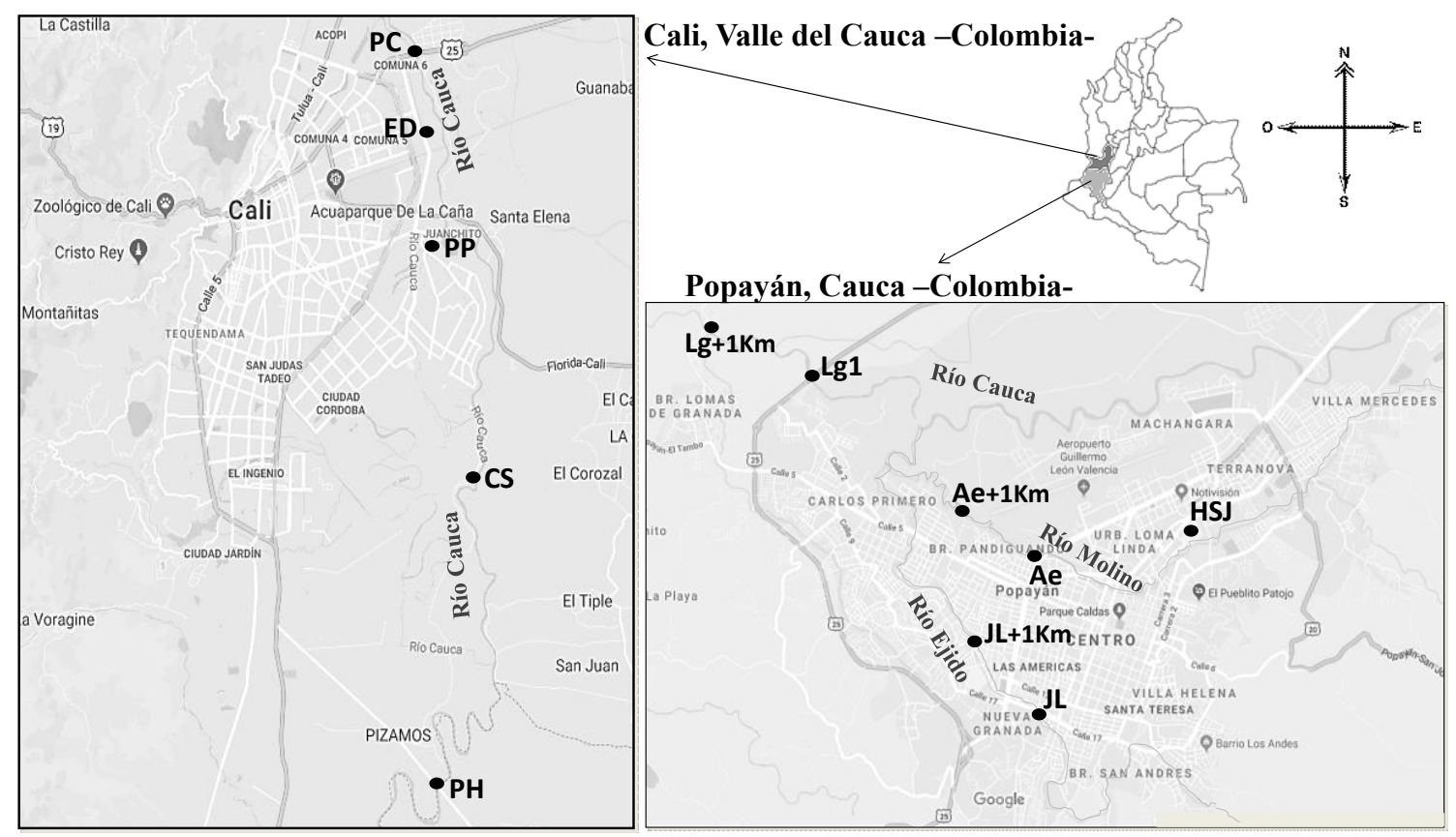

Figura 4.2 Sitios de muestreo para el diagnóstico de carbamazepina, sildenafil y metilparabeno en departamentos del Cauca y Valle del Cauca - Colombia.

Tabla 4.1 Descripción de los sitios muestreados en Argentina y Colombia

\begin{tabular}{|c|c|c|c|c|c|}
\hline Código & Sitio de muestreo & $\begin{array}{l}\text { Caudal } \\
\left(\mathrm{m}^{3} / \mathrm{s}\right)\end{array}$ & Ubicación & $\begin{array}{l}\text { Población de } \\
\text { vertimiento }\end{array}$ & Provincia \\
\hline & \multicolumn{5}{|c|}{ ARGENTINA } \\
\hline RDT & Arroyo Cala & 100 & Rosario del Tala & $13.723^{+}$ & Entre Ríos \\
\hline PA & Río Gualeguay & 210 & Gualeguay & ND & Entre Ríos \\
\hline $2 \mathrm{~B}$ & Río Gualeguay & 210 & Gualeguay & $12.211^{*}$ & Entre Ríos \\
\hline $\mathrm{CH} 1$ & Arroyo Carnaval & ND & City Bell & NA & Buenos Aires \\
\hline $\mathrm{CH} 2$ & Arroyo Carnaval & ND & City Bell & NA & Buenos Aires \\
\hline $\mathrm{CH} 3$ & Arroyo Carnaval & ND & City Bell & NA & Buenos Aires \\
\hline $\mathrm{CH} 4$ & Arroyo Carnaval & ND & City Bell & NA & Buenos Aires \\
\hline $\mathrm{CH} 5$ & Arroyo Carnaval & ND & City Bell & NA & Buenos Aires \\
\hline CL1 & Río La Plata & 22.000 & Gran La Plata & $176.175^{*}$ & Buenos Aires \\
\hline CL2 & Alcantarillado & NA & Gran La Plata & $176.175^{*}$ & Buenos Aires \\
\hline CL3 & Canal & NA & Gran La Plata & NA & Buenos Aires \\
\hline
\end{tabular}


Capítulo 4. Diagnóstico de contaminantes emergentes en aguas residuales y superficiales

\begin{tabular}{cccccc}
\hline Código & Sitio de muestreo & $\begin{array}{c}\text { Caudal } \\
\left(\mathrm{m}^{3} / \mathrm{s}\right)\end{array}$ & Ubicación & $\begin{array}{c}\text { Población de } \\
\text { vertimiento }\end{array}$ & Provincia \\
\hline $\mathrm{HSJ}$ & Caja de inspección & $\mathrm{NA}$ & Popayán & $\mathrm{ND}$ & Cauca \\
$\mathrm{Ae}$ & Río Molino & 1,09 & Popayán & $\mathrm{ND}$ & Cauca \\
$\mathrm{Ae}_{+1 \mathrm{Km}}$ & Río Molino & 1,09 & Popayán & $\mathrm{ND}$ & Cauca \\
$\mathrm{JL}$ & Río Ejido & 1 & Popayán & $\mathrm{ND}$ & Cauca \\
$\mathrm{JL}_{+1 \mathrm{Km}}$ & Río Ejido & 1 & Popayán & $\mathrm{ND}$ & Cauca \\
$\mathrm{Lg}$ & Río Cauca & 3.000 & Popayán & $\mathrm{ND}$ & Cauca \\
$\mathrm{Lg}_{+1 \mathrm{Km}}$ & Río Cauca & 3.000 & Popayán & $290.949^{+}$ & Cauca \\
$\mathrm{PH}$ & Río Cauca & 3.000 & Santiago de Cali & $\mathrm{ND}$ & Valle del Cauca \\
$\mathrm{CS}$ & colector & NA & NA & $200.000^{+}$ & Valle del Cauca \\
$\mathrm{PP}$ & PTAP & NA & Santiago de Cali & NA & Valle del Cauca \\
$\mathrm{PT}$ & PTAR & NA & Santiago de Cali & $2.245 .281^{+}$ & Valle del Cauca \\
$\mathrm{PC}$ & Río Cauca & 3.000 & Santiago de Cali & $2.445 .281^{+}$ & Valle del Cauca \\
\hline
\end{tabular}

NA: no aplica, debido a que no tiene una población de vertimiento directa; ND: no determinado.

* Población por viviendas conectadas a la red de alcantarillado, $\mathrm{y}^{+}$por número de habitantes.

\subsubsection{Fotos representativas de los sitios muestreadas}

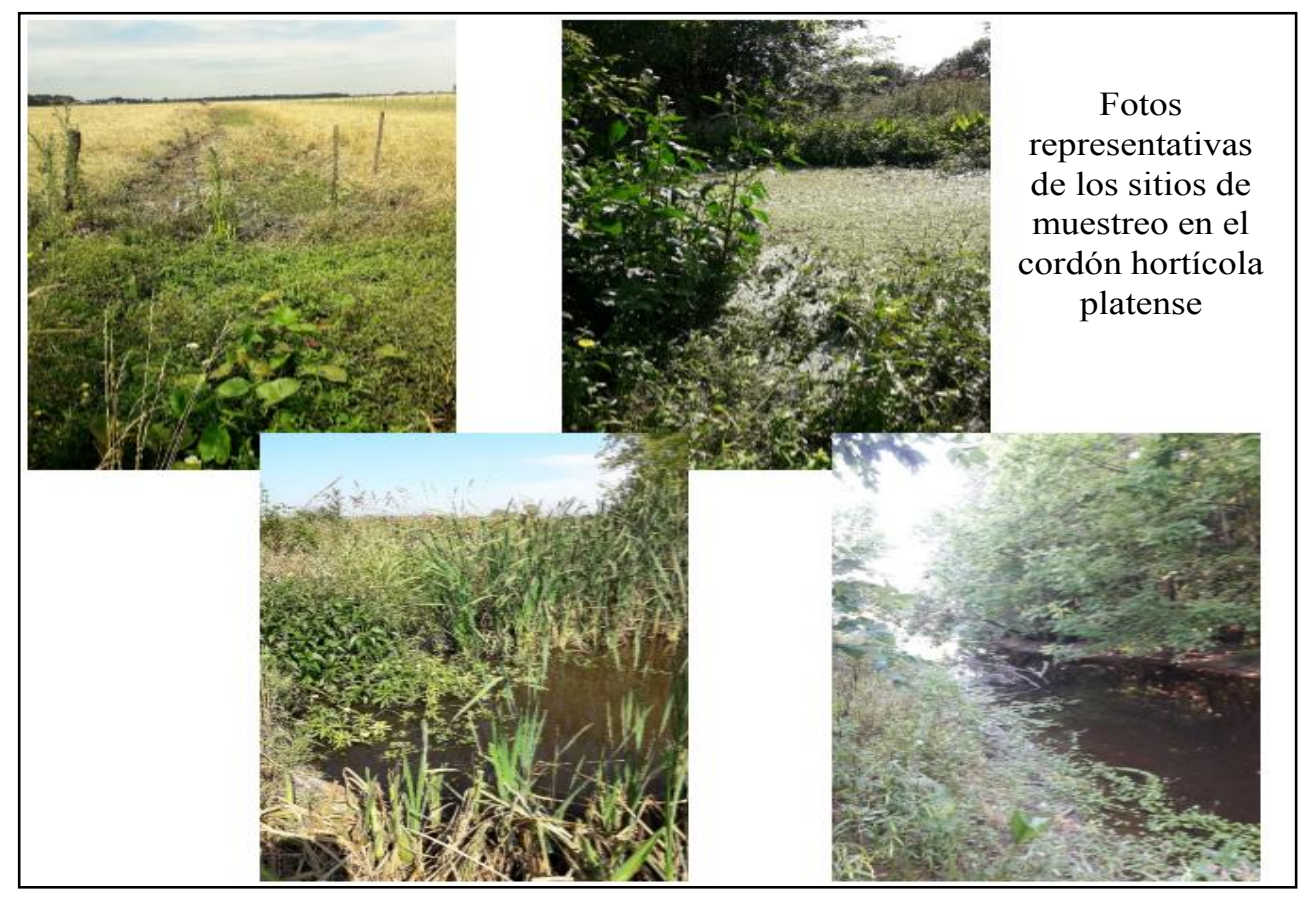



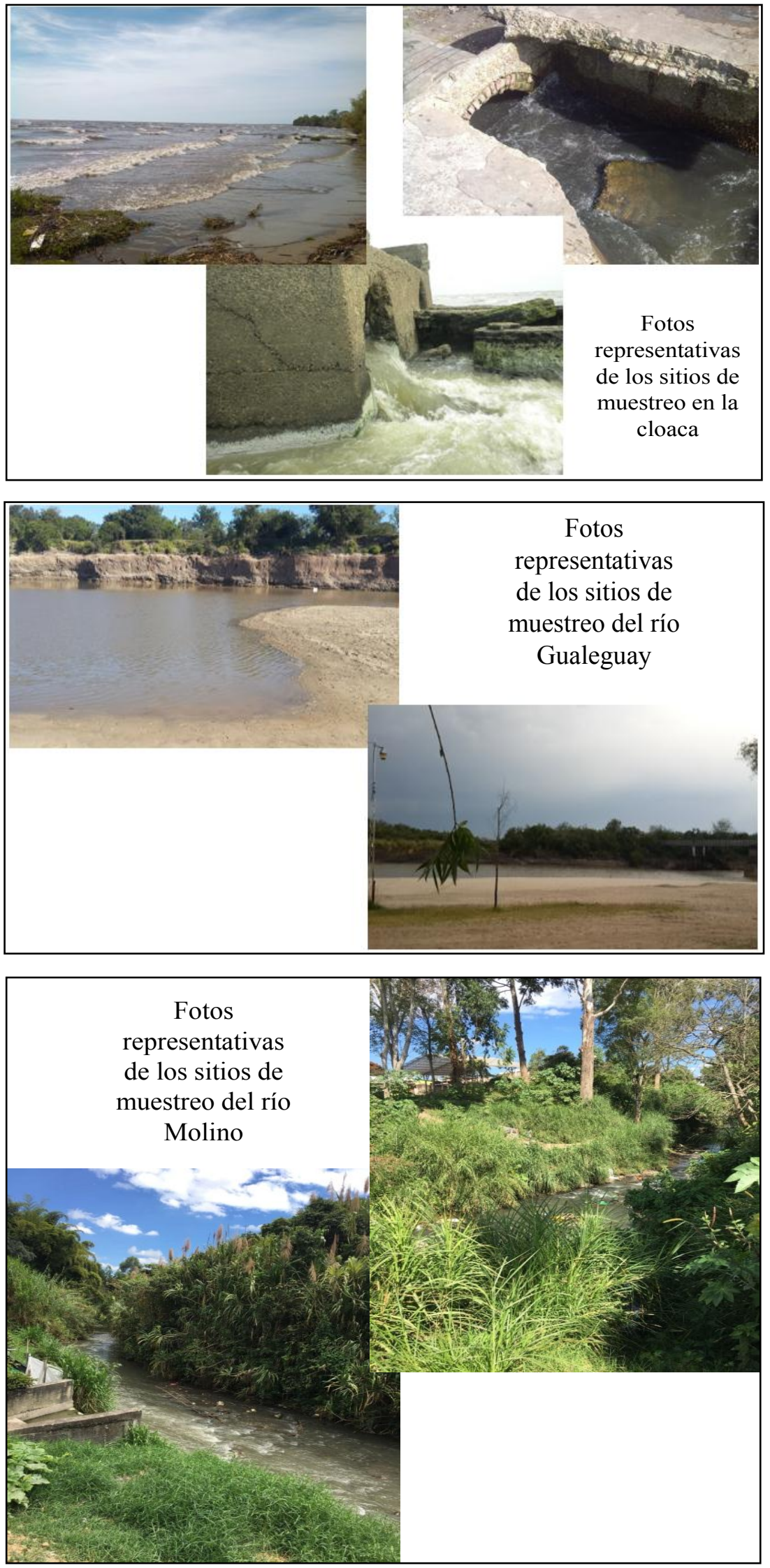

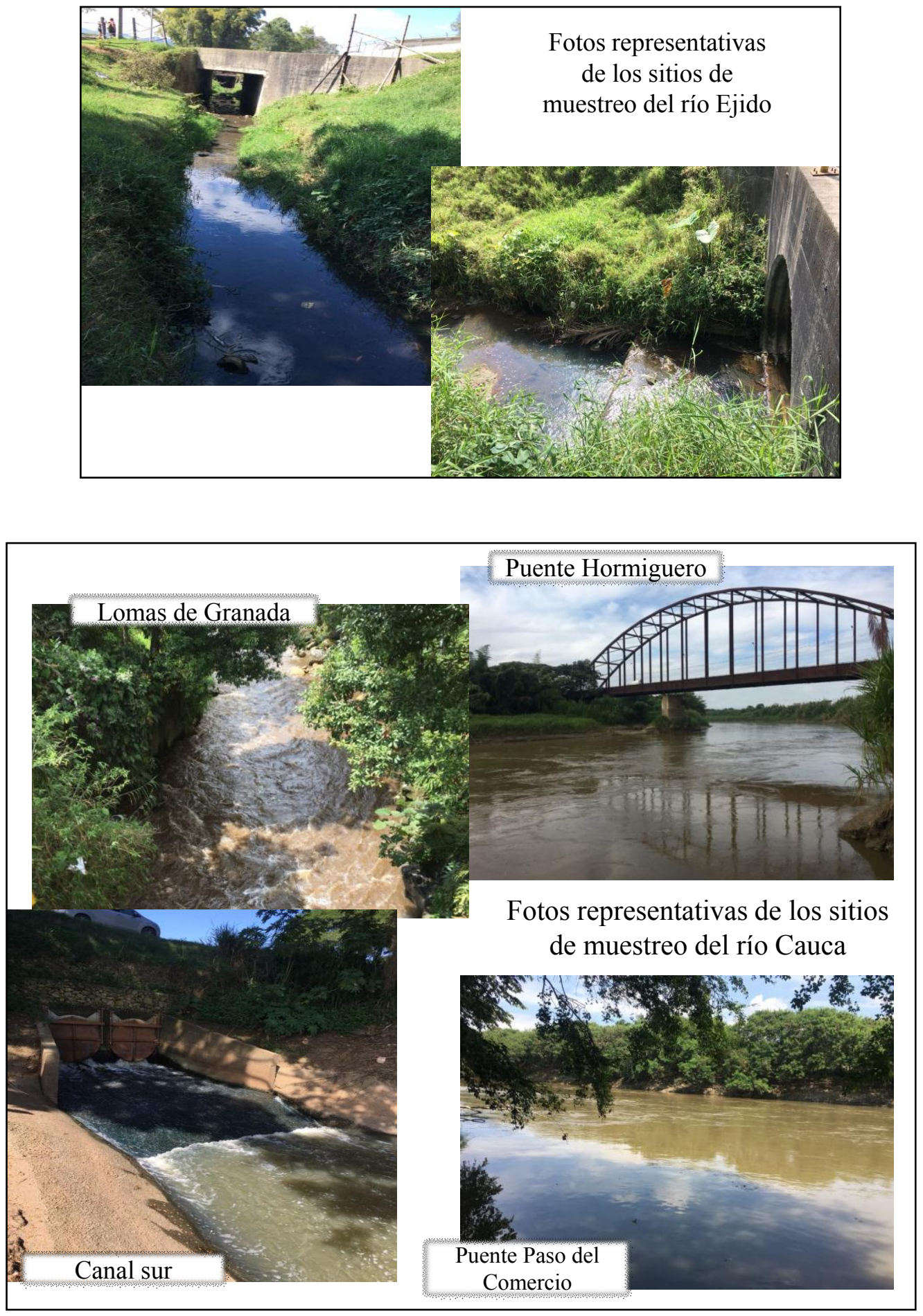


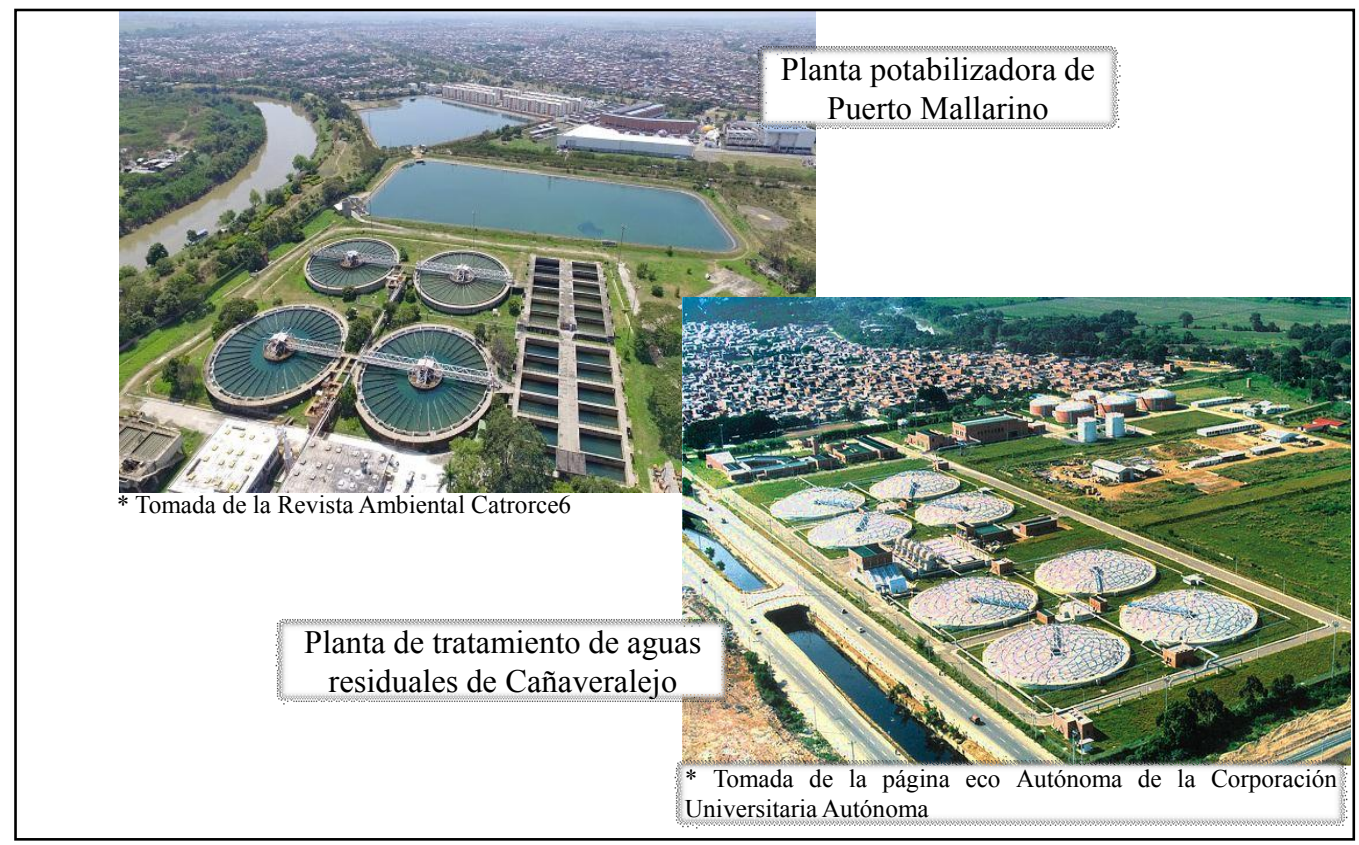

\subsubsection{Toma de muestras y técnicas analíticas}

Para la detección de PPCPs en matrices ambientales se recogieron muestras de $200 \mathrm{~mL}$ directamente de los ríos, de las descargas de las cloacas, y de la entrada y salida de la PTAR y la PTAP. Se dividieron en dos frascos de vidrio color ámbar, uno de ellos se sobre agregó con $200 \mu \mathrm{g} / \mathrm{L}$ de los compuestos de estudio, para evaluar la variación en la concentración en la matriz estudiada, por el transporte y almacenado. Se agregó azida de sodio y EDTA a cada muestra en concentraciones de $250 \mathrm{mg} / \mathrm{L}$ para evitar el crecimiento bacteriano y reacciones de complejación entre los fármacos y los iones naturales. La determinación de los PPCPs ( $\mathrm{Cbz}$ y Mp) se evaluó en el sedimento, la fracción soluble y particulada para las muestras de Argentina, utilizando un cromatógrafo líquido de ultraaltapresión (UPLC-MS/MS, Ultra performance liquid chromatography con detector de espectrómetro de masas en tándem MS/MS). En Colombia se evaluó únicamente la fracción soluble ( $\mathrm{Cbz}$, Si y Mp) mediante un equipo equivalente al utilizado en Argentina (HPLC-MS/MS). Los compuestos se determinaron en el Centro de Investigaciones del Medio Ambiente (CIM) de la Facultad de Ciencias Exactas de la Universidad Nacional de La Plata y en el Grupo de Diagnóstico y Control de la Contaminación (GDCON) de la Universidad de Antioquia. Los límites de cuantificación de cada técnica se presentan en la Tabla 4.2. 
Tabla 4.2: Límites de cuantificación para los PPCPs estudiados.

\begin{tabular}{cccc}
\hline Compuesto & $\begin{array}{c}\text { Fracción soluble } \\
(\mu \mathrm{g} / \mathrm{L})\end{array}$ & $\begin{array}{c}\text { Fracción } \\
\text { particulada* }(\mu \mathrm{g} / \mathrm{L})\end{array}$ & $\begin{array}{c}\text { Sedimento }(\mu \mathrm{g} / \mathrm{Kg}) \\
\text { UPLC-MS/MS (Argentina) }\end{array}$ \\
\hline Cbz & 0,001 & 0,001 & 0,003 \\
$\mathrm{Mp}$ & 0,007 & 0,007 & 0,15 \\
Sil & NA & NA & NA \\
\hline & \multicolumn{2}{c}{ HPLC-MS/MS (Colombia) } \\
\hline Cbz & 0,25 & NA & NA \\
Mp & 0,25 & NA & NA \\
Sil & 0,25 & NA & NA \\
\hline
\end{tabular}

* Corresponde a la referencia del volumen de agua filtrado; NA: no aplica.

\subsection{Resultados y discusión}

El impacto de los contaminantes emergentes es un área de la ciencia y la ingeniería ambiental en desarrollo y un campo de estudio de los últimos años en diferentes lugares del mundo (Archer et al., 2017b; Bu et al., 2013). En países como Colombia y Argentina, se necesita generar mayor volumen de información, para tener un mayor conocimiento acerca de su presencia y distribución en los cuerpos de agua. Así por ejemplo, en publicaciones anteriores se reportaron compuestos farmacéuticos en las aguas superficiales de Argentina (Elorriaga et al., 2013a; 2013 b; Pérez et al., 2018), y productos de cuidado personal en las de Colombia (Gracia-Lor et al., 2012), siendo la Cbz, el Sil y el Mp los detectados principalmente. Dado que en Colombia solo se contaba con valores reportados para el $\mathrm{Mp}$ y no para la $\mathrm{Cbz}$ y el Sil, y teniendo en cuenta que el espíritu del trabajo fue homogenizar esta situación en ambos países, se realizaron monitoreos para estos dos fármacos en Colombia y se complementó el estudio del $\mathrm{Mp}$ en Argentina. Además se evaluó nuevamente la Cbz en Argentina, para determinar si existía variabilidad respecto de las concentraciones reportadas anteriormente; y en Colombia se estudió nuevamente el $\mathrm{Mp}$, ya que las concentraciones informadas se determinaron en aguas de embalses, pero no se conoce sus niveles de concentración en las aguas residuales, ni en los cuerpos receptores. Igualmente se los estudió en el afluente y efluente de una planta potabilizadora y una depuradora, convencionales. 


\subsubsection{Diagnóstico en Argentina}

Las muestras de agua de Argentina se evaluaron en aguas superficiales y sedimentos. Para el agua superficial se consideró la fracción soluble y la particulada. Como se puede ver en los gráficos de la Figura 4.3 A, el Mp fue el compuesto más frecuentemente detectado y en mayores concentraciones, con valores entre $<\mathrm{LC}-0,5$ $\mu \mathrm{g} / \mathrm{L}$ en la fracción soluble, mientras que para la $\mathrm{Cbz}$ fueron $<0,1 \mu \mathrm{g} / \mathrm{L}$, siendo principalmente evidente su presencia en las muestras tomadas del río de La Plata ( CL1, CL2 y CL3). Como se puede ver en los gráficos de las Figura 4.3, no se detectó la $\mathrm{Cbz}$ en ninguno de los otros sitios muestreados. Las concentraciones del Mp en la fracción particulada estuvieron entre $130 \mu \mathrm{g} / \mathrm{Kg}-7.588 \mu \mathrm{g} / \mathrm{Kg}$ (ver Figura 4.3B), y en los sedimentos entre $53 \mu \mathrm{g} / \mathrm{Kg}-100 \mu \mathrm{g} / \mathrm{Kg}$ (ver Figura 4.3C).

Es importante tener en cuenta para la Figura 4.3 B que las concentraciones de los PPCPs se presentan en $\mu \mathrm{g} / \mathrm{Kg}$, por lo que se reportan valores altos en la fracción particulada, sin embargo los sólidos suspendidos en las muestras de agua analizadas estuvieron en el orden de los mg/L. Los valores de los PPCPs obtenidos compensados por la masa de material particulado en el volumen de muestra filtrada se presentan en la Tabla 4.3. La concentración mínima de Mp que se obtuvo es de 0,060 $\mu \mathrm{g} / \mathrm{L}$ y la máxima es de $0,198 \mu \mathrm{g} / \mathrm{L}$. La Cbz no se detectó en el material particulado de ninguna de las muestras. Por lo tanto al comparar el aporte de ambas fracciones a la columna de agua, se concluye que la fracción soluble tiene un mayor aporte que la fracción particulada (ver la Figura 4.3 D). A pesar de que la fracción particulada participa activamente en el reparto de los contaminantes, se propone que en el proceso de sedimentación para el Mp es degradado, debido a su baja detección en los sedimentos de fondo.

La presencia del Mp principalmente en la fracción soluble se puede atribuir a su mayor coeficiente de reparto con la materia $(\mathrm{koc}=2,4)$ que el Kow $(\mathrm{Kow}=1,96)$, permitiéndole tener una distribución más uniforme en la columna de agua. Además, de acurdo a las características físicoquímicas tanto de la Cbz como del Mp (ver Tabla 3.1), ambos compuestos presentan afinidad media baja con el suelo y con la biota acuática (Calamari, 1993). Resultados similares se han reportado anteriormente para la Cbz (Roca, 2016). 
La presencia de los contaminantes en el río Gualeguay (PA, 2B), el río La Plata (CL1, CL2, CL3) y el arroyo Cala (RDT) se deben al vertimiento de las aguas residuales urbanas sin un tratamiento previo. Mientras que su presencia en los cuerpos de agua inmersos en el Cordón Hortícola Platense (CH2-CH5), donde la disposición de viviendas es escasa, podrían estar asociadas al volcado de líquidos del río de La Plata provenientes de camiones atmosféricos para la fertilización de las plantaciones, tal como relatan algunos productores de la zona, aportando a contaminaciones difusas por escorrentía superficial. Por lo tanto, como era de esperarse, en el primer punto muestreado en cercanías a la Laguna García, donde nace el Arroyo Carnaval (CH1), y que no está influenciado por actividades humanas, no se detectó ninguno de los PPCPs evaluados sobre la fracción soluble.
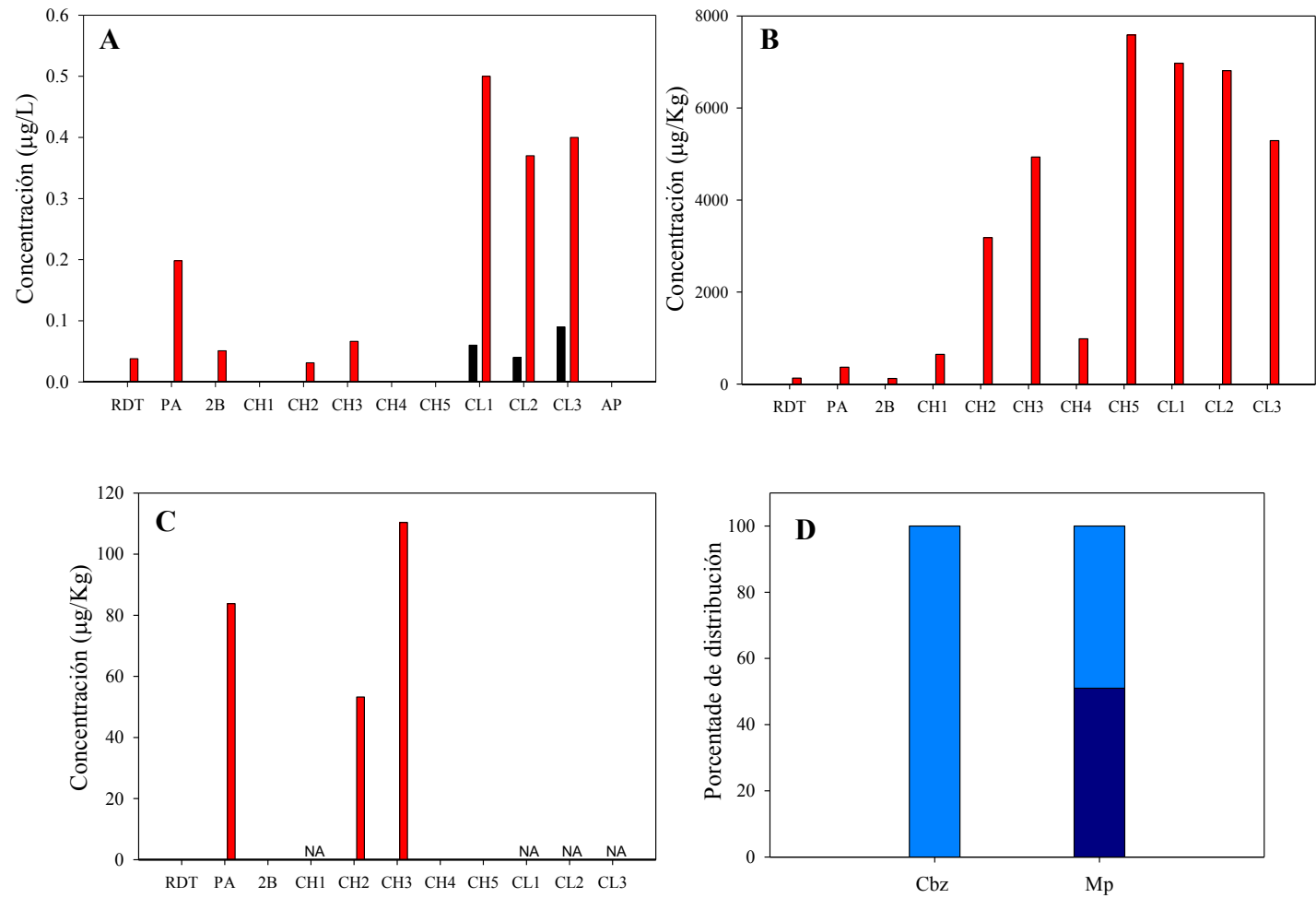

Figura 4.3: Concentración de ( I) carbamazepina y ( I ) metilparabeno en: (A) la fracción soluble, (B) la fracción particulada y (C) en el sedimento, en las muestras estudiadas en Argentina. En el gráfico D se presenta la distribución cada compuesto entre la ( I ) fracción soluble y ( I) particulada. NA: No analizado. AP: muestra de agua potable de La Plata. 
Tabla 4.3. Concentración del fármaco y el producto de cuidado personal (PPCPs) en el material particulado expresado en $\mu \mathrm{g} / \mathrm{L}$, compensando su masa en el volumen de muestra filtrado.

\begin{tabular}{llllllllllll}
\hline PPCPs & RDT & PA & 2B & CH1 & CH2 & CH3 & CH4 & CH5 & CL1 & CL2 & CL3 \\
\hline $\mathrm{Mp}$ & 0,12 & 0,16 & 0,11 & 0,19 & 0,14 & 0,12 & 0,06 & 0,14 & 0,19 & 0,11 & 0,15 \\
$\mathrm{Cbz}$ & $<\mathrm{LD}$ & $<\mathrm{LD}$ & $<\mathrm{LD}$ & $<\mathrm{LD}$ & $<\mathrm{LD}$ & $<\mathrm{LD}$ & $<\mathrm{LD}$ & $<\mathrm{LD}$ & $<\mathrm{LD}$ & $<\mathrm{LD}$ & $<\mathrm{LD}$ \\
\hline
\end{tabular}

$<$ LD: menor al límite de detección

\subsubsection{Diagnóstico en Colombia}

Dado que los PPCPs se movilizan principalmente sobre la fracción soluble, las muestras tomadas en Colombia se analizaron únicamente sobre esta fracción. Como se puede ver en la Figura 4.4, la presencia de los tres compuestos se hizo evidente en todos los sitios muestreados, con concentraciones entre $<$ LC y 10, $66 \mu \mathrm{g} / \mathrm{L}$ para la $\mathrm{Cbz}$, entre 0,8 y 7,24 $\mu \mathrm{g} / \mathrm{L}$ para el Mp y entre 0,13 y 2,64 $\mu \mathrm{g} / \mathrm{L}$ par el Sil. La mayores concentraciones de $\mathrm{Cbz}$ se presentaron sobre las descargas de los ríos Molino (Ae) y Ejido (JL), los cuales tienen los menores caudales de todos los ríos estudiados, con valores de aproximadamente $1 \mathrm{~m}^{3} / \mathrm{s}$. Su concentración disminuyó en aproximadamente un $80 \%$ en las muestras evaluadas a $1 \mathrm{Km}$ aguas abajo. La misma tendencia presentó el Mp sobre el río Molin(Ae), sin embargo su concentración se mantuvo estable en el río Ejido (JL) y Cauca (Lg). Por su parte, el Sil no presentó mayores variaciones en ninguno de los sitios estudiados.

Aunque el río Cauca tiene un recorrido de aproximadamente $200 \mathrm{~km}$ desde el último punto de vertimiento de la Ciudad de Popayán $\left(\operatorname{Lg}_{+1 \mathrm{Km}}\right)$ hasta llegar a la Ciudad de Santiago de Cali, la presencia de los PPCPs se hizo evidente en la cámara inicial de toma de muestras de la planta potabilizadora de Puerto Mallarino (PPA), incluso en concentraciones superiores a las determinadas en el punto $\mathrm{Lg}_{+1 \mathrm{~km}}$. Lo que indica el vertido de aguas residuales de los pueblos aledaños sobre el mismo río, manteniendo casi constante la concentración detectada sobre puente Hormiguero $(\mathrm{PH})$ y mostrando un comportamiento persistente o seudo persistente sobre las fuentes de agua, acorde a lo reportado anteriormente (Archer et al., 2017a). El mismo comportamiento se observó en Argentina sobre el Río Gualeguay (PA), el cual recibe las aguas del Arroyo Cala, y que tiene un recorrido de aproximadamente $160 \mathrm{~km}$ antes de su desembocadura. 
Además se pudo determinar que en el efluente de la planta potabilizadora, para abastecimiento de la Ciudad de Santiago de Cali (APC), se encontraron concentraciones de $1,5 \mu \mathrm{g} / \mathrm{L}$ y $2 \mu \mathrm{g} / \mathrm{L}$ de $\mathrm{Cbz}$ y Sil, respectivamente. Asimismo se detectaron los tres compuestos en el efluente de la planta de tratamiento de aguas residuales de Cañaveralejo (EDE), la cual cuenta con un tratamiento convencional, presentando un comportamiento similar al reportado anteriormente para sistemas similares (Bu et al., 2013; Gavrilescu et al., 2015; Rodriguez et al., 2017), encontrando eficiencias de remoción inferiores al 30 \% para el Mp (Matamoros et al., 2015), mientras que la $\mathrm{Cbz}$ se la reportó como contaminante recalcitrante (Zhang et al., 2008). Por lo tanto, como era de esperarse, su presencia también se hizo evidente en el río Cauca a 2,5 km después de recibir las aguas de la PTAR (PC). En este caso es importante tener en cuenta que las determinaciones en los afluentes de la PTAP y la PTAR se realizaron de forma directa, debido a interferencias analíticas, por lo cual se pueden ver alterados los resultados, mostrando un aparente aumento en la concentración de los PPCPs en sus efluentes (Ver Figura 4.4).

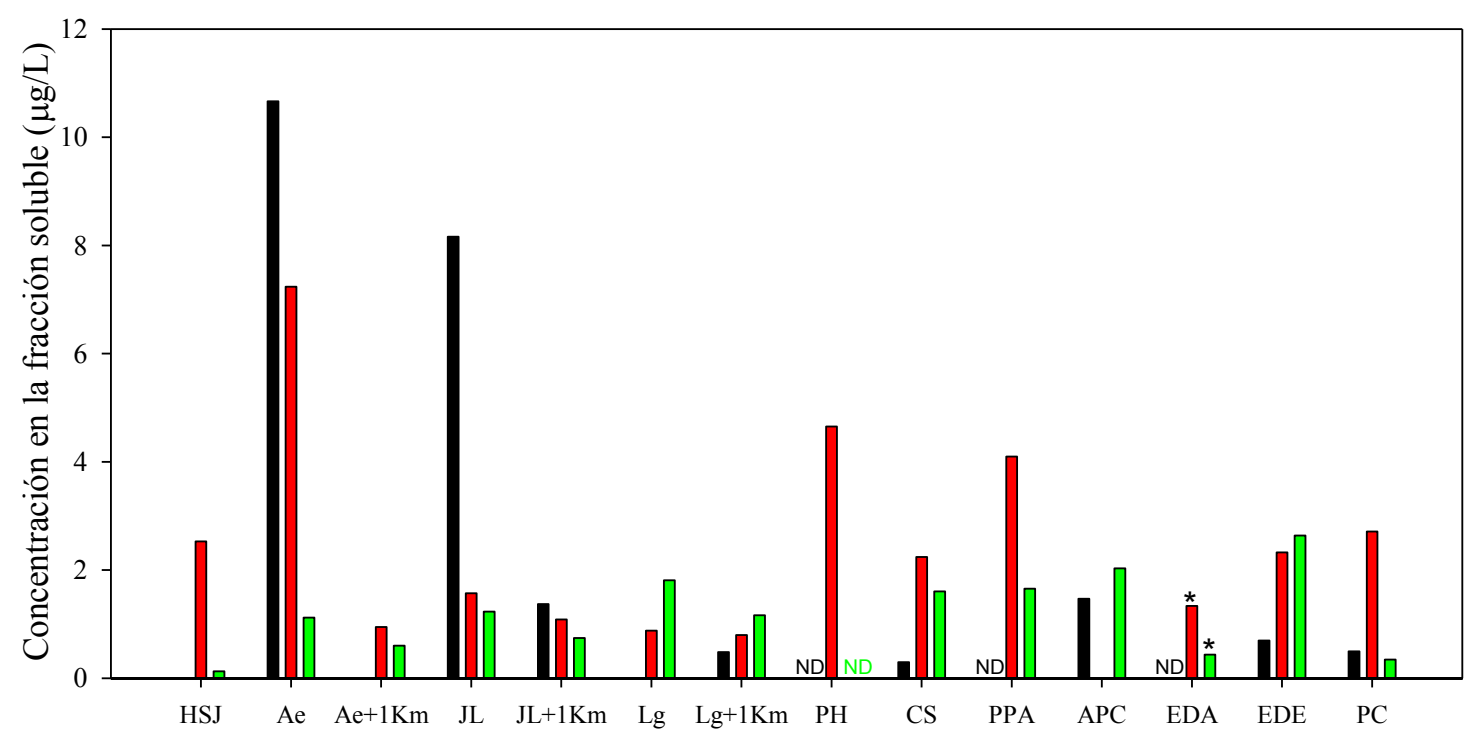

Figura 4.4: Concentración en la fracción soluble de la ( \) carbamazepina, ( \) el metilparabeno y ( I) el sildenafil, en las muestras estudiadas en Colombia. ND: no determinado por interferencia analítica. * Determinadas por inyección directa. PPA: afluente de la planta potabilizadora; APC: efluente de la planta potabilizadora de Puertomallarino. EDA y EDE: afluente y efluente de la planta de tratamiento de aguas residuales de Cañaveralejo, respectivamente. 


\subsubsection{Comparación de los niveles detectados entre los países de estudio}

La presencia de los PPCPs se hizo evidente en todos los sitios muestreados tanto de Argentina como de Colombia, pero se reflejaron concentraciones mayores en los cuerpos de agua de Colombia, con valores máximos de $11 \mu \mathrm{g} / \mathrm{L}, 9 \mu \mathrm{g} / \mathrm{L}$ y $3 \mu \mathrm{g} / \mathrm{L}$, para $\mathrm{Cbz}, \mathrm{Mp}$ y Sil, respectivamente, mientras que en Argentina fueron de $0,1 \mu \mathrm{g} / \mathrm{L}$ y $0,5 \mu \mathrm{g} / \mathrm{L}$, respectivamente. Sin embargo, es importante tener en cuenta que la capacidad de dilución de los ríos en Colombia no es lo suficientemente alta. Así por ejemplo, el río Molino (Ae) y el Ejido (JL) que cuentan con caudales de aproximadamente $1 \mathrm{~m}^{3} / \mathrm{s}$ reciben vertimientos de aproximadamente 90.000 personas, cada uno. Por su parte el río Cauca recibe aguas residuales de una población de 2.500.000 de Santiago de Cali (PC), volcadas en un caudal de $3.000 \mathrm{~m}^{3} / \mathrm{s}$, sin contar con la carga contaminante remanente que le llega de la Ciudad de Popayán y las poblaciones aledañas. Por el contrario, en Argentina, la carga contaminante resulta inferior, teniendo en cuenta los mayores caudales de sus ríos, que van desde los 100 $\mathrm{m}^{3} / \mathrm{s}$ a los $22.000 \mathrm{~m}^{3} / \mathrm{s}$, y las menores cargas de vertimientos (ver Tabla 4.1). En este caso se puede comparar la población de Gualeguay (43.000 personas), que es similar a la de un sector de Popayán (90.000), quienes vierten sus aguas residuales sobre un río con un caudal (Q) de $210 \mathrm{~m}^{3} / \mathrm{s}$, mientras que el de Popayán tan solo tiene un $\mathrm{Q}=1,09$ $\mathrm{m}^{3} / \mathrm{s}$, generándose así, una mayor concentración de los PPCPs sobre este último.

En estudios anteriores sobre del río Colastiné (Argentina), que cuenta con un caudal medio de $1700 \mathrm{~m}^{3} / \mathrm{s}$, y que recibe las aguas residuales de la ciudad de Santa Fé (525093 habitantes), se reportaron concentraciones entre $<\mathrm{LC}(0,001) \mu \mathrm{g} / \mathrm{L}-14 \mu \mathrm{g} / \mathrm{L}$ para la $\mathrm{Cbz}$ y entre $0,013 \mu \mathrm{g} / \mathrm{L}-0,56 \mu \mathrm{g} / \mathrm{L}$ para el Sil (Pérez et al., 2018), siendo similares a las informadas en los cuerpos de agua de Colombia, en los que se presenta una relación más cercana para los caudales de los ríos y las población de vertimiento (ver Figura 4.4 y Tabal 4.1). De lo que se puede concluir que los rangos de aparición de los PPCPs son del mismo orden de magnitud en ambos países.

En el trabajo reportado por Elorriaga et al. (2013a), la concentración de Cbz fue diez veces mayor $(0,63 \mu \mathrm{g} / \mathrm{L})$ a la determinada en el presente trabajo $(0,058 \mu \mathrm{g} / \mathrm{L})$, sobre el mismo punto de muestreo del río de La Plata (CL3). Las concentraciones de Caf de los dos trabajos, fueron de 13,32 $\mu \mathrm{g} / \mathrm{L}$ y 1,205 $\mu \mathrm{g} / \mathrm{L}$, respectivamente, sobre el mismo sitio. Las concentraciones detectadas para la Caf se presentan en la Tabla 4.4. Luego de evaluar el cociente de las concentraciones para cada estudio se determinó un 
valor de 0,05 para ambas relaciones, indicando que se mantiene la proporción de los compuestos en el tiempo. Además también se determinó la proporción respecto al trabajo de Pérez et al. (2018), en el que se reportó una concentración de Caf de 17 $\mu \mathrm{g} / \mathrm{L}$, obteniendo un cociente de 0,8 . Este valor resultó superior al determinado para el efluente del Río La Plata (CL3), sin embargo teniendo en cuenta que su caudal es 13 veces mayor al del río Colastiné, se dividió la proporción encontrada sobre el factor de dilución de los caudales, encontrando un valor de 0,06 , el cual es muy similar al cociente determinado sobre el Río de La Plata, indicando que la proporcionalidad en el ingreso de estos compuestos se mantiene sobre los distintos sitios muestreados en el tiempo.

Tabla 4.4. Concentración de la cafeína medida en los diferentes sitios muestreados.

\begin{tabular}{cccc}
\hline $\begin{array}{c}\text { Muestr } \\
\mathrm{a}\end{array}$ & $\begin{array}{c}\text { Fracción soluble } \\
(\mu \mathrm{g} / \mathrm{L})^{*}\end{array}$ & $\begin{array}{c}\text { Fracción particulada } \\
(\mu \mathrm{g} / \mathrm{kg})^{*}\end{array}$ & $\begin{array}{c}\text { Sedimento } \\
(\mu \mathrm{g} / \mathrm{kg})^{+}\end{array}$ \\
\hline $\mathrm{CH} 1$ & $<\mathrm{LC}$ & 1,78 & $\mathrm{ND}$ \\
$\mathrm{CH} 2$ & 0,08 & 73,82 & $<\mathrm{LC}$ \\
$\mathrm{CH} 3$ & 0,07 & $<\mathrm{LC}$ & $<\mathrm{LC}$ \\
$\mathrm{CH} 4$ & $<\mathrm{LC}$ & $4.048,99$ & $<\mathrm{LC}$ \\
$\mathrm{CH} 5$ & 0,30 & $<\mathrm{LC}$ & $<\mathrm{LC}$ \\
$\mathrm{RDT}$ & 0,09 & $<\mathrm{LC}$ & $<\mathrm{LC}$ \\
$2 \mathrm{~B}$ & 0,03 & 341,76 & $<\mathrm{LC}$ \\
$\mathrm{PA}$ & 0,27 & $<\mathrm{LC}$ & $<\mathrm{LC}$ \\
$\mathrm{CL} 1$ & 1,205 & 4.21 & $\mathrm{ND}$ \\
$\mathrm{CL} 2$ & 0,47 & $<\mathrm{LC}$ & $\mathrm{ND}$ \\
$\mathrm{CL} 3$ & 0,37 & $<\mathrm{LC}$ & $\mathrm{ND}$ \\
\hline
\end{tabular}

ND: no determinado; $\mathrm{LC}=$ límite de cuantificación; ${ }^{*} \mathrm{LC}=0,002 \mu \mathrm{g} / \mathrm{L} ;{ }^{+} \mathrm{LC}=0,045$

La Cbz y el Mp también se evaluaron anteriormente en muestras de agua de dos embalses, ubicados en el departamento de Antioquia (Colombia), utilizados para el suministro de agua potable (Gracia-Lor et al., 2012). Los autores no detectaron Cbz en ninguna de las muestras estudiadas. Las concentraciones del Mp estuvieron entre $0,017 \mu \mathrm{g} / \mathrm{L}-0,537 \mu \mathrm{g} / \mathrm{L}$. El no detectar el fármaco, lo atribuyeron a la alta dilución que se está produciendo debido a la gran capacidad de los reservorios, sin embargo la 
presencia del Mp lo relacionan con la influencia de las actividades humanas cerca de los reservorios, por ejemplo, el reservorio 1 se usa como un lugar de recreación y está rodeado de residencias (Gracia-Lor et al., 2012). En este caso no se pudo determinar si se mantenía el cociente de proporcionalidad debido a que no se tenían las concentraciones para los dos marcadores ( $\mathrm{Cbz}$ y Caf), además las muestras de agua se tomaron en diferentes lugares, los cuales presentaban características totalmente distintas.

La presencia en el ambiente de varios contaminantes emergentes se evidenció desde hace aproximadamente una década, incluida la $\mathrm{Cbz}$, con concentraciones máximas de $6 \mu \mathrm{g} / \mathrm{L}$ (Ternes, 1998). Recientemente otros autores han reportado concentraciones similares a los encontrados en el presente trabajo, en países como Eslovenia, Croacia y La India, con concentraciones de hasta $18 \mu \mathrm{g} / \mathrm{L}$ para la $\mathrm{Cbz}$ y de $2 \mu \mathrm{g} / \mathrm{L}$ para el Mp (Česen et al., 2019; Williams et al., 2019). El Sil es un compuesto del que se encuentra muy poca información, siendo estudiado únicamente en los trabajos discutidos anteriormente en Argentina (Elorriaga, 2013a; Elorriaga 2013b; Pérez et al., 2018), y mediante el presente trabajo en Colombia.

En consecuencia, la detección de estos contaminantes emergentes en el ambiente está generando una creciente preocupación debido sus efectos potenciales sobre la biota acuática y la salud humada, por contacto indirecto, como es el caso de su detección en las aguas residuales tratadas y el agua potable (Geissen et al., 2015). En estudios se ha informado que los efectos agudos para los productos farmacéuticos se relacionaron con concentraciones generalmente 100-1000 más altas que las encontradas en el medio ambiente acuático, pero se observaron efectos adversos crónicos en el rango de las concentraciones de aguas residuales (Fent et al., 2006; Li et al., 2010). Investigaciones en peces han demostrado que los órganos más sensibles a los PPCPs son el hígado y las branquias, debido a su papel en la desintoxicación y excreción de xenobióticos (Vieira et al., 2016).

En estudios ecotoxicologícos realizados en el efluente de las aguas residuales en Argentina, en las que se detectaron los PPCPs, se observó estrés oxidativo en las branquias y el hígado de peces. En el hígado, también se observaron cambios metabólicos y daño histológico, además de determinar apoptosis en el cerebro de los mismos (Pérez et al., 2018). El daño primario en el ADN, el aumento de las células micro-nucleadas y la apoptosis también se observaron sobre D. polymorpha después 
de un tiempo de exposición de $96 \mathrm{~h}$, incluso en concentraciones de $40 \mathrm{ng} / \mathrm{L}$ de $\mathrm{Cbz}$ (Binelli et al., 2012; Petrie et al., 2015). Se ha reportado que el efecto fisiológico antiepiléptico de la $\mathrm{Cbz}$ se dirige involuntariamente a organismos no blanco, induciendo alteraciones en las actividades de ciertas enzimas y afectando las características de alimentación, crecimiento y reproducción, incluso cuando se tienen concentraciones ambientales a nivel traza, por lo que se lo puede considerar como de alto riesgo para los humanos ya que puede afectar a las células embrionarias humanas (Secondes et al., 2014). Pomati et al., (2006) observaron que una mezcla de compuestos como atenolol, bezafibrato, carbamazepina, ciclofosfamida, ciprofloxacina, furosemida, hidroclorotiazida, ibuprofeno, lincomicina, ofloxacina, ranitidina, salbutamol y sulfametoxazol, en concentraciones entre $0,01-1 \mu \mathrm{g} / \mathrm{L}$ inhibe el crecimiento de células renales embrionarias humanas (HEK293), con el efecto más alto observado como una disminución del 30\% en la proliferación celular en comparación con los controles.

Hasta el momento existen únicamente normativas que regulan la comercialización y el uso de algunos contaminantes emergentes, como es el caso de ciertos plaguicidas, así como su presencia en los cuerpos de agua y el agua potable, sin embargo los compuestos como la Cbz que tiene evidentes efectos negativos sobre la biota acuática, no está regulada por ninguna normativa (Geissen et al., 2015). Aunque en el Centro Suizo de Ecotoxicidad del Instituto Federal de Ciencias y Tecnologías Acuáticas (EAWAG) ya se la considera como un criterio de calidad ambiental en aguas superficiales con una concentración anual media de $0,5 \mu \mathrm{g} / \mathrm{L}$ y una máxima admisible de 2,6 mg/L, pero aún no se tiene como un estándar de calidad ambiental, (Mailler et al., 2015). Además se hace evidente la necesidad de desarrollar e implementar sistemas eficientes de tratamiento para las aguas residuales, que sean capaces de remover los contaminantes tradicionales, así como los emergentes, y poder mitigar los efectos adversos que puedan generar sobre la biota acuática, como en la salud humana.

\subsubsection{Parámetros de calidad del agua de los sitios muestreados}

En la Tabla 4.5 se muestran algunos parámetros fisicoquímicos medidos en los sitios muestreados. Todos los cuerpos de agua estudiados mostraron características similares para ambos países. El parámetro que presentó mayor variabilidad fue el 
oxígeno disuelto, con los valores más bajos para los ríos que reciben las descargas cloacales de la ciudad de Popayán, mostrando su mayor contaminación debido a los grandes volúmenes de aguas residuales vertidas, y su menor capacidad de depuración, siendo consistente con los resultados obtenidos para la concentración los PPCPs, los que presentaron sus mayores valores sobre estos cuerpos de agua.

Tabla 4.5: Parámetros fisicoquímicos de los cuerpos de agua muestreados.

\begin{tabular}{|c|c|c|c|c|c|c|}
\hline Código & $\overline{\mathrm{pH}}$ & $\mathrm{OD}(\mathrm{mg} / \mathrm{L})$ & $\mathrm{Cd}(\mathrm{ms} / \mathrm{cm})$ & $\mathrm{T}\left({ }^{\circ} \mathrm{C}\right)$ & SST (mg/L) & Cuerpo de agua \\
\hline \multicolumn{7}{|c|}{ ARGENTINA } \\
\hline $\mathrm{RDT}$ & 7,89 & 5,9 & 0,435 & 27,7 & NA & Arroyo Cala \\
\hline PA & 7,76 & 7,7 & 0,445 & 25,5 & NA & Río Gualeguay \\
\hline $2 \mathrm{~B}$ & 7,65 & 6,4 & 0,340 & 21,4 & NA & Río Gualeguay \\
\hline $\mathrm{CH} 1$ & NA & NA & NA & NA & NA & Arroyo Carnaval \\
\hline $\mathrm{CH} 2$ & 7,13 & 0,6 & 0,828 & 23,3 & NA & Arroyo Carnaval \\
\hline $\mathrm{CH} 3$ & 7,41 & 2,1 & 0,957 & 23,3 & NA & Arroyo Carnaval \\
\hline $\mathrm{CH} 4$ & 7,50 & 4,1 & 0,947 & 24,3 & NA & Arroyo Carnaval \\
\hline $\mathrm{CH} 5$ & 7,60 & 1,8 & 0,935 & 26,1 & NA & Arroyo Carnaval \\
\hline CL1 & NA & NA & NA & NA & NA & Río La Plata \\
\hline \multicolumn{7}{|c|}{ COLOMBIA } \\
\hline HSJ & 6,7 & 1,75 & 0,081 & 17,21 & 41 & Manhole \\
\hline $\mathrm{Ae}$ & 7,1 & 1,59 & 0,085 & 17,63 & 42 & Río Molino \\
\hline $\mathrm{Ae}_{+1 \mathrm{Km}}$ & 7,29 & 1,23 & 0,193 & 18,65 & 98 & Río Molino \\
\hline JL & 6,99 & 0,56 & 0,273 & 19,02 & 137 & Río Ejido \\
\hline $\mathrm{JL}_{+1 \mathrm{Km}}$ & 7,18 & 1,00 & 0,206 & 18,46 & 103 & Río Ejido \\
\hline $\mathrm{Lg}$ & 5,43 & 1,86 & 0,152 & 15,46 & 76 & Río Cauca \\
\hline $\operatorname{Lg}_{+1 \mathrm{Km}}$ & 6,02 & 1,78 & 0,143 & 15,78 & 71 & Río Cauca \\
\hline $\mathrm{PH}$ & 6,35 & 7,11 & 0,108 & NA & NA & Río Cauca \\
\hline $\mathrm{CS}$ & 6,41 & 3,26 & 0,329 & NA & NA & Río Cauca \\
\hline PPA & 6,32 & 6,28 & 0,108 & NA & NA & PTAP \\
\hline CAG & 7,88 & 5,77 & 0,143 & NA & NA & PTAP \\
\hline APC & 6,97 & 0,12 & 0,029 & NA & NA & PTAP \\
\hline EDA & 6,99 & 1,11 & 0,723 & NA & NA & PTAR \\
\hline EDE & 6,62 & 2,00 & 0,736 & NA & NA & PTAR \\
\hline $\mathrm{PC}$ & 6,35 & 7,11 & 0,108 & NA & NA & Río Cauca \\
\hline
\end{tabular}




\subsection{Conclusiones parciales}

Tanto en este trabajo como en otros realizados anteriormente en Argentina, se determinó la presencia de los contaminantes emergenetes sobre las diferentes matrices acuosas estudiadas. De los tres contaminantes emergentes, la $\mathrm{Cbz}$ y el $\mathrm{Mp}$, que fueron los evaluados en Argentina, se hicieron evidentes en los diferentes puntos evaluados. En Argentina no se evaluó nuevamente el Sil ya que se tenían datos confiables de su concentración en la base de datos del grupo de trabajo. En Colombia todas las muestras de agua superficial mostraron la presencia de los fármacos y el producto de cuidado personal, así como también los afluentes y efluentes de las plantas de tratamiento de aguas residuales y la potabilizadora, evidenciando la necesidad de tomar medidas eficientes para mitigar la contaminación de ríos con estos compuestos debido a las actividades antropogénicas.

No se observaron variaciones en las concentraciones de los PPCPs detectados en las diferentes muestras de agua de ambos países, luego de evaluar la población de vertimiento y el caudal de los ríos receptores. Además se pudo determinar que en Argentina se mantiene el factor de proporcionalidad de ingreso de la $\mathrm{Cbz}$ en el tiempo, evaluado a partir de las concentraciones detectadas de cafeína.

Se concluye que las descargas cloacales, ya sean vertimientos directamente sobre los cuerpos de agua, tratados en las PTAR o que llegan a los mismos por escorrentía (como es el caso del Arroyo Carnaval, en el cordón hortícola Platense), alcanzan las aguas superficiales y que si bien algunos de los PPCPs como el Mp, son fácilmente biodegradables, su detección evidencia una posibilidad de seudo persistencia.

El uso generalizado de los PPCPs, y su constante ingreso en el ambiente es motivo de preocupación debido a los efectos que podría producir si ninguna reglamentación impide su acumulación durante las próximas décadas, dado su categoría de contaminantes emergentes. Estos ya están presentes en cantidades mensurables y pueden afectar la calidad del agua, el impacto sobre el ecosistema y la salud humana. 


\section{CAPÍTULO 5}

\section{CONTACTORES BIOLÓGICOS ROTATIVOS PARA REMOCIÓN DE FÁRMACOS Y PRODUCTOS DE CUIDADO PERSONAL}

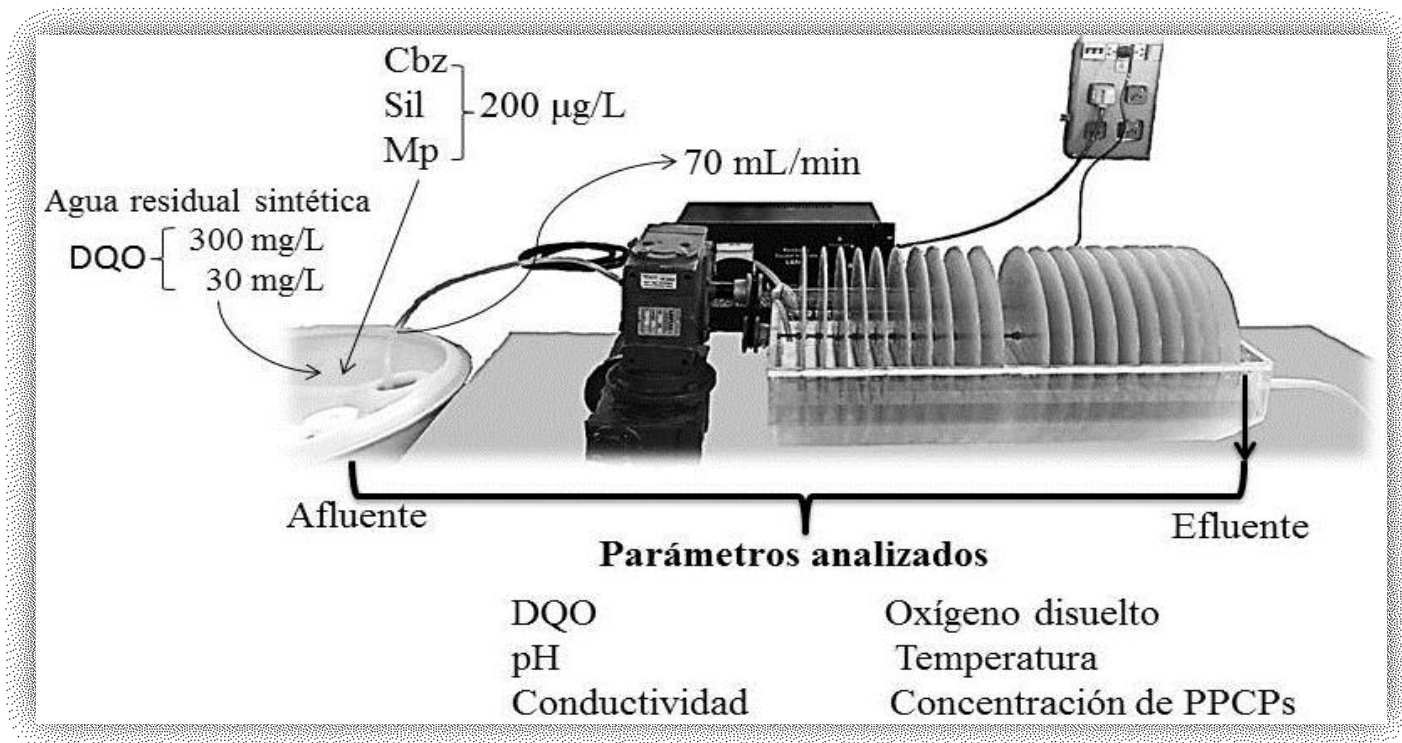




\section{Resumen}

El objetivo de este estudio fue evaluar un contactor biológico rotatorio a escala piloto como una tecnología aplicable a la eliminación de carbamazepina ( $\mathrm{Cbz}$, sildenafil (Sil) y metilparabeno (Mp). El comportamiento del sistema se evaluó para su incorporación individual y para su mezcla. Se estudiaron cargas orgánicas típicas provenientes a un tratamiento secundario y uno terciario. El caudal de trabajo fue de $70 \mathrm{~mL} / \mathrm{min}$ y la concentración de los PPCPs fue de $200 \mu \mathrm{g} / \mathrm{L}$. La carga orgánica afluente y efluente se evaluó en diferentes momentos durante el transcurso de la operación. El oxígeno disuelto, la temperatura, la conductividad y el pH se midieron in situ en cada muestreo. Se lograron eficiencias de remoción superiores al 98\% para el Mp, pero menores al 20\% para los productos farmacéuticos. La eficiencia de eliminación promedio para la materia orgánica fue del 95\% en las diferentes pruebas. En esta investigación, se observó que el RBC permitía la eliminación efectiva de contaminantes emergentes que presentaban estructura molecular simple y elementos químicos esenciales, como el Mp. Sin embargo, su efectividad fue pobre para la eliminación de contaminantes formados a partir de estructuras más complejas, como la Cbz y Sil. La estabilidad operativa del sistema no se vio afectada cuando estos compuestos se incorporaron en cantidades similares a las que se encuentran en las aguas residuales. 


\subsection{Introducción}

El ciclo natural del agua tiene una importante capacidad de purificación, sin embargo, no alcanza a eliminar muchos contaminantes de origen antrópico, debido a su alta concentración, persistencia y solubilidad en el agua, permaneciendo varios de ellos durante mucho tiempo en el ambiente acuático. Aquellos que son tóxicos además ponen en riesgo la vida de los organismos que allí habitan. En las aguas residuales urbanas se han cuantificado una gran variedad de sustancias químicas, que antes no se habían detectado por su baja concentración, pero gracias al desarrollo de las técnicas analíticas se ha logrado hacerlo (Elorriaga et al., 2013b; Gracia-Lor et al., 2012; Sui et al., 2015). Actualmente existen alrededor de unas 100 mil sustancias potencialmente peligrosas registradas, además de aquellos nuevos compuestos de síntesis que ingresan periódicamente al mercado (Petrie et al., 2015). Las sustancias de mayor consideración por su potencial toxicidad incluyen: antibióticos, esteroides estrógenos, antidepresivos, bloqueadores de los canales de calcio, drogas genotóxicas y antiepilépticos, entre los últimos se incluyen phenytoin, valproate y carbamazepina, que son capaces de iniciar apoptosis en cerebros en desarrollo. También se encuentran en esta categoría los parabenos, que son conservantes antimicrobianos usados en cosméticos, artículos de aseo, productos farmacéuticos e incluso alimenticios. Aunque la toxicidad aguda de estos compuestos es muy baja, existen datos de bibliografía que muestran una leve actividad estrógena (Gavrilescu et al., 2015; Li et al., 2015c; Stuart et al., 2012). Es por esta razón que es de creciente preocupación la contaminación del ambiente por vertidos urbanos debido a los numerosos riesgos que se pueden presentar (Boyd et al., 2003; Stackelberg et al., 2004).

Actualmente se buscan procedimientos alternativos de tratamiento como la adsorción, procesos de oxidación avanzada, tratamientos biológicos no convencionales, radiación ultravioleta, entre otros. La biosorción implica la acumulación de contaminantes por material biológico, ya sea por métodos metabólicos o puramente físico-químicos (Costley and Wallis, 2001). A diferencia de los tratamientos físicos y químicos, la biosorción generalmente no implica altos costos de operación. En particular los residuos sólidos generados durante el tratamiento se concentran en volúmenes más pequeños, que son fácilmente tratados (Bhide et al., 1996). 
Comparado con otros bioreactores, se ha demostrado que los contactores biológicos rotativos (CBR) presentan un tratamiento eficaz para aguas residuales complejas (Pakshirajan and Kheria, 2012) sobre todo porque ofrecen gran área superficial generada en el disco giratorio que establece un buen contacto entre las especies microbianas y los contaminantes presentes en el sistema. Es importante destacar que en los procesos de biopelícula, tales como los CBR, el tiempo medio de retención de las células microbianas se desacopla del tiempo de retención hidráulico, esto podría permitir mayores cargas orgánicas y ofrecer mayor resistencia a los choques tóxicos que los sistemas de cultivo en suspensión (Hassard et al., 2015), siendo además una tecnología atractiva debido a sus características operacionales tales como tiempos de retención hidráulico cortos, operación y diseños simples, altas eficiencias de tratamiento y bajo requerimiento de energía (Duque et al., 2011). Estos sistemas han sido exitosamente utilizados para tratar diversos contaminantes tales como fenol, colorantes, metales pesados, entre otros (Alemzadeh and Vossoughi, 2001; Malachova et al., 2013; Yamaguchi et al., 1999). Teniendo en cuenta que el tratamiento de contaminantes emergentes empleando los CBR no ha sido muy estudiado (Vasiliadou et al., 2014), en el presente trabajo se analiza este sistema para estudios de tratamiento de efluentes domésticos conteniendo dos fármacos: carbamazepina y sildenafil y un producto de cuidado personal: metilparabeno, elegidos por su representatividad en las aguas superficiales y residuales (Elorriaga et al., 2013b; Gracia-Lor et al., 2012).

\subsection{Metodología}

\subsubsection{Desarrollo y siembra del inóculo}

El inoculo se desarrolló en el laboratorio, utilizando un consorcio bacteriano característico de un agua residual doméstica. Se adicionaron $25 \mathrm{~mL}$ de un efluente cloacal a $250 \mathrm{~mL}$ del agua residual sintética, con una DQO de $200 \mathrm{mg} / \mathrm{L}$, sin superar el $30 \%$ del volumen total del recipiente, con el fin de favorecer la aireación y el crecimiento bacteriano. Esta mezcla se mantuvo en batch a temperatura ambiente y agitación constante. Posteriormente este cultivo se agregó al CBR, el cual se mantuvo en batch con agua residual sintética y con la misma carga orgánica, para favorecer el crecimiento en suspensión de los microorganismos y su posterior adherencia a la 
superficie de los discos. Se realizaron purgas diarias de 1 L de la solución y simultáneamente se adicionó la misma cantidad de agua residual fresca. Con esta etapa concluida, se trabajó en continuo con un caudal de alimentación de $70 \mathrm{~mL} / \mathrm{min}$ y una DQO de $100 \mathrm{mg} / \mathrm{L}$ hasta alcanzar un crecimiento constante de la biopelícula sobre la superficie de los discos.

\subsubsection{Características del sistema CBR a escala piloto}

El CBR a escala piloto utilizado en el presente trabajo fue similar a los encontrados a escala real. Consiste de veinte discos de acrílico de superficie rugosa, diámetro de $300 \mathrm{~mm}$ y espesor de $2 \mathrm{~mm}$, unidos a través de un eje central de acero inoxidable que los atraviesa longitudinalmente, y contenidos en una pileta de acrílico de 20L, que mantiene el perfil de los mismos. Un moto reductor de doble reducción a sinfín y corona de $0,25 \mathrm{HP}$, fue el encargado de mantenerlos en movimiento girando a 1,5 rpm. El 40\% del área superficial de los discos estaba sumergida en el agua residual contenida en la pileta (Cortez et al., 2008), de tal forma que al girar los discos a bajas revoluciones se formara una biopelícula, la cual en una etapa tomará el oxígeno del aire y en la siguiente el sustrato que lleve el agua a tratar. Completan el sistema, una bomba peristáltica utilizada para la carga del afluente y un tanque de alimentación de 200 L de capacidad como se observa en la Figura 5.1.

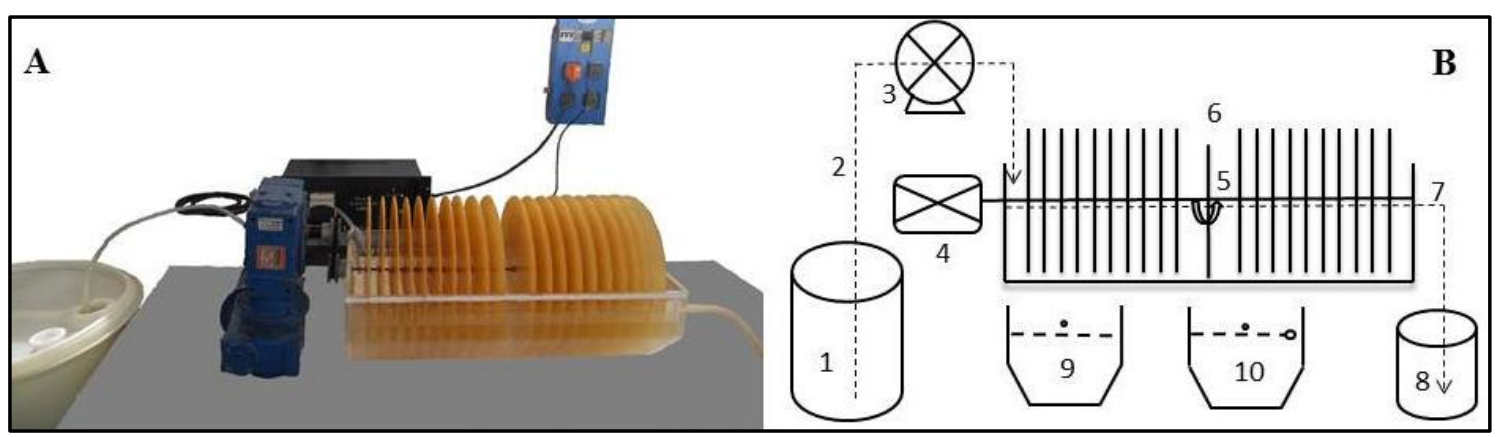

Figura 5.1 (A) Sistema de biodiscos a escala piloto y (B) Esquema del sistema de biodiscos: (1) tanque de $200 \mathrm{~L}$ que contiene el agua residual sintética y lugar de incorporación de los PPCPs; (2)línea de alimentación; (3) bomba peristáltica; (4) moto reductor de doble reducción a sinfín y corona; (5) soporte de los discos; (6) reactor de biodiscos (discos y pileta colectora del agua residual); (7)línea de efluente; (8) tanque colector del agua residual tratada; (9 y 10) vista lateral de la pileta en la entrada y salida del reactor respectivamente. 


\subsubsection{Diseño experimental para el CBR}

Se evaluó el comportamiento del CBR sin bacterias para determinar la interacción de los fármacos y el producto de cuidado personal (PPCPs) con los materiales del reactor y determinar si existen perdidas por adsorción. Para ello se colocaron soluciones de $5 \mathrm{mg} / \mathrm{L}$ en agua destilada con azida de sodio al $0,01 \%$, utilizada como agente antimicrobiano (Rossner et al., 2009). Se analizaron muestras de cada una de las soluciones antes del contacto con el sistema y a las $24 \mathrm{~h}$ de contacto. Éstas fueron determinadas por espectrofotometría a longitudes de onda de $285 \mathrm{~nm}$, $292 \mathrm{~nm}$ y $256 \mathrm{~nm}$ para Cbz, Sil y Mp, respectivamente. También se evaluaron las soluciones a las $24 \mathrm{~h}, 48 \mathrm{~h}$ y $72 \mathrm{~h}$ sin contacto con el reactor para determinar la degradación de los compuestos por acción de la luz. Luego, la concentración inicial para las soluciones de Cbz, Sil y Mp fueron 5,0 mg/L, 4,7 mg/L y 5,1 mg/L respectivamente; después de $24 \mathrm{~h}$ de contacto en el reactor fueron 5,6 mg/L, 4,6 mg/L y $5,3 \mathrm{mg} / \mathrm{L}$ respectivamente; por lo tanto no se determinaron pérdidas por efecto de adsorción de los PPCPs sobre los materiales del reactor. Tampoco se presentó foto degradación de los mismos, ya que los valores medios en las soluciones que contenían los PPCPs expuestos a la luz después de $24 \mathrm{~h}, 48 \mathrm{~h}$ y $72 \mathrm{~h}$ fueron iguales a los obtenidos en las soluciones preparadas inicialmente.

Después de establecido el inoculo en los discos del reactor y manteniendo el sistema en condiciones estables de operación en continuo, se realizaron ensayos incorporando los PPCPs, por separado y en su mezcla, en concentraciones de $200 \mu \mathrm{g} / \mathrm{L}$. Se trataron cargas orgánicas de $300 \mathrm{mg} / \mathrm{L}$ y $30 \mathrm{mg} / \mathrm{L}$, con el fin de evaluar el comportamiento de los PPCPs cuando se depuran afluentes con cargas orgánicas similares a las de ingreso a un tratamiento secundario y uno terciario. El seguimiento del sistema se efectuó en el afluente y el efluente, con toma de muestras cada $5 \mathrm{~h}$ durante el primer día, de acuerdo al tiempo de retención hidráulico, y luego cada $24 \mathrm{~h}$ hasta completar $168 \mathrm{~h}$. Los parámetros medidos para determinar la calidad del agua fueron $\mathrm{pH}$, temperatura, oxígeno disuelto, conductividad eléctrica y DQO (ver Tabla 5.1). Al mismo tiempo se tomaron muestras afluentes y efluentes para evaluar las concentraciones de los PPCPs incorporados, éstas se mantuvieron a $-20^{\circ} \mathrm{C}$ hasta el momento del análisis. Se extrajeron porciones de $0,5 \mathrm{~cm}^{2}$ de biofilm del disco $1 \mathrm{y}$ el disco 20, con el fin de determinar la adherencia de los PPCPs sobre la película bacteriana, éstas se mantuvieron a $4{ }^{\circ} \mathrm{C}$ en $1 \mathrm{~mL}$ de metanol. 
Tabla 5.1 Parámetros de diseño del CBR, parámetros físico-químicos medidos y condiciones experimentales evaluadas

\begin{tabular}{|c|c|c|c|}
\hline Parámetros del reactor & Dimensión & $\begin{array}{l}\text { Parámetros físico- } \\
\text { químicos }\end{array}$ & $\begin{array}{c}\text { Tiempos de muestreo } \\
\text { (h) }\end{array}$ \\
\hline Numero de discos & 20 & & $5^{a}$ \\
\hline Grosor de los discos & $2 \mathrm{~mm}$ & & 10 \\
\hline Diámetro de los discos & $300 \mathrm{~mm}$ & $\mathrm{pH}$ & 24 \\
\hline Espacio entre discos & $30 \mathrm{~mm}$ & temperatura & 48 \\
\hline Sumergencia de los discos & $40 \%$ & oxígeno disuelto & 72 \\
\hline Rotación de los discos & $1.5 \mathrm{rpm}$ & conductividad & 96 \\
\hline $\begin{array}{l}\text { Volumen del tanque de } \\
\text { alimentación }\end{array}$ & $20 \mathrm{~L}$ & DQO & 120 \\
\hline Caudal & $70 \mathrm{~mL} / \mathrm{min}$ & & 144 \\
\hline Volumen tanque & $200 \mathrm{~L}$ & & 168 \\
\hline \multicolumn{4}{|c|}{ Condiciones experimentales } \\
\hline Experimentos desarrollados & $\begin{array}{c}\mathrm{DQO} \\
(\mathrm{mg} / \mathrm{L})\end{array}$ & $\begin{array}{c}\text { Incorporación de } \\
\text { los PPCPs }\end{array}$ & $\begin{array}{c}\text { concentración de cada } \\
\text { PPCPs }(\mu \mathrm{g} / \mathrm{L})\end{array}$ \\
\hline Ensayo 1 & 300 & separados & 200 \\
\hline Ensayo 2 & 300 & mezcla & 200 \\
\hline Ensayo 3 & 30 & mezcla & 200 \\
\hline
\end{tabular}

${ }^{\mathbf{a}}$ Tiempo de retención hidráulico

\subsubsection{Métodos analíticos}

La determinación de los PPCPs se realizó en laboratorio mediante análisis cromatográfico HPLC-MS con columna CSH de C18, fuente de ionización electrospray en modo SIM positivo para cada compuesto (Elorriaga et al., 2013b), como se explica en el Capítulo 3. El mismo procedimiento se efectuó para el análisis de adherencia de los PPCPs sobre la masa microbiana.

El oxígeno disuelto, el $\mathrm{pH}$, la conductividad y la temperatura del medio se determinaron in situ mediante un multiparamétrico WA-2017SD. La DQO se realizó de acuerdo al método 5220 del Standard Methods (APHA, 1998) (ver Capítulo 3). 


\subsection{Resultados y discusión}

\subsubsection{Desarrollo inicial del CBR}

El desarrollo del inoculo en el laboratorio tardó 24h, posteriormente este volumen se adicionó al CBR. La mayor densidad de microorganismos en suspensión se presentó al tercer día de funcionamiento en batch, con la subsecuente formación del biofilm sobre los discos. Después del quinto día no se detectó crecimiento bacteriano en suspensión, indicando la adherencia en los discos y la estabilidad del sistema en batch, como se ve en la Figura 5.2 A, B y C. El funcionamiento en continuo fue operado con una carga orgánica de $100 \mathrm{mg} / \mathrm{L}$ hasta obtener un espesor de la película bacteriana constante (ver Figura 5.2 D), de aproximadamente $3 \mathrm{~mm}$ (Cortez et al., 2008), y condiciones estables del mismo. El oxígeno disuelto se mantuvo entre 6,2 $\mathrm{mg} / \mathrm{L}$ y $5,1 \mathrm{mg} / \mathrm{L}$, el pH entre 7,47 y 7,11 , la temperatura entre $14,0^{\circ} \mathrm{C}$ y $15,7{ }^{\circ} \mathrm{C}$, y la conductividad entre $1,230 \mathrm{~ms} / \mathrm{cm}$ y $0,911 \mathrm{~ms} / \mathrm{cm}$, medidos en el interior de la pileta. Se alcanzaron porcentajes de remoción superiores al 90\% para la DQO, consiguiendo una buena calidad efluente tras siete días de operación en continuo.

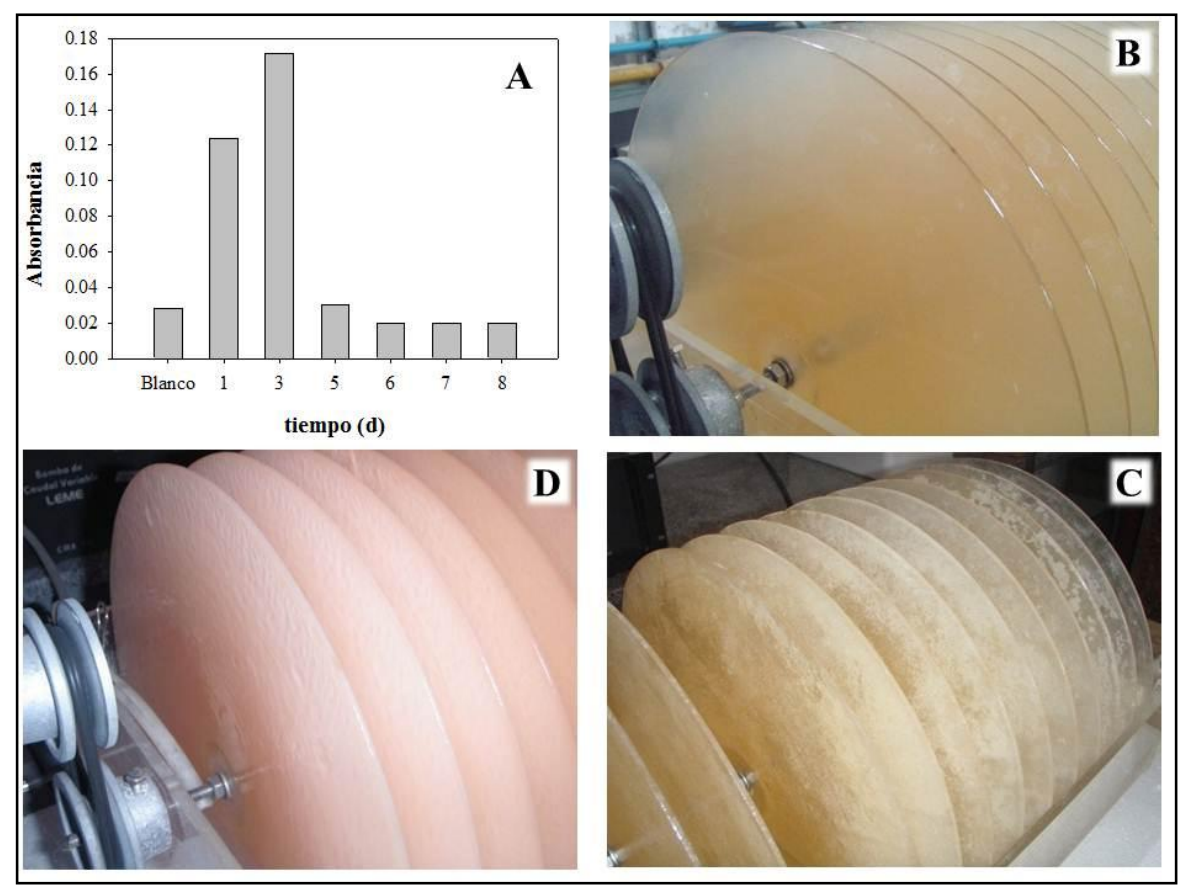

Figura 5.2 Seguimiento de la estabilización del CBR en batch. (A) Desarrollo del biofilm en la solución acuosa del reactor, determinado por espectrofotometría UV-vis a $600 \mathrm{~nm}$ (el blanco representa la absorbancia del agua antes de sembrar el inoculo), (B) imagen de los discos sin adherencia de microorganismos, (C) etapa inicial de la adherencia del biofilm y (D) estabilización del biofilm sobre los discos del CBR. 


\subsubsection{Problemas operativos}

El tiempo necesario para que el CBR funcionara correctamente fue de aproximadamente 3 meses, debido a inconvenientes operativos como:

\subsubsection{Desarrollo excesivo del biofilm}

Se observó un crecimiento excesivo de la película bacteriana sobre los discos y el tanque del rector al incorporar cargas orgánicas superiores a $450 \mathrm{mg} / \mathrm{L}$ (ver Figura 5.3). A pesar de estas condiciones extremas, se alcanzaron eficiencias de remoción para la DQO superiores al 90\%. La calidad del efluente, determinada mediante los parámetros físico-químicos, no se vio afectada. Sin embargo, el espesor del biofilm no pudo mantenerse en condiciones estables, desprendiéndose una gran porción después de $48 \mathrm{~h}$ de funcionamiento en continuo, debido a su peso. Además, con un espesor del biofilm superior a los $3 \mathrm{~mm}$ recomendados, los microorganismos no reciben la materia orgánica ni el oxígeno suficiente, produciéndose la muerte celular y con ello su desprendimiento. Bajo estas condiciones, se interrumpió la operación y se realizó una purga de microorganismos, para poder retomar la operación de del CBR. Para ello, se tomó una fracción de biopelícula de los discos y se la replicó en tubos de ensayo conteniendo un medio de cultivo no selectivo, conformado por $5 \mathrm{~g}$ de triptona, 2,5 $\mathrm{g}$ de extracto de levadura, $1 \mathrm{~g}$ de glucosa y $15 \mathrm{~g}$ de agar en $1 \mathrm{~L}$ de agua destilada, durante $48 \mathrm{~h}$ a $25^{\circ} \mathrm{C}$. El inóculo se conservó a $4^{\circ} \mathrm{C}$ mientras se realizó la limpieza del reactor. Luego en un matraz se desarrolló nuevamente el crecimiento de microorganismos como se explica en el inciso "desarrollo y siembra del inóculo". Es importante resaltar que el CBR alcanza un correcto funcionamiento bajo cargas orgánicas inferiores o iguales a $300 \mathrm{mg} / \mathrm{L}$. Además, la disminución de la carga orgánica se debe realizar de forma gradual para evitar choques bruscos en la formación de la biomasa. 


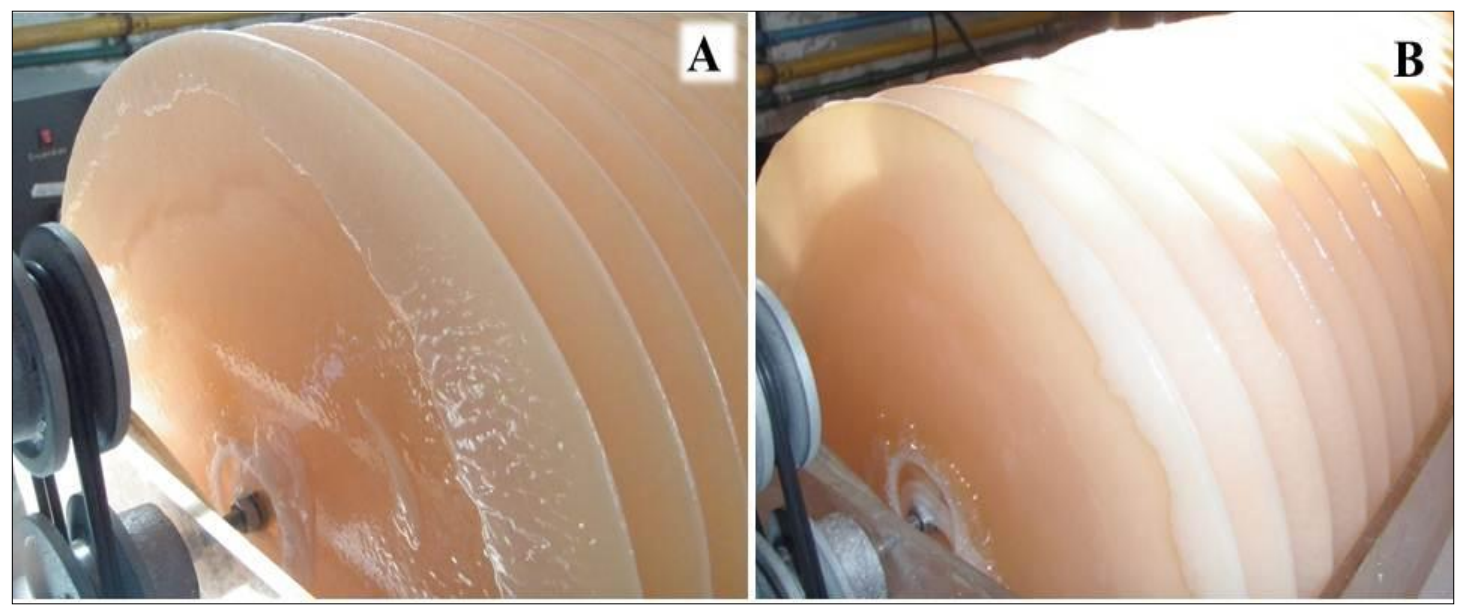

Figura 5. 3 (A) Crecimiento excesivo y (B) desprendimiento de la biopelícula debido a la incorporación de cargas orgánicas superiores a $450 \mathrm{mg} / \mathrm{L}$.

\subsubsection{Aparición de ciliados, algas y hongos}

Durante la puesta en marcha del reactor se presentaron otros inconvenientes como: fugas en la pileta del CBR debido a fisuras por cambios en la temperatura, y desgaste de las líneas de carga y descarga, obligando a mantenerlo en condiciones batch. Este tipo de fallas se deben evitar, ya que tener agua estancada en el reactor provoca el crecimiento de microorganismos ciliados (observados en microscopio) sobre el biofilm. Como se sabe, una característica de estos microorganismos es que se alimentan de bacterias, lo que puede causar desestabilización de la biopelícula, (Singh et al., 2006), además mantener el sistema en batch puede generar malos olores producidos por el desarrollo de bacterias anaerobias.

El desarrollo del biofilm también se vio afectado por el crecimiento proliferado de algas sobre los discos, ocasionando inconvenientes en el funcionamiento del reactor, debido al desplazamiento de la película bacteriana. Su aparición se atribuye a la mayor cantidad de horas de luz. Su propagación se desarrolló desde el disco final hacia los discos iniciales, debido posiblemente a la menor densidad bacteriana sobre los últimos discos, permitiendo que las algas empezaran una competencia desde las zonas menos cargadas del sistema (Figura 5.4 A). Este inconveniente se controló diseñando una cubierta para el CBR similar a las que utilizan los sistemas reales, de tal forma que se impidiera el paso de la luz. La remoción de las algas fue rápida y al cabo de seis días la biopelícula se desarrolló nuevamente, retomándose un funcionamiento estable en el sistema. 


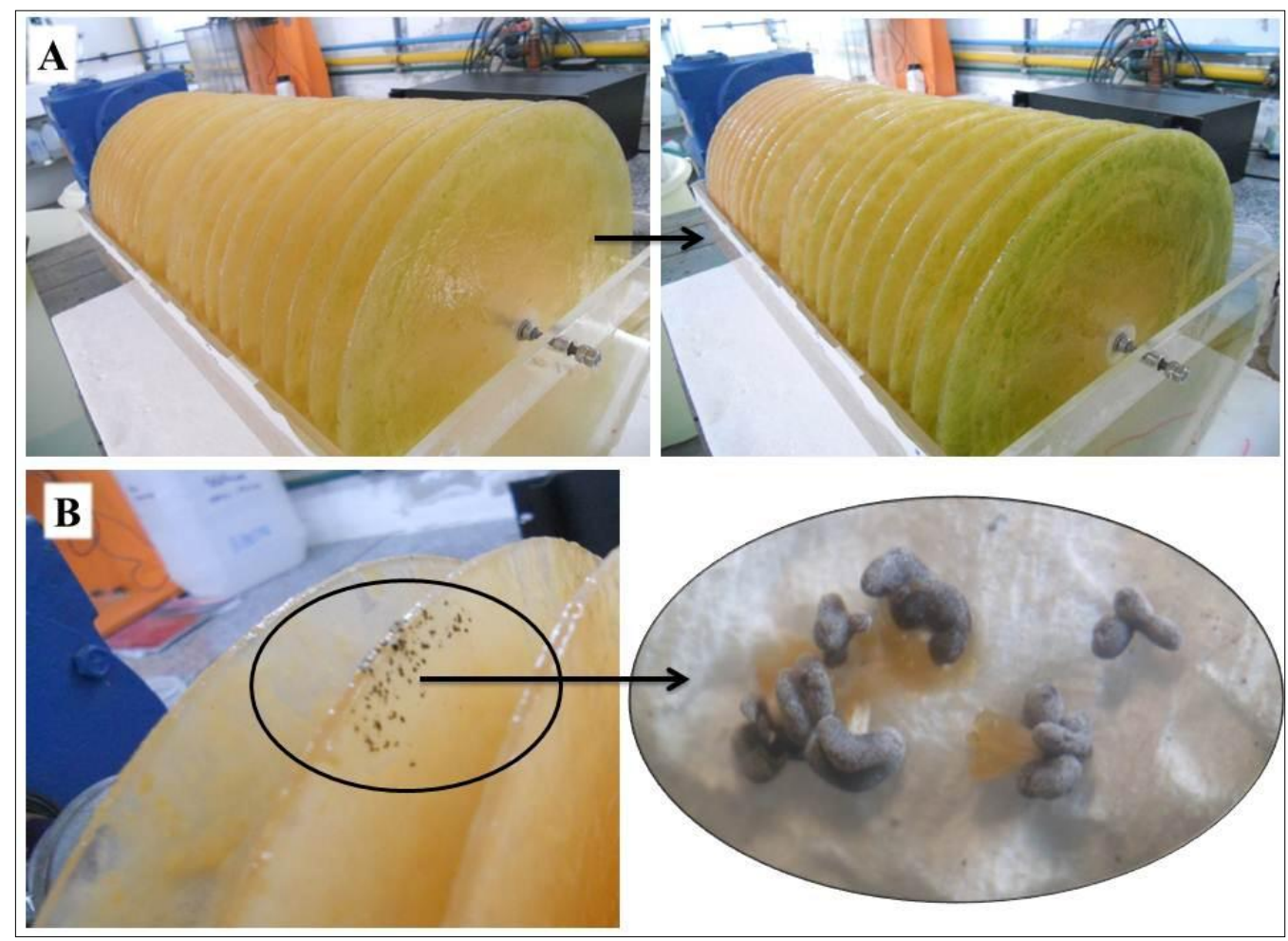

Figura 5. 4 (A) Desplazamiento de la biopelícula por proliferación de algas desde los discos finales hacia los iniciales y (B) crecimiento de hongos sobre los primeros discos del CBR.

Los primeros discos del reactor también se vieron afectado por el crecimiento de hongos, al trabajar con cargas orgánicas inferiores a $30 \mathrm{mg} / \mathrm{L}$ (Figura $5.4 \mathrm{~B}$ ). Este problema se solucionó retirando las porciones del biofilm afectadas, hasta que el sistema retomó su equilibrio. Quizá el mantener una carga orgánica baja y por ende una fina capa de biofilm, favorece el crecimiento de los hongos. La humedad ambiente del lugar de trabajo y temperaturas relativamente bajas $\left( \pm 15^{\circ} \mathrm{C}\right)$ también influyen en su aparición. Una vez que se logró controlar su proliferación, no se observó más su crecimiento sobre el sistema. Cortez et al. (2008) encontraron el mismo inconveniente en la primera etapa de su reactor. Para evitar el excesivo crecimiento de los hongos sobre la biopelícula invirtieron la entrada de alimentación, y con esta sencilla modificación les fue posible duplicar el tiempo de vida activo del biofilm.

\subsubsection{Remoción de PPCPs}

Después de obtener condiciones estables en el reactor, se procedió a evaluar su comportamiento tanto con una DQO en el afluente de $300 \mathrm{mg} / \mathrm{L}$, como con una de 30 $\mathrm{mg} / \mathrm{L}$, al incorporar los compuestos por separado y en su mezcla. En las experiencias 
denominadas como ensayo 1 se evaluó el comportamiento del sistema con una DQO de $300 \mathrm{mg} / \mathrm{L}$ y la adición de los PPCPs por separado; en el ensayo 2 la incorporación de la mezcla de los PPCPs con la misma carga orgánica; y el ensayo 3 para una DQO de $30 \mathrm{mg} / \mathrm{L}$ y la mezcla de los contaminantes emergentes (ver Tabla 5.1).

\subsubsection{Análisis particular de la carbamazepina}

Los resultados obtenidos para los ensayos 1, 2 y 3 se presentan en los gráficos A1, B1 y C1 de la Figura 5.5. Como puede verse, no se alcanzaron remociones significativas de Cbz para ninguno de los ensayos desarrollados. Además, al calcular los porcentajes de remoción para cada par de muestras (afluente y efluente), en algunos casos se obtuvieron porcentajes de remoción negativos de hasta un $60 \%$. Muy pocos trabajos informan este tipo de resultados (Onesios et al., 2009; Shaver, 2011). En el año 2014 se reportaron remociones de hasta un $-316 \%$ para la $\mathrm{Cbz}$ en tratamientos biológicos (Verlicchi and Zambello, 2014).

Distintas razones se proponen para explicar estos resultados. Por ejemplo, para la $\mathrm{Cbz}$, se explica por el hecho de que una parte de este compuesto después de consumido, es excretado e ingresa a las aguas residuales en su forma conjugada, que a su paso por el tratamiento secundario de las PTAR se degrada nuevamente a Cbz, aumentado la presencia de esta sustancia en el efluente del tratamiento secundario. Aunque esta puede ser una razón para explicar el aumento en la concentración de la $\mathrm{Cbz}$ en el efluente, es importante tener en cuenta que en este estudio se adicionaron los fármacos directamente al agua residual sintética, evidenciando que existen otros factores que generan valores negativos. Otra causa puede ser la evaporación parcial del agua residual contenida en el sistema, favoreciendo la concentración de los contaminantes; pero es de notar que en nuestro trabajo no se evidenció variación significativa del nivel del agua durante la operación del reactor en continuo.

Algunos estudios sugieren tener en cuenta la distribución del tiempo de residencia (DTR) en lugar del tiempo de retención hidráulico (TRH) (Majewsky et al., 2011), para el cual se deben considerar parámetros como el caudal, el volumen del tanque, la eficiencia de mezclado, la variabilidad en la concentración y su distribución dentro del sistema. Según Majewsky et al. (2011), los muestreos afines con el TRH o cada $24 \mathrm{~h}$, que son los más comunes para la evaluación de los sistemas de tratamiento, únicamente funcionan para medir remociones de DQO y sustancias fácilmente 
biodegradables, pero no cubren la carga total de xenobióticos. Por lo tanto, la fracción remanente de la DQO sirve como sustancia modelo para determinar la DTR. Teniendo en cuenta esta consideración, se determinó una DTR de $72 \mathrm{~h}$ para Cbz, como se muestra en la Figura 5.6A. En los resultados obtenidos se observaron porcentajes de remoción de hasta un $-48 \%$ considerando la DTR. Aunque estos valores fueron menores a los evaluados con el TRH, el inconveniente de valores negativos continúa.

Por otro lado, la liberación de los fármacos sorbidos en las partículas en suspensión después del tratamiento biológico puede ser otro factor que afecta el análisis del sistema, así como también la incertidumbre analítica, teniendo en cuenta que a bajas concentraciones los errores instrumentales pueden dar lugar a liberaciones aparentes de las sustancias estudiadas, en lugar de una eliminación insignificante durante su paso por los sistemas de tratamiento (Shaver, 2011; Verlicchi and Zambello, 2014). Consecuentemente, se realizó un test de t pareado, tomando como base la DTR, con el fin de verificar si existen diferencias estadísticamente significativas entre las concentraciones de los afluentes y efluentes. Los resultados se analizaron para una prueba de significancia de 0,05 . Para los ensayos 1 y 2 , no se observaron diferencias significativas, con resultados del p-valor de 0.795 y 0.176 , respectivamente. Mientras que para el ensayo 3, se obtuvo un p-valor de 0.004, determinando un porcentaje de remoción promedio inferior al 20\%. Resultados similares se presentan para muchos tratamientos biológicos (Matamoros et al., 2016; Onesios et al., 2009).

La remoción baja de la Cbz se debe a su resistencia frente a la degradación bacteriana y además presenta toxicidad en algunos microorganismos (Li et al., 2015b). Así, aunque la carga orgánica se redujo hasta $30 \mathrm{mg} / \mathrm{L}$, no se lograron alcanzar eficiencias de remoción significativas. En la presente experiencia se pudo observar el efecto tóxico de la $\mathrm{Cbz}$ con el desprendimiento del biofilm, ocasionado en cuanto entró en contacto con el fármaco (Figura 5.7). Esta perturbación se prolongó hasta las 48h. A las 72 h se observó un rápido crecimiento de la biopelícula, con la consecuente recuperación de la masa microbiana y estabilidad del CBR. 

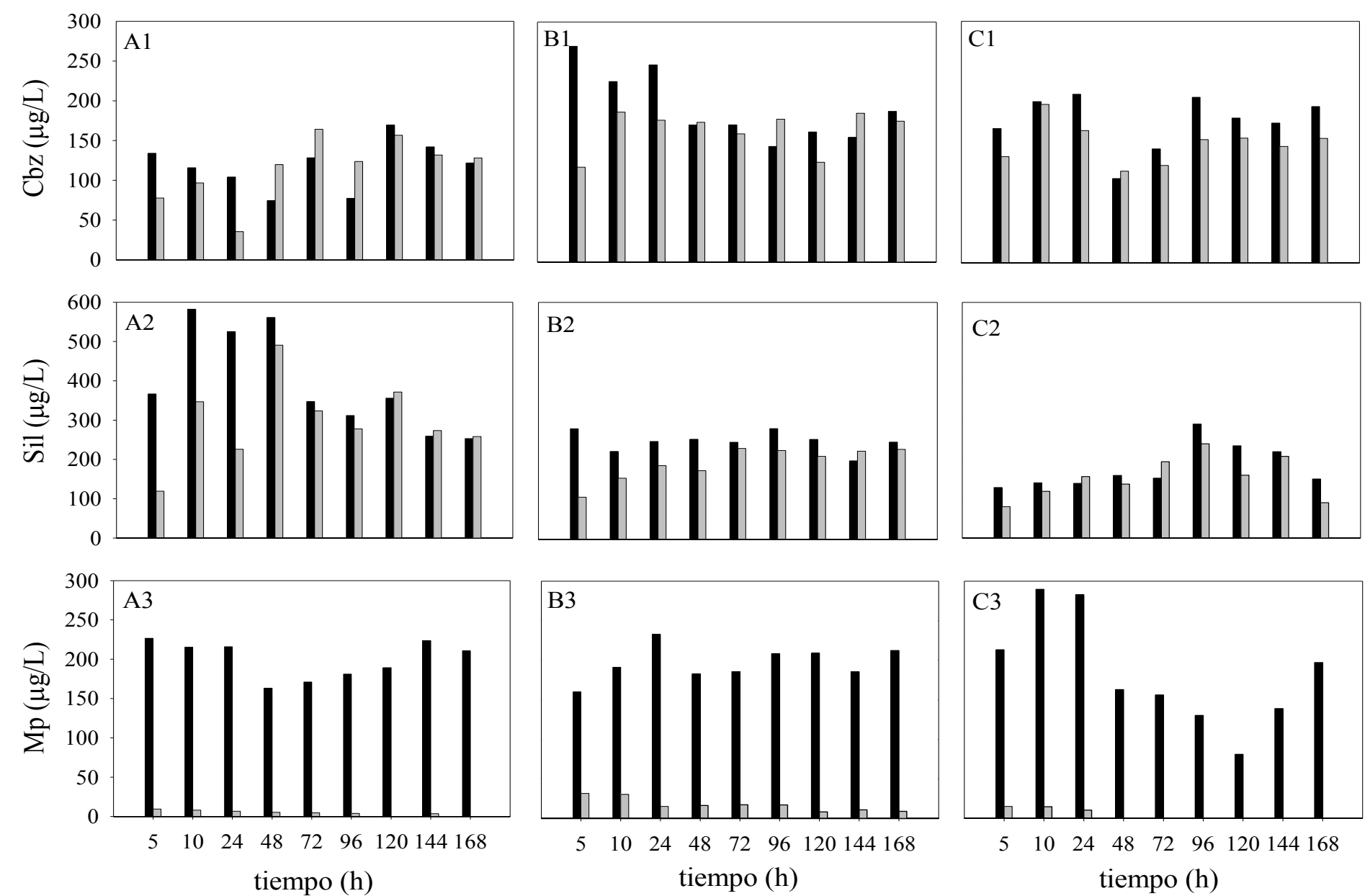

Figura 5.5 Concentraciones afluentes ( 1 ) y efluentes ( 1 ) de para Cbz (1), Sil (2) y Mp (3), cuando se emplea una carga orgánica de $300 \mathrm{mg} / \mathrm{L}$ y se incorporan los compuestos de forma (A) individual y (B) en su mezcla; y (C) para la mezcla de los 3 compuestos con una carga orgánica afluente de $30 \mathrm{mg} / \mathrm{L}$. 


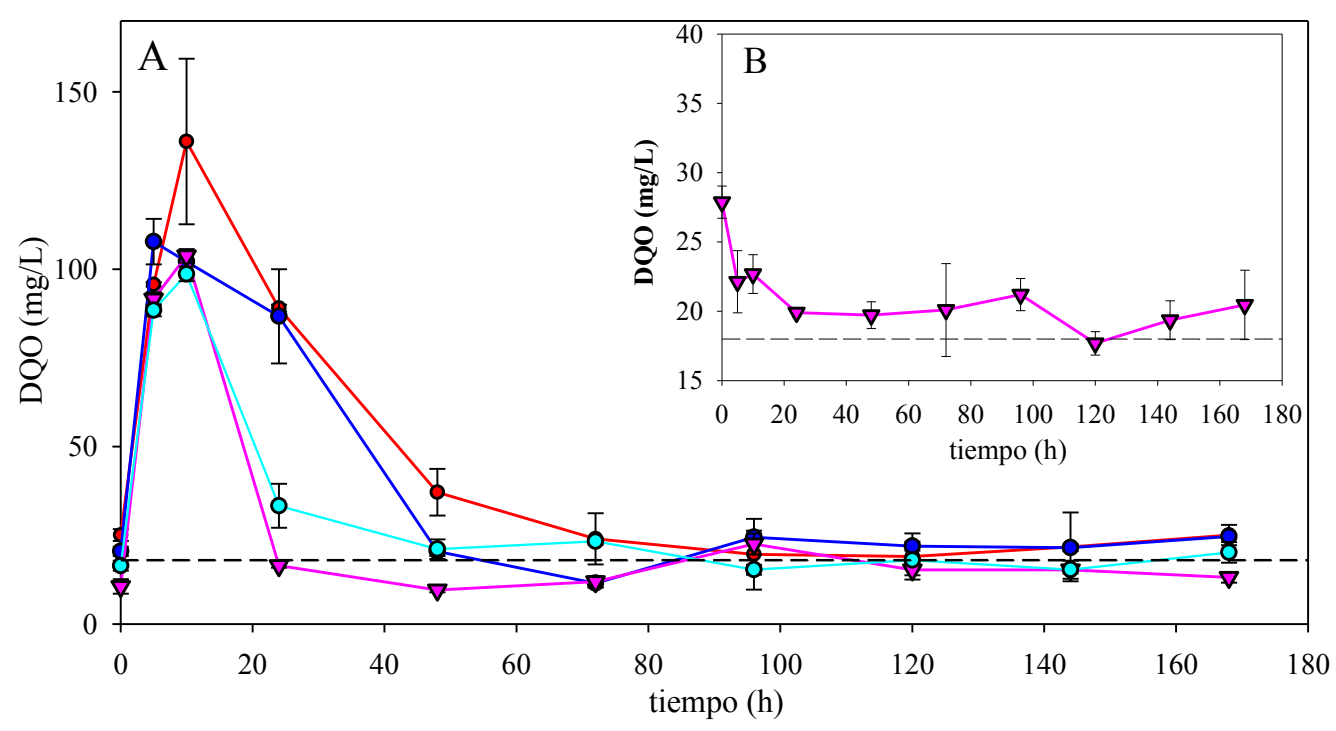

Figura 5.6 En el gráfico se presenta el comportamiento de la DQO efluente después de incorporar $\mathrm{Cbz}(\bullet)$, Sil $(\bullet), \operatorname{Mp}(\bullet)$ y la mezcla de los compuestos $(\nabla)$, con cargas orgánicas afluentes de (A) $300 \mathrm{mg} / \mathrm{L} \mathrm{y}$ (B) $30 \mathrm{mg} / \mathrm{L}$. La línea punteada representa el promedio de la DQO remanente.

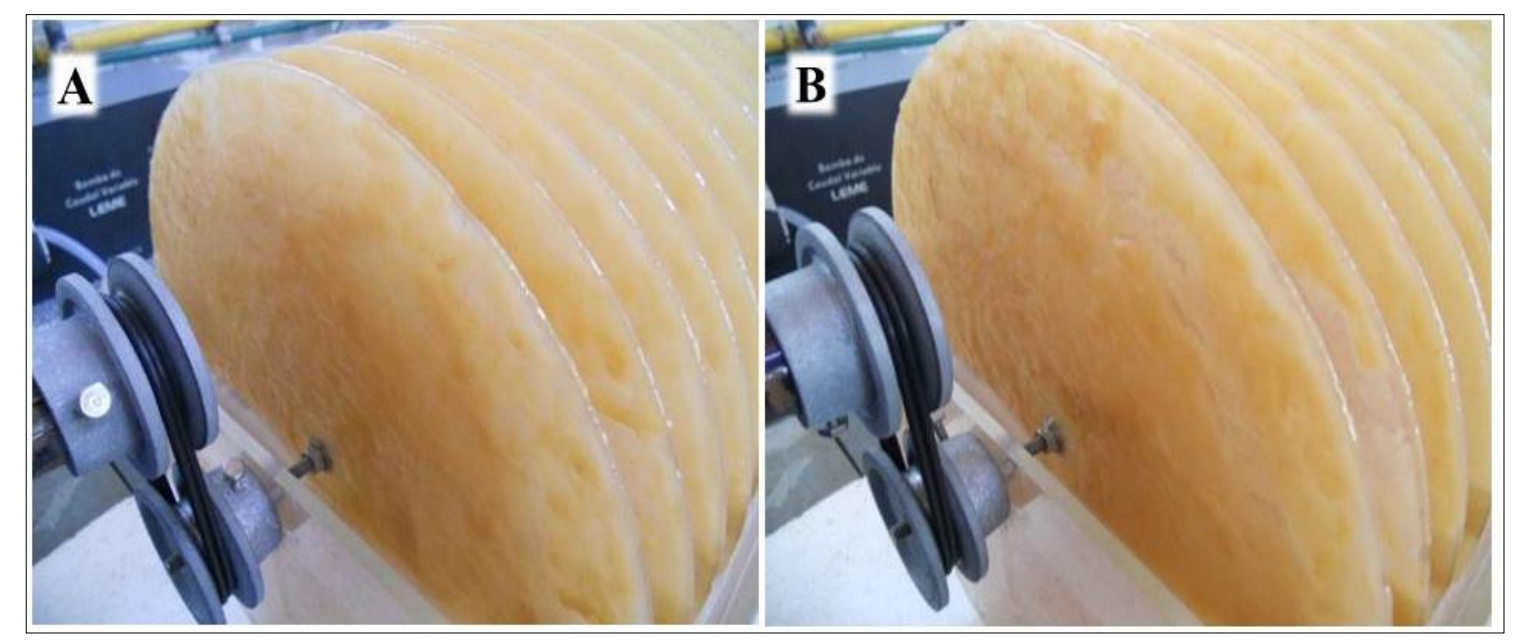

Figura 5.7 Desprendimiento de la biopelícula a las (A) $5 \mathrm{~h}$ y (B) $48 \mathrm{~h}$ de contacto con la carbamazepina. 


\subsubsection{Análisis particular del sildenafil}

Los resultados obtenidos para el Sil se listan en los gráficos A2, B2 y C2 de la Figura 5.5. Al analizar la eficiencia de remoción para cada par de muestras teniendo en cuenta el TRH, al igual que para la Cbz, se obtienen algunos valores negativos de hasta $-28 \%$.

El tiempo de análisis determinado para la DTR fue de 48 h (Figura 6.6A). Se obtuvieron porcentajes de remoción negativos de hasta un $-10 \%$, siendo inferiores a los encontrados con el TRH. En el análisis global de remoción mediante la prueba tpareada no se encontraron diferencias significativas entre las concentraciones de los afluentes y efluentes para los ensayos 1 y 3, con resultados del p-valor de 0,058 y 0,077, respectivamente. Para el ensayo 2, el p-valor fue 0,018, indicando que existen diferencias estadísticamente significativas entre las concentraciones afluentes y efluentes, con eficiencias de remoción inferiores al 13\%. Esto demuestra que el sistema de biodiscos tampoco resulta ser un tratamiento eficiente para remover sildenafil de las aguas residuales domésticas.

\subsubsection{Análisis particular del metilparabeno}

Tal como puede verse en los gráficos A3, B3 y C3 de la Figura 5.5, se alcanzaron altas eficiencias de remoción para el Mp en el sistema CBR; a diferencia de las obtenidas para Cbz y el Sil.

Se alcanzaron porcentajes de remociones superiores al 98\% para el Mp y superiores al 95\% para la materia orgánica, evaluados mediante el TRH. Como era de esperarse, en la prueba t para muestras pareadas se obtuvieron $\mathrm{p}$-valores inferiores a 0,001. De acuerdo a lo planteado por Majewsky et al. (2011) el metilparabeno sería un compuesto fácilmente biodegradable ya que su eficiencia de remoción se puede determinar teniendo en cuenta únicamente el TRH. Matamoros et al. (2016) encontraron remociones de $\mathrm{Mp}$ en sistema de biodiscos de hasta el 69\% y en lagunas de estabilización del 74\%. Así, el reactor en estudio presentó un 27\% más de eficiencia, siendo una opción viable para remover $\mathrm{Mp}$ de las aguas residuales domésticas con cargas orgánicas de hasta $300 \mathrm{mg} / \mathrm{L}$. 
La alta eficiencia de remoción conseguida para el Mp se puede deber a su estructura y composición molecular simple, la cual está formada únicamente de elementos químicos esenciales $(\mathrm{C}, \mathrm{H}, \mathrm{O})$ conformando un solo anillo aromático, que son fácilmente degradados por los microorganismos; además tiene una estereoquímica favorable (molécula plana) a la adsorción sobre la biopelícula, y presenta una fácil dispersión en las aguas residuales $(\log$ kow $=1,96)$ y un coeficiente de adsorción que puede favorecer su adherencia sobre la capa bacteriana, considerando que el Log $\mathrm{k}_{\mathrm{oc}}=$ 2,4 . Es importante resaltar que los fármacos presentan coeficientes de reparto octanolagua y carbono orgánico-agua similares al $\mathrm{Mp}$, sin embargo estos compuestos no fueron eficientemente removidos del sistema, indicando que uno de los principales factores se debe a su estructura molecular más compleja, consideraciones similares se han reportado por algunos autores (Kümmerer and Al-Ahmad, 1997). Recientemente se reportó al Sil como un compuesto recalcitrante (Grossberger et al., 2014), así como la Cbz (Li et al., 2015c). Los cuales están formados por elementos estructurales que raramente se encuentran en la naturaleza. También se sabe que la resistencia de un compuesto aromático al ataque de microorganismos aumenta con el número de sustituyentes que tiene, cualquiera que sea su naturaleza química. Estas estructuras químicas tan estables de los compuestos farmacéuticos resultan ser tóxicas para los microorganismos, convirtiéndose en contaminantes resistentes al ataque biológico. Por lo tanto, aunque se han aclimatado bacterias específicas con estos fármacos como fuente de carbono, durante períodos superiores a 30 días, solo encontraron eficiencias de eliminación inferiores al 20\% (Gauthier, 2008; Grossberger et al., 2014; Kruglova et al., 2014); siendo similares a las encontradas en el presente estudio para un período de tiempo de 168 h. Sin embargo, algunos autores informan eficiencias de remoción del 99.9\% usando cepas específicas en pruebas de laboratorio en batch (De Felice et al., 2008). La inoculación de CBR con cepas específicas resulta interesante en sistemas a escala piloto; sin embargo, debe tenerse en cuenta que en los sistemas a escala real, los consorcios bacterianos provenientes de aguas residuales pueden inhibir fácilmente su crecimiento, tomando su lugar en la superficie de los discos (Pearce et al., 2003). 


\subsubsection{Efecto de los PPCPs sobre la calidad del agua tratada}

Se alcanzaron altas remociones de materia orgánica durante el proceso, con valores superiores al 95\%. Como puede observarse en la Figura 5.6 A, el sistema va adecuándose después de la incorporación de los PPCPs hasta alcanzar condiciones estables, lo cual puede deberse a la adaptación o selección de microorganismos, que se vuelven resistentes a los efectos tóxicos de los compuestos recalcitrantes. El tiempo necesario para alcanzar condiciones de estabilidad al adicionar sildenafil y metilparabeno fue de $48 \mathrm{~h}$; viéndose menos perturbado el CBR con el paso de Mp. La mayor alteración se presentó al incorporar $\mathrm{Cbz}$, ya que el equilibrio se alcanzó a las $72 \mathrm{~h}$. Este tiempo más prolongado se debe al efecto tóxico que causa el fármaco sobre las bacterias del biofilm (Ferrari et al., 2003).

Resultados similares a los obtenidos con el tratamiento de Mp se observaron cuando se incorporó la mezcla de los compuestos con una DQO afluente de $300 \mathrm{mg} / \mathrm{L}$, pero alcanzándose el equilibrio a las $24 \mathrm{~h}$. Para este caso, el sistema logra recuperarse rápidamente, debido posiblemente a la transferencia horizontal de genes o la deriva genética que pudo haberse producido en los microorganismos después de haber estado en contacto con los PPCPs de forma individual (Singh et al., 2006). Un comportamiento similar se presentó para el ensayo 3, tal como puede verse en la Figura 5.6 B, en el que el sistema se estabiliza a las $24 \mathrm{~h}$ y se confirma la adaptabilidad de los microorganismos frente a los compuestos estudiados.

Se realizó una matriz de correlación de los coeficientes y sus probabilidades para analizar el efecto de la incorporación de los PPCPs sobre la estabilidad del efluente. Así, para 9 mediciones con n-2 grados de libertad, el coeficiente de correlación debe ser $\mathrm{r}>0,754$ para un intervalo de confianza del 95\%. Un p-valor $<$ 0.05 indica un buen ajuste de la regresión.

En todos los ensayos se determinó una correlación positiva significativa entre el porcentaje de remoción del Mp y la DQO, como se ve en la Tabla 5.2. Esto se debe a que el Mp resultó ser un compuesto fácilmente biodegradable y entra a ser parte de la materia orgánica disponible; la misma afirmación es sugerida por otros autores (Amin et al., 2010). También se presentaron correlaciones significativas con la temperatura y el oxígeno disuelto cuando se incorporó $\mathrm{Mp}$ en el ensayo 1. La correlación positiva con la temperatura se debe a que el aumento de ésta favorece el 
crecimiento microbiano y con ello la degradación del Mp. Además, un aumento de la temperatura causa diminución en el oxígeno disuelto, presentándose una correlación negativa con este parámetro. Para $\mathrm{Cbz}$ y Sil no se observaron correlaciones significativas con ninguna de las variables medidas.

Cuando se incorporó una carga orgánica al CBR de aproximadamente 300 $\mathrm{mg} / \mathrm{L}$, el pH no presentó influencia sobre la degradación del Mp, mientras que a bajas concentraciones $(30 \mathrm{mg} / \mathrm{L})$ este parámetro presenta una correlación positiva con la remoción del Mp.

El oxígeno disuelto siempre estuvo por encima de $2 \mathrm{mg} / \mathrm{L}$, superando el limite recomendado (Cortez et al., 2008). Los valores estuvieron entre 3 y $8,7 \mathrm{mg} / \mathrm{L}$, como puede verse en la Figura 5.8. Una disminución en su concentración media se observó en el efluente, esto debido a la estabilización biológica de la materia orgánica (Droste, 1997). El pH se mantuvo dentro del intervalo recomendado para un funcionamiento óptimo de las bacterias (Pope, 1978 ), con valores entre 6,5 y 8. La temperatura también se mantuvo dentro del intervalo establecido $\left(10-32{ }^{\circ} \mathrm{C}\right)$ para el correcto funcionamiento del sistema (Cortez et al., 2008). Este es un factor importante ya que afecta la velocidad de los procesos biológicos. Un incremento conduce a un aumento en la actividad microbiana, y por ende, una mayor remoción del sustrato. Grandes disminuciones pueden afectar la estabilidad del biofilm, principalmente en sus etapas iniciales (Costley and Wallis, 2000). Los valores de la conductividad se mantuvieron entre $0,6-1,0 \mathrm{~ms} / \mathrm{cm}$. Con estos resultados se determinó que esté parámetro no se modificó durante el tratamiento. Conductividades elevadas indican la presencia de impurezas, como sales. Como resultado del uso doméstico del agua, estos valores aumentan y se sitúan normalmente en el intervalo 1,0 - 2,0 ms/cm. Aguas con niveles inferiores a 1,2 $\mathrm{ms} / \mathrm{cm}$ no suelen presentar ningún problema ni impiden la supervivencia de especies animales y vegetales en las aguas superficiales (Shrestha and Kazama, 2007). Así se determinó que la calidad del efluente no fue afectada por la incorporación de los fármacos y el producto de cuidado personal (ver Figura 5.8). 
Tabla 5.2 Matriz para determinar la influencia de los PPCPs sobre los parámetros fisicoquímicos del efluente, vinculando el porcentaje de remoción (\%) con la probabilidad y el (coeficiente de correlación)

\begin{tabular}{|c|c|c|c|c|c|}
\hline Compuesto & $\overline{\mathrm{DQO}}$ & $\mathrm{pH}$ & $\mathrm{T}\left({ }^{\circ} \mathrm{C}\right)$ & O.D. (mg/L) & Cond $(\mathrm{ms} / \mathrm{cm})$ \\
\hline \multicolumn{6}{|c|}{ Ensayo 1 DQO: $300 \mathrm{mg} / \mathrm{L}$, analizando cada PPCPs por separado } \\
\hline $\mathrm{Mp}$ & $0,006(0,89) *$ & 0,198 & $0,008(0,96)^{*}$ & $0,013(-0,86)^{*}$ & 0.292 \\
\hline $\mathrm{Cbz}$ & NA & NA & NA & NA & NA \\
\hline Sil & NA & NA & NA & NA & NA \\
\hline \multicolumn{6}{|c|}{ Ensayo 2 DQO: $300 \mathrm{mg} / \mathrm{L}$ y estudio para la mezcla de los 3 PPCPs } \\
\hline $\mathrm{Mp}$ & $0,003(0,86)^{*}$ & 0,382 & 0,884 & 0,983 & 0,941 \\
\hline $\mathrm{Cbz}$ & NA & NA & NA & NA & NA \\
\hline Sil & 0,805 & 0,102 & 0,852 & 0,295 & 0,263 \\
\hline \multicolumn{6}{|c|}{ Ensayo 3 DQO: $30 \mathrm{mg} / \mathrm{L}$ y estudio para la mezcla de los 3 PPCPs } \\
\hline $\mathrm{Mp}$ & $0,002(0,88) *$ & $0,008(0,81) *$ & 0,434 & 0,327 & 0,633 \\
\hline $\mathrm{Cbz}$ & 0,558 & 0,990 & 0,846 & 0,203 & 0,875 \\
\hline Sil & NA & NA & NA & NA & NA \\
\hline
\end{tabular}

NA: no aplica porque no hubo remoción; * Casos significativos; T: temperagtura; O.D: oxígeno disuelto; Cond: conductividad. 

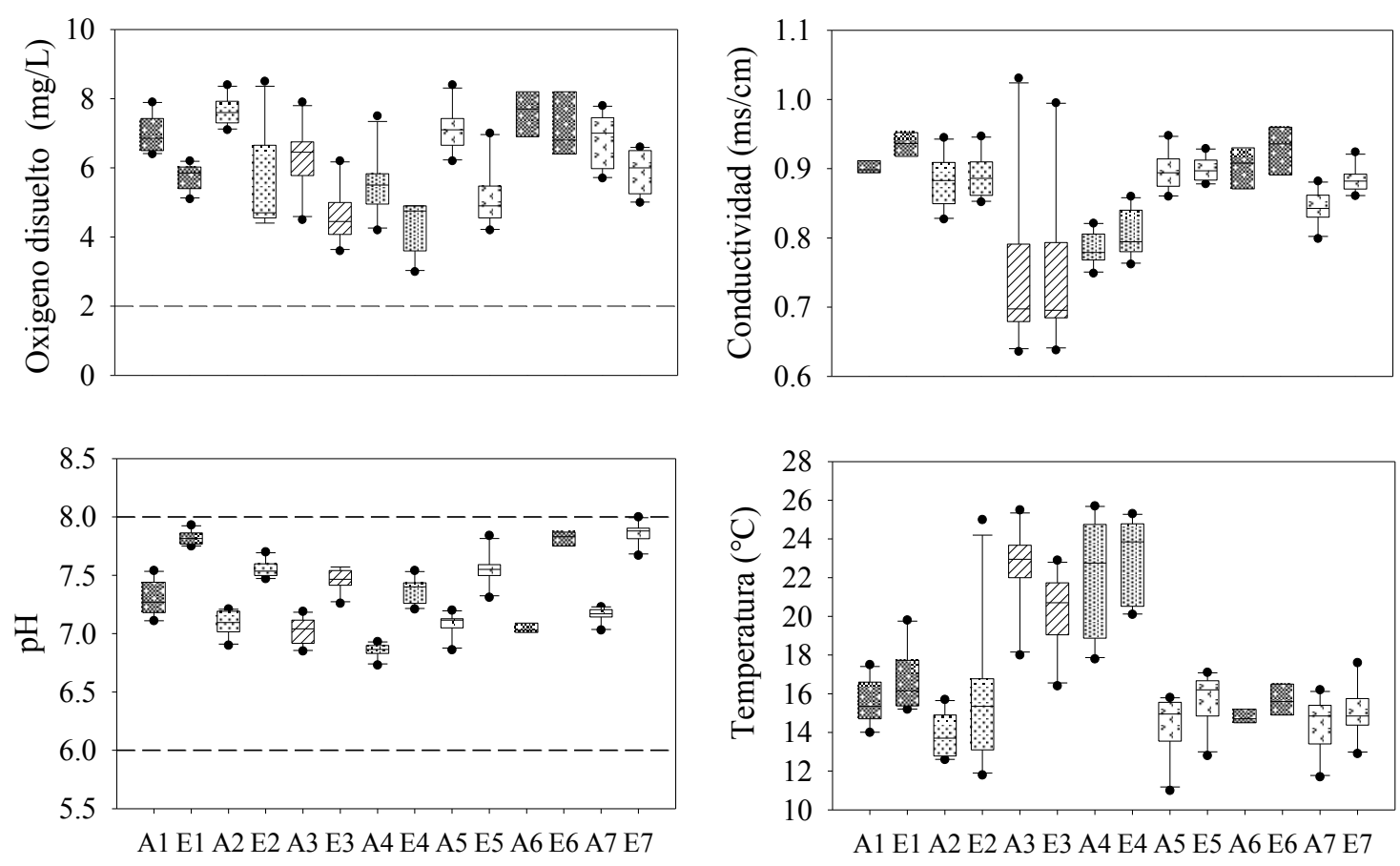

Figura 5.8 Parámetros de calidad del agua (A) afluente y (E) efluente, para cada ensayo desarrollado, indicando en líneas punteadas los límites de referencias. (1) Blanco del sistema; (2) incorporación de metilparabeno, (3) carbamazepina , (4) sildenafil; y mezcla de los tres compuestos, (5) con una carga orgánica de $300 \mathrm{mg} / \mathrm{L}$. (6) Blanco del sistema y (7) mezcla de los tres compuestos con una DQO de $30 \mathrm{mg} / \mathrm{L}$.

\subsubsection{Adsorción de los PPCPs sobre la biopelícula}

De acuerdo a los resultados de adsorción sobre el biofilm en el ensayo 3, se determinó que en promedio un $10 \%$ de los fármacos es adherido sobre la película de los discos 1 y 20, como se observa en la Tabla 5.3. No se observó adherencia de Mp en ninguno de los discos para los diferentes tiempos muestreados, confirmando la biodegradación del compuesto. Seguidamente se realizó un test t para comparar alternativamente dos grupos (disco 1 y disco 20 para cada fármaco; disco 1 y disco 20 para ambos fármacos). La diferencia en los valores medios no fue lo suficientemente significativa para rechazar la posibilidad de que la discrepancia observada en la Tabla 5.3 (Cbz y Sil) se puede deber a la variabilidad del muestreo aleatorio. Las probabilidades del test fueron superiores a 0.05 en todos los casos, con un $95 \%$ de confianza. Por lo tanto, no se determinó una diferencia estadísticamente significativa 
entre la cantidad de Cbz y Sil adsorbida en los discos 1 y 20 o para las cantidades adsorbidas de ambos fármacos sobre el mismo disco. Consecuentemente, las remociones bajas determinadas para la $\mathrm{Cbz}$ y el Sil se pueden atribuir a la adsorción en la biopelícula y no a la degradación propiamente dicha.

Tabla 5.3 Porcentaje de adsorción de los PPCPs sobre el biofilm

\begin{tabular}{|c|c|c|c|c|c|c|}
\hline \multirow{2}{*}{$\begin{array}{c}\text { Tiempo } \\
\text { (h) }\end{array}$} & \multicolumn{2}{|c|}{$\mathrm{Cbz}$} & \multicolumn{2}{|c|}{ Sil } & \multicolumn{2}{|c|}{$\mathrm{Mp}$} \\
\hline & Disco 1(\%) & Disco 20(\%) & Disco 1(\%) & Disco 20(\%) & Disco 1 & Disco 20 \\
\hline 24 & 8 & 5 & 10 & 7 & - & - \\
\hline 72 & 10 & 8 & 17 & 10 & - & - \\
\hline 168 & 4 & 6 & 24 & 11 & - & - \\
\hline
\end{tabular}




\subsection{Conclusiones parciales}

Se obtuvieron altas eficiencias de remoción para el metilparabeno, mientras que remociones inferiores al 20\% se alcanzaron para la carbamazepina y el sildenafil. Así, se determinó que compuestos con una estructura molecular simple y con una composición de elementos químicos esenciales $(\mathrm{C}, \mathrm{H} \mathrm{O})$, como es el caso del Mp, resultan ser eficientemente removidos en el contactor biológico rotativo. Sin embargo, es necesario estudiar otros procesos para remover compuestos de estructura molecular compleja, como es el caso de los fármacos, ya que la disminución de la DQO durante el proceso de tratamiento no generó mejoras en las eficiencias de remoción para los fármacos.

La calidad del efluente, medida a través de sus parámetros fisicoquímicos generales, no se vio afectada por la incorporación de los PPCPs después de alcanzar las condiciones de estabilidad, así, se alcanzaron eficiencias de remoción de hasta el 95\% para la materia orgánica durante los diferentes ensayos realizados.

La DQO remanente o la distribución del tiempo de residencia deben ser consideradas para realizar el análisis de remoción de compuestos complejos, con el fin de evaluar la eficiencia del proceso cuando éste se encuentre en condiciones estables. Además, un análisis estadístico cuidadoso de los datos debe tenerse en cuenta para evitar resultados erróneos.

Los contactores biológicos rotativos han sido extensamente utilizados para remoción de materia orgánica y nutrientes (nitrógeno y fósforo). Sin embargo, su diseño no está totalmente terminado, y otros estudios, como inoculación de cepas específicas se deben llevar a cabo para evaluar la remoción de contaminantes emergentes de estructura molecular compleja. 


\section{CAPÍTULO 6}

\section{HUMEDALES CONSTRUIDOS PARA REMOCIÓN DE FÁRMACOS Y PRODUCTOS DE CUIDADO PERSONAL}

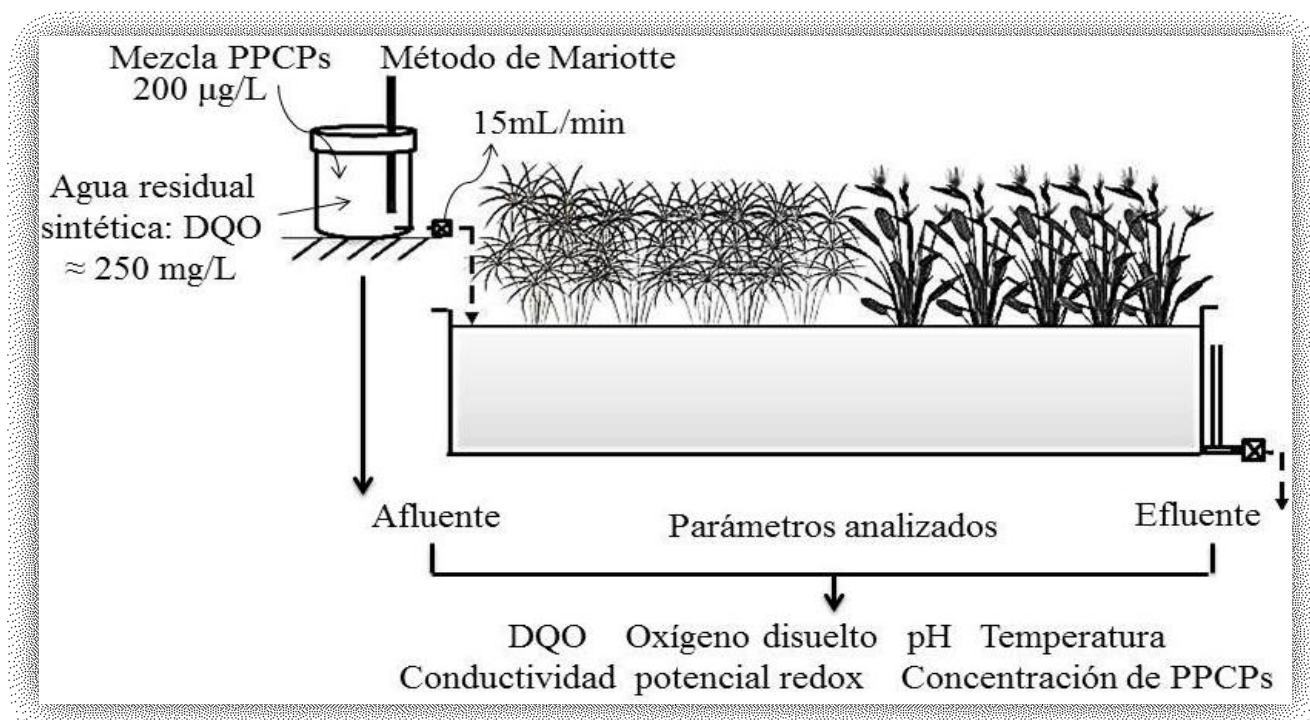




\section{Resumen}

Los fármacos y los productos de cuidado personal (PPCPs) se están convirtiendo en un serio problema para el vertimiento de las aguas residuales a los cuerpos de agua. Por lo tanto, el objetivo del presente estudio fue evaluar la eficiencia de cuatro humedales construidos de flujo horizontal subsuperficial, dos plantados con policultivo y dos sin plantar, para remover dos fármacos, carbamazepina $(\mathrm{Cbz})$ y sildenafil (Sil), y un producto de cuidado personal, metilparabemo (Mp), presentes en aguas residuales domésticas. Los PPCPs se incorporaron en su mezcla, en concentraciones de $0,2 \mathrm{mg} / \mathrm{L}$ para cada compuesto. El caudal de trabajo fue de 15 $\mathrm{mL} / \mathrm{min}$ y el tiempo de retención hidráulico de tres días. Se realizaron muestreos cada 20 días del afluente y efluente, para evaluar parámetros fisicoquímicos, tales como: carga orgánica, oxígeno disuelto, temperatura, conductividad, potencial redox, sólidos disueltos y pH. En estos mismos periodos se muestrearon los PPCPs. Se alcanzaron eficiencias de remoción superiores al 97\% para el Mp, mientras que fueron inferiores al $10 \%$ para la $\mathrm{Cbz}$, evaluados en ambos tratamientos. Por su parte, para el Sil se alcanzaron eficiencias de hasta el $97 \%$ en los sistemas plantados, mientras que en los no plantados disminuyó en un $30 \%$. El porcentaje de remoción promedio para la carga orgánica fue del $95 \%$. Se determinó que los humedales construidos son capaces de remover eficientemente compuestos de estructura molecular simple, como el $\mathrm{Mp}$ y de estructura compleja, como el Sil. Sin embargo, la $\mathrm{Cbz}$ se mantuvo como un contaminante recalcitrante. 


\subsection{Introducción}

La vida humana se ha visto revolucionada por el consumo de miles de compuestos orgánicos sintéticos. Entre ellos se destacan los fármacos y los productos de cuidado personal (PPCPs). Su administración se ha convertido en un componente indispensable de una sociedad saludable y consumista (Duca and Boldescu, 2009; Ortiz de García et al., 2013). La proliferación de estos compuestos y su facilidad de acceso han aumentado significativamente su carga en entornos naturales (Gorito et al., 2017). Su presencia en el medio acuático se ha relacionado con efectos negativos, que aún no se comprenden por completo (Farré et al., 2008).

Se ha demostrado que los humedales naturales pueden eliminar contaminantes presentes en el agua que fluye a través de ellos; por tal motivo, se han diseñado y construido sistemas artificiales para replicar los procesos de la naturaleza (Gorito et al., 2017). En los mismos pueden ocurrir procesos simultáneos complejos, como la volatilización, sorción, sedimentación, fotodegradación, absorción por las plantas y degradación microbiana, contribuyendo a remover o transormar varios tipos de compuestos (Matamoros and Bayona, 2008). Su ocurrencia va a depender de diferentes factores, por ejemplo, la volatilización está estrechamente relacionada con la presión de vapor de los compuestos, y por lo tanto aquellos contaminantes con valores más altos tienen mayor probabilidad de volatilizarse, presentando vidas medias más cortas (Hijosa-Valsero et al., 2011). Las propiedades físico-químicas de los compuestos, como el coeficiente de reparto $\mathrm{k}_{\mathrm{ow}} \mathrm{y} \mathrm{k}_{\mathrm{oc}}$, así como la constante de ionización Pka, también afectan su sorción en el suelo, plantas, superficies minerales y biofilms (Zhao et al., 2014).

La eliminación de los contaminantes también se puede ver afectada por los factores operacionales y de diseño de los humedales, como su configuración, matriz de suelo/sustrato, profundidad del sustrato y modo de operación (Gorito et al., 2017). La selección de las especies de plantas es otro parámetro importante, ya que presentan una capacidad variable para absorber nutrientes y oxigenar el suelo, además interfieren con el funcionamiento y la estructura de las comunidades microbianas involucradas en la eliminación de contaminantes (Gorito et al., 2017). Las especies más evaluadas son Typha ssp y Phragmites ssp (Li et al., 2014). Además, el tiempo de retención hidráulico (TRH), es otro factor transcendental, ya que un mayor TRH permite una 
mayor interacción de los contaminantes con el humedal, mientras que un TRH bajo reduce el tiempo de contacto entre el agua residual, la rizosfera y los microorganismos. En general, el TRH es variable y depende del tipo de tratamiento que se requiera. Por ejemplo, en climas tropicales se han reportado TRH entre 2-4 días (Zhang et al., 2012), mientras que en Europa se han reportado tiempos entre 4 y 15 días (Li et al., 2014; Özengin and Elmaci, 2016).

Dichos sistemas se los ha utilizado comúnmente para tratar las aguas residuales de poblaciones aisladas, ya que no requieren de energía externa, y la producción de lodo es baja. Sin embargo, la información disponible sobre la eficiencia de estos sistemas está limitada a parámetros de contaminación comunes, como sólidos suspendidos totales, materia orgánica soluble, nutrientes, bacterias, metales pesados, herbicidas y pesticidas (Hijosa-Valsero et al., 2011; Matamoros and Bayona, 2008). Debido a su gran potencial, en los últimos años han surgido como una tecnología alternativa para la remoción de contaminantes emergentes (Ávila et al., 2013; Verlicchi and Zambello, 2014). Así, en el presente trabajo se evaluó la eficiencia de los humedales construidos de flujo horizontal subsuperficial para remover dos fármacos: carbamazepina y sildenafil, y un producto de cuidado personal: metilparabeno, presentes en aguas residuales domésticas. Los sistemas utilizados a escala piloto fueron sembrados en policultivo con macrófitas propias de la zona de estudio (Heliconea Zingiberales y Cyperus Haspan) y evaluados durante los meses de febrero a julio de 2018.

\subsection{Metodología}

\subsubsection{Características de los humedales artificiales a escala piloto}

Se evaluaron cuatro humedales construidos de flujo horizontal subsuperficial, a escala piloto. Cada sistema consta de una pileta construida con fibra de vidrio de 0.60 $\mathrm{m}$ de largo, por $0,55 \mathrm{~m}$ de ancho y $0,55 \mathrm{~m}$ de alto, manteniendo una pendiente del $1 \%$. Se usó grava de tamaño 3/4"-1/2" como medio de soporte, hasta una altura de $0,3 \mathrm{~m}$. Dos de los sistemas se sembraron en policultivo con plantas típicas de la zona de estudio (Heliconea Zingiberales y Cyperus Haspan), cada $0,06 \mathrm{~m}^{2}$, mientras que dos se dejaron sin plantar, como se muestra en la Figura 6.1. En la base inferior, a la salida de la pileta, se colocó una cañería (flauta) perforada de 1/2" para la recolección del 
agua tratada, conectada a una tubería ajustable de 1" para mantener el nivel del agua subsuperficial, a una altura de 0,20 m. Se colocaron dos piezómetros de 1" a 0,15 m de los bordes internos del humedal para seguimiento del desarrollo del biofilm, como se detalla en la Figura 6.1 B.

Se adaptó el método del frasco de Mariotte, a cuatro tanques de $25 \mathrm{~L}$ de capacidad, de sello hermético, con el fin de mantener un flujo de alimentación constante para cada sistema. En la parte superior de cada tanque se instaló un tubo vertical hueco de $4 \mathrm{~mm}$ de diámetro, para mantener la presión constante, y en la parte inferior se incorporó una válvula de cierre lento, a $2 \mathrm{~cm}$ por debajo del tubo vertical. El flujo de salida de los humedales se reguló con sistemas de perfusión macrogoteo. Los sistemas fueron instalados en predios del Centro de Estudios Vegetales y Diversidad Asociada La Rejoya de la Universidad del Cauca, en el departamento del Cauca - Colombia.
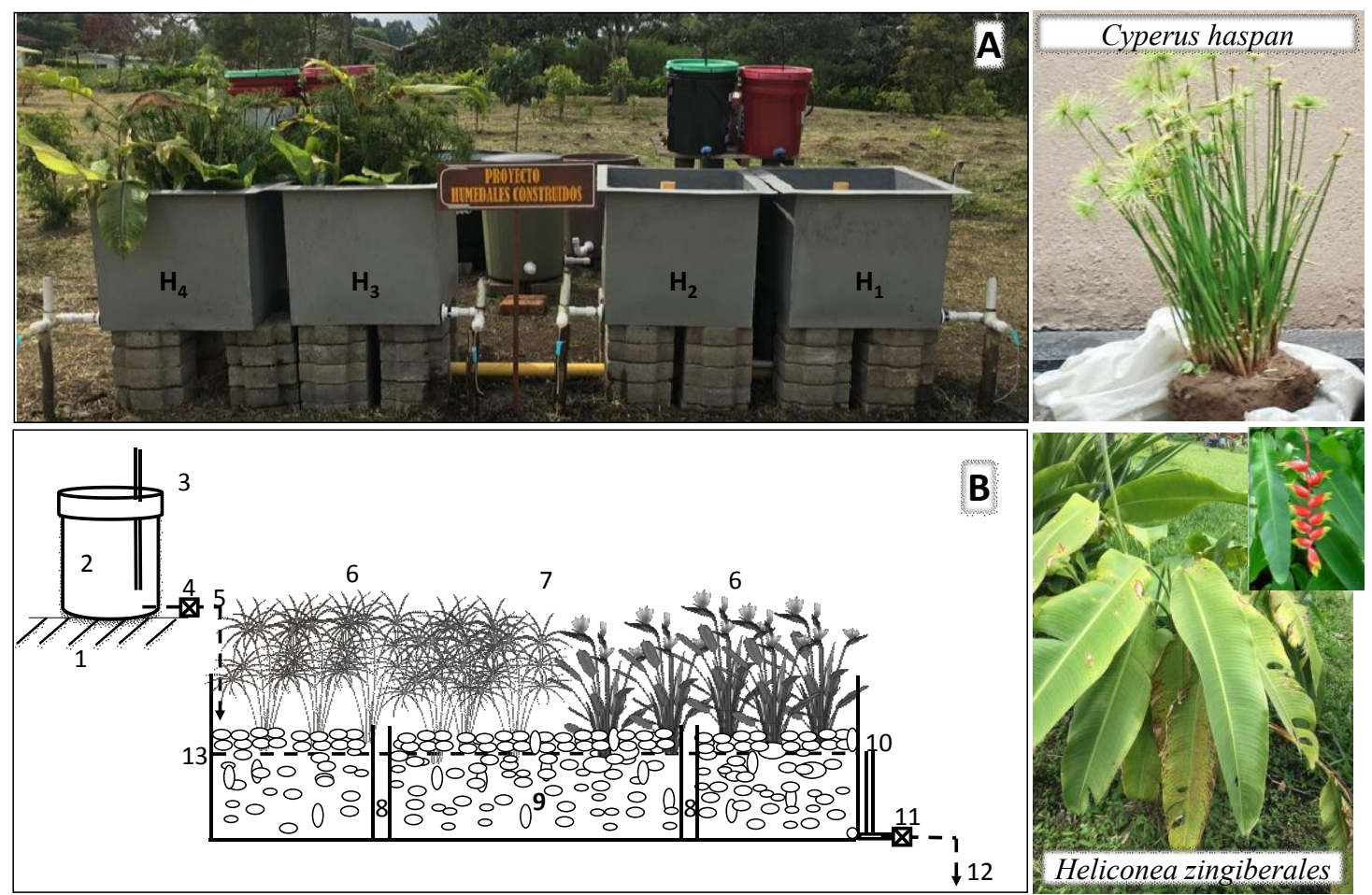

Figura 6.1. (A) Humedales construidos a escala piloto y (B) esquema de los humedales de flujo horizontal subsuperficial: (1) base del tanque de alimentación; (2) tanque de 25 L que contiene el agua residual sintética y lugar donde se incorporan los PPCPs; (3) controlador de presión en el tanque de alimentación; (4) válvula de cierre lento; (5) línea afluente; (6) plantas macrófitas (Cyperus Haspan y Heliconea Zingiberales); (7) Humedal construido; (8) piezómetros; (9) sustrato; (10) tubería ajustable; (11) sistema de perfusión macrogotero; (12) línea efluente; (13) flujo subsuperficial. 


\subsubsection{Diseños experimentales para los humedales construidos}

La prueba de estanqueidad de cada humedal se evaluó en batch durante dos semanas, con agua de lluvia colectada en la finca. Luego se agregó agua residual doméstica filtrada (tamiz $\mathrm{N}^{\mathrm{o}} 35$ - según la serie de Tylor) cada cinco días, con el fin de desarrollar un consorcio bacteriano sobre el lecho de grava, manteniendo el funcionamiento en batch. El desarrollo del biofilm se determinó mediante la formación de una delgada película bacteriana sobre la superficie de los piezómetros (Casas et al., 2013) a los 30 días. Con esta etapa concluida, se sembraron las plantas macrófitas, dejando el sistema en batch durante otros 30 días con alimentación de agua residual doméstica. Transcurrido este tiempo se operaron los reactores en continuo con agua residual sintética, simulando un agua residual doméstica (Ver detalles en el Capítulo 3), con cargas orgánicas de aproximadamente $250 \mathrm{mg} / \mathrm{L}$ (DQO), durante 30 días. El tiempo de retención hidráulico (TRH) fue de 72 h, (Li et al., 2014; Özengin and Elmaci, 2016), manejando un caudal de aproximadamente $15 \mathrm{~mL} / \mathrm{min}$.

Finalmente se incorporaron los tres PPCPs en su mezcla en los tanques de alimentación, en concentraciones nominales de $0,2 \mathrm{mg} / \mathrm{L}$ para cada uno, y una DQO de $250 \mathrm{mg} / \mathrm{L}$ similar a la de un tratamiento secundario. El funcionamiento de cada reactor se evaluó midiendo parámetros físicoquímicos, como $\mathrm{pH}$, temperatura, conductividad, oxígeno disuelto y demanda química de oxígeno en el afluente y el efluente, además de las determinaciones de las concentraciones de cada contaminante. Las muestras se tomaron cada 20 días, durante un periodo de seis meses. En la Tabla 6.1 se resumen las condiciones de trabajo.

Para determinar la capacidad de absorción de los PPCPs por las plantas, se tomó un ejemplar de cada especie y cada humedal. Las macrófitas se lavaron, se secaron al ambiente y se mantuvieron a $-20{ }^{\circ} \mathrm{C}$ hasta el momento de su análisis. Conjuntamente se tomó una porción del lecho filtrante recubierto por biofilm, el cual se mantuvo en metanol a $4{ }^{\circ} \mathrm{C}$ hasta su análisis, con el fin de determinar la degradación microbiana de los compuestos. 
Tabla 6.1 Parámetros de diseño de los humedales, parámetros físico-químicos medidos y condiciones experimentales evaluadas

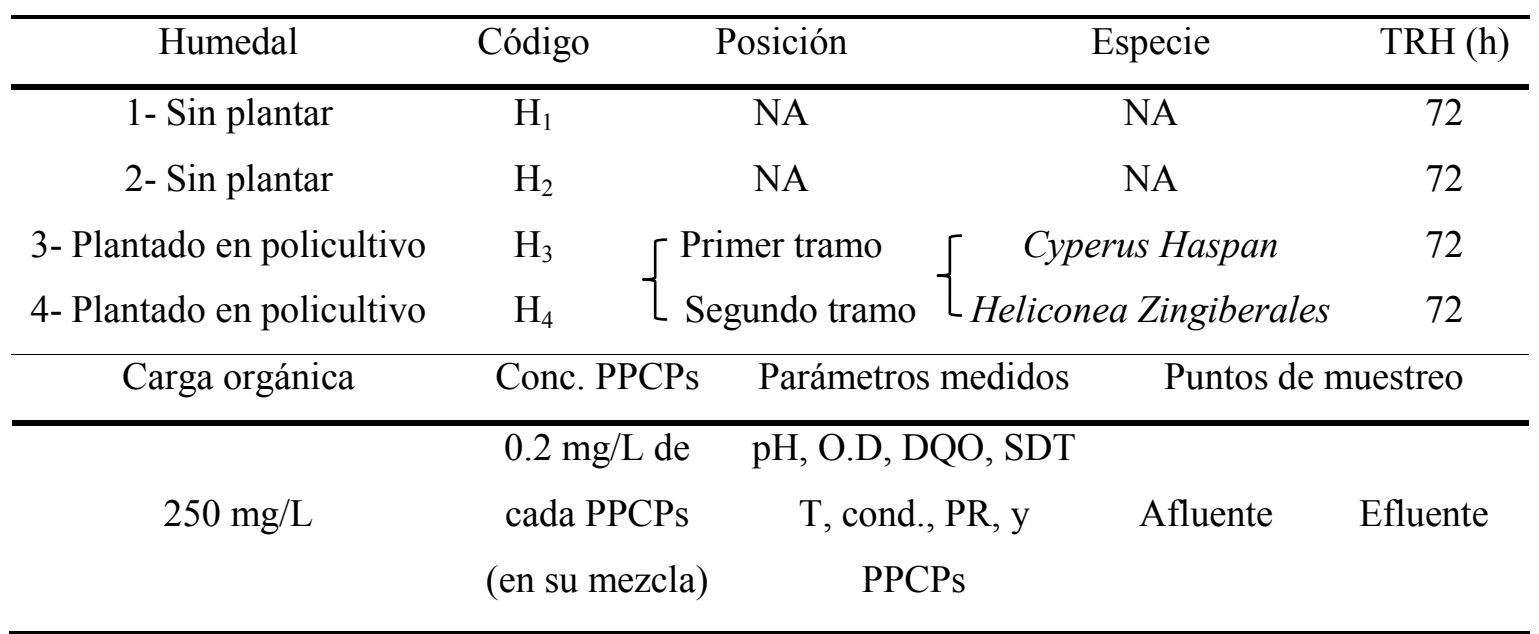

NA: no aplica; O.D: oxígeno disuelto; DQO: demanda química de oxigeno; SDT: sólidos disueltos totales; T: temperatura; Cond: conductividad; PR: potencial redox; PPCPs: fármacos y productos de cuidado personal.

\subsubsection{Cálculo del balance de materia de los PPCPs en los humedales construidos}

Teniendo en cuenta la masa total de los PPCPs incorporados, la masa total detectada en el efluente, la masa total retenida en las plantas y la cantidad detectada por adsorción en el sustrato, se realizó un balance de materia para los PPCPs en los humedales construidos. La diferencia restante de los compuestos se atribuyó a la remoción por otro tipo de mecanismos como biodegradación, biotransformación, etc. El balance de masas se calculó de acuerdo a la Ecuación (6.1) (Tejeda et al., 2017):

$$
\begin{gathered}
\text { Masa-PPCPs en el afluente = masa-PPCPs en el efluente }+ \text { masa-PPCPs en plantas }+ \\
\text { masa-PPCPs en el sustrato }+ \text { eliminación de masa-PPCPs por otros mecanismos }
\end{gathered}
$$

\subsubsection{Métodos analíticos}

La determinación los PPCPs se realizó en laboratorio del Grupo de Diagnóstico y Control de la Contaminación, de la Universidad de Antioquia, mediante cromatografía liquida acoplada a espectrometría de masas en tándem (Aristizabal et al., 2017). El mismo procedimiento se efectuó para el análisis de adherencia de los PPCPs sobre el sustrato y su absorción en el material vegetal. Se utilizó el método AOAC para el análisis del material vegetal. El oxígeno disuelto, el $\mathrm{pH}$, la 
conductividad y la temperatura del medio en afluente y efluente se determinaron in situ mediante un multiparamétrico HI98194 Hanna. La DQO se realizó de acuerdo al método 5220 del Standard Methods (APHA, 1998) en el grupo GCISA de la Universidad del Cauca.

\subsection{Resultados y discusión}

Los humedales construidos han surgido en las últimas décadas como una solución ecológicamente eficaz para el tratamiento de los contaminantes emergentes en aguas residuales. Los humedales construidos de flujo horizontal subsuperficial tienen la ventaja frente a los de flujo superficial, que evitan la propagación de vectores (como mosquitos), logrando una operación de mantenimiento más segura, además, requieren de tiempos de contacto menores $\mathrm{y}$, menor disponibilidad de áreas en terreno (Matamoros et al., 2017). Teniendo en cuenta éstas características, en la presente investigación se evaluó este tipo de diseño para la remoción de la Cbz, el Sil y el Mp de las aguas residuales domésticas.

El tiempo necesario para alcanzar un buen funcionamiento de los sistemas fue de aproximadamente cuatro meses, debido a problemas operativos que se presentaron durante la configuración de los reactores, como fugas en las adaptaciones y líneas de alimentación, y la elección del mecanismo adecuado para su alimentación manteniendo un flujo estable y continuo, debido a la falta de energía eléctrica en el lugar. Este mismo tiempo fue suficiente para garantizar la aclimatación de los humedales y las interacciones entre el biofilm, las plantas y el medio de soporte (Casas et al., 2013).

\subsubsection{Problemas operativos}

Debido a la ubicación de los reactores, los prolongados tiempos de operación y la cantidad de humedales en estudio, fue necesario evaluar diferentes instrumentos y metodologías para regular y mantener un flujo de alimentación continuo y constante sin gasto de energía eléctrica. Para tal fin se utilizaron medidores de flujo de área variable, goteros autocompensantes, reguladores de caudal, y adaptación de la técnica del método del frasco de Mariotte, implementada a escala piloto luego de una prueba en laboratorio. 


\subsubsection{Instrumentos evaluados para regular el flujo de alimentación}

Inicialmente se utilizaron medidores de flujo de área variable (rotámetros) marca ABB/10A61, para regular el caudal. Sin embargo, el hecho de trabajar con aguas residuales genera obstrucción en los instrumentos debido a la incorporación de material en suspensión y al crecimiento de algas (ver Figura 6.2 A). Por lo tanto, se realizaron diferentes ensayos con goteros autocompensantes y no autocompensantes, de $2 \mathrm{~L} / \mathrm{h}, 4 \mathrm{~L} / \mathrm{h}$ y $8 \mathrm{~L} / \mathrm{h}$, como se observa en la Figura $6.2 \mathrm{~B}$. Estos goteros son capaces de mantener un caudal constante mientras se trabaje con carga hidráulica mínima de siete metros. Sin embargo, al no contar con esta condición debido a la manipulación diaria de tanques de alimentación, no se implementaron.

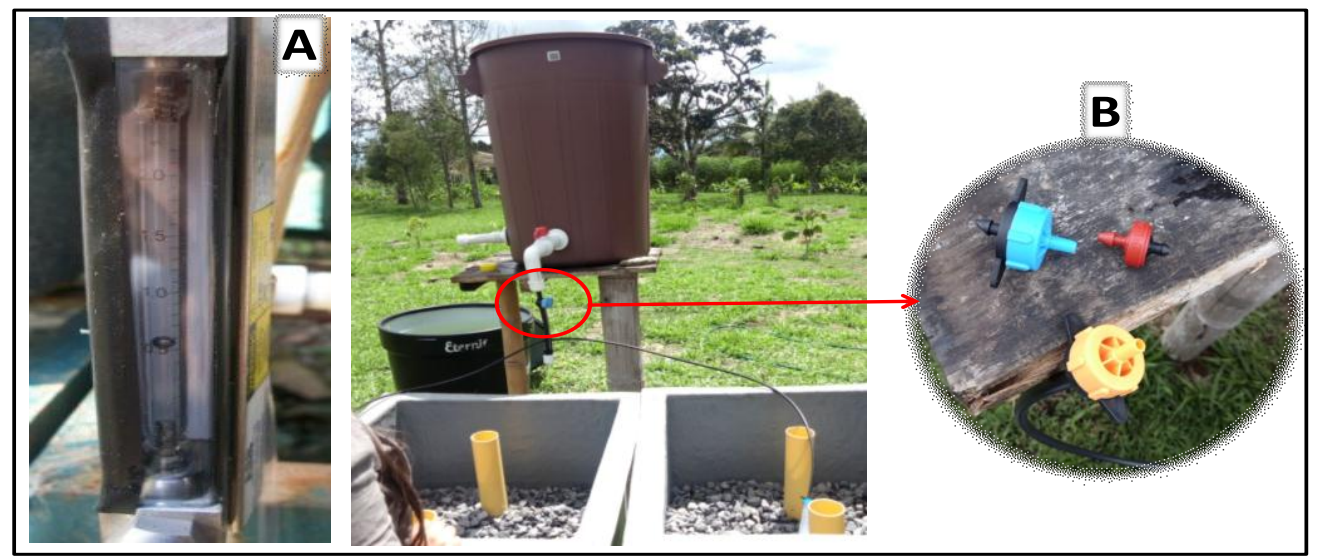

Figura 6.2. Uso de un (A) Medidor de flujo de área variable y de (B) goteros autocompensantes y no autocomnesantes para regular el flujo de alimentación de los humedales.

\subsubsection{Adaptación del método del frasco de Mariotte a escala piloto}

El frasco de Mariotte consiste en un recipiente lleno de líquido hasta una altura h, este recipiente está cerrado herméticamente, siendo atravesado por un tubo abierto por ambos extremos (Schwertz, 1950). El extremo inferior $p$ está sumergido en el líquido contenido en el tanque. El líquido sale por un orificio $q$ en la pared lateral del tanque, de modo que la altura entre el orificio $p$ y $q$ es $H$ (ver Figura $6.3 \mathrm{~A}$ ). Al salir el líquido por el orificio $q$, el volumen del aire contenido en la parte superior del frasco aumenta, disminuyendo por consiguiente su presión. Como dicha presión es inferior a la atmosférica, el líquido desciende más rápidamente por el interior del tubo, ya que este comunica directamente con la atmósfera. Al llegar el nivel del líquido en el tubo 
al extremo inferior $p$, el aire que penetra en dicho tubo asciende en burbujas a través del líquido, alojándose en la parte superior del mismo. A medida que se va vaciando el tanque, la presión en el extremo inferior del tubo es igual a la atmosférica, así como en el punto de salida $q$. Aplicando la ecuación de Bernoulli (Ecuación 6.2) a los puntos $p$ y $q$, tenemos:

$$
\frac{P_{p}}{\rho}+\frac{v_{p}^{2}}{2}+g H_{p}=\frac{P_{q}}{\rho}+\frac{v_{q}^{2}}{2}+g H_{q}
$$

Tomando como punto de referencia el punto $q$, la velocidad en $p$ es cero, la altura $q$ es cero, y teniendo en cuenta que la presión en el punto $p$ y $q$ es igual a la atmosférica, entonces la Ecuación 5.1 se reduce a la Ecuación (6.3)

$$
v=\sqrt{2 g H}
$$

De lo anterior se obtiene que la velocidad de salida del líquido por el orificio $q$ sea constante, ya que depende de la distancia entre $p$ y $q$, es decir de la altura $H$, la cual también se mantiene constante. Esta velocidad se mantendrá estable siempre que el nivel del líquido en el frasco este por encima del extremo inferior del tubo $p$. El volumen del líquido que sale por el orificio $q$ por unidad del tiempo es proporcional a la velocidad, por lo que también resulta ser constante, como se ve en la Ecuación (6.3). Cuando el nivel del líquido está por debajo del extremo inferior del tubo, la velocidad del líquido disminuye a medida que lo hace la altura $h$, disminuyendo el caudal del líquido. A partir de ese momento, el vaciado del tanque sigue la ley de Torricelli, en la que la velocidad de salida va a depender de la carga hidráulica $(h)$.

Se evaluaron diferentes configuraciones en los tanques de alimentación para llevar a cabo el método del frasco de Mariotte de laboratorio a escala piloto. Inicialmente se utilizó un tanque de 120 L de capacidad, con una salida doble para verter el agua a tratar; adaptándole un tubo vertical de PVC de $1 / 2$ " en la parte superior. Después de $24 \mathrm{~h}$ de funcionamiento se observó flujo preferencial en una de las salidas y el caudal disminuía considerablemente con el tiempo (ver Figura 6.3 B), debido posiblemente a la falta de hermeticidad en los tanques. Por lo tanto, se realizó un nuevo ensayo con tanques más pequeños $(60 \mathrm{~L})$ y con una única salida, controlada por un equipo de perfusión macrogoteo (ver Figura $6.3 \mathrm{C}$ ). Nuevamente el caudal disminuía considerablemente con el paso del tiempo. Concluyendo que no se logró 
hermetizar completamente ambos tanques y por esta razón el caudal de salida dependía principalmente de la columna de líquido y no de la presión atmosférica. Además la relación con la que se trabajó, entre el diámetro del tubo vertical y el diámetro del tanque resultó ser excesiva.

Se realizaron nuevos ensayos con recipientes herméticos de $25 \mathrm{~L}$, con un tubo vertical de $4 \mathrm{~mm}$ de diámetro y la salida regulada por el mismo equipo de perfusión, como se observa en la Figura 6.3 D. Este ensayo funcionó adecuadamente, con una disminución del caudal de $5 \mathrm{~mL}$ en $24 \mathrm{~h}$. Sin embargo, al tratarse de un recipiente de material flexible, tardaba más de 30 minutos en igualar las presiones y en estabilizar el flujo, perdiendo aproximadamente $3 \mathrm{~L}$ de agua residual durante este procedimiento.

Finalmente, se adaptó el método de Mariotte a tanques rígidos herméticos de $25 \mathrm{~L}$. Se evaluaron diseños iniciales utilizando tubos verticales de $10 \mathrm{~mm}$ y $4 \mathrm{~mm}$ de diámetro, y una salida controlada por un sistema de perfusión macrogotero (ver Figura $6.3 \mathrm{E}$ ). En el primer caso (diámetro $10 \mathrm{~mm}$ ), la presión atmosférica fue superada por la carga hidráulica. En el segundo caso (diámetros $4 \mathrm{~mm}$ ) se logró controlar la presión atmosférica en el punto $p$, pero la incorporación del sistema de macrogoteo no permitió regular el caudal, debido a la extensión vertical de la manguera, que aumentaba la altura H. Por consiguiente, se evaluó el método adaptando una válvula horizantal de cierre lento para la salida. Concluyendo que la mejor configuración para llevar a cabo el método de Mariotte a escala piloto era instalando en un tanque hermético rígido un tubo vertical de $4 \mathrm{~mm}$ de diámetro, ubicado a dos centímetros por encima del punto $q$, y regulando el flujo en la salida mediante una válvula de cierre lento de $1 / 4$ '. Con esta configuración se logró mantener un caudal estable y continuo durante $24 \mathrm{~h}$. El caudal inicial para obtener finalmente $\operatorname{los} 15 \mathrm{~mL} / \mathrm{min}$, debía ser de aproximadamente $18 \mathrm{~mL} / \mathrm{min}$, como se observa en la Figura 6.4 .

El hecho de utilizar metodologías alternativas para regular el flujo de alimentación de los reactores resulta de mucha utilidad en los trabajos de investigación a escala piloto, ya que se evitan altos consumos de energía eléctrica, requerida por las bombas dosificadoras de caudal, las cuales son comúnmente utilizadas en este tipo de estudios (Ávila et al., 2013; Li et al., 2014; Westerhoff, 2014). 

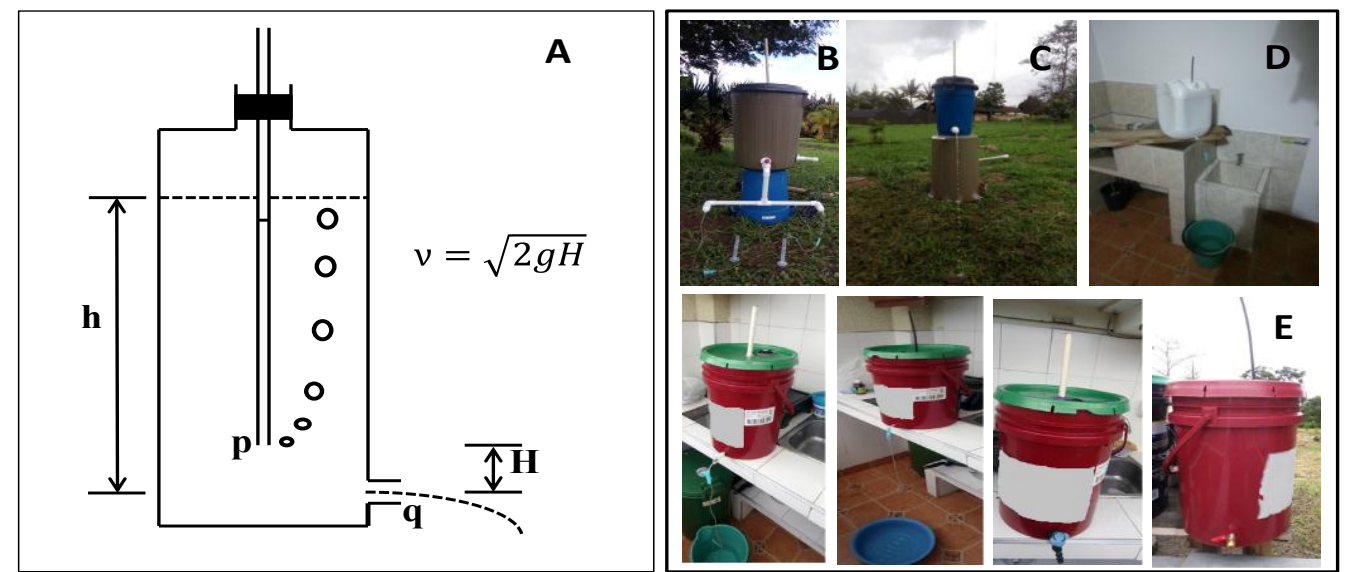

Figura 6.3. (A) Esquema del método del frasco de Mariotte y (B)

Evaluación del método del frasco de Mariotte a escala piloto

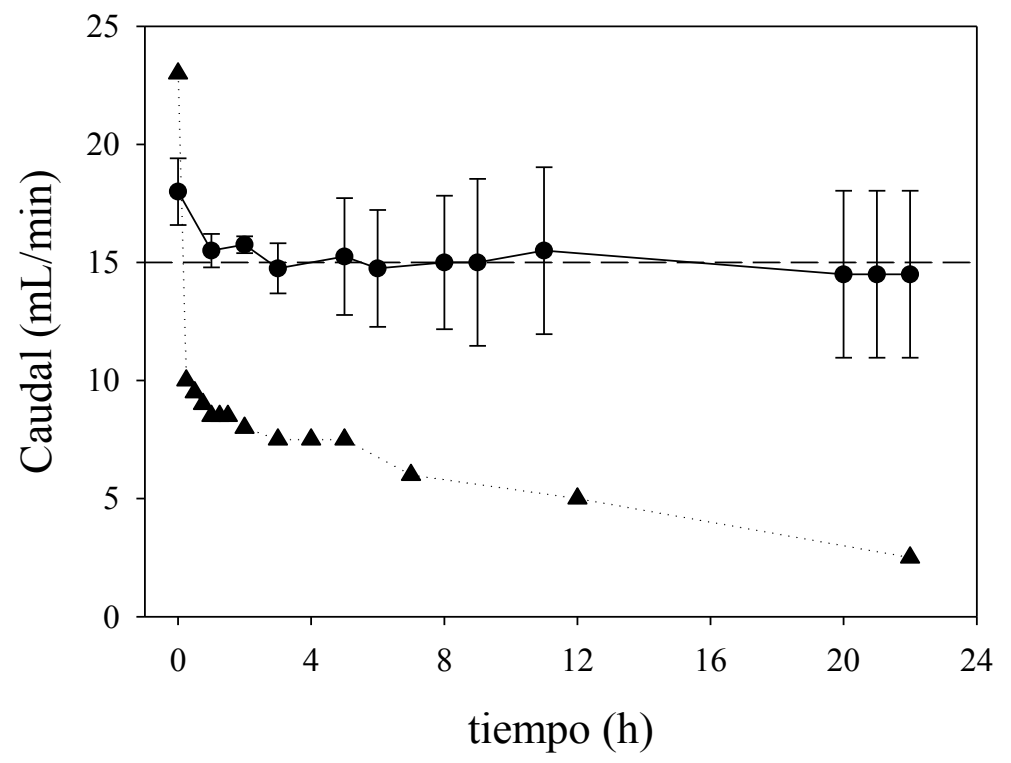

Figura 6.4. Comparación de la estabilización del caudal (•) con y ( $\mathbf{\Delta})$ sin el método de Mariotte. Los guiones representan el flujo que se pretende alcanzar $(15 \mathrm{~mL} / \mathrm{min})$. Las barras de error indican la variabilidad del flujo al realizar experimentos por triplicado.

Para evitar cualquier tipo de contaminación en el agua residual, se realizó un lavado exhaustivo de los tanques de alimentación. Inicialmente se lavaron con agua caliente, luego con jabón neutro, y finalmente se realizó un lavado con hipoclorito de sodio diluido al 10\%, el cual se dejó actuar durante 24 h. Pasado este tiempo se retiró 
el hipoclorito de sodio y se agregó ácido nítrico diluido al 10\% dejándolo actuar durante el mismo periodo de tiempo.

\subsubsection{Remoción de los PPCPs}

Después de lograr controlar el caudal de alimentación, de obtener el desarrollo bacteriano y la adaptación de las plantas al medio, se procedió a evaluar el comportamiento de los sistemas incorporando los PPCPs en su mezcla, en concentraciones de alimentación de $0,17 \pm 0,04 \mathrm{mg} / \mathrm{L}$ para la $\mathrm{Cbz} ; 0,11 \pm 0,07 \mathrm{mg} / \mathrm{L}$ para el Sil y $0,18 \pm 0,05 \mathrm{mg} / \mathrm{L}$ para el Mp.

\subsubsection{Análisis particular de la carbamazepina}

Los resultados obtenidos para el tratamiento de la $\mathrm{Cbz}$ en los humedales piloto de flujo horizontal subsuperficial se presentan en la Figura 6.5 A. Como se puede ver, en el primer muestreo se alcanza una aparente eficiencia de remoción de aproximadamente el $60 \%$, tanto en los sistemas plantados como en los no plantados. Sin embargo, al evaluar los siguientes siete muestreos, se determinó que dicha eficiencia disminuyó considerablemente. Al evaluar los valores de las concentraciones afluentes y efluentes de cada sistema, mediante un test de t pareado, con un nivel de significancia de 0,05 , se obtuvieron resultados del p-valor de 0,$497 ; 0,369 ; 0,687$ y 0,710 para el $\mathrm{H}_{1}, \mathrm{H}_{2}, \mathrm{H}_{3}$ y $\mathrm{H}_{4}$, respectivamente. Por ende, se determinó que no había diferencias estadísticamente significativas entre las concentraciones de afluentes y efluentes. Los humedales presentaron periodos de estabilización superiores a veinte días para lograr la remoción de los PPCPs, por tanto, realizar ensayos con tiempos inferiores pueden llevar a conclusiones erróneas.

Para determinar si existían diferencias entre los efluentes de cada tratamiento se realizó un análisis de varianza unifactorial, para el mismo nivel de significancia de la prueba t pareada. Se obtuvo un p-valor de 0,809. Determinándose que no había una diferencia estadísticamente significativa entre los tratamientos plantados y los no plantados. Concluyendo que después del tiempo de estabilización no se alcanzaron eficiencias de remoción superiores al 10\%.

Se han reportado diferentes configuraciones de humedales construidos para evaluar la efíciencia de remoción de contaminantes recalcitrantes como la Cbz. Sin embargo, rara vez las remociones superaron el 50 \% (Hijosa-Valsero et al., 2010; Kahl 
et al., 2017; Tejeda et al., 2017; Verlicchi and Zambello, 2014). Los tiempos de retención hidráulico también se han modificado entre 2 y 15 d para mejorar su eliminación, pero su eficiencia tampoco varió de manera significativa (Li et al., 2014). La estabilidad de la Cbz se puede atribuir a su notable resistencia a la biodegradación, debido a su estructura molecular compleja y a su efecto tóxico para los microorganismos (Matamoros and Bayona, 2008; Matamoros and Salvadó, 2012).

Recientemente se ha investigado mejorar la eliminación de este fármaco utilizando lechos con soportes diferentes a la grava convencional. La arcilla expandida ligera (LECA) ha resultado de gran interés, ya que se alcanzaron eficiencias de remoción de hasta un $90 \%$ durante 6 días de trabajo (Dordio et al., 2010; Özengin and Elmaci, 2016). Sin embargo, como se puntualizó anteriormente, es importante evaluar tiempos de operación superiores a 40 días para determinar la estabilidad operativa del sistema o por el contrario existe saturación en la superficie de la LECA (Özengin and Elmaci, 2016).

\subsubsection{Análisis particular del sildenafil}

Teniendo en cuenta los prolongados periodos de aclimatación en los humedales y los resultados obtenidos en el Capítulo 5, sobre el efecto tóxico de los PPCPs en los microorganismos (Cbz: resultó ser toxica, el Mp no los afectó significativamente, y el Sil presentó efectos menos tóxicos que la $\mathrm{Cbz}$, pero un poco más tóxicos que el $\mathrm{Mp}$ ), se decidió incorporar gradualmente el Sil para contrarrestar efectos negativos sobre los microorganismos desarrollados. Las concentraciones iniciales incorporadas para los primeros cuatro muestreos fueron de 0,044 $\pm 0,006 \mathrm{mg} / \mathrm{L}$. La concentraciones incorporadas durante las cuatro últimas campañas fueron de $0,168 \pm 0,040 \mathrm{mg} / \mathrm{L}$. Los resultados obtenidos para el Sil en los humedales se muestran la Figura 6.5 B.

Se realizó un análisis estadístico similar al que se planteó anteriormente, mediante pruebas de $\mathrm{t}$ pareadas y un nivel de significancia de 0,05. Los resultados obtenidos del el p-valor, para determinar la variabilidad entre las concentraciones afluentes y efluentes, de los reactores no plantados y los plantados fueron de 0,0003 y $<0,001$, respectivamente, para ambas concentraciones. En ambos casos las diferencias en los valores medios de los dos grupos evaluados fueron mayores de lo que se esperaría por errores aleatorios; indicando que existía una diferencia estadísticamente significativa entre los valores de las concentraciones de entrada y de salida. Además se 
determinaron diferencias estadísticamente significativas entre los sistemas plantados y los no plantados, obteniéndose un p-valor inferior a 0,001. No se observaron diferencias estadísticamente significativas para las concentraciones efluentes de los sistemas no plantados, ni para las efluentes de los humedales plantados, con p-valores de 0,158 y 0,619, respectivamente, comportándose efectivamente como sus réplicas y no como sistemas individuales. Se determinó que tiempos de evaluación superiores a 60 días eran necesarios para alcanzar la estabilidad operativa de los sistemas.

Se obtuvieron eficiencias de remoción superiores al 97\% para concentraciones bajas de Sil en los humedales plantados, mientras que en los no plantados, la eficiencia se redujo en un $40 \%$. Para las concentraciones más altas se alcanzaron eficiencias promedio de remoción del 91\%, con un máximo del 97\% en los sistemas plantados. Mientras que en los no plantados se alcanzaron remociones promedio del 65\%. Resultados similares se publicaron anteriormente al comparar la remoción de algunos fármacos, como el ketoprofeno y el ibuprofeno, en sistemas plantados y no plantados (Hijosa-Valsero et al., 2010; Hijosa-Valsero et al., 2016). Se determinó entonces que las plantas juegan un rol importante en la remoción del Sil, el cual se reportó como un compuesto recalcitrante en trabajos anteriores (Delgado et al., 2018; Grossberger et al., 2014). En las plantas de tratamiento convencionales y en tratamientos biológicos de película fija se han reportado eficiencias inferiores al $20 \%$ para dicho compuesto (Delgado et al., 2018; Rivera-Utrilla et al., 2013). Sin embargo no se han encontraron trabajos que evalúen la eliminación del Sil en humedales construidos.

\subsubsection{Análisis particular del metilparabeno}

En la Figura $6.5 \mathrm{C}$ se muestran los resultados obtenidos para la remoción del Mp en los humedales. Las concentraciones efluentes de $\mathrm{Mp}$ en cada uno de los sistemas estuvieron por debajo del límite de cuantificación de la técnica $(0,005 \mathrm{mg} / \mathrm{L})$, por lo que se puede aseverar que se obtuvieron eficiencias de remoción superiores al $97 \%$. No se observaron diferencias estadísticamente significativas en la eficiencia de remoción de los sistemas plantados y los no plantados. Tampoco existió una diferencia entre sus réplicas, con p-valores superiores a 0,05. El tiempo de estabilización necesario para remover el $\mathrm{Mp}$ fue inferior a los veinte días. Un comportamiento similar se observó en la degradación de la materia orgánica, como se muestra la Figura 
6.5 D. La carga orgánica inicial fue de $198 \pm 25 \mathrm{mg} / \mathrm{L}$, y su eficiencia de remoción fue superior al $97 \%$.

Es poca la información que se tiene sobre la remoción de Mp utilizando métodos naturales. En estudios anteriores se evaluó la remoción del mismo, mediante humedales construidos a escala real, en los que se alcanzó una eficiencia de eliminación promedio del 42\% (Matamoros et al., 2016). Los humedales en el presente estudio mostraron un aumento en la eficiencia de remoción del 55\%. Los mejores resultados se deben probablemente a las condiciones climáticas de trabajo, las cuales presentan temperaturas medias de $22{ }^{\circ} \mathrm{C}$ durante todo el año, permitiendo una mejor biodegradación de $\mathrm{Mp}$ en climas templados, que en lugares con temperaturas diferentes (Tejeda et al., 2017). Siendo así, se puede decir que el principal proceso de remoción del Mp es debido a la degradación bacteriana (Naipal, 2014).

Su alta eficiencia de remoción se puede deber a su estructura molecular simple, como se mencionó anteriormente en el Capítulo 5, donde se obtuvieron resultados similares. El Mp presenta en su composición molecular elementos químicos esenciales $(\mathrm{C}, \mathrm{H}, \mathrm{O})$, los cuales son fácilmente degradados por microorganismos (Reddy and DeLaune, 2008). Además, el tener un anillo aromático único unido a un grupo hidroxilo y una cadena de metilo, ambos en posición para, le confiere una estequiometria favorable (molécula plana) para su adsorción moderada al sustrato $(\log \operatorname{koc}=2,4)$ y fácil dispersión en el agua residual $(\log$ kow $=1,96)$. Estudios anteriores han llegado a la misma conclusión, reportando que los compuestos orgánicos con estructuras simples que poseen alta solubilidad en agua y moderada capacidad de adsorción, son degradados fácilmente por los microorganismos (Matamoros et al., 2017).

Por el contrario, se ha reportado que aquellos compuestos orgánicos recalcitrantes, como la $\mathrm{Cbz}$, que tienen elementos químicos y estructuras muy diferentes de los compuestos naturales, son degradados lentamente por los microorganismos (Li et al., 2014). Sin embargo, para el Sil, que presenta una estructura molecular compleja, se alcanzaron altas eficiencias de eliminación (>90\%) en los sistemas evaluados en el presente trabajo. Por lo tanto, existen otros factores, diferentes a la estructura molecular de los compuestos, que pueden influir en la remoción de los contaminantes emergentes de estructura molecular compleja. 

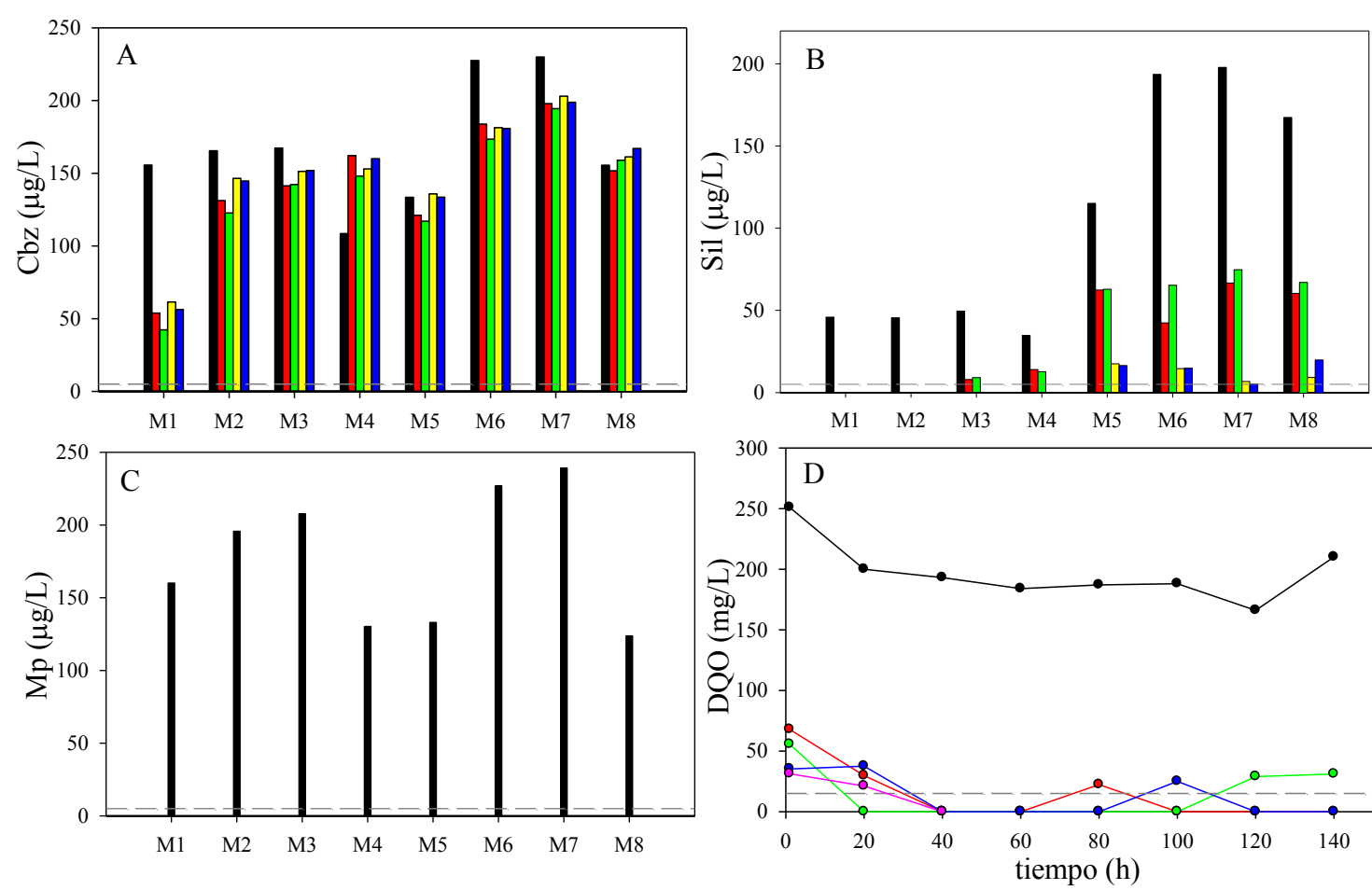

Figura 6.5. Concentraciones afluentes ( I ), y efluentes de los humedales sin plantar $\mathrm{H}_{1}$ ( I ) y $\mathrm{H}_{2}$ ( I ); y en los humedales plantados $\mathrm{H}_{3}$ ( I ) y $\mathrm{H}_{4}$ ( I ), para (A) Cbz , (B) Sil y (C) Mp, durante los ocho muestreos realizados (M1, M2, M3, M4, M5, M6, M7, M8 (M= muestreo)). El gráfico (D) presenta el comportamiento de la DQO afluente (•) y la efluente para $\mathrm{H}_{1}(\bullet), \mathrm{H}_{2}(\bullet), \mathrm{H}_{3}(\bullet), \mathrm{H}_{4}(\bullet)$. Las líneas grises punteadas representa el límite de cuantificación de cada técnica.

\subsubsection{Absorción de los PPCPs por las macrófitas}

Luego de 140 días de operación, la especie con la menor biomasa en pie fue la Heliconea Zingiberales, con un promedio de 12 plantas por humedal y un peso promedio de 135 g por planta. El peso de la biomasa total fue de $1400 \mathrm{~g}$. El Cyperus Haspan presentó buenas condiciones de desarrollo y población, con un promedio de 230 plantas por humedal y un peso promedio de $12 \mathrm{~g}$ por planta, con un total de biomasa de 3000 g. Durante los primeros tres meses de aclimatación la Heliconea Zingiberales presentó un buen desarrollo, sin embargo, luego de dos meses de incorporar continuamente los PPCPs, fue claramente la especie que exhibió más signos de estrés, como se puede ver en la Figura 6.6. Además, la competencia entre ellas podría haber sido también una fuente de estrés adicional. 
Los niveles de absorción promedios de Cbz, Sil y Mp en Cyperus Haspan fueron de $0,51 \mu \mathrm{g} / \mathrm{g}, 0,14 \mu \mathrm{g} / \mathrm{g}$ y $0,03 \mu \mathrm{g} / \mathrm{g}$, respectivamente. En la Heliconea Zingiberales, se determinaron valores promedios de absorción de 0,29 $\mu \mathrm{g} / \mathrm{g}, 0,05 \mu \mathrm{g} / \mathrm{g}$ y $0,03 \mu \mathrm{g} / \mathrm{g}$, respectivamente.

El compuesto mayormente absorbido fue $\mathrm{Cbz}$, seguido por Sil y Mp. Se determinó que el Cyperus Haspan tiene mayor capacidad de absorción de Cbz y Sil que la Heliconea Zingiberales, como se ve en la Tabla 6.2. Estos resultados sugieren que el rendimiento de las macrófitas cuando se exponen a los PPCPs varían según la especie (Tejeda et al., 2017). No hay muchos estudios referidos en policultivo para plantas típicas de las zonas templadas, sin embargo Tejada et al. (2017) encontraron comportamientos similares para plantas ornamentales en clima tropical expuestas a la Cbz. Otros estudio han reportado mayores niveles de absorción de Cbz en especies como Scirpus validus, con concentraciones entre 3,6-19,7 $\mu \mathrm{g} / \mathrm{g}$ (Zhang et al., 2013), y $1-17 \mu \mathrm{g} / \mathrm{g}$ en typha spp (Dordio et al., 2011).

Existen estudios en los que se reporta que los contaminantes pueden ser removidos por absorción directa de las plantas si presentan un log $\mathrm{K}_{\mathrm{ow}}$ entre 0.5-3 (Dordio et al., 2010). Tal como se observó anteriormente para la Cbz, el Sil y el Mp que presentan un $\log \mathrm{K}_{\mathrm{ow}}$ de 2,45; 2,75 y 1,96 respectivamente. Es importante tener en cuenta que los bajos niveles detectados de Sil y Mp se pueden deber a su metabolización por las macrófitas. Por el contrario la mayor concentración detectada de Cbz, y su baja eficiencia de remoción en cualquiera de los sistemas, indican la estabilidad de la molécula, la cual no resultó fácil de ser metabolizada por las plantas estudiadas.
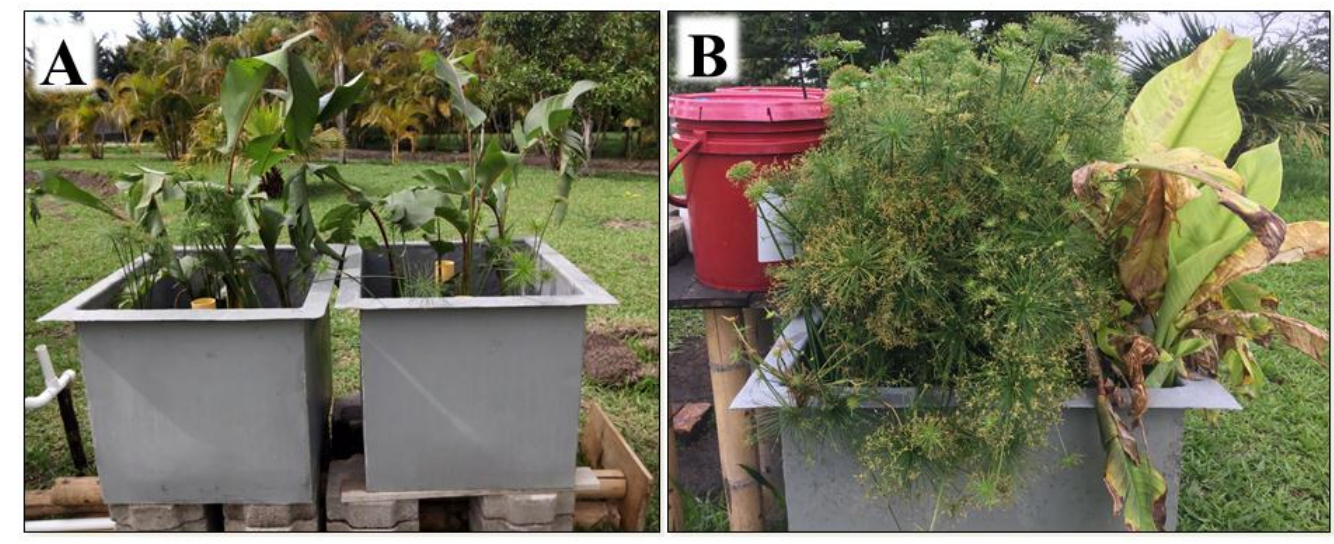

Figura 6.6. Desarrollo de las plantas (A) al inicio de su aclimatación y (B) seis meses después de incorporar los PPCPs. 
Tabla 6.2. Concentración de los PPCPs detectada en el material vegetal

\begin{tabular}{|c|c|c|c|c|c|c|}
\hline \multirow[b]{2}{*}{ Reactor } & \multicolumn{3}{|c|}{ Cyperus Haspan $(\mu \mathrm{g} / \mathrm{g})$} & \multicolumn{3}{|c|}{ Heliconea Zingiberales $(\mu \mathrm{g} / \mathrm{g})$} \\
\hline & $\mathrm{Cbz}$ & Sil & $\mathrm{Mp}$ & $\mathrm{Cbz}$ & Sil & $\mathrm{Mp}$ \\
\hline $\mathrm{H}_{3}$ & 0,32 & $0,03^{*}$ & $0,03^{*}$ & 0,40 & $0,03^{*}$ & $0,03^{*}$ \\
\hline $\mathrm{H}_{4}$ & 0,69 & 0,25 & $0,03^{*}$ & 0,19 & 0,07 & $0,03^{*}$ \\
\hline Promedio & 0,51 & 0,14 & $0,03^{*}$ & 0,29 & 0,05 & $0,03^{*}$ \\
\hline
\end{tabular}

*<LC: valor $=$ LC/2 (Kahl et al., 2017).

\subsubsection{Adsorción de los PPCPs sobre el sustrato}

El sustrato (también conocido como lecho soporte) es un componente importante en los humedales construidos, especialmente en los humedales de flujo subsuperficial. Además de ofrecer un soporte para el crecimiento de las plantas, proporciona un medio de adherencia para el biofilm.

Para determinar la adsorción de los PPCPs sobre el sustrato, se analizó una muestra de grava de aproximadamente $9 \mathrm{mg}$, recubierta por biofilm. Esta muestra se tomó de entre la rizosfera de las plantas. El peso total del sustrato en los humedales fue de aproximadamente $144.000 \mathrm{~g}$. Se detectaron en la muestra concentraciones promedio de Cbz, Sil y Mp de 0,23 $\mu \mathrm{g} / \mathrm{g} ; 1,95 \mu \mathrm{g} / \mathrm{g}$ y $0,18 \mu \mathrm{g} / \mathrm{g}$, respectivamente, como se ve en la Tabla 6.3. El compuesto que presentó mayor afinidad por el sustrato fue el Sil, seguido de la Cbz y finalmente el Mp. Se presentó una tendencia positiva entre el coeficiente de reparto agua-carbono orgánico (Log Koc) y la concentración de los PPCPs detectados en el sustrato, con un coeficiente de correlación de $0.971 \mathrm{y}$ un nivel de significancia de 0,1 (ver Figura 6.7). Esta correlación no se correspondió con la eficiencia de remoción de los PPCPs, ya que el Mp que es el compuesto con menor nivel de adsorción detectado, es el que presenta mayor eficiencia de remoción ( $>97 \%)$, seguido por el Sil $(\approx 90 \%)$ y finalmente la $\mathrm{Cbz}$, la cual presentó una eliminación inferior al $10 \%$. La baja detección de $\mathrm{Mp}$ en el sustrato y su alta eliminación, da evidencia de su biodegradación en los reactores. Actualmente se dispone de muy pocos datos sobre los niveles de adsorción de los PPCPs sobre el lecho soporte, sin embargo se han reportado concentraciones de adsorción de Cbz sobre la grava de 0,09 $\mu \mathrm{g} / \mathrm{g}$ (Matamoros et al., 2005). 
Tabla 6.3. Concentración de los PPCPs detectada en el sustrato

\begin{tabular}{cccc}
\hline Reactor & $\mathrm{Cbz}(\mu \mathrm{g} / \mathrm{g})$ & $\mathrm{Sil}(\mu \mathrm{g} / \mathrm{g})$ & $\mathrm{Mp}(\mu \mathrm{g} / \mathrm{g})$ \\
\hline $\mathrm{H}_{1}$ & 0,22 & 1,68 & 0,17 \\
$\mathrm{H}_{2}$ & 0,22 & 2,54 & 0,18 \\
$\mathrm{H}_{3}$ & 0,23 & 2,81 & 0,18 \\
$\mathrm{H}_{4}$ & 0,24 & 0,76 & 0,17 \\
promedio & 0,23 & 1,95 & 0,18 \\
\hline
\end{tabular}

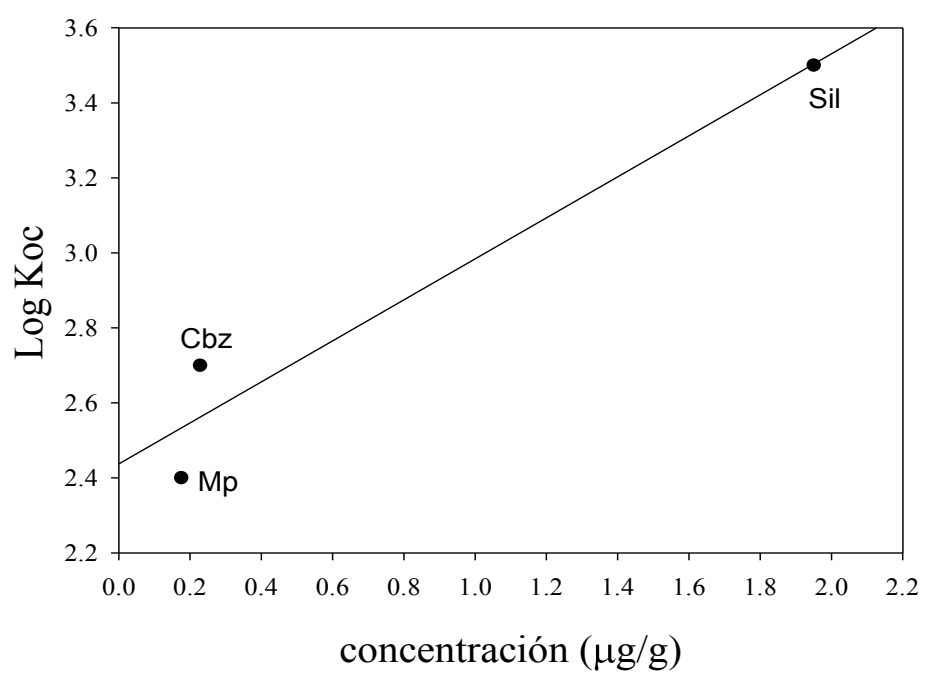

Figura 6.7. Correlación entre el coeficiente de reparto agua-carbono orgánico (Log Koc) de los PPCPs y la concentración detectada en el sustrato.

\subsubsection{Balance de materia de los PPCPs}

\subsubsection{Balance de materia para $\mathrm{la} \mathrm{Cbz}$}

Se realizó un balance de masas general para los humedales plantados, aplicando la Ecuación 6.1, con el fin de determinar de manera global cuáles fueron los mecanismos de remoción de los contaminantes en los mismos, y cuál de ellos fue de mayor importancia.

Teniendo en cuenta la concentración promedio afluente de Cbz $(168 \mu \mathrm{g} / \mathrm{L})$, la concentración efluente $(157 \mu \mathrm{g} / \mathrm{L})$, el nivel de absorción por las macrófitas $(0,51 \mu \mathrm{g} / \mathrm{g}$ 
y $0,29 \mu \mathrm{g} / \mathrm{g})$ y la adsorción sobre el sustrato $(0,23 \mu \mathrm{g} / \mathrm{g})$, durante los 140 días de estudio, se tiene:

$$
\begin{gathered}
\text { masa afluente de Cbz }=168 \frac{\mu g}{L} * \frac{22 L}{d} * \frac{140 \mathrm{~d}}{1000}=518 \mathrm{mg} \\
\text { masa efluente de Cbz }=157 \frac{\mu g}{L} * \frac{22 \mathrm{~L}}{\mathrm{~d}} * \frac{140 \mathrm{~d}}{1000}=483 \mathrm{mg} \\
\text { absorción de Cbz en Cyperus Haspan }=0,51 \frac{\mu \mathrm{g}}{\mathrm{g}} * 3000 \mathrm{~g} * \frac{1 \mathrm{mg}}{1000 \mu \mathrm{g}}=1,5 \mathrm{mg} \\
\text { absorción de Cbz en Heliconea Zingiberales }=0,29 \frac{\mu g}{g} * 1400 \mathrm{~g} * \frac{1 \mathrm{mg}}{1000 \mu \mathrm{g}}=0,4 \mathrm{mg} \\
\text { adsorción de Cbz en el sustrato }=0,23 \frac{\mu g}{g} * 144000 \mathrm{~g} * \frac{1 \mathrm{mg}}{1000 \mathrm{\mu g}}=33 \mathrm{mg}
\end{gathered}
$$

De acuerdo con la Ecuación (6.1) se determinó el balance de masas para la Cbz, como se muestra en la Ecuación (6.9):

$518 \mathrm{mg} \mathrm{Cbz}$ afluente $=483 \mathrm{mg}$ efluente $+1,9 \mathrm{mg}$ en plantas $+33 \mathrm{mg}$ en sustrato

$$
518 \mathrm{mg} \mathrm{Cbz}=518 \mathrm{mg} \mathrm{Cbz} \rightarrow \text { no se determinó remoción de Cbz }
$$

De los cálculos obtenidos en la Ecuación (6.9), se determinó que solamente alrededor del 7\% de $\mathrm{Cbz}$ fue retenida en los humedales plantados, de los cuales aproximadamente un $6,6 \%$ fue detectado en la grava, y un $0,3 \%$ fue retenido por el Cyperus Haspan y un $0,1 \%$ por la Heliconea Zingiberales. Del total de la Cbz adherida en la grava, el 22\% fue retenido durante los primeros 20 días de estudio, lo cual generó una aparente remoción, como se ve en la gráfica A de la Figura 6.5.

\subsubsection{Balance de materia para el Sil}

El mismo procedimiento se realizó para determinar la eficiencia global de remoción del Sil, con el balance de materia correspondiente. Para Sil se determinaron los siguientes valores promedios: alimentación de $170 \mu \mathrm{g} / \mathrm{L}$, concentración efluente de $13 \mu \mathrm{g} / \mathrm{L}$, absorción por el material vegetal de $0,14 \mu \mathrm{g} / \mathrm{g}$ y $0,05 \mu \mathrm{g} / \mathrm{g}$ para Cyperus Haspan y Heliconea Zingiberales, respectivamente (ver Tabla 6.2), y adsorción en el sustrato de 1,95 $\mu \mathrm{g} / \mathrm{g}$ (ver Tabla 6.3). 
Capítulo 6. Humedales construidos para remoción de fármacos y productos de cuidado personal

$$
\begin{aligned}
& \text { masa afluente de Sil }=170 \frac{\mu g}{L} * \frac{22 L}{d} * \frac{140 \mathrm{~d}}{1000}=524 \mathrm{mg} \\
& \text { masa efluente de Sil }=13 \frac{\mu g}{L} * \frac{22 L}{d} * \frac{140 \mathrm{~d}}{1000}=40 \mathrm{mg} \\
& \text { absorción de Sil en Cyperus Haspan }=0,14 \frac{\mu g}{g} * 3000 \mathrm{~g} * \frac{1 \mathrm{mg}}{1000 \mu \mathrm{g}}=0,4 \mathrm{mg} \\
& \text { absorción de Sil en Heliconea Zingiberales }=0,05 \frac{\mu g}{g} * 1400 \mathrm{~g} * \frac{1 \mathrm{mg}}{1000 \mu \mathrm{g}}=0,07 \mathrm{mg} \\
& \text { adsorción de Sil en el sustrato }=1,95 \frac{\mu g}{g} * 144000 \mathrm{~g} * \frac{1 \mathrm{mg}}{1000 \mu \mathrm{g}}=281 \mathrm{mg}
\end{aligned}
$$

En la Ecuación (6.16) se presenta el balance de materia para Sil:

$524 \mathrm{mg}$ Sil afluente $=40 \mathrm{mg}$ efluente $+0,47 \mathrm{mg}$ en plantas $+281 \mathrm{mg}$ en sustrato

$$
524 \mathrm{mg} \mathrm{Sil}=202 \mathrm{mg} \mathrm{Sil} \rightarrow 322 \mathrm{mg} \text { de Sil se eliminan por otros mecanismos }
$$

De acuerdo a los cálculos realizados se determinó que un 93\% de Sil se retuvo en los sistemas plantados. Un 0,08\% fue detectado en el Cyperus Haspan y un 0,01\% en la Heliconea Zingiberales. El nivel encontrado en el sustrato fue del 52\%. La eliminación por otros mecanismos fue del 41\%. La adherencia del Sil sobre el lecho parece contribuir en su biodegradación, ya que los niveles detectados en el efluente fueron inferiores al $7 \%$.

\subsubsection{Balance de materia para el Mp}

Para el caso del Mp los promedios fueron: concentración en alimentación de $177 \mu \mathrm{g} / \mathrm{L}$, concentración en efluente de $2,5 \mu \mathrm{g} / \mathrm{L}$, absorción sobre el material vegetal de $0,03 \mu \mathrm{g} / \mathrm{g}$ para ambas macrófitas (ver Tabla 6.2), y adsorción sobre el sustrato de $0,18 \mu \mathrm{g} / \mathrm{g}$ (ver Tabla 6.3).

$$
\begin{gathered}
\text { masa afluente de } M p=177 \frac{\mu g}{L} * \frac{22 L}{d} * \frac{140 \mathrm{~d}}{1000}=545 \mathrm{mg} \\
\text { masa efluente de } M p=2,5 \frac{\mu g}{L} * \frac{22 \mathrm{~L}}{\mathrm{~d}} * \frac{140 \mathrm{~d}}{1000}=8 \mathrm{mg} \\
\text { absorción de Mp en Cyperus Haspan }=0,03 \frac{\mu \mathrm{g}}{\mathrm{g}} * 3000 \mathrm{~g} * \frac{1 \mathrm{mg}}{1000 \mathrm{\mu g}}=0,09 \mathrm{mg} \\
\text { absorción de Mp en Heliconea Zingiberales }=0,03 \frac{\mu \mathrm{g}}{\mathrm{g}} * 1400 \mathrm{~g} * \frac{1 \mathrm{mg}}{1000 \mu \mathrm{g}}=0,04 \mathrm{mg}
\end{gathered}
$$


adsorción de Mp en el sustrato $=0,18 \frac{\mu g}{g} * 144000 \mathrm{~g} * \frac{1 \mathrm{mg}}{1000 \mu \mathrm{g}}=26 \mathrm{mg}$

Se determinó el balance de materia para el $\mathrm{Mp}$, como se muestra en la Ecuación (6.22):

$545 \mathrm{mg}$ Mp afluente $=8 \mathrm{mg}$ efluente $+0,13 \mathrm{mg}$ en plantas $+26 \mathrm{mg}$ en sustrato

$545 \mathrm{mg}$ Sil $=34 \mathrm{mg}$ Sil $\rightarrow 511 \mathrm{mg}$ de Mp se eliminan por otros mecanismos

Realizando el análisis anterior, se encontró que el 99\% de Mp se retuvo en ambos sistemas estudiados. Menos de un 0,01\% fue detectado en las plantas y el 4,6 \% se detectó en el sustrato. Por lo tanto la remoción por biodegradación fue del 94\%. Es posible entonces indicar que el mecanismo preponderante de remoción fue el biofilm, debido a que su detección en el efluente tanto de los sistemas plantados, como en los no plantados fue muy baja, lo que sugiere la metabolización del compuesto por los microorganismos, como se discutió anteriormente en el capítulo 5.

Es ampliamente aceptado que los compuestos orgánicos con log Kow entre 0,5-3 pueden pasar a través de las membranas celulares y entrar a las corrientes de transpiración de las plantas (Dordio et al., 2011; Reyes-Contreras et al., 2012). Por lo tanto, es probable que las macrófitas hayan desempeñado un papel activo en la eliminación de Sil a través de la absorción directa, ya que su coeficiente de partición octanol-agua es de 2,75. Sin embargo, la Cbz que tiene un log Kow similar $(2,45)$, no presentó la misma eficiencia de eliminación. Por lo que la capacidad de degradación del Sil se puede deber a la velocidad de adaptación y al metabolismo de las macrófitas evaluadas (Petrie et al., 2017). Además, los microorganismos que se desarrollan en la rizosfera también pudieron jugar un papel importante en la degradación de este compuesto, ya que el uso de un policultivo promueve el crecimiento de una mayor variedad de microorganismos, los cuales pueden adaptarse para descomponer las moléculas orgánicas a intermedios simples y en muchos casos a degradación completa (Li et al., 2014). El Mp tiene un $\log \operatorname{Kow}(1,96)$ dentro del rango establecido anteriormente, para entrar en las membranas celulares de las plantas, sin embargo los estudios evaluados solamente con microorganismos demuestran que su principal mecanismo de remoción es la biodegradación bacteriana. 
La eliminación por fotodegradación no se tuvo en cuenta, ya que no es un factor relevante en humedales de flujo subsuperficial. Además, en estudios en batch en laboratorio, en los cuales se expusieron los PPCPs a la radiación solar durante tres días, no se presentaron diferencias significativas en las concentraciones iniciales y las detectadas luego de la exposición. Tampoco se tuvo en cuanta la eliminación por volatilización, debido a que los compuestos evaluados presentan valores muy bajos de la constante de Henry, con valores de $7,2 \times 10^{-21}$ y $2,23 \times 10^{-9}$, para Sil y Mp, respectivamente.

\subsubsection{Efecto de los PPCPs sobre la calidad del agua tratada}

La concentración afluente de la carga orgánica fue de $197 \pm 25 \mathrm{mg} / \mathrm{L}$, alcanzando eficiencias de remoción superiores al 95\% luego de cada tratamiento (ver Figura 6.5 D). Los valores de los parámetros físicoquímicos determinados en campo para el afluente fueron: 5,0 $\pm 0,4 \mathrm{mg} / \mathrm{L}$ para el oxígeno disuelto; 6,9 $\pm 0,1$ para el $\mathrm{pH}$; $21 \pm 1{ }^{\circ} \mathrm{C}$ para la temperatura; $105 \pm 8 \mathrm{mg} / \mathrm{L}$ para los sólidos totales disueltos; $0,22 \pm$ $0,03 \mathrm{~ms} / \mathrm{cm}$ para la conductividad y $195 \pm 31 \mathrm{mV}$ para el potencial de óxido reducción (ver Figura 6.8).

Los valores promedios de oxígeno disuelto (O.D) en los efluentes de cada sistema fueron de $0,2 \pm 0,1 \mathrm{mg} / \mathrm{L}$, presentando una drástica reducción respecto de los valores afluentes, como se muestra en la Figura 6.8. La baja concentración de O.D se debe a que en los humedales subsuperficiales predominan las condiciones anóxicas, debido a la matriz de agua saturada que impide la difusión de oxígeno de la superficie (Saeed and Sun, 2012).

Los valores del $\mathrm{pH}$ en el efluente de los sistemas plantados y los no plantados fueron de 5,9 $\pm 0,3$ y 7,0 $\pm 0,1$, respectivamente (ver Figura 6.8). No se observó una diferencia significativa entre los valores del $\mathrm{pH}$ del agua residual de alimentación y los efluentes de los sistemas no plantados ( $\mathrm{p}$-valor 0,371), evaluado mediante un test de $\mathrm{t}$ para comparar dos grupos. Sin embargo se determinó un p-valor de 0,001, comparando los valores de $\mathrm{pH}$ efluentes de los sistemas plantados y los no plantados, indicando una diferencia estadísticamente significativa. Se determinó que el pH en los sistemas plantados disminuye respecto del afluente y de los sistemas no plantados, debido posiblemente a la intervención de procesos biológicos extras para la 
descomposición del material vegetal, lo cual eleva la cantidad de $\mathrm{CO}_{2}$ libre en la columna de agua (Travaini and Sipaúba, 2012). Es importante resaltar que los niveles promedio de $\mathrm{pH}$ de los sistemas plantados, como no plantados, se encontraron dentro de los limites aceptados (4-8) para un buen desarrollo de los microorganismos (HijosaValsero et al., 2010).

Teniendo en cuenta que se trabajó en un clima templado, no se observaron diferencias significativas entre las temperaturas afluentes y efluentes, con valores de $19 \pm 1{ }^{\circ} \mathrm{C}$ (Ver Figura 6.8). Existen trabajos en los cuales se han reportado aumento en las eficiencias de remoción de $\mathrm{Cbz}$ en un $40 \%$, en temperatura similares a las trabajadas en el presente estudio (Dordio et al., 2010). Sin embargo, al igual que los resultados encontrados por Matamoros et al. (2017), no se encontró mejoras en las eficiencias de remoción de este compuesto bajo las condiciones de estudio. Por el contrario, se han obtenido altas remociones de $\mathrm{Mp}$, similares a las obtenidas en la presente investigación (Anjos et al., 2018). La temperatura puede ser un factor importante en la remoción de este compuesto, ya que eficiencias inferiores han sido reportadas a bajas temperaturas (Verlicchi et al., 2015).

Los valores medios efluentes para los sólidos disueltos totales en los humedales plantados y no plantados fueron de $65 \pm 19 \mathrm{mg} / \mathrm{L}$ y $132 \pm 14 \mathrm{mg} / \mathrm{L}$, respectivamente, (ver Figura 6.8). Determinándose una diferencia estadísticamente significativa para ambos tratamientos, con un p-valor inferior a 0,001. Esta diferencia se debe a la capacidad que tienen las macrófitas para incorporar estos sólidos. Por lo tanto la mayor eficiencia de remoción del Sil en los humedales plantados, podría estar relacionada a la mayor capacidad de adsorción sobre los sólidos y su posterior absorción y asimilación por las plantas. Conclusiones similares fueron reportadas en otros estudios (Verlicchi and Zambello, 2014), sin embargo, son necesarias más investigaciones experimentales específicas sobre estas interacciones. Los sólidos disueltos totales tienen una relación estrecha con la conductividad eléctrica, y cuanto mayor sea la cantidad de sales disueltas en el agua, mayor será el valor de la conductividad, por lo tanto, se observó un comportamiento similar para este parámetro, presentándose una diferencia significativa entre los sistemas plantados y no plantados, con valores medios de $0,13 \pm 0,04 \mathrm{~ms} / \mathrm{cm}$ y $0,26 \pm 0,03 \mathrm{~ms} / \mathrm{cm}$, respectivamente. 
Se detectaron valores inferiores del potencial redox, respecto de los valores afluentes, con resultados promedios de $61 \pm 47 \mathrm{mV}$ y $-36 \pm 57 \mathrm{mV}$ para los humedales plantados y los no plantados, respectivamente (Ver figura 6.8). El p-valor fue inferior a 0,001 comparando ambos tratamientos, determinándose una diferencia estadísticamente significativa. Estas variaciones en el potencial redox se deben a la transferencia de oxígeno en la solución por las plantas durante el día, presentando condiciones oxidantes en los humedales plantados; mientras que en los no plantados se presentaron condiciones reductivas. Se ha reportado que el potencial redox es uno de los parámetros más interesantes para evaluar la capacidad de remoción de un compuesto específico en un humedal construido (Verlicchi and Zambello, 2014). El Sil presentó mejores eficiencias de remoción en condiciones oxidantes, sin embargo no se han encontrado estudios comparativos. Por el contrario, la $\mathrm{Cbz}$ se comportó como un contaminante recalcitrante en todas las condiciones redox; resultados similares se han reportado anteriormente (Kahl et al., 2017). Se alcanzaron altas eficiencias de remoción en todas las condiciones redox para el Mp, lo cual era de esperarse, ya que como se ha analizado anteriormente, este compuesto es fácilmente biodegradable y no presenta características recalcitrantes. 

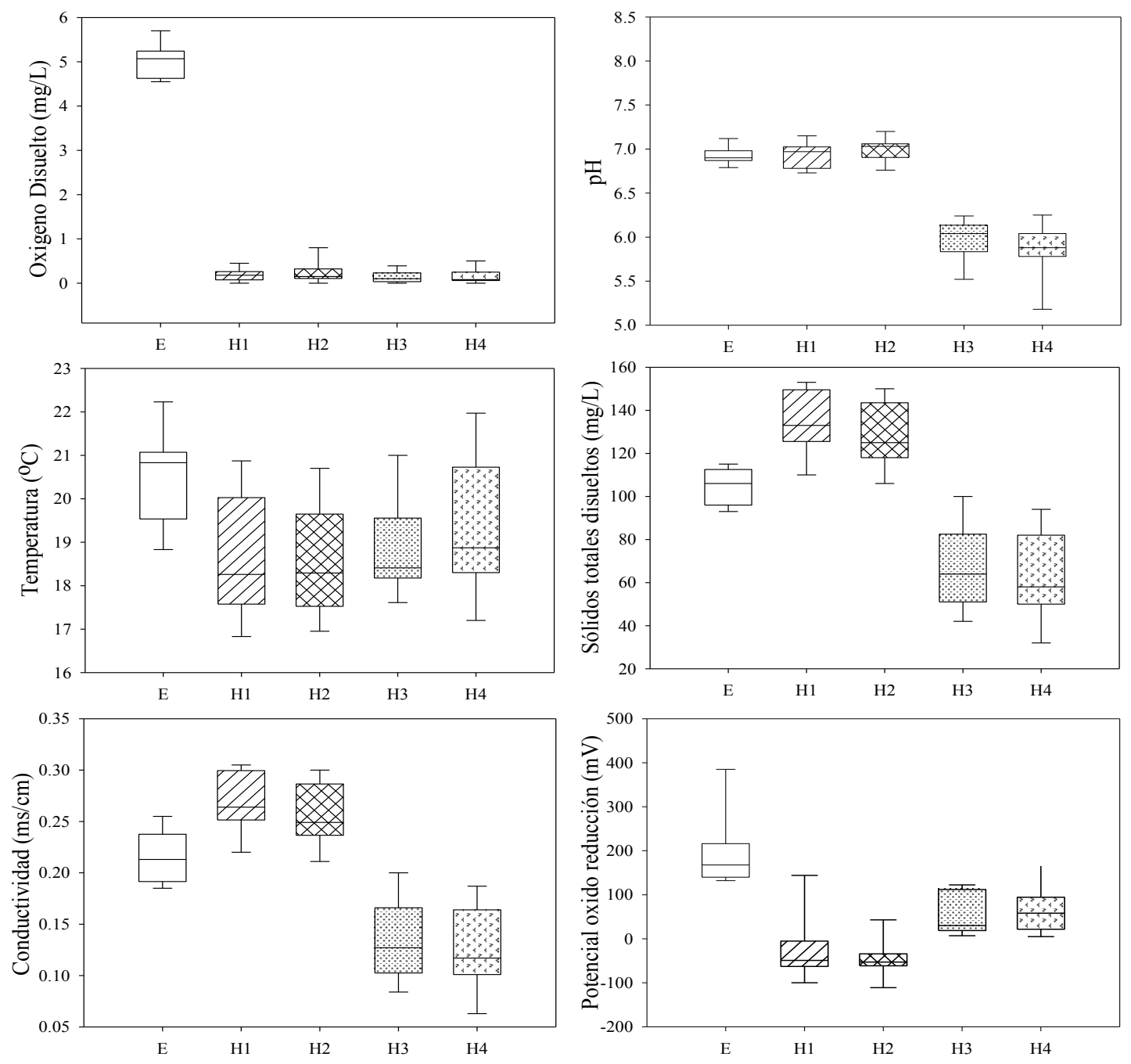

Figura 6.8. Parámetros fisicoquímicos medidos a la entrada (E) y a la salida de cada humedal, para los sistemas no plantados $\left(\mathrm{H}_{1}\right.$ y $\left.\mathrm{H}_{2}\right)$ y los plantados $\left(\mathrm{H}_{3}\right.$ y $\left.\mathrm{H}_{4}\right)$, y su respectiva replica. La concentración afluente de $\mathrm{Cbz}$, Sil y Mp fue de 0,2 mg/L, en su mezcla; y una carga orgánica de aproximadamente $250 \mathrm{mg} / \mathrm{L}$. 


\subsection{Conclusiones parciales}

Se obtuvieron altas eficiencias de eliminación para el metilparabeno en todos los sistemas evaluados. Para el sildenafil se alcanzaron remociones de hasta el $97 \%$ en los humedales plantados; mientras que en los no plantados, la eficiencia se redujo en aproximadamente un 30\%. La carbamazepina se comportó como un contaminante recalcitrante, con remociones inferiores al 10\%. Así, se determinó que los sistemas plantados son capaces de remover eficientemente compuestos de estructura molecular simple, como el Mp, como compuestos de estructuras más complejas, como el Sil, el cual, si bien en la literatura ha sido reportado como un contaminante recalcitrante aplicando otras tecnologías de remedición, fue eficientemente removido en presencia de macrófitas autóctonas de climas templados de Colombia. Estos resultados sugieren que el compuesto es susceptible al tipo de microorganismos presentes en estos humedales. En consecuencia, el uso de estas plantas puede constituir un medio adecuado para eliminar este contaminante emergente.

El compuesto mayormente detectado en las macrófitas fue la $\mathrm{Cbz}$, seguido del Sil y finalmente el Mp. Por su parte, el Sil presentó mayor afinidad por el sustrato, seguido de la $\mathrm{Cbz}$ y finalmente el $\mathrm{Mp}$. Estos niveles detectados por absorción y adsorción, no reflejaron en su mismo orden las mejores eficiencias de remoción, ya que, el Mp que fue el compuesto con menores concentraciones detectado en ambos procesos, fue más eficientemente removido, dando evidencias de su biodegradación o biotransformación en los reactores.

Después de analizar el balance de masas, se concluye que la Cbz no se biodegrada, ya que la masa total afluente coincidió con la sumatoria de la masa total efluente, la masa absorbida por las plantas y la adherida al sustrato. Para el Sil uno de los principales mecanismos que contribuyó en su degradación se ve reflejado en la adsorción sobre el lecho de soporte, que al parecer permite retener este compuesto el tiempo suficiente para ser degradado por las plantas o por los microorganismos específicos desarrollados a partir de ellas. El principal mecanismo de remoción para el Mp parece ser la degradación bacteriana, debido a que no fue detectado en el efluente, ni en el lecho de soporte, ni en las macrófitas, además no se determinaron diferencias entre los sistemas plantados y los no plantados. Igualmente, en los experimentos con 
Capítulo 6. Humedales construidos para remoción de fármacos y productos de cuidado personal

biodiscos (capítulo 5) se determinaron eficiencias de remoción altas para el Mp por efecto bacteriano, mientras que las remociones para el Sil fueron inferiores al $20 \%$. 


\section{CAPÍTULO 7}

\section{CARBÓN ACTIVADO GRANULAR PARA REMOCIÓN DE CONTAMINANTES EMERGENTES: EXPERIMENTOS EN BATCH}

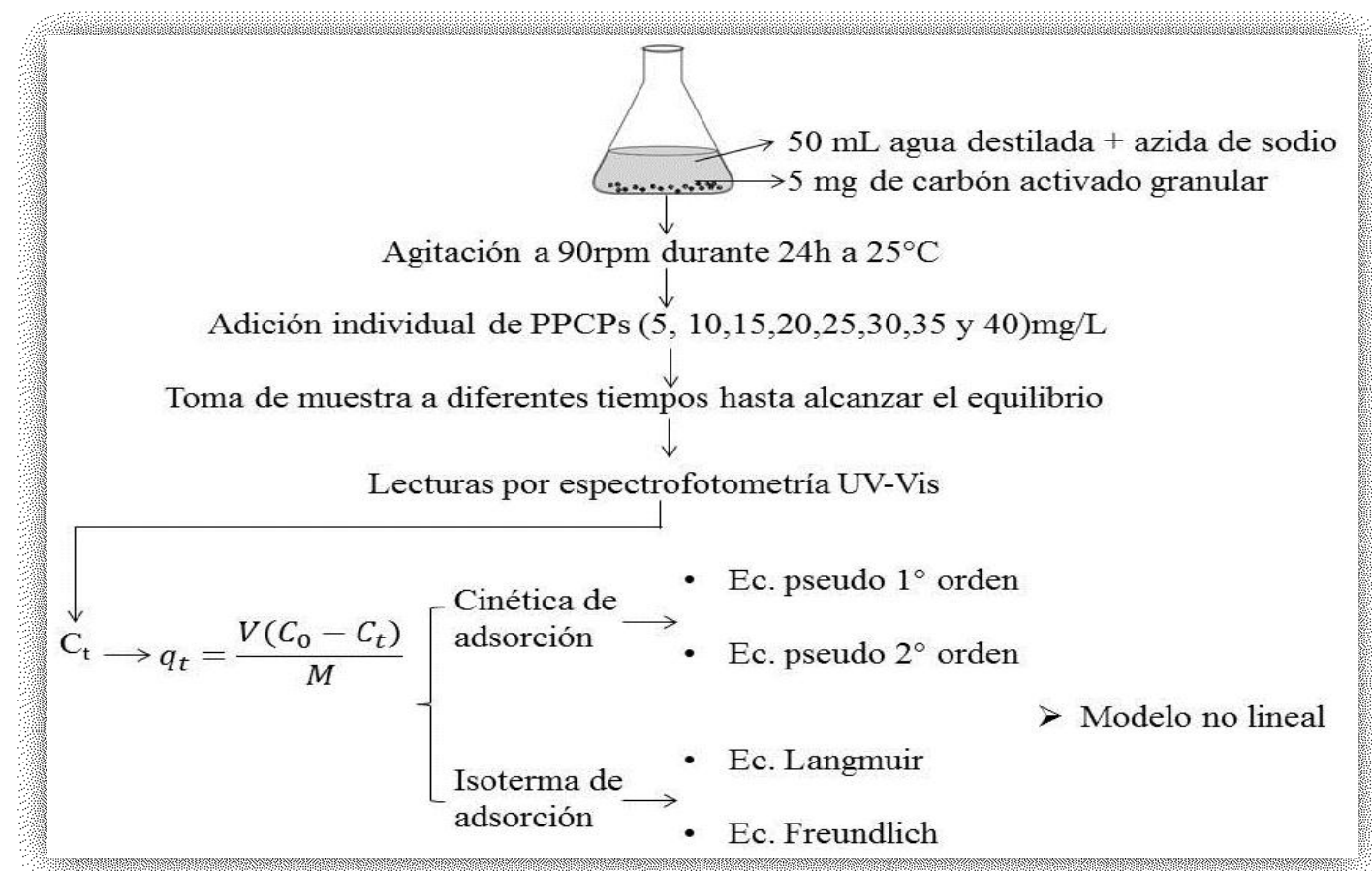




\section{Resumen}

En el presente trabajo se estudió la adsorción de dos productos farmacéuticos (Cbz y Sil) y un producto para el cuidado personal (Mp) sobre carbón activado granular comercial en solución acuosa. Se caracterizó el carbón y se determinó su capacidad en el equilibrio y cinética adsorción. Se ajustaron los datos a las isotermas de adsorción de los modelos de Langmuir y de Freundlich. La velocidad de adsorción se evaluó con modelos de seudo primer y seudo segundo orden; este mismo análisis se realizó sobre la base del comportamiento de la velocidad inicial. Además, se evaluó la potencialidad de un ajuste no lineal para estudiar la cinética y el equilibrio de adsorción, mediante un enfoque que no requiere ni conocimiento de las condiciones de equilibrio ni suposiciones a priori con respecto al orden de la reacción. Los resultados indicaron que el modelo no lineal era capaz de describir el comportamiento cinético de adsorción, las concentraciones adsorbidas en el equilibrio, la velocidad de adsorción del sistema, la capacidad máxima de adsorción y la constante de velocidad global. El carbón granular mostró una capacidad de adsorción para carbamazepina y metilparabeno de aproximadamente $323 \mathrm{mg} / \mathrm{g}$ y para el sildenafil de aproximadamente $142 \mathrm{mg} / \mathrm{g}$, aunque con una cinética de adsorción lenta caracterizada por tiempos de adsorción superiores a168 h para los tres compuestos estudiados. 


\subsection{Introducción}

Debido a los hábitos de consumo actuales en nuestra sociedad, se vienen incorporando a los circuitos ambientales una serie de contaminantes, cuya presencia pasó inadvertida hasta unos pocos años atrás. Estos contaminantes, denominados emergentes son compuestos de distinto origen y naturaleza química, entre los cuales cabe destacar plaguicidas, hormonas, drogas de abuso, fármacos y productos de cuidado y de higiene personal, entre otros (Elorriaga et al., 2013a; Gracia-Lor et al., 2012; Kasprzyk-Hordern et al., 2008; Moldovan, 2006). Estos contaminantes, luego de su administración o uso se incorporan al ambiente vía aguas servidas. Algunas de estas sustancias, por su carácter refractario no son removidas en las plantas de tratamiento convencional, llegando a las aguas superficiales y a los sistemas de potabilización (Boyd et al., 2003; Kolpin et al., 2004; Stackelberg et al., 2004; Ternes, 1998). Consecuentemente en la actualidad se vienen realizando investigaciones relacionadas con estrategias de tratamiento para su remoción. Estos procedimientos se basan en el conocimiento de propiedades fisicoquímicas de este tipo de contaminantes y su comportamiento ambiental (Bolong et al., 2009).

Entre estos procedimientos, las tecnologías de adsorción sobre carbón activado presentan gran potencial para su empleo en los sistemas de tratamiento para remoción de trazas de contaminantes emergentes debido a su gran superficie específica, estructura de microporos y alta capacidad de adsorción (Banerjee et al., 2014; Gil et al., 2012; Grassi et al., 2012; Nielsen et al., 2014; Rashed, 2013; Sing, 2008; Worch, 2012). La predicción de la velocidad a la cual se lleva a cabo la adsorción para un sistema dado, es probablemente el factor más importante en los sistemas de diseño basados en esta tecnología (Ho, 2006). A finales del siglo XIX Lagergren propuso el modelo de seudo primer orden para determinar la velocidad de adsorción sobre carbón activado (Plazinski, 2010). Este es quizá el modelo más antiguo y más frecuentemente utilizado para el estudio de la cinética de adsorción, al cual debe sumarse el modelo de cinética de seudo segundo orden.

Es importante, dentro del conocimiento de la capacidad adsorbente, conocer los valores de concentración del adsorbato en el equilibrio $\left(\mathrm{q}_{\mathrm{e}}\right)$, la capacidad máxima adsorción $\left(\mathrm{q}_{\mathrm{m}}\right)$, las constantes de velocidad aparente $\left(\mathrm{k}_{1} \mathrm{o} \mathrm{k}_{2}\right)$, la constante de velocidad global $(\mathrm{K})$ y la fracción de cobertura $(\theta)$, para tener un panorama completo 
de la cinética y el equilibrio de adsorción. En este trabajo se estudian estos procesos mediante el análisis de regresión no lineal de la información experimental que obvia las hipótesis de cinéticas de seudo primer orden y/o seudo segundo orden, permitiendo resolver algunas limitaciones de los modelos clásicos en los que se plantean hipótesis para considerar el tipo de cinética que describe al sistema. Así los parámetros más importantes de las ecuaciones que describen la adsorción surgen sin ninguna hipótesis previa, como se discutirá más adelante.

En el presente trabajo, se estudió la cinética y equilibrio de adsorción sobre carbón activado granular comercial de tres contaminantes emergentes: metilparabeno, carbamazepina y sildenafil, seleccionados por su representatividad en vertidos al ambiente (Elorriaga et al., 2013a; Gracia-Lor et al., 2012). El objetivo de esta investigación fue proveer nueva información para entender los factores y mecanismos involucrados en los procesos de adsorción y desarrollar una técnica para la remoción de fármacos y productos de cuidado personal (PPCPs) de las aguas residuales domésticas.

\subsection{Metodología}

\subsubsection{Adsorbente y adsorbatos}

Como material adsorbente para determinar la eficiencia de adsorción de la carbamazepina (Cbz), el sildenafil (Sil) y el metilparabeno (Mp), se utilizó carbón activado granular Tamiz-29 grado comercial, con un área superficial de $956 \mathrm{~m}^{2} / \mathrm{g}$, tamaño de poro de $20 \AA$, diámetro medio de $1 \mathrm{~mm}$ y volumen de poros de $0,458 \mathrm{~cm}^{3} / \mathrm{g}$, evaluados a partir de medidas Brunauer-Emmett-Teller (BET). Considerando que los compuestos estudiados presentan equilibrios acido-base se realizó un seguimiento del $\mathrm{pH}$ del sistema carbón activado-agua, con masas de $5 \mathrm{mg}$ y $500 \mathrm{mg}$, mediante electrodo específico (WA-2017SD).

\subsubsection{Ensayos de adsorción}

La determinación de la relación óptima adsorbente/solución acuosa se realizó en ensayos en batch, de manera independiente para cada compuesto, manteniendo constante la concentración del adsorbato en $5 \mathrm{mg} / \mathrm{L}$ en contacto un volumen fijo de solución de $50 \mathrm{~mL}$, y variando la masa de carbón activado: 5, 25, 50, 100 y $200 \mathrm{mg}$. 
Se definió una cantidad óptima de trabajo de $5 \mathrm{mg}$. Basado en estos resultados, para estudiar la cinética y el equilibrio de adsorción, se prepararon ocho muestras con $5 \mathrm{mg}$ de adsorbente añadido a $50 \mathrm{ml}$ de agua destilada con azida de sodio ( $0,01 \%$ como agente antimicrobiano) (Rossner et al., 2009), en agitación constante a 90 rpm durante $24 \mathrm{~h}$ a $25^{\circ} \mathrm{C}$ (Agitador Arcano modelo SHZ-88). Posteriormente, se agregaron diferentes volúmenes de una solución stock de $1000 \mathrm{mg} / \mathrm{L}$ preparada en metanol con el fin de obtener concentraciones de: 5, 10, 15, 20, 25, 30, 35 y $40 \mathrm{mg} / \mathrm{L}$ de cada compuesto, manteniendo constante la temperatura y la agitación. Se tomaron muestras de 2,5 $\mathrm{ml}$ en diferentes tiempos durante $312 \mathrm{~h}$ para Cbz y Sil, y durante $168 \mathrm{~h}$ para Mp. Los procesos de adsorción se realizaron sin adición de solución buffer para controlar el $\mathrm{pH}$ con el fin de evitar la presencia de un nuevo electrolito en el sistema. Se incluyeron blancos en los ensayos de adsorción para verificar el cambio de $\mathrm{pH}$, la adsorción de los PPCPs sobre las paredes del matraz y la interferencia del metanol. La concentración de cada soluto remanente en la fase acuosa se monitoreó usando un espectrofotómetro UV/Vis.

Las cantidades adsorbidas de los PPCPs sobre carbón activado se calcularon como

$$
q_{t}=\frac{\left(C_{0}-C_{t}\right) V}{W}
$$

Donde $\mathrm{q}_{\mathrm{t}}$ es la cantidad (mg/g) de PPCPs adsorbida en el tiempo $\mathrm{t}, \mathrm{C}_{0}$ es la concentración inicial en $(\mathrm{mg} / \mathrm{L}), \mathrm{C}_{\mathrm{t}}$ es la concentración en el tiempo $\mathrm{t}(\mathrm{mg} / \mathrm{L}), \mathrm{V}$ es el volumen de la solución (L) y W es el peso de carbón utilizado (g).

Se estudiaron los modelos de Langmuir (Ecuación 7.2) (Langmuir, 1918) y de Freundlich (Ecuación 7.3) (Freundlich, 1906) para el ajuste de los datos de las isotermas de adsorción, mediante las siguientes expresiones

$$
\begin{aligned}
& q_{e}=\frac{q_{m} K_{L} C_{e}}{1+K_{L} C_{e}} \\
& q_{e}=K_{F} C_{e}^{1 / n}
\end{aligned}
$$

Donde $\mathrm{C}_{\mathrm{e}}$ es la concentración del adsorbato (mg/L) en el equilibrio, $\mathrm{q}_{\mathrm{e}}$ es la cantidad adsorbida por unidad de masa de adsorbente en equilibrio ( $\mathrm{mg} / \mathrm{g}), \mathrm{q}_{\mathrm{m}}$ es la adsorción máxima en la monocapa de carbón activo, y $\mathrm{K}_{\mathrm{L}}$ es la constante de adsorción en el equilibrio ( $\mathrm{L} / \mathrm{mg}$ ) para el modelo de Langmuir, la cual está relacionada con la 
energía de adsorción. $\mathrm{K}_{\mathrm{F}}$ es la constante de equilibrio para el modelo de Freundlich y $\mathrm{n}$ es una constante relacionada con la afinidad entre el adsorbente y el adsorbato, si $1 / \mathrm{n}$ es $\ll<1$ la adsorción será favorable.

La cinética de adsorción se estudió utilizando los modelos de seudo primer orden (Ecuación 7.4) (Lagergren, 1898) y de seudo segundo orden ( Ecuación 7.5) (McCoy and Liapis, 1991). Las ecuaciones lineales de velocidad de adsorción de estos comportamientos se expresan como

$$
\begin{aligned}
& \ln \left(\frac{q_{e}-q_{t}}{q_{e}}\right)=-k_{1} t \\
& \frac{q_{e} * t}{q_{t}}=\frac{1}{k_{2} q_{e}}+t
\end{aligned}
$$

donde $\mathrm{q}_{\mathrm{t}} \mathrm{y} \mathrm{q}_{\mathrm{e}}$ son los gramos de adsorbato adsorbido por gramo de adsorbente en el tiempo $\mathrm{t} y$ en equilibrio, respectivamente; $\mathrm{k}_{1}$ es la constante aparente de velocidad para la ecuación de seudo primer orden y $\mathrm{k}_{2}$ es la constante de velocidad de seudo-segundo orden.

\subsection{Resultados y discusión}

Dos factores son importantes en el proceso de adsorción de los compuestos seleccionados. De hecho, la adsorción de estos PPCPs sobre el carbón activado granular es un proceso lento. Por lo tanto, desde un punto de vista práctico, se requiere una cantidad mínima de carbón activado para seguir la evaluación cinética dentro de un intervalo de tiempo razonable, y para asegurar la reproducibilidad de los resultados experimentales. En este caso $5 \mathrm{mg}$ fue la cantidad mínima razonable para llevar a cabo los ensayos.

\subsubsection{Evaluación de interferencias sobre el proceso de adsorción}

El pH antes y después de los procesos de adsorción osciló entre: $6,4-6,6$ para la Cbz; 6,2 - 6,4 para el Sil; 6,4 - 6,5 para el Mp y 6,4-6,6 para la solución control sin PPCPs. De acuerdo a los resultados obtenidos no se observaron variaciones estadísticamente significativas entre las pruebas y el control. Tampoco se registró adsorción sobre las paredes de vidrio de los matraces según las pruebas realizadas para las soluciones con PPCPs sin carbón activado. Los tratamientos con y sin metanol se evaluaron mediante una prueba $t$ de student para la comparación de dos muestras, para 
un nivel de significancia de 0,050. Los p-valores obtenidos fueron superiores a 0,084 desde las muestras iniciales, por lo tanto la diferencia en los valores medios de los dos grupos no fue lo suficientemente grande como para rechazar la posibilidad de que la discrepancia se deba a la variabilidad del muestreo aleatorio. Se determinó que no existían diferencias estadísticamente significativas entre los tratamientos con y sin metanol.

\subsubsection{Análisis de las isotermas de adsorción}

Las isotermas de adsorción se evaluaron de acuerdo a los modelos de Langmuir y Freundlich, planteados en las Ecuaciones (7.2) y (7.3), respectivamente. Se muestra solamente la Isoterma de Langmuir ya que se ajustó mejor a los datos obtenidos para los tres compuestos, como se observa en la Figura 7.1 y la Tabla 7.1. Para el análisis de las ecuaciones se usó el valor final de la cantidad adsorbida de PPCPs sobre el carbón ( $\mathrm{q}_{\mathrm{e}}$ ) obtenido de las curvas de la cinética de adsorción (ver Figura 7.2).

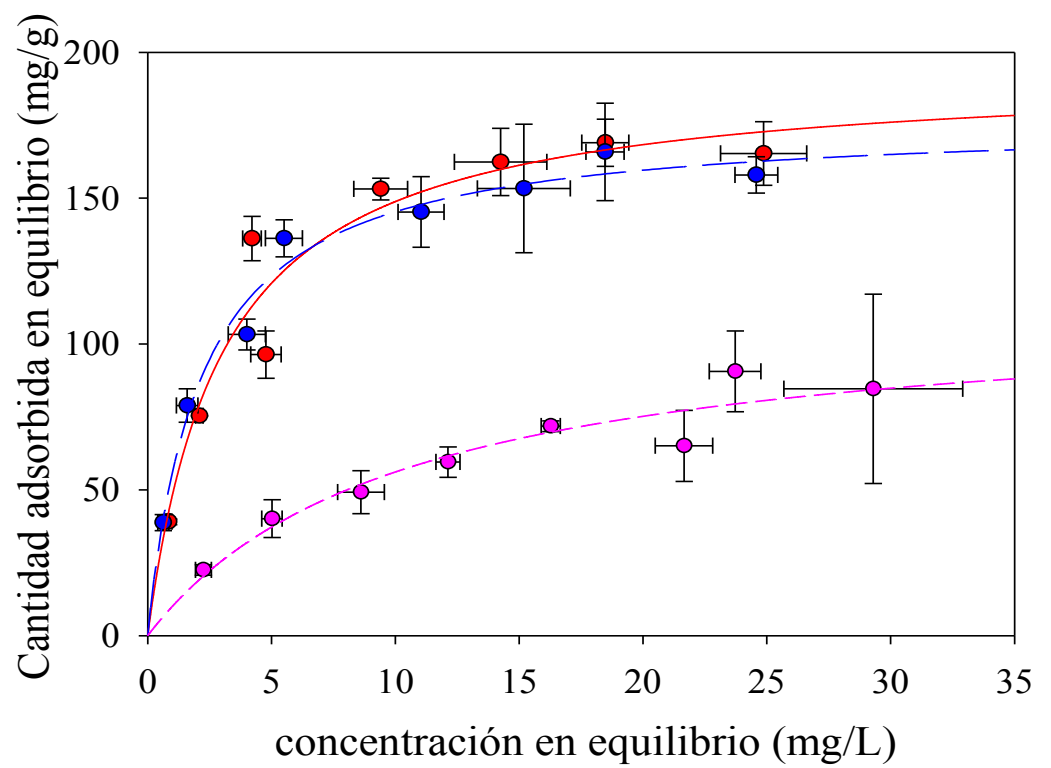

Figura 7.1 Isotermas de adsorción para el metilparabeno a $168 \mathrm{~h}(\bullet)$, carbamazepina a $312 \mathrm{~h}(\bullet)$ y sildenafil a $312 \mathrm{~h}(\bullet)$, sobre carbón activado granular. Se indican los errores en cada medida. Las líneas corresponden al ajuste no lineal del modelo de Langmuir. 
Tabla 7.1 Parámetros obtenidos para los datos experimentales del ajuste de la ecuación de Langmuir y Freundlich

\begin{tabular}{|c|c|c|c|c|c|c|}
\hline & \multicolumn{3}{|c|}{ Langmuir } & \multicolumn{3}{|c|}{ Freundlich } \\
\hline & $\begin{array}{c}\mathrm{K}_{\mathrm{L}} \\
(\mathrm{L} / \mathrm{mg})\end{array}$ & $\underset{(\mathrm{mg} / \mathrm{g})}{\mathrm{q}_{\mathrm{m}}}$ & $\mathrm{R}^{2}$ & $\frac{\mathrm{k}_{\mathrm{F}}}{(\mathrm{mg} / \mathrm{g})(\mathrm{L} / \mathrm{mg})^{1 / \mathrm{n}}}$ & $1 / \mathrm{n}$ & $\mathrm{R}^{2}$ \\
\hline $\mathrm{Mp}$ & $0,3 \pm 0,1$ & $194 \pm 17$ & $0,90 \pm 0,05$ & $66 \pm 12$ & $0,32 \pm 0,08$ & $0,8 \pm 0,2$ \\
\hline $\mathrm{Cbz}$ & $0,5 \pm 0,3$ & $174 \pm 54$ & $0,93 \pm 0,05$ & $70 \pm 3$ & $0,28 \pm 0,06$ & $0,8 \pm 0,1$ \\
\hline Sil & $0,1 \pm 0,1$ & $114 \pm 70$ & $0,70 \pm 0,40$ & $19 \pm 12$ & $0,40 \pm 0,3$ & $0,7 \pm 0,6$ \\
\hline
\end{tabular}

\subsubsection{Análisis de la cinética de adsorción}

El análisis de la cinética de adsorción también requiere conocer la concentración en el equilibrio $\mathrm{q}_{\mathrm{e}}$ (Lagergren, 1898; McCoy and Liapis, 1991). Sin embargo, esto no fue posible para la mayoría de las concentraciones de trabajo como se puede ver en la Figura 7.2.

Aunque puede aplicarse un análisis de prueba y error para estimar $\mathrm{q}_{\mathrm{e}}$, el error de esta evaluación es mayor en las soluciones de menor concentración, lo que complica evaluar si la cinética sigue alguna de las expresiones descritas en las Ecuaciones (7.4) y (7.5).

En concentraciones iniciales de $30 \mathrm{mg} / \mathrm{L}, 35 \mathrm{mg} / \mathrm{L}$ y $40 \mathrm{mg} / \mathrm{L}$, el $\mathrm{Mp}$ fue el único compuesto que alcanzó el equilibrio, (Figura 7.3). La Cbz y el Sil deberían seguir este mismo comportamiento cuando se estudia la cinética de adsorción mediante las ecuaciones citadas. Dado que los fármacos no lograron alcanzar el equilibrio, no se pudieron determinar los parámetros correspondientes. De acuerdo al análisis para el Mp se determinó que el modelo que mejor se ajustó para las tres concentraciones fue el modelo de seudo primer orden, con constantes de velocidad aparente $\left(\mathrm{k}_{1}\right)$ de $0.026 \pm 0.010 / \mathrm{h}, 0.026 \pm 0.020 / \mathrm{h}$ y $0.028 \pm 0.020 / \mathrm{h}$, respectivamente. Los valores obtenidos en el equilibrio para las mismas concentraciones iniciales fueron de $160 \pm 25 \mathrm{mg} / \mathrm{g}, 167 \pm 23 \mathrm{mg} / \mathrm{g}$ y $164 \pm 32 \mathrm{mg} / \mathrm{g}$, respectivamente. 

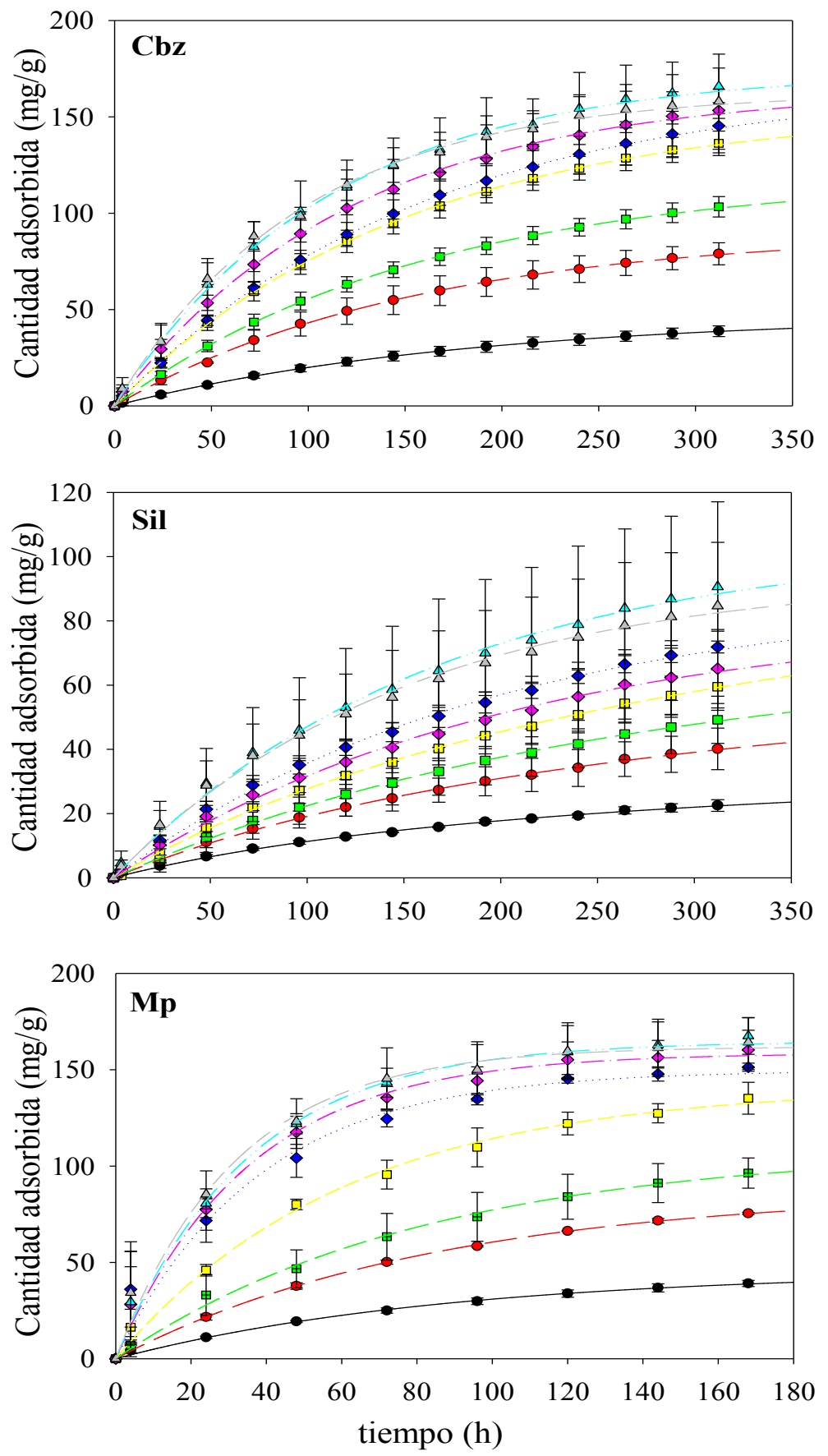

Figura 7.2 Curvas para la cinética de adsorción de carbamazepina (Cbz), sildenafil (Sil) y metilparabeno (Mp) sobre carbón activado granular. Se indican los errores en cada medida. Las líneas corresponden al ajuste no lineal descrito en Ecuación (7.9) para $5 \mathrm{mg} / \mathrm{L}(\bullet), 10 \mathrm{mg} / \mathrm{L}(\bullet), 15 \mathrm{mg} / \mathrm{L}(\bullet), 20 \mathrm{mg} / \mathrm{L}(\bullet), 25 \mathrm{mg} / \mathrm{L}(\bullet)$, $30 \mathrm{mg} / \mathrm{L}(\diamond), 35 \mathrm{mg} / \mathrm{L}(\Delta)$ y $40 \mathrm{mg} / \mathrm{L}(\Delta)$. 


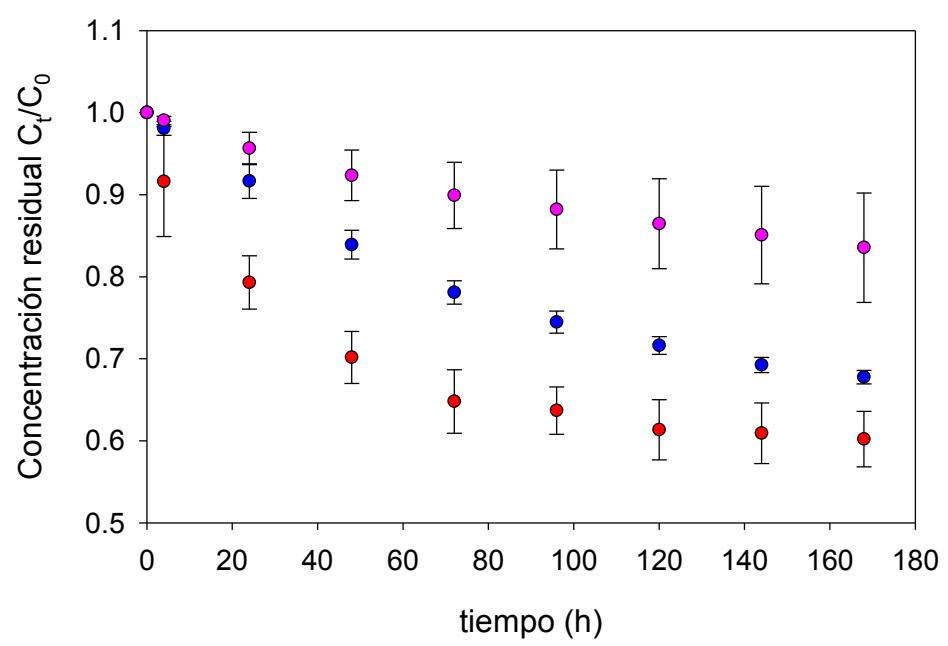

Figura 7.3 Comparación de la cinética de adsorción sobre carbón activado granular para metilparabeno $(\bullet)$, carbamazepina $(\bullet)$ y sildenafil (•) en concentraciones iniciales de aproximadamente $40 \mathrm{mg} / \mathrm{L}$.

\subsubsection{Evaluación de un modelo de velocidad no lineal}

Varios autores han tenido en cuenta diferentes enfoques para estudiar la cinética de adsorción de un contaminante en solución acuosa. El proceso se ha explicado mediante una cinética de seudo primer y segundo orden (Azizian, 2004; Azizian and Fallah, 2010; Derylo-Marczewska et al., 2010; Ho et al., 2002; Limousin et al., 2007). En el presente trabajo, se analizó este proceso utilizando un modelo no lineal, que no requiere del conocimiento del valor de $\mathrm{q}_{\mathrm{e}}$, el cual anteriormente ha sido indispensable para determinar la constante de velocidad.

La cinética de adsorción se estudió considerando un proceso reversible. Si $\theta$ es la fracción de cobertura superficial en el momento t, y $\mathrm{C}$ es la concentración del adsorbato en la solución, la velocidad de reacción está dada por la diferencia entre la velocidad de adsorción y la velocidad de desorción de la siguiente manera

$$
\frac{\mathrm{d} \theta}{\mathrm{dt}}=\mathrm{k}_{\mathrm{a}} \mathrm{C}(1-\theta)-\mathrm{k}_{\mathrm{d}} \theta
$$

donde $\mathrm{k}_{\mathrm{a}} \mathrm{y} \mathrm{k}_{\mathrm{d}}$ son las constantes de velocidad de adsorción y desorción. Si $\mathrm{C}_{0}$ es la concentración inicial (en $\mathrm{mg} / \mathrm{L}$ ), entonces la concentración remanente $\mathrm{C}$ se puede escribir como $\mathrm{C}=\mathrm{C}_{0}-\beta \theta$, donde $\beta \theta$ es la concentración adsorbida y $\beta$ tiene unidades 
de $\mathrm{mg} / \mathrm{L}$ (ver anexo: evaluación de $\beta$ ). Introduciendo la anterior expresión en la Ecuación (7.6) y reagrupando, se obtiene lo siguiente

$$
\frac{\mathrm{d} \theta}{\mathrm{dt}}=\mathrm{k}_{\mathrm{a}} \mathrm{C}_{0}-\left(\mathrm{k}_{\mathrm{a}} \beta+\mathrm{k}_{\mathrm{a}} \mathrm{C}_{0}+\mathrm{k}_{\mathrm{d}}\right) \theta+\mathrm{k}_{\mathrm{a}} \beta \theta^{2}
$$

Redefiniendo: $\mathrm{a}=\mathrm{k}_{\mathrm{a}} \beta ; \mathrm{b}=-\left(\mathrm{k}_{\mathrm{a}} \beta+\mathrm{k}_{\mathrm{a}} \mathrm{C}_{0}+\mathrm{k}_{\mathrm{d}}\right)$ y $\mathrm{c}=\mathrm{k}_{\mathrm{a}} \mathrm{C}_{0}$, la Ecuación (7.7) toma la siguiente forma

$$
\frac{d \theta}{c+b \theta+a \theta^{2}}=d t
$$

Al desarrollar la integración de la ecuación diferencial anterior y por la reorganización de términos, se puede obtener la Ecuación (7.9) como se describe en el anexo: integración de la Ecuación (7.8).

$$
q_{t}=\frac{q_{e^{*} e^{\tau}\left(1-e^{\lambda t}\right)}^{\left(1-e^{\tau} e^{\lambda t}\right)}}{(10)}
$$

Conociendo los valores de $\mathrm{q}_{\mathrm{t}} \mathrm{y} \mathrm{t}$, puede analizarse la Ecuación (7.9) mediante regresión no lineal, y por mayor conveniencia definiremos las magnitudes $A=q_{e}, B=$ $\lambda, \mathrm{y} \mathrm{C}=\mathrm{e}^{\tau}$. Los resultados obtenidos para el ajuste y el análisis de la regresión con respecto a la Ecuación (7.9) se resumen en la Figura 7.2 y en la Tabla 7.2. Los valores para el parámetro $\mathrm{C}$ obtenidos para cada dato estudiado fueron mucho mayores que 1 , con valores promedios de $1 \times 10^{6}$.

Tabla 7.2 Valores calculados para los parámetros A y B, obtenidos usando la regresión no lineal de la Ecuación (7.9)

\begin{tabular}{ccccccccc}
\hline $\mathrm{C}_{0}$ & \multicolumn{2}{c}{$\mathrm{Cbz}$} & & \multicolumn{2}{c}{ Sil } & & \multicolumn{2}{c}{$\mathrm{Mp}$} \\
\cline { 2 - 3 } & $\mathrm{A}$ & $\mathrm{B}$ & & $\mathrm{A}$ & $\mathrm{B}$ & & $\mathrm{A}$ & $\mathrm{B}$ \\
\hline 5 & $47 \pm 8$ & $0,005 \pm 0,001$ & & $33 \pm 18$ & $0,003 \pm 0,008$ & & $45 \pm 11$ & $0,011 \pm 0,004$ \\
10 & $91 \pm 11$ & $0,006 \pm 0,002$ & & $53 \pm 29$ & $0,004 \pm 0,002$ & & $87 \pm 9$ & $0,012 \pm 0,003$ \\
15 & $120 \pm 16$ & $0,006 \pm 0,002$ & & $66 \pm 7$ & $0,005 \pm 0,001$ & & $114 \pm 40$ & $0,012 \pm 0,010$ \\
20 & $155 \pm 14$ & $0,007 \pm 0,002$ & & $84 \pm 28$ & $0,004 \pm 0,002$ & & $141 \pm 23$ & $0,017 \pm 0,002$ \\
25 & $168 \pm 36$ & $0,006 \pm 0,001$ & & $90 \pm 17$ & $0,005 \pm 0,002$ & & $151 \pm 7$ & $0,026 \pm 0,006$ \\
30 & $165 \pm 53$ & $0,008 \pm 0,001$ & & $83 \pm 39$ & $0,005 \pm 0,002$ & & $158 \pm 18$ & $0,029 \pm 0,013$ \\
35 & $175 \pm 27$ & $0,009 \pm 0,004$ & & $106 \pm 29$ & $0,006 \pm 0,003$ & & $166 \pm 44$ & $0,032 \pm 0,019$ \\
40 & $163 \pm 12$ & $0,010 \pm 0,003$ & & $95 \pm 80$ & $0,006 \pm 0,002$ & & $160 \pm 28$ & $0,032 \pm 0,025$ \\
\hline
\end{tabular}

$\mathrm{C}_{0}=$ concentración inicial nominal $(\mathrm{mg} / \mathrm{L}) ; \mathrm{A}=\mathrm{q}_{\mathrm{e}}$ en $(\mathrm{mg} / \mathrm{g})$ y $\mathrm{B}=\lambda=\mathrm{k}_{1}$ en $(1 / \mathrm{h})$ 
En la Ecuación (7.9) si C >>1, se obtiene lo siguiente (el análisis completo se muestra en el anexo: análisis del parámetro $\lambda$ ).

$$
\ln \left(\frac{q_{e}-q_{t}}{q_{e}}\right)=-\lambda t
$$

En la Ecuación (7.10), $\lambda$ representa la constante de velocidad $\mathrm{k}_{1}$, de acuerdo a la Ecuación (7.4).

Además, si $\mathrm{A}=\mathrm{q}_{\mathrm{e}}, \mathrm{y} \Theta \mathrm{e}=\mathrm{q}_{\mathrm{e}} / \mathrm{q}_{\mathrm{m}}$, entonces por reorganización de términos la Ecuación (7.7) resulta en la siguiente expresión (ver anexo: evaluación de $\mathrm{q}_{\mathrm{m}}$ )

$$
\frac{1}{q_{e}}=\frac{1}{q_{m}}+\frac{1}{q_{m} K C_{0}}
$$

Esta ecuación sugiere una dependencia lineal entre $1 / \mathrm{q}_{\mathrm{e}} \mathrm{y} 1 / \mathrm{C}_{0}$, en la cual, de la ordenada al origen y de la pendiente se obtiene los valores de la máxima capacidad de adsorción $\left(\mathrm{q}_{\mathrm{m}}\right)$ y la constante global de equilibrio $(\mathrm{K})$, respectivamente, cuyos resultados se listan en la Tabla 7.3.

Además, el análisis del parámetro $\mathrm{B}$ en función de $\mathrm{C}_{0}$ muestra un comportamiento lineal $\left(\mathrm{B}=\mathrm{k}_{\mathrm{a}} \mathrm{C}_{0}+\mathrm{k}_{\mathrm{d}}\right.$ ), del cual de la ordenada al origen puede estimarse la constante de desorción $\left(\mathrm{k}_{\mathrm{d}}\right) \mathrm{y}$ de la pendiente puede estimarse la constante de adsorción $\left(\mathrm{k}_{\mathrm{a}}\right)$ tal como se listan en la Tabla 7.3.

Tabla 7.3 Resultados obtenidos para los parámetros $\mathrm{K}$ y q $\mathrm{q}_{\mathrm{m}}$ mediante la Ecuación (7.11) y valores calculados para la constante de adsorción $\mathrm{k}_{\mathrm{a}} \mathrm{y}$ la constante de desorción $\mathrm{k}_{\mathrm{d}}$

\begin{tabular}{ccccccc}
\hline Muestra & $\mathrm{K}(\mathrm{L} / \mathrm{mg})$ & $\mathrm{q}_{\mathrm{m}}(\mathrm{mg} / \mathrm{g})$ & $\mathrm{R}^{2}$ & Pendiente $=\mathrm{k}_{\mathrm{a}}$ & intercepto $=\mathrm{k}_{\mathrm{d}}$ & $\mathrm{R}^{2}$ \\
& & & & & & \\
\hline Mp & $0,04 \pm 0,02$ & $322 \pm 138$ & $0,98 \pm 0,02$ & $7,2 \times 10^{-4}$ & $5,1 \times 10^{-3}$ & 0,9195 \\
Cbz & $0,04 \pm 0,03$ & $325 \pm 170$ & $0,98 \pm 0,01$ & $1,2 \times 10^{-4}$ & $4,6 \times 10^{-3}$ & 0,8353 \\
Sil & $0,07 \pm 0,08$ & $142 \pm 68$ & $0,86 \pm 0,30$ & $2,3 \times 10^{-4}$ & $4,5 \times 10^{-3}$ & 0,9003 \\
\hline
\end{tabular}

Con el valor calculado de $\mathrm{q}_{\mathrm{m}}$, el parámetro $\beta$ se puede evaluar y definir como (ver anexo: evaluación de $\beta$ ):

$$
\beta=\frac{m_{c} q_{m}}{V}
$$


Donde $\mathrm{m}_{\mathrm{c}}$ es la masa de adsorbente $(\mathrm{g}), \mathrm{q}_{\mathrm{m}}$ es la capacidad máxima de adsorción, y $\mathrm{V}$ es el volumen de solución (L).

Este parámetro permite discriminar entre una cinética de seudo primer orden y una de seudo segundo orden. En efecto, si $\mathrm{C}_{0} \gg \beta \Theta$, siendo $\Theta=\mathrm{q} / \mathrm{q}_{\mathrm{m}}$, se cumplen las condiciones para que el sistema pueda ser descrito por una cinética de seudo primer orden, pero si $\beta \Theta \approx \mathrm{C}_{0}$ debería esperarse una cinética de seudo segundo orden (Azizian, 2004). En la Tabla 7.4 se listan los valores de $\beta \Theta$ para las distintas concentraciones. Como se puede observar los parámetros sugieren fuertemente una cinética de seudo primer orden.

Tabla 7.4 Resultados obtenidos para el parámetro * $\beta \Theta$

\begin{tabular}{cccc}
\hline $\mathrm{C}_{0}(\mathrm{mg} / \mathrm{L})$ & $\mathrm{Mp}$ & $\mathrm{Cbz}$ & Sil \\
\hline 5 & $3,9 \pm 0,4$ & $3,9 \pm 1,0$ & $2,0 \pm 0,0$ \\
10 & $7,6 \pm 0,2$ & $7,9 \pm 2,0$ & $4,0 \pm 2,0$ \\
15 & $9,1 \pm 1,9$ & $10,0 \pm 1,0$ & $5,0 \pm 2,0$ \\
20 & $13,6 \pm 2,0$ & $14,0 \pm 1,0$ & $6,0 \pm 1,0$ \\
25 & $15,2 \pm 0,7$ & $14,0 \pm 3,0$ & $7,0 \pm 0,0$ \\
30 & $16,1 \pm 2,3$ & $15,0 \pm 5,0$ & $6,0 \pm 3,0$ \\
35 & $16,8 \pm 2,4$ & $16,0 \pm 4,0$ & $9,0 \pm 3,0$ \\
40 & $16,5 \pm 3,3$ & $16,0 \pm 2,0$ & $9,0 \pm 8,0$ \\
\hline $\mathrm{C}_{0}:$ concentración nominal inicial * $\beta \theta(\mathrm{mg} / \mathrm{L})$ &
\end{tabular}

\subsubsection{Evaluación de la velocidad inicial}

Otra alternativa para analizar el comportamiento del sistema se basa en el análisis de la velocidad inicial (Benson, 1960). La estimación de la velocidad inicial a partir de los datos experimentales se tomó del primer par de puntos de los gráficos "cantidad adsorbida vs tiempo" de la Figura 7.2. Los valores de las velocidades iniciales como función de la concentración se muestran en la Figura 7.4, en la cual la ecuación $\mathrm{v}_{0}=\mathrm{dq} / \mathrm{dt}=\mathrm{kC}_{0}$ representa la pendiente de una línea recta pasando a través del origen. Por lo tanto, este comportamiento sugiere fuertemente una cinética de seudo primer orden, siendo consistente con el análisis realizado previamente, como se ve en la Tabla 7.4 (para $C_{0} \gg \beta \theta$ ) y en la Ecuación (7.10), deducida en el Anexo: análisis del parámetro $\lambda$. El ajuste y los valores obtenidos para el parámetro $\mathrm{k}$ para cada PPCPs se listan en: "valores experimentales" de la Tabla 7.5. 
Si en la Ecuación (7.9) q q se deriva respecto al tiempo, se obtiene la Ecuación (7.13) y luego, se puede determinar la velocidad de adsorción en un momento dado, como se muestra en el anexo (Expresión de la velocidad de adsorción en términos del modelo no lineal) y la Figura 7.5.

$$
\frac{d q}{d t}=v_{t}=(u-w)(A * C)
$$

donde: $u=\frac{-B X}{[1-C X]} \quad$ y $\quad w=\frac{[1-X][-C B X]}{[1-C X]^{2}} ; \mathrm{X}$ definida como $X=e^{B t}$

Ahora, si se toma el límite para $\mathrm{t} \rightarrow 0$ (ver anexo: Expresión de la velocidad de adsorción en términos del modelo), se obtiene la expresión de la velocidad inicial (Ecuación (7.14)), como se observa en la Figura 7.4 y en los "valores teóricos" de la Tabla 7.5.

$$
\frac{d q}{d t}=A * B=v_{0}
$$

Como se puede ver en la Tabla 7.5, la Figura 7.4 y la Figura 7.5, los valores obtenidos a partir de las ecuaciones teóricas y los datos experimentales muestran un buen ajuste, lo que permite calcular la velocidad inicial y la velocidad del sistema en un momento dado.

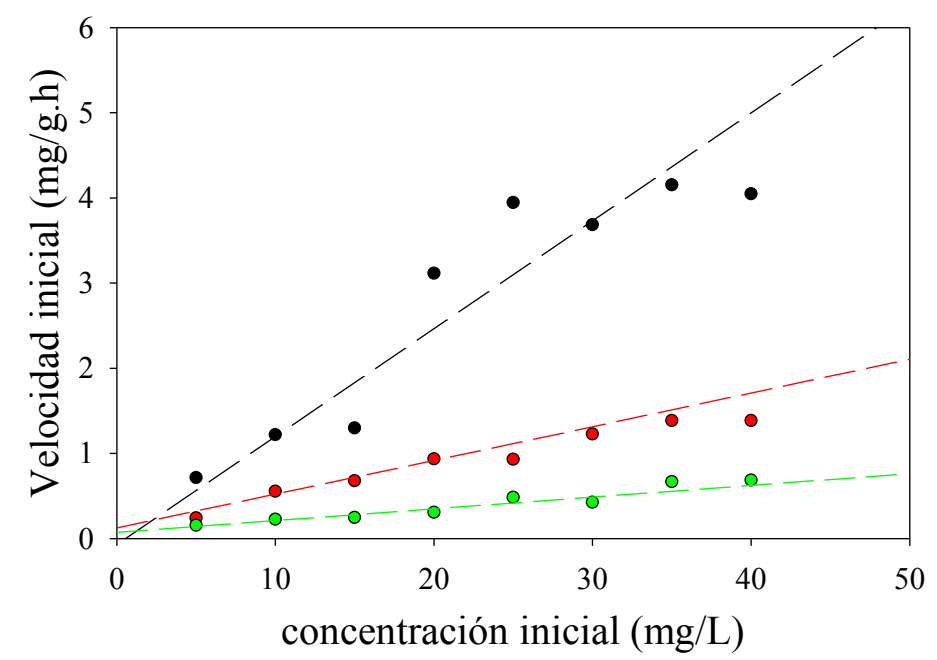

Figura 7.4 Velocidad inicial experimental $v_{0}(\bullet, \bullet, \bullet)$ y velocidad inicial teórica (---,---,---; Ecuación (7.14)) en función de la concentración inicial $\left(\mathrm{C}_{0}\right)$ para metilparabeno $(\bullet)$, carbamazepina $(\bullet)$ y sildenafil $(\bullet)$. 

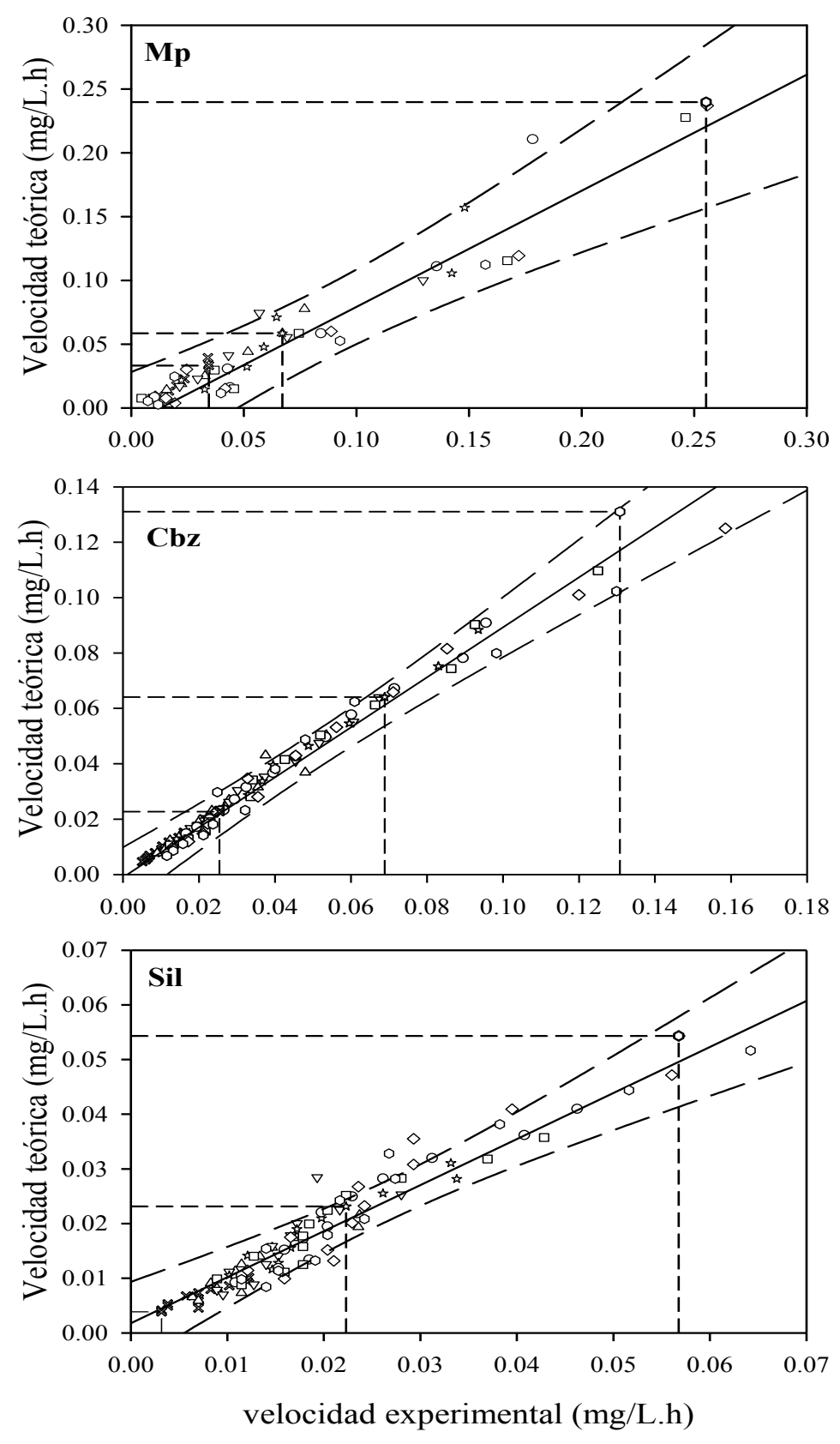

Figura 7.5 Comparación de las velocidades experimentales $\left(v_{\exp }\right)$ y las evaluadas a partir de la Ecuación (7.13) $\left(v_{t}\right)$ para (Mp) metilparabeno, (Cbz) carbamazepina y (Sil) sildenafil, en concentraciones iniciales de $5 \mathrm{mg} / \mathrm{L}(\approx), 10 \mathrm{mg} / \mathrm{L}(\Delta), 15$ $\mathrm{mg} / \mathrm{L}(\nabla), 20 \mathrm{mg} / \mathrm{L}$ (穴), $25 \mathrm{mg} / \mathrm{L}(\circ), 30 \mathrm{mg} / \mathrm{L}(\square), 35 \mathrm{mg} / \mathrm{L}$ $(\diamond)$ y $40 \mathrm{mg} / \mathrm{L}(\square)$. La línea continua corresponde a la regresión lineal y las líneas punteadas corresponden al intervalo de confianza del 95\%. 
Tabla 7.5 Parámetros obtenidos del análisis de la velocidad inicial (experimental y teórica) en función de la concentración inicial de cada uno de los compuestos estudiados

\begin{tabular}{ccccccccc}
\hline \multirow{2}{*}{ Compuesto } & \multicolumn{3}{c}{ Valores experimentales } & & \multicolumn{3}{c}{ Valores teóricos } \\
\cline { 2 - 3 } \cline { 7 - 8 } & $\mathrm{k}(1 / \mathrm{h})$ & $\mathrm{Y}^{*}$ & $\mathrm{R}^{2}$ & & $\mathrm{k}(1 / \mathrm{h})$ & $\mathrm{Y}$ & $\mathrm{R}^{2}$ \\
\hline $\mathrm{Mp}$ & 0,109 & 0,307 & 0,858 & & 0,127 & $-0,067$ & 0,916 \\
$\mathrm{Cbz}$ & 0,033 & 0,177 & 0,961 & & 0,040 & 0,124 & 0,966 \\
$\mathrm{Sil}$ & 0,016 & 0,044 & 0,926 & & 0,014 & 0,071 & 0,908 \\
\hline
\end{tabular}

*Y: ordenada al origen

En el caso de metilparabeno, para las concentraciones de $30 \mathrm{mg} / \mathrm{L}, 35 \mathrm{mg} / \mathrm{L}$ y $40 \mathrm{mg} / \mathrm{L}$ no se observaron diferencias significativas al comparar los datos obtenidos a partir de los diferentes modelos (ecuación de seudo primer orden, ecuación no lineal y el análisis de velocidad inicial mediante el estudio de los datos experimentales y el modelo teórico), estas consideraciones permiten trabajar sobre la base de los mismos combinando las Ecuaciones (7.9) y (7.14) para discriminar el orden de las cinéticas estudiadas. El modelo resultante puede ser muy útil, ya que existen algunos estudios en los cuales la cinética y el equilibrio de adsorción no se han podido definir claramente utilizando las ecuaciones tradicionales (Cai and Larese-Casanova, 2014; Chang et al., 2015; Stoykova et al., 2013; Zhao et al., 2008).

En el análisis para determinar la capacidad máxima de adsorción, utilizando el modelo de Langmuir con los últimos datos experimentales de los valores de $\mathrm{q}_{\mathrm{e}}$, se determinó una diferencia de aproximadamente un 40\% en la capacidad de adsorción respecto a los valores obtenidos con el análisis del modelo no lineal, del que se determinó una capacidad máxima de adsorción de aproximadamente 300 $\mathrm{mg} / \mathrm{g}$. Resultados similares se reportan para la adsorción de la carbamazepina sobre carbón activado granular obtenido a partir de semillas de durazno (Torrellas et al., 2015a).

Aunque el carbón activado estudiado presenta una capacidad de adsorción alta comparado con otros adsorbentes más selectivos, como minerales de arcilla, residuos industriales y agrícolas (Grassi et al., 2012; Rossner et al., 2009), el tiempo necesarios para alcanzar el equilibrio es muy lento, con periodos superiores a 6 días para Mp, y mayores a 14 días para Cbz y Sil. Se obtuvieron tiempos de adsorción similares para 
la adsorción de naproxeno, carbamazepina y nonilfenol sobre carbones activados usados comúnmente en plantas potabilizadoras (carbón calgon F-400 y carbón a base de coco PICATIFTE) (Yu et al., 2009). De igual modo, Rossner et al. (2009) demostraron una capacidad de adsorción alta con carbón activado granular, obtenido a partir de cáscara de coco para remover contaminantes emergentes en agua de lago, pero sin tener en cuenta los tiempos de contacto tan largos que necesita el sistema. Consecuentemente, el potencial uso del carbón activado granular comercial, para remoción de contaminantes emergentes en tecnologías a escala real, con área superficial similar a la estudiada en el presente trabajo, requerirá de investigaciones ulteriores, que impliquen pasos tales como el diseño de un conjunto de columnas, la proporción y tipos de materiales adsorbentes o la combinación de diferentes tecnologías de tratamiento. 


\subsection{Conclusiones parciales}

En este trabajo se realizaron estudios de cinética y equilibrio de adsorción sobre carbón activado granular con el fin de demostrar su viabilidad para remover contaminantes emergentes - Mp, Cbz y Sil- en soluciones acuosas. El carbón activado granular presentó una capacidad de adsorción alta para los tres compuestos, con aproximadamente $300 \mathrm{mg} / \mathrm{g}$ para la carbamazepina y el metilparaben, y de $150 \mathrm{mg} / \mathrm{g}$ para el sildenafil, (esta molécula dobla el área superficial respecto de los otros dos), pero con una cinética de adsorción lenta que conduce a tiempos medios superiores a $168 \mathrm{~h}$, en el siguiente orden para alcanzar el equilibrio MP $<$ CBZ $<$ SIL. Además, el tiempo necesario para que estos compuestos alcancen el plateau aumenta progresivamente tras la reducción de su concentración inicial. Dicha cinética excesivamente prolongada complicará el análisis de los parámetros de adsorción a través de las ecuaciones propuestas tradicionalmente porque su uso requiere que se alcance el equilibrio en la solución.

El ajuste del modelo no lineal planteado en la Ecuación (7.9), permite evaluar los parámetros de la cinética de adsorción, particularmente $\mathrm{q}_{\mathrm{e}} \mathrm{y} \mathrm{q}_{\mathrm{m}}$, ya que se obtienen resultados comparables sin necesidad de llegar al equilibrio. Sobre la base de este modelo se determinó que el parámetro $\beta \theta$ fue mucho menor que $C_{0}$, por tanto la adsorción sigue una cinética de seudo primer orden, sin suposiciones previas sobre el orden de la cinética de adsorción o el análisis por prueba y error.

A partir del conocimiento de los datos proporcionados por ajuste de la Ecuación (7.9), se puedo deducir una ecuación para la velocidad inicial. El comportamiento estimado de los valores determinados fue similar al de las velocidades obtenidas con los datos experimentales. Estas consideraciones nos permiten concluir que los procesos de adsorción sobre carbón activado granular para los compuestos evaluados siguen una cinética de seudo primer orden.

Los resultados encontrados en este estudio permitieron obtener información valiosa de la interacción de los contaminantes emergentes con el carbón activado granular comercial. El uso de este material como tecnología para la remoción de PPCPs del agua, debe contemplar la velocidad de adsorción lenta al momento de diseñar un reactor que emplee carbón activado granular. Para mejorar la eficiencia de 
Capítulo 7. Carbón activado granular para remoción de contaminantes emergentes: experimentos en batch

remoción, se deben tener en cuenta otros materiales de adsorción, otros diseños tecnológicos de dispositivos de adsorción o enfoques tecnológicos combinados. 


\subsection{Anexo}

\section{Evaluación de $\beta$}

Considerando la cinética de adsorción como un proceso reversible para un compuesto $\mathrm{Z}$ sobre un sólido Se tiene:

$$
\mathrm{Z}+\mathrm{S} \underset{k_{d}}{\stackrel{k_{a}}{\rightleftarrows}} \mathrm{ZS}
$$

La velocidad de adsorción se puede expresar como se ve en las Ecuaciones (7.6) y (7.7). La magnitud de $\beta$ es necesaria para analizar la cinética de adsorción.

Como se define en el texto, $\mathrm{C}$ es la concentración del adsorbato en la solución en el tiempo t; que se puede escribir como $C=C_{0}-\beta \theta$.

$\beta \theta$ es la concentración de adsorbato adsorbida sobre el carbón activado, donde el parámetro $\beta$ expresa los moles adsorbidos por unidad de volumen (mol/L). En el equilibrio de adsorción, $\beta$ se puede expresar en términos de $\theta_{\mathrm{e}}$ (es decir, fracción de cobertura en el equilibrio) y $\mathrm{C}_{\mathrm{e}}$ (es decir, la concentración del adsorbato en el equilibrio). Entonces, $\mathrm{C}_{\mathrm{e}}=\mathrm{C}_{0}-\beta \theta_{\mathrm{e}} ; \mathrm{y} \beta=\left(\mathrm{C}_{0}-\mathrm{C}_{\mathrm{e}}\right) / \theta_{\mathrm{e}}$.

Entonces $\beta$ se puede evaluar en términos de datos experimentales como

$$
\beta\left[m o l . L^{-1}\right]=\frac{m_{c} q_{m}}{M_{w} V} \quad \text { o } \quad \beta\left[m g . L^{-1}\right]=\frac{m_{c} q_{m}}{V}
$$

donde $\mathrm{m}_{\mathrm{c}}$ es la masa de adsorbente $(\mathrm{g}), \mathrm{q}_{\mathrm{m}}$ es la capacidad máxima de adsorción, $\mathrm{M}_{\mathrm{w}}$ es la masa molar del adsorbato $(\mathrm{g} / \mathrm{mol})$ y $\mathrm{V}$ es el volumen de la solución (L).

\section{Integración de la Ecuación (7.8)}

Se sabe que $\frac{d \theta}{d t}=c+b \theta+a \theta^{2}$. Después de la separación de variables, se obtiene

$$
\frac{d \theta}{c+b \theta+a \theta^{2}}=d t \quad 0 \quad \int_{0}^{\theta} \frac{d \theta}{c+b \theta+a \theta^{2}}=\int_{0}^{t} d t
$$

Como se ve en la literatura (Lide, 2004), la solución es posible si el término d $=4 \mathrm{ac}-\mathrm{b}^{2}<0$. Por lo tanto

$$
\frac{1}{\sqrt{-d}}\left[\ln \frac{2 a \theta+b-\sqrt{-d}}{2 a \theta+b+\sqrt{-d}}-\ln \frac{b-\sqrt{-d}}{b+\sqrt{-d}}\right]=t
$$


Renombrando los términos en la ecuación anterior como $\lambda=\sqrt{-d} ; \gamma=b-$ $\lambda ; \varepsilon=b+\lambda$ y $\tau=\ln \frac{\gamma}{\varepsilon}$ y reagrupando, se tiene

$$
\ln \left(\frac{2 a \theta+\gamma}{2 a \theta+\varepsilon}\right)-\tau=\lambda t
$$

Aplicando el antilogaritmo y reorganizando la ecuación anterior, se puede obtener la siguiente expresión para $\theta$

$$
\theta=\frac{e^{\tau} e^{\lambda t} \varepsilon-\gamma}{2 a\left(1-e^{\tau} e^{\lambda t}\right)}
$$

Tomando $\varepsilon$ como factor común en el numerador, $\theta$ es dado ahora por la Ecuación (A7.6)

$$
\theta=\frac{\varepsilon}{2 a} \frac{\left(e^{\tau} e^{\lambda t}-\gamma / \varepsilon\right)}{\left(1-e^{\tau} e^{\lambda t}\right)}
$$

En el equilibrio $(\mathrm{t} \rightarrow \infty), \theta_{\mathrm{e}} \rightarrow-\varepsilon / 2 \mathrm{a}$ y sabiendo que $\mathrm{e}^{\tau}=\gamma / \varepsilon$; se obtiene la siguiente ecuación

$$
\frac{\theta}{\theta_{e}}=\frac{-\left(e^{\tau} e^{\lambda t}-e^{\tau}\right)}{\left(1-e^{\tau} e^{\lambda t}\right)}
$$

Los factores de la ecuación anterior se pueden escribir en términos de los parámetros evaluados experimentalmente. Si $\theta=\mathrm{q}_{\mathrm{t}} / \mathrm{q}_{\mathrm{m}}$ y $\theta_{\mathrm{e}}=\mathrm{q}_{\mathrm{e}} / \mathrm{q}_{\mathrm{m}}$, entonces $\theta / \theta_{\mathrm{e}}=$ $\mathrm{q}_{\mathrm{t}} / \mathrm{q}_{\mathrm{e}} \mathrm{y}$ reorganizando, se obtiene la Ecuación (A 7.8)

$$
\frac{q_{t}}{q_{e}}=\frac{e^{\tau}\left(1-e^{\lambda t}\right)}{\left(1-e^{\tau} e^{\lambda t}\right)} \quad \text { ó } \quad q_{t}=\frac{q_{e^{*} e^{\tau}\left(1-e^{\lambda t}\right)}}{\left(1-e^{\tau} e^{\lambda t}\right)}
$$

Donde $\mathrm{q}_{\mathrm{t}}, \mathrm{q}_{\mathrm{e}} \mathrm{y} \mathrm{q}_{\mathrm{m}}$ son la cobertura en el momento $\mathrm{t}$, en el equilibrio y en la saturación superficial, respectivamente. Los parámetros $\mathrm{q}_{\mathrm{t}}, \mathrm{q}_{\mathrm{e}} \mathrm{y} \mathrm{q}_{\mathrm{m}}$ se expresan en miligramos de compuesto adsorbido por gramo de carbón activado utilizado.

Remplazando: $A=q_{e} ; C=e^{\tau} ; B=\lambda, \mathrm{q}_{\mathrm{t}}$ se puede escribir en una expresión simplificada que se evalúa mediante análisis de regresión para obtener los parámetros relevantes (ver Ecuación (7.9) en el texto).

$$
q_{t}=\frac{A * C\left(1-e^{B t}\right)}{\left(1-C e^{B t}\right)}
$$


Luego, graficando $\mathrm{q}_{\mathrm{t}} v s \mathrm{t}$, se pueden calcular los parámetros de regresión $\mathrm{A}, \mathrm{C}$, y B. Los resultados para A y B se enumeran en la Tabla 7.2. El valor de C es mucho mayor que 1 en las presentes condiciones.

\section{Análisis del parámetro $\lambda$}

Para $\mathrm{C}>>1$ en el presente trabajo, se puede deducir la siguiente expresión

$$
q_{t}=A *\left(1-e^{-B t}\right) \text { ó } q_{t}=q_{e}\left(1-e^{-\lambda t}\right)
$$

Reorganizando,

$$
\frac{q_{t}-q_{e}}{-q_{e}}=e^{-\lambda t} \quad \text { ó } \quad \ln \left(\frac{\boldsymbol{q}_{e}-\boldsymbol{q}_{\boldsymbol{t}}}{\boldsymbol{q}_{e}}\right)=-\lambda \boldsymbol{t}
$$

Por lo tanto, esta expresión es compatible con una cinética de seudo primer orden si se identifica $\lambda$ con la constante de velocidad $k_{1}$ (Ver la Ecuación (7.4) en el texto).

Igualmente, se pueden obtener los valores de $\mathrm{q}_{\mathrm{e}}$ mediante el análisis de regresión no lineal (Ecuación (7.9) en el texto).

\section{Evaluación de $q_{m}$}

Tan pronto como $C_{0}>>\beta \theta$, el termino $\beta \theta$ se puede ignorar en la Ecuación (7.7). Luego, esta ecuación puede escribirse como

$$
\frac{d \theta}{d t}=k_{a} C_{0}(1-\theta)-k_{d} \theta
$$

En el equilibrio, $\mathrm{d} \theta / \mathrm{dt}=0$ y $\theta=\theta_{\mathrm{e}}$. La constante de equilibrio global de adsorción $\mathrm{K}$ es ahora $=\mathrm{k}_{\mathrm{a}} / \mathrm{k}_{\mathrm{d}}$. Por lo tanto, bajo las suposiciones previas y por reordenamiento de terminos se obtiene la ecuación (A13), siendo consistente a lo reportado por Azizian (2004), en donde se presenta un análisis detallado de este procedimiento.

$$
\frac{1}{\theta_{e}}=\frac{K C_{0}+1}{K c_{0}}
$$

Sabiendo que $\theta_{\mathrm{e}}=\mathrm{q}_{\mathrm{e}} / \mathrm{q}_{\mathrm{m}}$ se obtiene 


$$
\frac{q_{m}}{q_{e}}=\frac{1+K C_{0}}{K c_{0}}=1+\frac{1}{K c_{0}} \quad \text { ó } \quad \frac{1}{q_{e}}=\frac{1}{q_{m}}+\frac{1}{K q_{m}} \frac{1}{C_{0}}
$$

Del gráfico de $1 / \mathrm{q}_{\mathrm{e}} v s 1 / \mathrm{C}_{0}$, se pueden encontrar los valores de $\mathrm{q}_{\mathrm{m}} \mathrm{y} \mathrm{K}$.

\section{Expresión de la velocidad de adsorción en términos del modelo no lineal.}

La expresión teórica obtenida para $\mathrm{q}_{\mathrm{t}}$ anteriormente, $q_{t}=\frac{A * C\left(1-e^{B t}\right)}{\left(1-c e^{B t}\right)}$, es la base para el análisis cinético descrito en el texto. De hecho, $\mathrm{dq}_{\mathrm{t}} / \mathrm{dt}$ es la velocidad de adsorción en función del tiempo. Esta velocidad se puede escribir de la siguiente manera:

ó

$$
\begin{array}{r}
\frac{1}{A * C} \frac{d q}{d t}=\frac{\left[1-e^{B t}\right]^{\prime} *\left[1-C e^{B t}\right]-\left[1-e^{B t}\right] *\left[1-C e^{B t}\right]^{\prime}}{\left[1-C e^{B t}\right]^{2}} \\
\frac{1}{A * C} \frac{d q}{d t}=\frac{-B e^{B t}\left[1-C e^{B t}\right]-\left[1-e^{B t}\right]\left[-C B e^{B t}\right]}{\left[1-C e^{B t}\right]^{2}}
\end{array}
$$

(A7.15)

Aplicando la propiedad distributiva

$$
\frac{1}{A * C} \frac{d q}{d t}=\frac{-B e^{B t}}{\left[1-C e^{B t}\right]}-\frac{\left[1-e^{B t}\right]\left[-C B e^{B t}\right]}{\left[1-C e^{B t}\right]^{2}}
$$

Esta ecuación toma una forma muy simple al introducir los parámetros $X=e^{B t} ; u=\frac{-B X}{[1-C X]} ; w=\frac{[1-X][-C B X]}{[1-C X]^{2}}$

Entonces, la velocidad de adsorción en función del tiempo viene dada por la Ecuación (A 7.17)

$$
\frac{d q}{d t}=v=(u-w)(A * C)
$$

La expresión de velocidad inicial $v_{0}$ se obtiene al analizar la última ecuación en el límite de $\mathrm{t} \rightarrow 0$

$$
\begin{gathered}
\lim _{t \rightarrow 0} v=v_{0}=(A * C) *\left\{\lim _{t \rightarrow 0}\left[-\frac{B e^{B t}}{1-C e^{B t}}\right]-\lim _{t \rightarrow 0}\left[\frac{\left(1-e^{B t}\right)\left(-C B e^{B t}\right)}{\left(1-C e^{B t}\right)^{2}}\right]\right\} \\
=A * C *\left[-\frac{B}{1-C}\right]
\end{gathered}
$$


Tan pronto como $\mathrm{C}>>1$, la velocidad inicial de adsorción puede ser escrita como sigue

$$
v_{0}=A * B
$$

Esta velocidad teórica puede contrastarse con los valores experimentales obtenidos a partir de la pendiente de una línea recta que pasa por el origen en la curva de adsorción en $\mathrm{t}=0$ (ver Figura 7.4). 


\section{CAPÍTULO 8}

\section{CARBÓN ACTIVADO EN POLVO PARA REMOCIÓN DE COMPUESTOS FARMACÉUTICOS: EXPERIMENTOS EN BATCH}

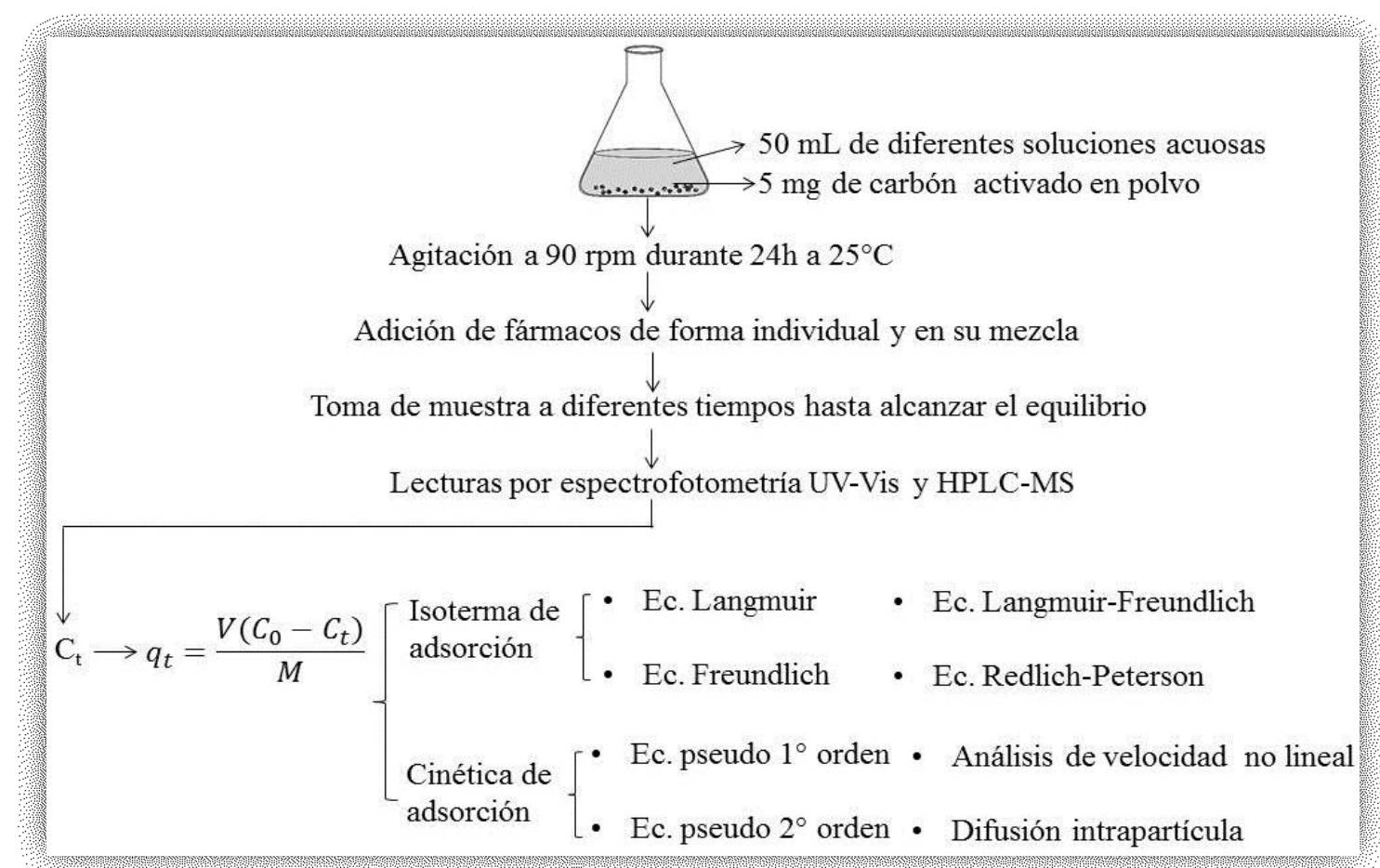




\section{Resumen}

Se ha comprobado que muchos compuestos farmacéuticos no se remueven eficientemente en las plantas de tratamiento convencionales, requiriendo procesos más eficaces y específicos. Recientemente se está investigando con mayor detalle la adsorción sobre carbón activado, debido a la falta de datos de buena calidad sobre los mecanismos involucrados en este proceso. En el presente trabajo se estudió la adsorción de dos fármacos: carbamazepina y sildenafil, sobre carbón activado en polvo, utilizando las isotermas de Langmuir, Freundlich, Langmuir-Freundlich y el modelo de Redlich-Peterson. Se evaluó la cinética de seudo primer orden, seudo segundo orden, un análisis de velocidad no lineal y el modelo de difusión intrapartícula. Además, se estudió el efecto de la matriz acuosa y la mezcla de los fármacos. Se determinó que los datos experimentales siguen una cinética de seudo primer orden para ambos compuestos. El modelo que mejor describió el comportamiento en el equilibrio para Sil fue la isoterma de Langmuir, mientras que para la Cbz fue el modelo de Redlich-Peterson. No se observaron diferencias significativas en la cinética de adsorción de los fármacos al comparar un agua residual con otras soluciones acuosas. 


\subsection{Introducción}

El desarrollo industrial, ha traído consigo la síntesis de nuevos productos químicos utilizados en la agricultura, la industria, la salud humana y veterinaria. La eliminación de estos compuestos, los sintetizados recientemente y los más antiguos, impactan negativamente en los cuerpos de agua, en el aire y en el suelo, convirtiéndose en un problema grave en varios países, debido al vertimiento directo y a la falta plantas de tratamiento de aguas residuales eficientes (Geissen et al., 2015). El estudio de los contaminantes farmacéuticos son de gran interés entre los investigadores, ya que se han detectado más de 3.000 compuestos biológicamente activos en concentraciones muy bajas (ng/L) en matrices acuosas muy complejas (Richardson, 2010). Su concentración en el ambiente depende en gran medida de los patrones de consumo de la población, las regiones y los países. Su estabilidad química y solubilidad en las aguas son factores que pueden introducir fluctuaciones en las concentraciones medidas (Ma et al., 2017; Petrie et al., 2015).

La eliminación eficiente de estos compuestos de las aguas residuales antes de su descarga a las aguas superficiales es un tema emergente en la ciencia e ingeniería ambiental (Rivera-Utrilla et al., 2013), por ejemplo la carbamazepina y el sildenafil se encuentran entre los compuestos recalcitrantes en los tratamientos convencionales (Grossberger et al., 2014; Tejeda et al., 2017). Se pueden utilizar procesos adicionales, tales como la adsorción por carbón activado, y, por lo que se sabe, este adsorbente no genera productos farmacológicamente activos (Katsigiannis et al., 2015).

Utilizando carbón activado se pueden eliminar colorantes, metales pesados y algunos compuestos orgánicos (Chang et al., 2015; Mailler et al., 2016a). El carbón activado granular se emplea normalmente en varias plantas de tratamiento de América del Norte y Canadá como consecuencia de su capacidad de adsorción (Snyder et al., 2007). Mientras que el carbón activado en polvo se ha aplicado para eliminar muchos contaminantes orgánicos problemáticos, compuestos saborizantes y malolientes, pesticidas y herbicidas (Westerhoff et al., 2005).

En los últimos años, diferentes estudios han evaluado la eficiencia del carbón activado para remover contaminantes emergentes de las soluciones acuosas. Sin embargo escasos datos experimentales respecto a su comportamiento y modelado 
matemático están disponibles para estos compuestos (Katsigiannis et al., 2015; Snyder et al., 2007).

En el presente trabajo, se evaluó la eficiencia de remoción de la carbamazepina y el sildenafil de diferentes soluciones acuosas utilizando carbón activado en polvo en función de la concentración inicial de los compuestos. Además se evaluaron las características fisicoquímicas de las soluciones acuosas empleadas en los experimentos.

Se analizó el equilibrio de adsorción mediante las isotermas de Langmuir, Freundlich, el modelo combinado de Langmuir-Freundlich y la isoterma de RedlichPeterson. La cinética de adsorción se analizó utilizando los modelos de seudo primer orden, seudo segundo orden, el modelo de difusión intrapartícula y el modelo combinado de velocidad no lineal, estudiada en la Ecuación 7.9 del Capítulo 7.

\subsection{Metodología}

\subsubsection{Adsorbentes y adsorbatos}

Se utilizó carbón activado en polvo de origen vegetal marca Biopack, CAS [7440-44-0], pH entre 2-4 frente a papel tornasol, pureza del 99\%, tamaño de partículas entre 1 y $150 \mu \mathrm{m}$, densidad aparente de $250 \mathrm{~kg} / \mathrm{m}^{3}$, área superficial de $1328.3 \mathrm{~m}^{2} / \mathrm{g}$, tamaño de poro de $37 \AA$ y volumen de poros de $1.06 \mathrm{~cm}^{3} / \mathrm{g}$, evaluados a partir de medidas Brunauer-Emmett-Teller (BET). Los fármacos utilizados fueron carbamazepina (Cbz) y sildenafil (Sil). En la Tabla 3.1 del Capítulo 3, se detallan las características fisicoquímicas de los dos compuestos.

\subsubsection{Ensayos de adsorción}

Todos los experimentos se realizaron por triplicado en un sistema batch a 25 ${ }^{\circ} \mathrm{C}$ bajo agitación constante a $90 \mathrm{rpm}$ utilizando $100 \mathrm{mg} / \mathrm{L}$ de CAP. Se utilizaron frascos Erlenmeyer para llevar a cabo las experiencias. El volumen total de cada experimento fue de $50 \mathrm{~mL}$. Con el fin de evitar el crecimiento bacteriano en las soluciones acuosas se adicionó azida sódica al 0,01\% (Delgado et al., 2016).

Se preparó una solución stock en metanol de cada compuesto farmacéutico. A partir de estos stocks, se prepararon soluciones que contenían concentraciones 
nominales de $10,15,20,25,30,35$ y $40 \mathrm{mg} / \mathrm{L}$ de cada compuesto individualmente. Antes de llevar a cabo los estudios de cinética y equilibrio de adsorción se evaluó la solubilidad máxima de cada fármaco en metanol. La eficiencia de eliminación de los productos farmacéuticos utilizando carbón activado en polvo (CAP) se comparó con la del carbón activado granular (CAG).

El pH permaneció casi constante durante las mediciones, es decir, el pH inicial fue de 6,15 y 5,97 y los valores finales fueron 6,33 y 6,17 para Cbz y Sil, respectivamente. Por lo tanto, los estudios de adsorción se realizaron sin agregar una solución buffer para evitar la presencia de otros electrolitos en el sistema.

Las mediciones se llevaron a cabo durante $72 \mathrm{~h}$, tomando muestras cada $2 \mathrm{~h}$ durante las primeras $24 \mathrm{~h}$, y cada $24 \mathrm{~h}$ hasta completar $72 \mathrm{~h}$. Los resultados experimentales para la cinética de adsorción se evaluaron empleando los modelos de seudo primer orden, seudo segundo orden y el modelo de difusión intrapartícula; mientras que el equilibrio de adsorción se estudió comparando las isotermas de Langmuir, Freundlich, las isotermas de adsorción combinadas Langmuir-Freundlich y modelo de Redlich-Peterson.

Se empleó la Ecuación (8.1) para determinar la cantidad de fármacos adsorbidos sobre el carbón activado.

$$
q_{t}=\frac{\left(C_{0}-C_{t}\right) V}{W}
$$

donde $\mathrm{q}_{\mathrm{t}}$ es la cantidad (mg/g) de fármaco adsorbida en el tiempo $\mathrm{t}, \mathrm{C}_{0}$ es la concentración inicial de fármaco en la solución $(\mathrm{mg} / \mathrm{L}), \mathrm{C}_{\mathrm{t}}$ es la concentración $(\mathrm{mg} / \mathrm{L})$ en el tiempo t, $\mathrm{V}$ es el volumen (L) de la solución y W es el peso (g) de carbón usado.

\subsubsection{Efecto de la matriz acuosa}

Para determinar el efecto de la matriz acuosa sobre la eficiencia de remoción de los fármacos, con distintas concentraciones iniciales y en contacto con diferentes soluciones acuosas, se realizaron un conjunto de experimentos empleando una concentración inicial nominal de $5 \mathrm{mg} / \mathrm{L}$ y otra de $0,2 \mathrm{mg} / \mathrm{L}$, esta última, similar a las concentraciones encontradas en el ambiente. Para estos ensayos se preparó la solución stock en agua destilada. Los estudios de adsorción se llevaron a cabo en las mismas condiciones descritas anteriormente, en soluciones preparadas con agua destilada, agua declorinada y un agua residual doméstica, proveniente de un tratamiento 
secundario de un reactor de biodiscos. La concentración del CAP se mantuvo en 100 $\mathrm{mg} / \mathrm{L}$. Los perfiles de adsorción en estos experimentos se evaluaron individualmente y en su mezcla.

Se determinó la eficacia de remoción de los fármacos sobre el CAP mediante la Ecuación (8.2).

$$
\% \text { Remoción }=\frac{C_{0}-C_{t}}{C_{0}} * 100
$$

Las determinaciones analíticas de los compuestos se realizaron mediante espectrofotometría UV-vis, para las soluciones conteniendo los fármacos de forma individual y en concentraciones iniciales superiores a $5 \mathrm{mg} / \mathrm{L}$. Los compuestos con concentraciones inferiores, estando en su mezcla y de forma individual, se evaluaron por HPLC-MS, como se detalla en el Capítulo 3.

\subsection{Resultados y discusión}

\subsubsection{Solubilidad}

Se realizaron estudios de solubilidad de los fármacos en $\mathrm{MeOH}$, ya que su uso es indispensable para llevar a cabo los estudios de equilibrio de adsorción para concentraciones entre $20 \mathrm{mg} / \mathrm{L}$ y $40 \mathrm{mg} / \mathrm{L}$, las cuales son superiores a la concentración de solubilidad de la $\mathrm{Cbz}$ en agua $(18 \mathrm{mg} / \mathrm{L})$. Las solubilidades de los compuestos en este solvente a $25^{\circ} \mathrm{C}$ fueron del orden de $1 \times 10^{4} \mathrm{mg} / \mathrm{L}$ para $\mathrm{Cbz}$ y $5 \times 10^{3} \mathrm{mg} / \mathrm{L}$ para $\mathrm{Sil}$. Luego se preparó una solución stock que contenía la mayor concentración de los compuestos en $\mathrm{MeOH}$.

Seguidamente, se realizaron experimentos que contenían diferentes relaciones en mezclas de agua-metanol (expresado como porcentaje en volumen de metanol en agua) para estudiar su interferencia potencial. En todos los casos las concentraciones iniciales reales de $\mathrm{Cbz}$ y Sil fueron de 9,7 $\pm 0,3 \mathrm{mg} / \mathrm{L}$ y 10,1 $\pm 0,6 \mathrm{mg} / \mathrm{L}$, respectivamente, estando preparadas a partir de un stock de $5000 \mathrm{mg} / \mathrm{L}$. En la Figura 8.1 se muestran los perfiles experimentales de la concentración de los fármacos en función del tiempo en agua pura, y en mezclas de 0,8\% y 4\% de metanol en agua. Se determinó que el efecto del metanol es relativamente mayor en la solución que contiene un $4 \%$ en un intervalo de tiempo inferior a $10 \mathrm{~h}$, pero no hay una diferencia 
significativa entre ellos cuando se alcanza el equilibrio. Debido a que este solvente es importante para preparar las soluciones de estudio, en todos los casos, éstas contenían un $0.8 \%$ de $\mathrm{MeOH}$ después de la preparación.
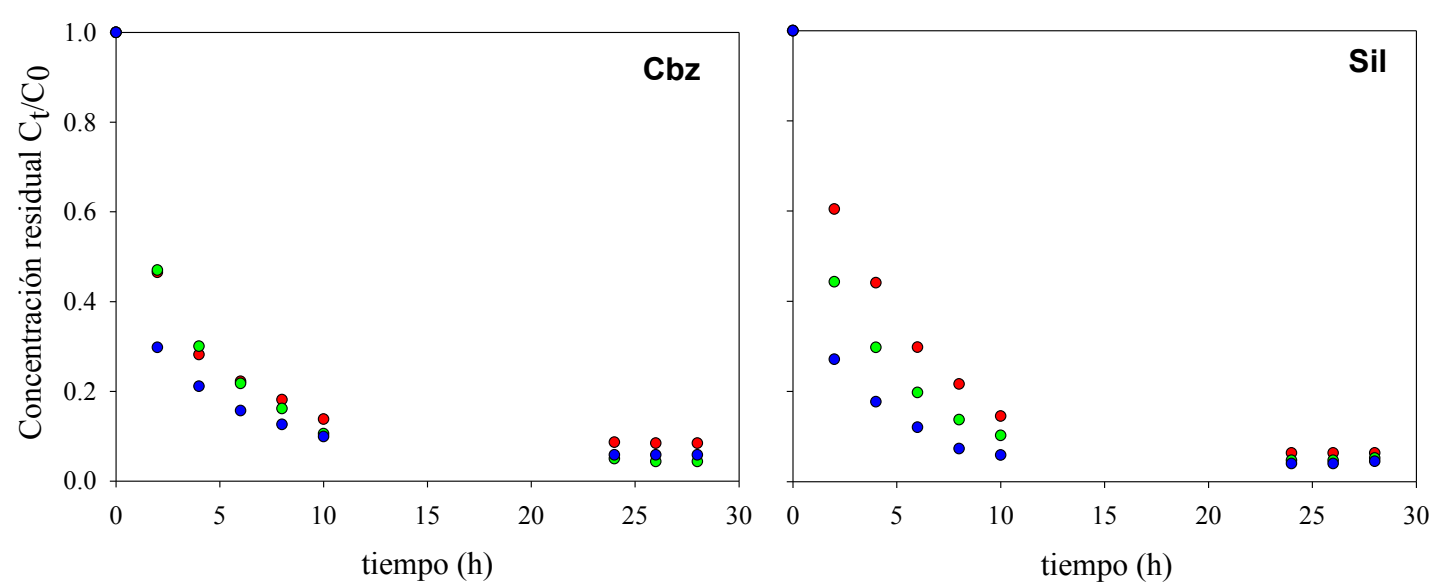

Figura 8.1. Comparación de la adsorción de carbamazepina (Cbz) y sildenafil (Sil) sobre carbón activado en polvo en función del tiempo. Las concentraciones iniciales de los compuestos se fijaron en $10 \mathrm{mg} / \mathrm{L}$. Las concentraciones de metanol en agua fueron del $4 \%(\bullet), 0.8 \%(\bullet)$ y agua pura $(\bullet)$.

\subsubsection{Carbón activado en polvo versus carbón activado granular}

En la Figura 8.2 se muestra la adsorción de Cbz y Sil sobre carbón activado granular y carbón activado en polvo. Como se puede ver, la velocidad de adsorción y la eficacia de remoción son mayores en el último caso, es decir, más del 95\% de los compuestos se eliminan de la solución acuosa en un lapso de tiempo de $10 \mathrm{~h}$ en presencia de carbón activado en polvo. Los mejores resultados obtenidos usando CAP se deben a su área superficial mayor, comparada con la del CAG, con valores de 1328 $\mathrm{m}^{2} / \mathrm{g}$ and $956 \mathrm{~m}^{2} / \mathrm{g}$, respectivamente, tal como se reportó anteriormente (Kim et al., 2010). 


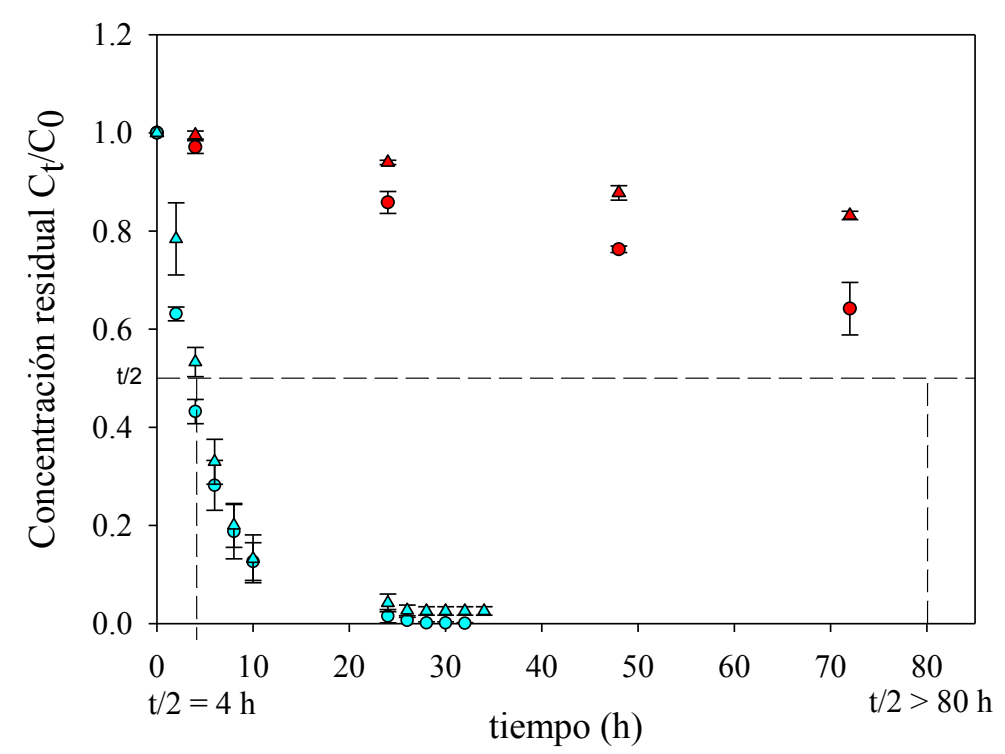

Figura 8.2. Velocidad de adsorción para la $\mathrm{Cbz}(\bullet, \bullet)$ y el Sil $(\Delta, \Delta)$, sobre carbón activado granular $(\bullet, \Delta) \mathrm{y}$ carbón activado en polvo $(\odot, \triangle)$. La concentración inicial fue de $10 \mathrm{mg} / \mathrm{L}$. También se indican los errores experimentales en la figura. Las líneas puenteadas corresponden a $\mathrm{C}_{0} / 2$ (tiempo medio de adsorción).

\subsubsection{Isotermas de adsorción}

El equilibrio de adsorción, entre el adsorbato y el adsorbente, se analizó utilizando modelos de isotermas de dos y tres parámetros. Entre los modelos de dos parámetros se estudiaron las ecuaciones de Langmuir y Freundlich; y entre los de tres parámetros, se evaluaron las isotermas combinadas Langmuir-Freundlich y RedlichPeterson. Los resultados para los diferentes parámetros obtenidos se enumeran en la Tabla 8.1.

Como se ha informado en la literatura (Ho, 2004), es mejor utilizar un análisis de regresión no lineal, que reorganizar las ecuaciones para que se ajusten a una forma lineal. El conocimiento del mejor modelo que se ajusta a los datos experimentales es una tarea importante en el diseño de un sistema de adsorción.

Los valores de las concentraciones iniciales reales de los fármacos para los estudios de la cinética y el equilibrio de adsorción fueron $(9,7 \pm 0,3 ; 15,1 \pm 0,2 ; 20,5 \pm$ $0,3 ; 25,6 \pm 0,4 ; 30,4 \pm 0,1 ; 34,9 \pm 0,2 ; 39,2 \pm 0,2) \mathrm{mg} / \mathrm{L}$ para la Cbz y $(10,0 \pm 0,7 ; 15,0$ $\pm 0,6 ; 19,8 \pm 0,5 ; 24,6 \pm 0,4 ; 30,0 \pm 0,0 ; 34,9 \pm 0.2 ; 40,2 \pm 0.2) \mathrm{mg} / \mathrm{L}$ para el Sil. Estas 
concentraciones se eligieron con el fin de obtener el equilibrio en el sistema y para poder determinar claramente el tipo de comportamiento que sigue el proceso de adsorción, tal como se determinó en el capítulo 7, para el CAG, y como se ha reportado anteriormente por otros autores (Al-Othman et al., 2012; Baccar et al., 2012; Mestre et al., 2007).

\subsubsection{Isoterma de Langmuir}

En el marco de este modelo, se admite una adsorción en monocapa sobre la superficie, así como también un número finito de sitios energéticamente equivalentes. Esta isoterma está descrita por la Ecuación (8.3)

$$
q_{e}=\frac{q_{m} K_{L} C_{e}}{1+K_{L} C_{e}}
$$

donde $\mathrm{q}_{\mathrm{e}}$ es la cantidad adsorbida por unidad de masa de adsorbente en equilibrio (mg/g), $\mathrm{C}_{\mathrm{e}}$ es la concentración del adsorbato $(\mathrm{mg} / \mathrm{L})$ en el equilibrio, $\mathrm{q}_{\mathrm{m}}$ es la adsorción máxima en la monocapa de carbón activado $(\mathrm{mg} / \mathrm{g})$ y $\mathrm{K}_{\mathrm{L}}$ es la constante de adsorción (L/mg).

La relación adimensional RL también se puede introducir

$$
R L=\frac{1}{1+K_{L} C_{0}}
$$

donde $\mathrm{C}_{0}$ es la concentración inicial del adsorbato $(\mathrm{mg} / \mathrm{L})$ y $\mathrm{K}_{\mathrm{L}}$ tiene el mismo significado que en la Ecuación (8.3). Los valores de RL indican si la isoterma es favorable $(0<R L<1)$, lineal $(R L=1)$, desfavorable $(R L>1)$ o irreversible $(R L=0)$.

En la Figura 8.3 A se muestra el comportamiento de la isoterma de adsorción para Cbz y Sil. En la Tabla 8.1 se enumeran los parámetros que resultan del ajuste de la isoterma de Langmuir para ambos compuestos. El coeficiente de correlación de ajuste fue 0,961 para Cbz y 0,975 para Sil, además se obtuvo un p-valor inferior a 0,003 para un nivel de significancia de 0,05, y se calculó un rango de datos para el RL entre 0,01 - 0,09 para Cbz y 0,01 - 0,05 para Sil, de acuerdo a la Co de 5mg/L y 40 $\mathrm{mg} / \mathrm{L}$, dando algunos indicios sobre la aplicabilidad de la isoterma de Langmuir para estos sistemas.

Los valores de $\mathrm{q}_{\mathrm{m}}$ obtenidos de la isoterma de Langmuir fueron de $242 \pm 11$ mg/g y $395 \pm 64 \mathrm{mg} / \mathrm{g}$ para Cbz y Sil, respectivamente. El valor de $\mathrm{q}_{\mathrm{m}}$ para la Cbz es 
similar a los reportados en la literatura sobre carbón activado en polvo ( $\mathrm{Li}$ et al., 2011), es decir, $287 \mathrm{mg} / \mathrm{g}$ usando la isoterma de Langmuir. Por lo que sabemos, no se han reportado valores de $\mathrm{q}_{\mathrm{m}}$ para el Sil.

\subsubsection{Isoterma de Freundlich}

Esta isoterma, a veces considerada como una expresión empírica aplicable a una adsorción en multicapa con diferente heterogeneidad en la energía de los sitios de adsorción (se admite una dependencia logarítmica entre la entalpía de adsorción y el grado de cobertura de la superficie) se expresa por la Ecuación 8.5

$$
q_{e}=K_{F} C_{e}^{1 / n}
$$

En la Ecuación $(8.5), \mathrm{K}_{\mathrm{F}}(\mathrm{mg} / \mathrm{g})(\mathrm{L} / \mathrm{mg})^{1 / \mathrm{n}}$ se considera como una constante de equilibrio y $\mathrm{n}$ se puede asociar a la afinidad del adsorbente y el adsorbato. Normalmente, $1 / \mathrm{n}<1$. El ajuste de los datos experimentales se muestra en la Figura 8.3 A. En la Tabla 8.1 se puede observar que esta isoterma se ajusta únicamente a los resultados experimentales de la $\mathrm{Cbz}$, con un coeficiente de correlación de 0,985.

\subsubsection{Isoterma combinada de Langmuir -Freundlich}

Se aplicó la Ecuación (8.6) en este análisis.

$$
q_{e}=\frac{q_{m}\left(K_{L F} C_{e}\right)^{n_{L F}}}{1+\left(K_{L F} C_{e}\right)^{n_{L F}}}
$$

Como se ve en la Ecuación (8.6), este es un modelo de tres parámetros, $\mathrm{K}_{\mathrm{LF}}$ es la constante de afinidad expresada en $\mathrm{L} / \mathrm{mg}, \mathrm{n}_{\mathrm{LF}}$ se conoce como un índice de heterogeneidad y $\mathrm{q}_{\mathrm{m}}$ que tiene el mismo significado que en la Ecuación (8.3). Sin embargo, aunque la Ecuación (8.6) contiene algunas características de las isotermas anteriores, no se ajustó a los resultados experimentales que se muestran en la Figura 8.3. Por lo tanto, no será considerado en el presente estudio.

\subsubsection{Modelo de Redlich-Peterson}

Este modelo contiene algunas características de las isotermas de Langmuir y Freundlich. La expresión está dada por la Ecuación (8.7a).

$$
q_{e}=\frac{q_{m}\left(K_{R P} C_{e}\right)}{1+\left(K_{R P} C_{e}\right)^{n} P}
$$


La Ecuación (8.7a) puede reescribirse como se muestra en la Ecuación (8,7b). Un análisis detallado de esta deducción se presenta en el trabajo de (Wu et al., 2010).

$$
\frac{q_{e}}{q_{r e f}}=\left(\frac{C_{e}}{C_{r e f}}\right) \frac{\left(1 / K_{R P} C_{r e f}^{n_{R P}}\right)+1}{\left(1 / K_{R P} C_{r e f}^{n_{R P}}\right)+\left(C_{e} / C_{r e f}\right)^{n_{R P}}}
$$

donde $\mathrm{C}_{\text {ref }}$ es la concentración de equilibrio más alta, $\mathrm{q}_{\mathrm{ref}}$ es la concentración adsorbida en el equilibrio correspondiente en $\mathrm{C}_{\mathrm{ref}}, \mathrm{K}_{\mathrm{RP}}$ (en $\mathrm{L} / \mathrm{mg}$ ) es una constante en la isoterma Redlich-Peterson $\mathrm{y}_{\mathrm{RP}}$ es un exponente similar al modelo de Freundlich (rango de valores de $\mathrm{n}_{\mathrm{RP}}$ en el intervalo $0<\mathrm{n}_{\mathrm{RP}}<1$ ). Una vez que se encuentra el valor de $\mathrm{n}_{\mathrm{RP}}$ (este valor se determinó por reordenamiento de términos de la Ec. $8.7 \mathrm{~b}$ y su respectivo ajuste mediante regresión no lineal utilizando el programa sigma plot, con la ecuación: $\mathrm{f}=(\mathrm{x}(1+\mathrm{c})) /\left(\mathrm{c}+\mathrm{x}^{\mathrm{a}}\right)$, donde $\left.\mathrm{x}=\mathrm{C}_{\mathrm{e}} / \mathrm{C}_{\mathrm{ref}} ; \mathrm{c}=1 / \mathrm{K}_{\mathrm{RP}}{ }^{*} \mathrm{C}_{\mathrm{ref}}{ }^{n R P} ; \mathrm{a}=\mathrm{n}_{\mathrm{RP}}\right)$, la ecuación (8.7b) se puede reordenar a una forma lineal según lo dado por la Ecuación (8.8).

$$
\frac{C_{e}}{q_{e}}=\frac{1}{K_{R P} q_{m}}+\left(\frac{1}{q_{m}}\right) C_{e}^{n_{R P}}
$$

Un análisis de regresión conduce a los valores de $q_{m}$ y $K_{R P}$. Esta expresión se asemeja a la forma lineal de la isoterma de Langmuir cuando $\mathrm{n}_{\mathrm{RP}}=1$, mientras que, si la intersección es cero en el origen, la ecuación 8.8 se reduce a la isoterma de Freundlich. En este último caso, $\mathrm{K}_{\mathrm{RP}}$ debe ser lo suficientemente grande como para reducir el valor de intersección.

Tabla 8.1. Parámetros calculados para los resultados experimentales obtenidos de las isotermas de adsorción de Langmuir, Freundlich, la ecuación combinada Langmuir-

\begin{tabular}{|c|c|c|c|c|c|c|}
\hline & Langmuir & & & Freundlich & & \\
\hline & $\mathrm{q}_{\mathrm{m}}(\mathrm{mg} / \mathrm{g})$ & $\mathrm{k}_{\mathrm{L}}(\mathrm{L} / \mathrm{mg})$ & $\mathrm{R}$ & $\overline{\left.\mathrm{K}_{\mathrm{F}}(\mathrm{mg} / \mathrm{g})(\mathrm{L} / \mathrm{mg})^{1 / \mathrm{n}}\right)}$ & $\mathrm{n}$ & $\mathrm{R}$ \\
\hline $\mathrm{Cbz}$ & $242 \pm 11$ & $2 \pm 1$ & $0,961 \pm 0,006$ & $163 \pm 7$ & $7 \pm 1$ & $0,985 \pm 0,005$ \\
\hline \multirow[t]{3}{*}{ Sil } & $395 \pm 64$ & $3,6 \pm 0,9$ & $0,975 \pm 0,006$ & NA & NA & NA \\
\hline & Langmuir- & \multicolumn{5}{|c|}{ Redlich - Peterson } \\
\hline & Freundlich & $\mathrm{n}_{\mathrm{RP}} *$ & $\mathrm{R}$ para $\mathrm{n}_{\mathrm{RP}} *$ & $\mathrm{q}_{\mathrm{m}}(\mathrm{mg} / \mathrm{g})^{+}$ & $\mathrm{k}_{\mathrm{RP}}(\mathrm{L} / \mathrm{mg})$ & $\mathrm{R}^{+}$ \\
\hline $\mathrm{Cbz}$ & NA & $0,905 \pm 0,009$ & $0,989 \pm 0,005$ & $220 \pm 51$ & $15 \pm 23$ & $0,999 \pm 0,001$ \\
\hline Sil & NA & $1,079 \pm 0,114$ & $0,977 \pm 0,008$ & $428 \pm 105$ & $3 \pm 1$ & $0,999 \pm 0,002$ \\
\hline
\end{tabular}
Freundlich y el modelo de Redlich-Peterson

*Ajuste para la Ecuación (8.7b); ${ }^{+}$Ajuste para la Ecuación (8.8); NA = no ajusta. 

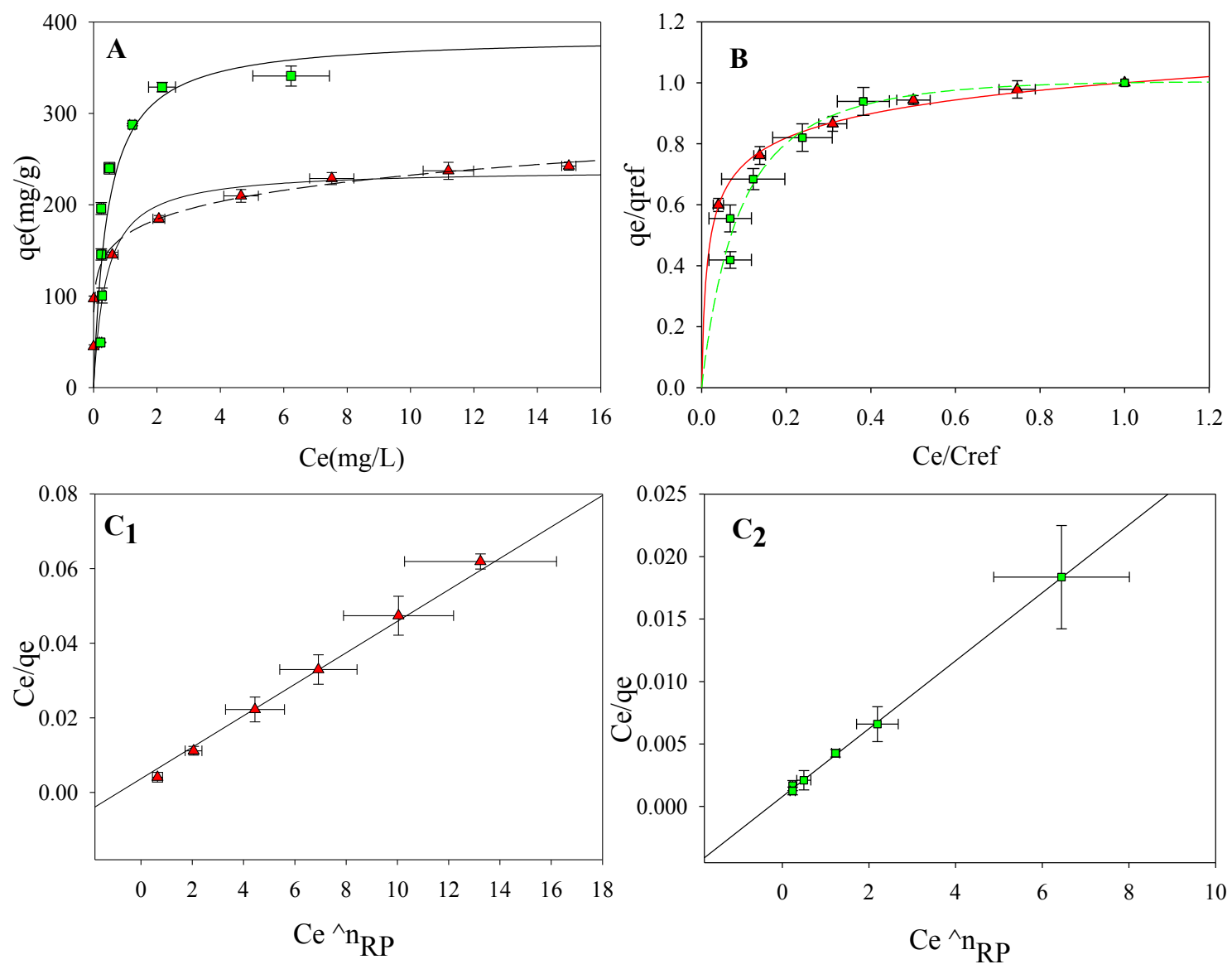

Figura 8.3. Isotermas de adsorción para (A) Cbz ( $\mathbf{\Delta})$ después de 32 horas y Sil ( $\square$ ) después de 34 horas de contacto con el carbón activado en polvo. También se indican las barras de error de las mediciones experimentales. Se muestran los ajustes de Langmuir (-) y Freundlich (---). (B) Regresión no lineal para el modelo R-P según lo expresado en la Ecuación (8.8) para Cbz (-) y Sil (---). El Ajuste de la regresión para la forma lineal de la isoterma de R-P se muestra en (C1) y (C2). En ambos casos, $\mathrm{n}_{\mathrm{RP}}$ se conoce del análisis que se muestra en $(\mathbf{B})$.

A partir de la regresión no lineal para la isoterma R-P, los valores obtenidos para el parámetro $\mathrm{n}_{\mathrm{RP}}$ fueron: 0,905 para Cbz y 1,079 para Sil (ver Tabla 8.1). La diferencia en los valores del exponente para ambos fármacos sugiere una diferencia en la homogeneidad superficial, que puede atribuirse al carácter iónico del Sil en el pH (5,97-6,33) donde se realizó este estudio, y al volumen molecular de la Cbz en comparación con el volumen molecular del Sil. Teniendo en cuenta el Sil presenta un volumen molecular más alto $\left(1303,37 \AA^{3}\right)$ que la Cbz $\left(686,20 \AA^{3}\right)$, y que las moléculas con electrones $\pi$ tienden a adsorberse paralelamente sobre la superficie del grafito 
debido a las fuerzas de dispersión, los $\mathrm{q}_{\mathrm{m}}$ más grandes sugieren que el Sil $\left(\mathrm{q}_{\mathrm{m}}\right.$ : 395 $\mathrm{mg} / \mathrm{g}$ ) se adsorbe perpendicularmente a la superficie, mientras que la Cbz ( $\mathrm{q}_{\mathrm{m}}: 242$ $\mathrm{mg} / \mathrm{g}$ ) se adsorbe paralelamente a la misma superficie (Cai and Larese-Casanova, 2014; Xu et al., 2012).

Se puede observar que la forma lineal de la isoterma R-P se ajusta muy bien a los resultados experimentales, con coeficientes de regresión superiores a 0,99 para ambos fármacos (ver Figura $8.3 \mathrm{C} 1 \mathrm{y} \mathrm{C}$ ). Tan pronto como ambos compuestos presentan un $\mathrm{n}_{\mathrm{RP}} \approx 1$, la isoterma R-P apoya la idea de que la isoterma de Langmuir es una buena aproximación para describir el equilibrio de adsorción de la Cbz y el Sil sobre el carbón activo en polvo, resultados similares se reportaron en la literatura (Li et al., 2011).

\subsubsection{Cinética de adsorción}

La velocidad de adsorción es uno de los criterios para definir la eficiencia del adsorbente.

La evolución temporal del compuesto adsorbido $\mathrm{q}_{\mathrm{t}}$ en diferentes concentraciones iniciales se analizó utilizando el modelo de seudo primer orden, el de seudo segundo orden y la ecuación de velocidad no lineal descrita anteriormente en la Ecuación 7.9, del Capítulo 7 (Delgado et al., 2016). También se aplicó el modelo de difusión intrapartícula para interpretar el posible mecanismo de adsorción.

\subsubsection{Modelo de seudo primer orden}

La Ecuación (8.9) describe la evolución temporal del compuesto adsorbido $\mathrm{q}_{\mathrm{t}}$ en $\mathrm{mg} / \mathrm{g}$

$$
q_{t}=q_{e}\left(1-e^{-k_{1} t}\right)
$$

donde $\mathrm{k}_{1}$ es la constante de velocidad aparente y $\mathrm{q}_{\mathrm{e}}(\mathrm{mg} / \mathrm{g})$ es la concentración de equilibrio. Las mediciones se realizan en un intervalo de tiempo de varias horas y $\mathrm{k}_{1}$ se expresa en $1 / \mathrm{h}$.

Se aplicó una regresión no lineal para calcular $\mathrm{q}_{\mathrm{e}} \mathrm{y} \mathrm{k}_{1}$ para diferentes concentraciones iniciales de los productos farmacéuticos estudiados. Los coeficientes de regresión fueron superiores a 0,99 con un p-valor menor que 0,0001. Los resultados 
se enumeran en las Tablas 8.2 y 8.3, y el comportamiento experimental se muestra en los gráficos de la Figura 8.4 .
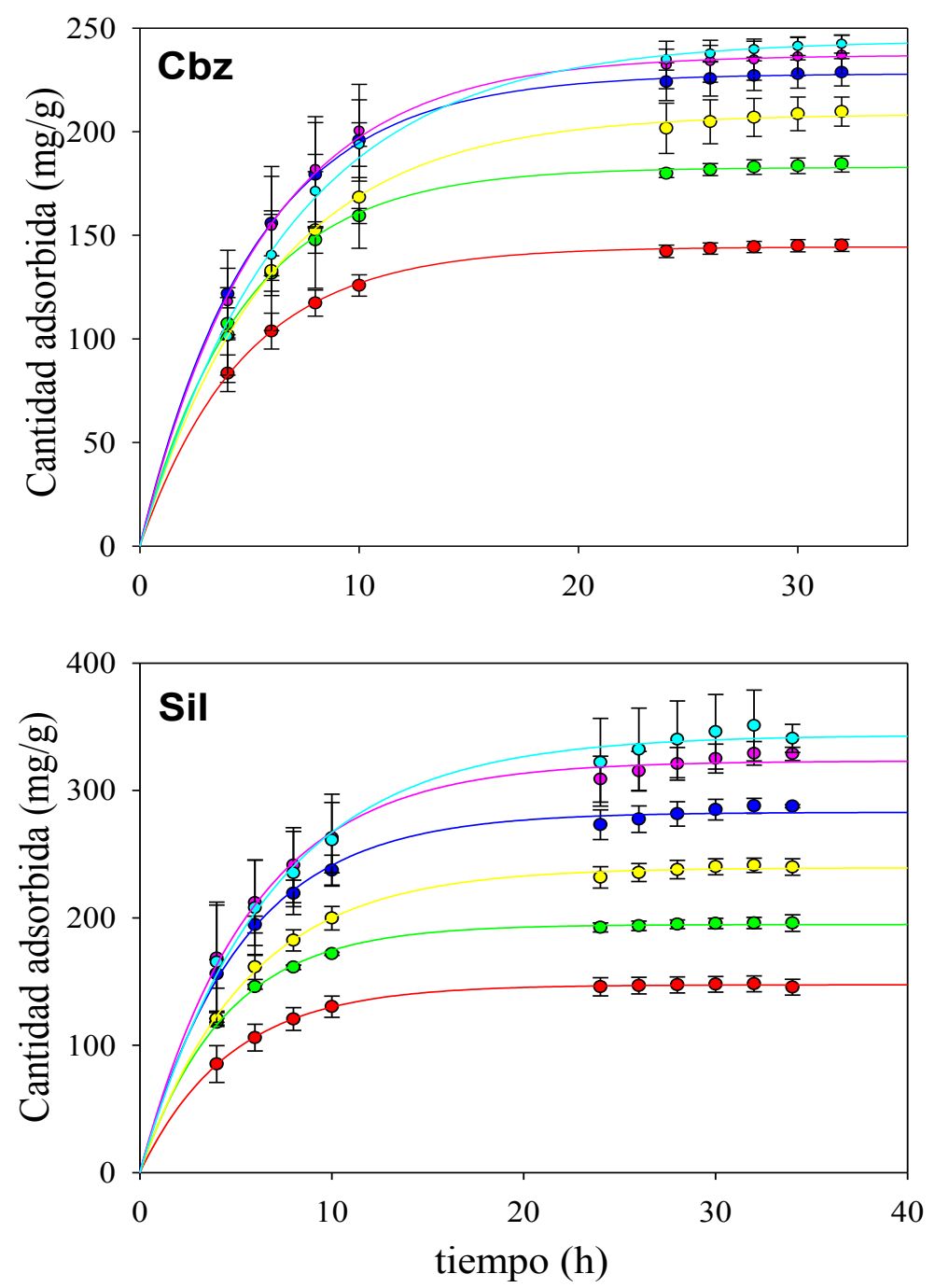

Figura 8.4. Análisis de la cinética de adsorción de seudo primer orden para carbamazepina (Cbz) y sildenafil (Sil) sobre carbón activado en polvo. Las concentraciones iniciales en $\mathrm{mg} / \mathrm{L}$ fueron: $15(\bullet), 20(\bullet), 25(\bullet), 30(\bullet), 35$ $(\bullet)$ y $40(\bullet)$. Las líneas corresponden al modelo de seudo primer orden calculado mediante un análisis de regresión no lineal. 


\subsubsection{Modelo de seudo segundo orden}

Los resultados experimentales se analizaron mediante la expresión dada en la Ecuación (8.10)

$$
\frac{t}{q_{t}}=\frac{1}{k_{2} q e^{2}}+\frac{1}{q e} t
$$

Las unidades de la constante de velocidad aparente $\mathrm{k}_{2}$ se dan en (g/mg.h). Los resultados obtenidos usando esta ecuación también se presentan en las Tablas 8.2 y 8.3 .

Aunque los coeficientes de correlación del ajuste están muy cercanos a la unidad, los valores de los $\mathrm{q}_{\mathrm{e}}$ teóricos y los obtenidos experimentalmente presentan diferencias estadísticamente significativas entre ellos, con un p-valor de 0,002, indicando que este ajuste no es el más apropiado para los resultados obtenidos.

\subsubsection{Análisis de velocidad no lineal}

Se puede deducir una expresión general que combina una cinética de primer y segundo orden, de la cual se obtiene una ecuación no lineal, y se puede aplicar un análisis de regresión como se analizó en el Capítulo 7. Esta expresión está dada por la Ecuación (8.11)

$$
q_{t}=\frac{q_{e} e^{\tau}\left(1-e^{\lambda t}\right)}{\left(1-e^{\tau} e^{\lambda t}\right)}
$$

En la ecuación anterior, $\lambda$ coincide con la constante de velocidad de seudo primer orden $\mathrm{k}_{1}$ si el parámetro $\mathrm{e}^{\tau}>1$. Todos los valores obtenidos para $\mathrm{e}^{\tau}$ en el presente estudio alcanzaron valores superiores a $10^{6}$. Los resultados se presentan en las Tablas 8.2 y 8.3 para Cbz y Sil. 
Tabla 8.2. Parámetros cinéticos obtenidos de la Ecuación (8.9), (8.10) y (8.11) para la carbamazepina

\begin{tabular}{|c|c|c|c|c|c|c|c|c|c|c|}
\hline \multirow{2}{*}{$\begin{array}{c}\mathrm{C}_{0} \\
(\mathrm{mg} / \mathrm{L})\end{array}$} & \multicolumn{4}{|c|}{ Cinética de seudo primer orden Ec. (8.9) } & \multicolumn{3}{|c|}{ Cinética de seudo segundo orden Ec. (8.10) } & \multicolumn{3}{|c|}{ Análisis de velocidad no lineal Ec. (8.11) } \\
\hline & $\begin{array}{l}q_{\mathrm{e}} \exp \\
(\mathrm{mg} / \mathrm{g})\end{array}$ & $\mathrm{q}_{\mathrm{e}}(\mathrm{mg} / \mathrm{g})$ & $\mathrm{k}_{1}(1 / \mathrm{h})$ & $\mathrm{R}$ & $\mathrm{q}_{\mathrm{e}}(\mathrm{mg} / \mathrm{g})$ & $\mathrm{k}_{2}(\mathrm{~g} / \mathrm{mgh})$ & $\mathrm{R}$ & $\mathrm{q}_{\mathrm{e}}(\mathrm{mg} / \mathrm{g})$ & $\lambda$ & $\mathrm{R}$ \\
\hline 15 & $145 \pm 3$ & $144 \pm 3$ & $0,21 \pm 0,03$ & $0,998 \pm 0,001$ & $161 \pm 4$ & $0,0020 \pm 0,0005$ & $1,000 \pm 0,000$ & $144 \pm 2$ & $0,21 \pm 0,03$ & $0,998 \pm 0,002$ \\
\hline 20 & $184 \pm 4$ & $183 \pm 4$ & $0,21 \pm 0,04$ & $0,998 \pm 0,002$ & $204 \pm 10$ & $0,0016 \pm 0,0006$ & $1,000 \pm 0,000$ & $183 \pm 3$ & $0,21 \pm 0,02$ & $0,988 \pm 0,009$ \\
\hline 25 & $210 \pm 7$ & $210 \pm 5$ & $0,17 \pm 0,05$ & $0,997 \pm 0,002$ & $247 \pm 13$ & $0,0010 \pm 0,0005$ & $0,999 \pm 0,001$ & $211 \pm 5$ & $0,16 \pm 0,04$ & $0,986 \pm 0,013$ \\
\hline 30 & $229 \pm 7$ & $229 \pm 7$ & $0,20 \pm 0,05$ & $0,999 \pm 0,001$ & $260 \pm 13$ & $0,0011 \pm 0,0006$ & $0,999 \pm 0,000$ & $230 \pm 8$ & $0,18 \pm 0,04$ & $0,980 \pm 0,024$ \\
\hline 35 & $237 \pm 9$ & $238 \pm 9$ & $0,18 \pm 0,04$ & $0,997 \pm 0,004$ & $273 \pm 11$ & $0,0009 \pm 0,0004$ & $0,999 \pm 0,000$ & $238 \pm 10$ & $0,17 \pm 0,03$ & $0,989 \pm 0,013$ \\
\hline 40 & $242 \pm 4$ & $245 \pm 3$ & $0,15 \pm 0,03$ & $0,997 \pm 0,003$ & $297 \pm 18$ & $0,0006 \pm 0,0002$ & $0,997 \pm 0,003$ & $243 \pm 5$ & $0,15 \pm 0,01$ & $0,988 \pm 0,015$ \\
\hline
\end{tabular}

Tabla 8.3. Parámetros cinéticos obtenidos de la Ecuación (8.9), (8.10) y (8.11) para el sildenafil.

\begin{tabular}{|c|c|c|c|c|c|c|c|c|c|c|}
\hline \multirow{2}{*}{$\begin{array}{l}\mathrm{C}_{0} \\
(\mathrm{mg} / \mathrm{L})\end{array}$} & \multicolumn{4}{|c|}{ Cinética de seudo primer orden Ec. (8.9) } & \multicolumn{3}{|c|}{ Cinética de seudo segundo orden Ec. (8.10) } & \multicolumn{3}{|c|}{ Análisis de velocidad no lineal Ec. (8.11) } \\
\hline & $\begin{array}{l}\mathrm{q}_{\mathrm{e}} \exp \\
(\mathrm{mg} / \mathrm{g})\end{array}$ & $\mathrm{q}_{\mathrm{e}}(\mathrm{mg} / \mathrm{g})$ & $\mathrm{k}_{1}(1 / \mathrm{h})$ & $\mathrm{R}$ & $\mathrm{q}_{\mathrm{e}}(\mathrm{mg} / \mathrm{g})$ & $\mathrm{k}_{2}(\mathrm{~g} / \mathrm{mgh})$ & $\mathrm{R}$ & $\mathrm{q}_{\mathrm{e}}(\mathrm{mg} / \mathrm{g})$ & $\lambda$ & $\mathrm{R}$ \\
\hline 15 & $146 \pm 6$ & $145 \pm 5$ & $0,19 \pm 0,00$ & $0,996 \pm 0,002$ & $163 \pm 7$ & $0,0017 \pm 0,0001$ & $0,9999 \pm 0,0008$ & $148 \pm 6$ & $0,193 \pm 0,005$ & $0,996 \pm 0,002$ \\
\hline 20 & $196 \pm 6$ & $194 \pm 5$ & $0,23 \pm 0,01$ & $0,997 \pm 0,002$ & $213 \pm 8$ & $0,0017 \pm 0,0002$ & $1,0000 \pm 0,0002$ & $196 \pm 4$ & $0,222 \pm 0,009$ & $0,986 \pm 0,010$ \\
\hline 25 & $240 \pm 6$ & $237 \pm 6$ & $0,19 \pm 0,01$ & $0,996 \pm 0,001$ & $269 \pm 3$ & $0,0009 \pm 0,0001$ & $1,0000 \pm 0,0002$ & $241 \pm 8$ & $0,178 \pm 0,004$ & $0,986 \pm 0,016$ \\
\hline 30 & $288 \pm 1$ & $279 \pm 1$ & $0,19 \pm 0,00$ & $0,992 \pm 0,000$ & $319 \pm 1$ & $0,0007 \pm 0,0000$ & $0,9999 \pm 0,0003$ & $284 \pm 8$ & $0,183 \pm 0,002$ & $0,992 \pm 0,000$ \\
\hline 35 & $329 \pm 5$ & $321 \pm 5$ & $0,16 \pm 0,01$ & $0,995 \pm 0,000$ & $383 \pm 3$ & $0,0004 \pm 0,0000$ & $0,9999 \pm 0,0002$ & $325 \pm 7$ & $0,147 \pm 0,007$ & $0,993 \pm 0,001$ \\
\hline 40 & $341 \pm 11$ & $334 \pm 14$ & $0,14 \pm 0,03$ & $0,992 \pm 0,000$ & $412 \pm 39$ & $0,0003 \pm 0,0002$ & $0,9999 \pm 0,0016$ & $347 \pm 24$ & $0,132 \pm 0,028$ & $0,990 \pm 0,001$ \\
\hline
\end{tabular}


Los resultados obtenidos soportan la cinética de seudo primer orden para describir los datos experimentales (ver Figura 8.4).

Se pudo determinar que a igualdad de concentración inicial para Cbz y Sil sobre la misma masa de adsorbente e iguales condiciones de trabajo, la velocidad de adsorción usando carbón activado en polvo es de aproximadamente 15 veces mayor que la del carbón activado granular, con valores de las constantes cinéticas entre 0.14 $1 / \mathrm{h}$ y $0,231 / \mathrm{h}$ para carbón activado en polvo y entre $0,0031 / \mathrm{h}$ y $0,0101 / \mathrm{h}$ sobre carbón activado granular, respectivamente (ver Capítulo 7). Además, el tiempo medio experimental de adsorción para ambos compuestos, con concentraciones iniciales de $10 \mathrm{mg} / \mathrm{L}$, fue de aproximadamente $4 \mathrm{~h}$ en carbón en polvo, mientras que fue superior a 80 h utilizando el carbón granular (ver Figura 8.2). Asimismo, la capacidad de adsorción fue mayor para el carbón activado en polvo, con valores de $240 \mathrm{mg} / \mathrm{g}$ para la Cbz y 395 mg/g para el Sil, mientras que con el carbón granular fueron de $174 \mathrm{mg} / \mathrm{g}$ y $114 \mathrm{mg} / \mathrm{g}$, respectivamente, evaluados con la isoterma de Langmuir. Por lo tanto, utilizar este material puede resultar de gran interés en el diseño de sistemas de adsorción a escala real, capaces de remover Cbz y Sil de forma eficiente.

\subsubsection{Modelo de difusión intrapartícula}

Este modelo puede ayudar a evaluar el mecanismo de adsorción. Se predice una dependencia de $\mathrm{t}^{1 / 2}$ para la adsorción y el tiempo de contacto. Esta relación está dada por la Ecuación (8.12)

$$
q_{t}=k_{p} t^{1 / 2}
$$

Siendo $\mathrm{k}_{\mathrm{p}}$ la constante de velocidad de difusión intrapartícula $\left(\mathrm{mg} / \mathrm{g} \mathrm{h}^{1 / 2}\right)$. Para el mecanismo de adsorción, en la literatura se reconocen tres etapas (Sarkar et al., 2003): (a) transporte del adsorbato a la película límite de la superficie externa del adsorbente (difusión de película); (b) transferencia del compuesto de la superficie a los sitios activos (difusión de partículas); (c) adsorción del sustrato por los sitios activos del adsorbente.

Si el modelo de difusión intrapartícula es válido, los pasos a, b y c no se pueden diferenciar y se debe observar un comportamiento lineal con una intercepción nula, de lo contrario podrían verse al menos dos o las tres etapas con diferentes 
pendientes. En la Figura 8.5 se muestra el comportamiento para la Cbz y el Sil, con concentraciones iniciales de $20 \mathrm{mg} / \mathrm{L}$ y $40 \mathrm{mg} / \mathrm{L}$; se puede observar que los compuestos estudiados parten del modelo de difusión intrapartícula, es decir, dos fases lineales están implicadas en el proceso. Este comportamiento sugiere que, la adsorción externa ocurre pero no se observa en los sistemas evaluados. Luego, el segundo paso indica que el control de la difusión intrapartícula corresponde a la última etapa del paso de equilibrio. En todo el proceso, el adsorbato se mueve lentamente desde los poros más grandes a los microporos disminuyendo la velocidad de adsorción según lo descrito en la literatura (Wu et al., 2009). Por lo tanto, este mecanismo no juega un papel relevante para describir la adsorción de los compuestos, pero no excluye la contribución de la transferencia de masa al proceso de adsorción.

Aunque existen varios trabajos en los que se analiza el modelo de difusión intrapartícula, principalmente para remoción de colorantes en soluciones acuosas (Aljeboree et al., 2017; Cheung et al., 2007; Ho and McKay, 1998; Wu et al., 2001), son pocos los trabajos en los que se estudia este comportamiento para adsorción de fármacos sobre carbón activado en polvo. Resultados similares a los mostrados en la Figura 8.5 se reportaron en la literatura para metronidasol, carbamazepina, sulfametoxazol y diclofenaco (Çalışkan and Göktürk, 2010; Suriyanon et al., 2013; Torrellas et al., 2015b). Los autores plantean que la principal etapa de adsorción se atribuye al proceso de difusión sobre la película superficial y en menor medida a la difusión intrapartícula.
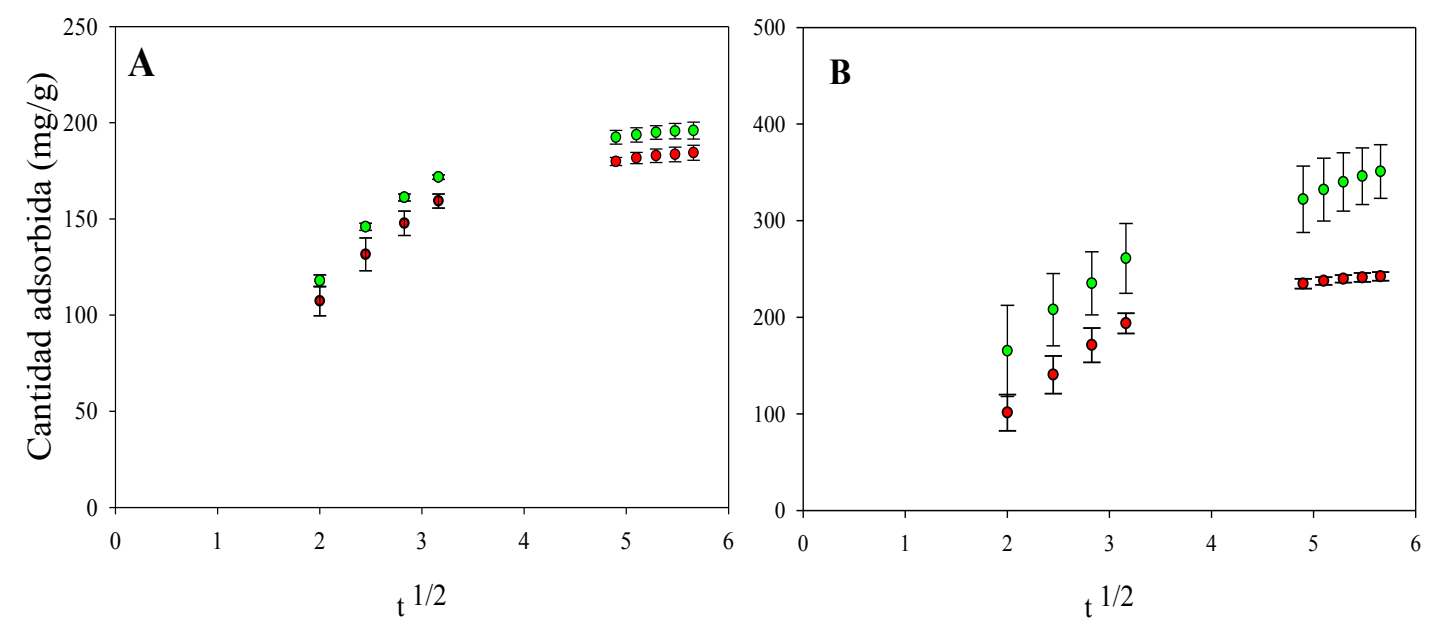

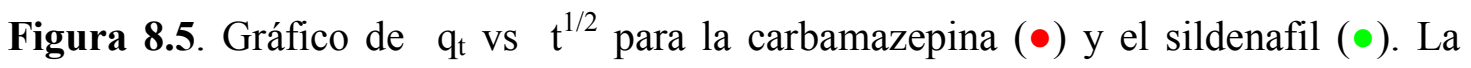
concentración inicial fue de (A) $20 \mathrm{mg} / \mathrm{L}$ y (B) $40 \mathrm{mg} / \mathrm{L}$. Se observó un comportamiento similar para las otras concentraciones iniciales. 


\subsubsection{Efecto de la matriz acuosa}

Varios estudios evaluaron el comportamiento de adsorción de los contaminantes emergentes en condiciones experimentales, la cuales difieren a aquellas que se presentan en un ambiente natural, con matrices complejas y concentraciones bajas de los compuestos (Chang et al., 2015; Mestre et al., 2007; Putra et al., 2009).

En este trabajo se presentan algunos resultados que comparan las mediciones con diferentes fuentes de agua, empleadas para la preparación de las soluciones, con concentraciones ambientalmente relevantes. Los efectos observados fueron los siguientes:

Los valoresd de las concentraciones iniciales reales para los estudios evaluados fueron $(4,5 \pm 0,2 ; 0,13 \pm 0,01) \mathrm{mg} / \mathrm{L}$ para la Cbz y $(5,1 \pm 0,1 ; 0,21 \pm 0,05) \mathrm{mg} / \mathrm{L}$ para el Sil.

\subsubsection{Efectos de la concentración}

La cinética de adsorción de la $\mathrm{Cbz}$ y el Sil se estudió con cada fármaco individual, asi como una mezcla de ambos en agua destilada. Las concentraciones iniciales de cada compuesto fueron de $\approx 0,2 \mathrm{mg} / \mathrm{L}$, similares a las encontradas en ambientes naturales para compuestos farmacéuticos (Kasprzyk-Hordern et al., 2009; Miège et al., 2009; Yang et al., 2011), y de $\approx 5 \mathrm{mg} / \mathrm{L}$, como las evaluadas en la literatura (Baccar et al., 2012). Las condiciones de estudio fueron similares a las trabajadas en los experimentos de equilibrio de adsorción.

Para la mezcla Cbz-Sil (Figura $6 \mathrm{~A}_{1}$ ) se detectó que a una concentración inicial de $5 \mathrm{mg} / \mathrm{L}$, la adsorción de la Cbz fue más lenta que la cinética de adsorción del Sil (Figura $6 \mathrm{~A}_{2}$ ) principalmente en un intervalo de tiempo de 10 horas. No se encontraron diferencias significativas a concentraciones de $0,2 \mathrm{mg} / \mathrm{L}$ para ambos sustratos, ya sea de forma individual o en su mezcla, como se puede ver en la Figura 8.6 (A1 y A2). 


\subsubsection{Agua residual}

En este conjunto de mediciones, para la preparación de las soluciones de Cbz y Sil, se emplearon aguas residuales obtenidas de un tratamiento secundario que utiliza un contactor biológico rotativo a escala piloto, disponible en nuestro laboratorio ( ver Capitulo 5). Los parámetros fisicoquímicos de estas aguas residuales fueron: $\mathrm{pH}$ (7,37,5), oxígeno disuelto $(4,7-5,3 \mathrm{mg} / \mathrm{L})$, temperatura $\left(19,2-21,5{ }^{\circ} \mathrm{C}\right)$, conductividad (0,96-1,03 mS/cm) y carga orgánica (18-27 mg/L). La concentración de los fármacos fueron de 0,2 mg/L para Cbz y Sil, evaluados de forma indiviadual y en su mezcla.

No se observaron diferencias significativas en los perfiles de concentración para ninguno de los experimentos realizados. Se alcanzaron eficiencias de eliminación superiores al $90 \%$ en una escala de tiempo inferior a 10 horas. Estos resultados se muestran en la Figura 8.6 (B1 y B2).

\subsubsection{Perfiles de concentración en el tiempo con diferentes fuentes de agua}

Se prepararon soluciones de aproximadamente $0,2 \mathrm{mg} / \mathrm{L}$ de $\mathrm{Cbz}$ y $\mathrm{Sil}$ en su mezcla. Los perfiles de la cinética de adsorción, obtenidos a partir de las determinaciones por HPLC-MS, se muestran en la Figura 8.6 (C1 y C2). Las soluciones se prepararon con agua desclorinada, agua residual obtenida como se describió previamente y agua destilada. Las mediciones se realizaron por triplicado. Los parámetros fisiciquímicos del agua declorinada fueron: $\mathrm{pH}(7,9-8,2)$, oxigeno disuelto $(6,4-7,3 \mathrm{mg} / \mathrm{L})$, temperatura $\left(21,7-24,1^{\circ} \mathrm{C}\right)$, conductividad $(1,12-1,25$ $\mathrm{mS} / \mathrm{cm}$ ) y la carga orgánica medida como DQO fue $<15 \mathrm{mg} / \mathrm{L}$.

Como se puede ver en la Figura $8.6 \mathrm{C}_{1}$ y $\mathrm{C}_{2}$, las concentraciones de los compuestos medidos en agua cuyo $\mathrm{pH}$ es aproximadamente 6, son similares a las determinadas en agua declorinada, la cual presentaba un $\mathrm{pH}$ promedio de 8 . Por lo tanto, dentro del error experimental de la técnica, no se detrminaron diferencias significativas ( $\mathrm{p}$ valor $>0,05$ ) en los experimentos de adsorción utilizando diferentes soluciones acuosas. Después de 6 horas, se obtuvo una eficacia de eliminación superior al $80 \%$. Aunque en la literatura se ha informado que debería existir interferencia en la adsorción de los fármacos debido a la presencia de materia orgánica (Real et al., 2017; Torrellas et al., 2015b; Yu et al., 2008), estas suposiciones de hicieron basándose sobre un solo ensayo, en lugar de un triplicado, como se evaluó en 
el presente estudio. Yu et al (2008) estudiaron la adsorción de Cbz sobre carbón activado granular (área superficial $=1030 \mathrm{~m}^{2} / \mathrm{g}$ ), en contacto con un agua residual de sedimentación (DQO 3,3 - 5,4 mg/L), observando un efecto negativo de la materia orgánica sobre la adsorción. De igual modo, Torellas et al. (2015) reportaron que hay un efecto competitivo en la adsorción del ibuprofeno con la materia orgánica (DQO = $34 \mathrm{mg} / \mathrm{L}$ ) presente en el agua residual empleada en su estudio, usando $\mu \mathrm{GAC}$ como adsorbente (área superficial $1102 \mathrm{~m}^{2} / \mathrm{g} \mathrm{y} \mathrm{V}_{\text {microporos }} 0,26 \mathrm{~cm}^{3} / \mathrm{g}$ ). Real at al. (2017) reportaron el mismo comportamiento para tres contaminantes emergentes sobre carbón activado en polvo (área superficial $=990 \mathrm{~m}^{2} / \mathrm{g} \mathrm{y} \mathrm{V}_{\text {microporos }} 0,41 \mathrm{~cm}^{3} / \mathrm{g}$ ), presentes en un agua residual con una carga orgánica similar a la del presente trabajo. No se encontraron referencias que reporten el comportamiento para el Sil. 
Capítulo 8. Carbón activado en polvo para remoción de compuestos farmacéuticos: experimentos en batch
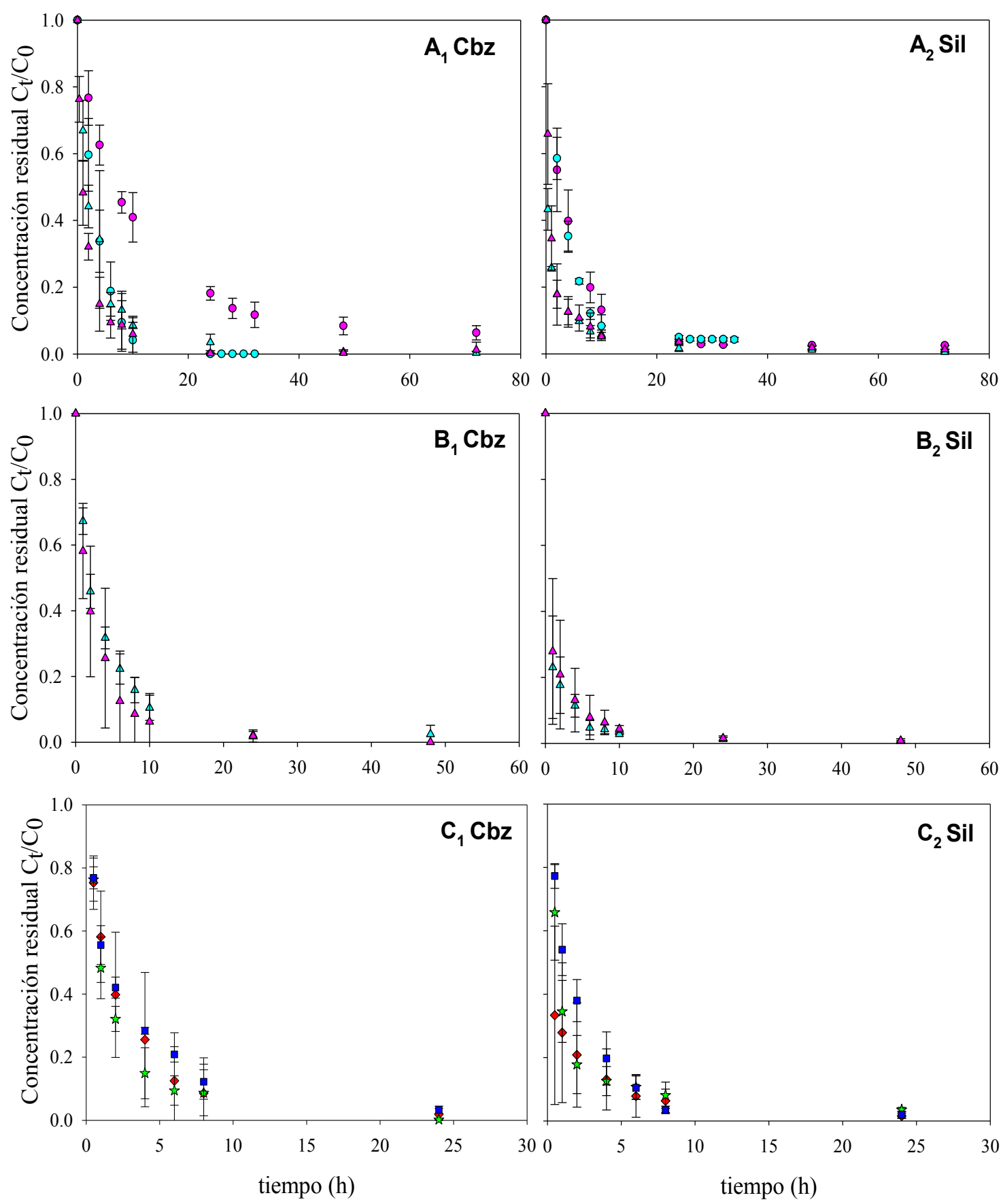

Figura 6. Cinética de adsorción de Cbz y Sil. $\left(\mathbf{A}_{1}\right)$ y $\left(\mathbf{A}_{2}\right)$ perfiles de concentración-tiempo de Cbz y Sil, respectivamente, evaluados de forma individual (símbolos celestes) y mezcla de Cbz-Sil (símbolos rosas). Las soluciones se prepararon con agua destilada. Los gráficos $\mathbf{B}_{1} \mathrm{y}$ $\mathbf{B}_{2}$ presentan resultados similares a A1 y A2, pero la solución se preparó con un efluente proveniente de un sistema de biodiscos. Las concentraciones iniciales fueron $5 \mathrm{mg} / \mathrm{L}(\bullet, \bullet) \mathrm{y}$ $0.2 \mathrm{mg} / \mathrm{L}(\Delta, \mathbf{\Delta})$. Los gráficos $\mathbf{C}_{1}$ y $\mathbf{C}_{2}$ muestran el perfil de concentración-tiempo en el proceso de adsorción que involucra la mezcla de Cbz y Sil en concentraciones iniciales de 0,2 $\mathrm{mg} / \mathrm{L}$ en $(\boldsymbol{\bullet})$ agua declorinada, $(\star)$ agua destilada y $(\diamond)$ agua residual de un RBC, sobre carbón activado en polvo. 


\subsection{Conclusiones parciales}

Los resultados experimentales obtenidos en este estudio mostraron la capacidad de adsorción que tiene el carbón activado en polvo para remover Cbz y Sil de las soluciones acuosas. También se analizaron las diferencias con el carbón activado granular y su comportamiento en diferentes matrices acuosas. Se aplicaron modelos de isotermas de adsorción de dos y tres parámetros para el análisis de los resultados experimentales, así como también los modelos de seudo primer orden, seudo segundo orden, una ecuación de velocidad no lineal y el modelo de difusión intrapartícula. El modelo que mejor se ajustó a los datos obtenidos fue el de seudo primer orden, con constantes de velocidad de $0,141 / \mathrm{h}$ y $0,231 / \mathrm{h}$, para la Cbz y el Sil, respectivamente.

La isoterma de Langmuir y el modelo de seudo primer orden parecen ser el mejor enfoque para evaluar la eficiencia de remoción de Cbz y Sil de la fase acuosa. Aunque, la isoterma de Redlich-Peterson describió el comportamiento de los datos experimentales de la $\mathrm{Cbz}$, sugiriendo un mecanismo híbrido entre las isotermas de Langmuir y Freundlich. Los valores de $\mathrm{q}_{\mathrm{m}}$ fueron de $220 \mathrm{mg} / \mathrm{g}$ y $395 \mathrm{mg} / \mathrm{g}$ para la Cbz y el Sil, respectivamente.

Los experimentos mostraron que el carbón activo en polvo presenta ventajas en comparación con la forma granular. De hecho, el carbón activo en polvo presenta una mayor capacidad y velocidad de adsorción. Los experimentos realizados con Cbz y Sil (individual o su mezcla) disueltos en agua residual proveniente de un tratamiento secundario no mostraron diferencias significativas en comparación con los resultados que emplean agua declorinada o agua destilada, aunque se observó una gran dispersión en los resultados obtenidos.

Finalmente, el carbón activo en polvo surge como una tecnología prometedora para la eliminación de estos compuestos farmacéuticos presentes en los cuerpos de agua. 


\section{CAPÍTULO 9}

\section{REMOCIÓN DE COMPUESTOS FARMACÉUTICOS EN COLUMNAS CON CARBÓN ACTIVADO EN POLVO}

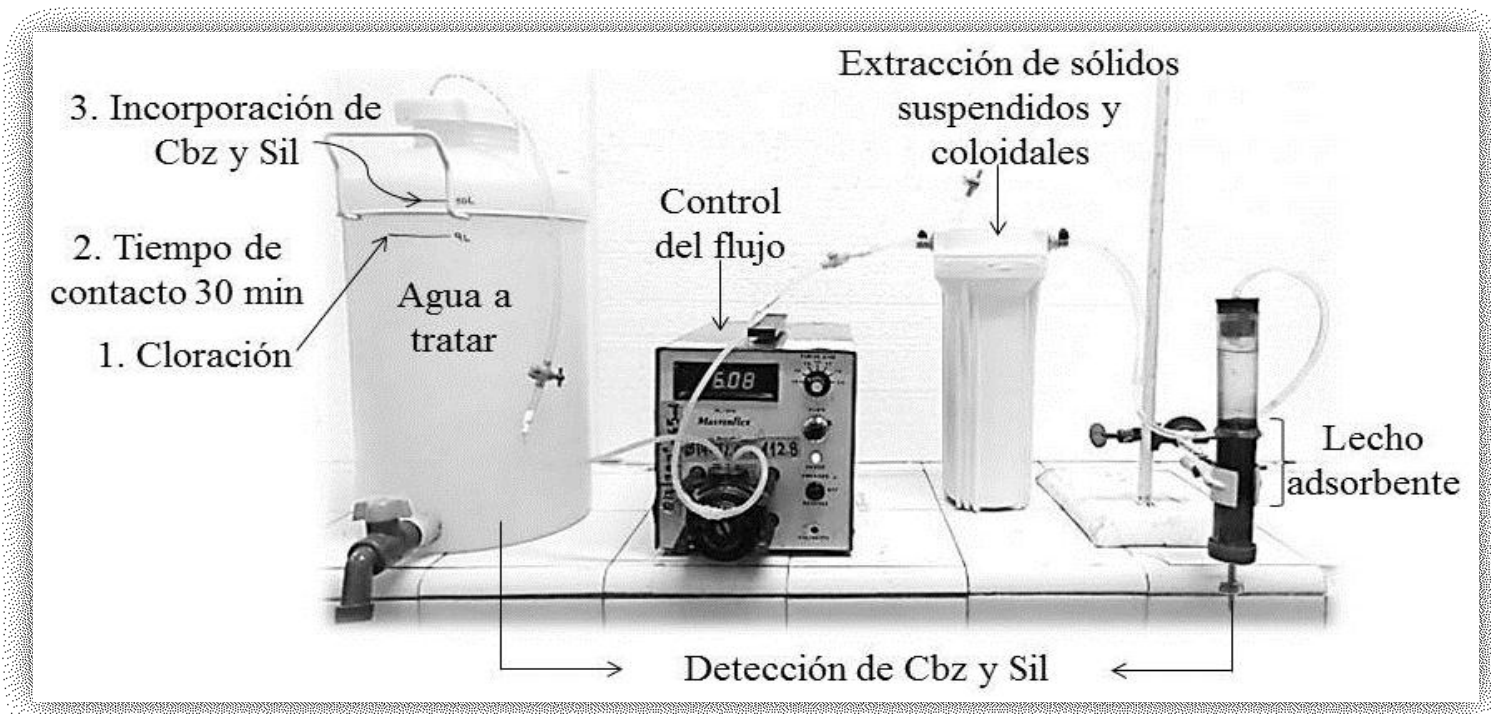




\section{Resumen}

Los contaminantes emergentes (CE) están generando preocupación entre la población, ya que pueden causar efectos adversos en la biota acuática, como en la salud humana. Consecuentemente la nueva información existente sobre CE y su potencial impacto en los ecosistemas está impulsando medidas en los de control y regulación de la calidad de las aguas residuales que se vierten en los cursos naturales después de los tratamientos adaptados con este fin. En las últimas décadas se han venido desarrollando diferentes metodologías para remover este tipo de contaminantes de las aguas residuales, como del agua potable. Por lo tanto, el objetivo principal de esta investigación fue desarrollar una tecnología que resultara eficiente para remover dos contaminantes modelos, carbamazepina (Cbz) y sildenafil (Sil), presentes en los cuerpos de agua de Argentina y Colombia. Se diseñó una columna de adsorción con carbón activado en polvo (CAP) en lecho fijo, en la cual se mezcló arena con CAP, en relación 1:50, para generar porosidad al material adsorbente. Este diseño se evaluó inicialmente a escala de laboratorio, para determinar su operatividad y el comportamiento de los compuestos, observando que el Sil se removía eficientemente, mientras que la Cbz alcanzó la saturación luego de 25 d de operación en continuo, definiendo este compuesto como el limitante para el diseño de la columna. Luego se llevó a escala piloto, en el que se alcanzaron eficiencias de remoción superiores al 90 \% para ambos fármacos, durante 3 meses de operación en continuo. Se concluye que mediante el empleo de esta tecnología se puede reducir la magnitud de los efectos adversos que producen estos contaminantes sobre los recursos hídricos, la biota acuática y la salud humana. Además, este es el primer trabajo en el que se ha logrado operar una columna con CAP en lecho fijo, sin necesidad de incorporar procedimientos adicionales para separar el CAP del agua tratada. 


\subsection{Introducción}

Muchos contaminantes emergentes son detectados frecuentemente en los cuerpos de agua debido a que no se eliminan eficientemente de las plantas de tratamiento de aguas residuales convencionales (PTAR), afectando los recursos hídricos (Geissen et al., 2015). Con el fin de proteger el ambiente acuático y las fuentes de agua potable, actualmente se están llevando a cabo investigaciones a nivel científico y tecnológico para optimizar la eliminación de los contaminantes recalcitrantes en las PTAR (Katsigiannis et al., 2015; Streicher et al., 2016). Entre algunas de las tecnologías estudiadas se encuentran: la filtración por membranas, los procesos de oxidación avanzada con ozono y la adsorción con carbón activado (Altmann et al., 2014; Altmann et al., 2015). Los procesos de adsorción resultan de gran interés ya que se reportan como una técnica poderosa para el tratamiento de contaminantes orgánicos (Aksu et al., 2002).

En numerosas aplicaciones se ha probado el carbón activado granular (CAG) como un proceso avanzado en el tratamiento de aguas residuales. (Karunarathne and Amarasinghe, 2013; Mailler et al., 2016a; Sotelo et al., 2013). Entre las ventajas del CAG se incluyen su aplicación simple y la posibilidad de su regeneración/reutilización. Debido a su tamaño de partícula más pequeño, el carbón activado en polvo (CAP) es más eficiente que el CAG (Delgado et al., 2016; Kim et al., 2010), convirtiéndose en una opción prometedora para reducir el vertimiento de contaminantes recalcitrantes sobre las aguas superficiales. Sin embargo, debido a que es un material difícil de manipular, no es muy utilizado en las PTAR a escala real, y la mayoría de los estudios reportados lo utilizan en sistemas en batch (Altmann et al., 2014). Así por ejemplo, se ha aplicado el CAP mediante adiciones sucesivas en etapas independientes de adsorción en batch, seguida de sedimentación / filtración, y como alternativa menos costosa se ha propuesto adicionarlo en la etapa biológica, pero su capacidad de adsorción se ha visto afectada por la materia orgánica y el desarrollo del biofilm (Streicher et al., 2016), contrarrestando este inconveniente con grandes demandas de CAP (Kovalova et al., 2013; Mailler et al., 2015). Adicionalmente se ha estudiado como alternativa la dosificación directa de CAP en el afluente de un filtro de lecho profundo, de flujo ascendente, con el fin reducir espacio y material adsorbente, adicionando coagulantes y floculantes para evitar la pérdida del CAP con el agua 
tratada (Mailler et al., 2016b; Meinel et al., 2016; Munz et al., 2007). Sin embargo distintos autores concluyen que aunque los procesos con carbón CAP son considerados técnicas efectivas para remover contaminantes orgánicos traza, pueden resultar costosas y complejas debido a que se requieren pasos adicionales de separación, adaptando membranas o compuestos químicos para retenerlo (Secondes et al., 2014). Son pocos los estudios que han demostrado el potencial de esta tecnología a escala piloto (Mailler et al., 2015; Margot et al., 2013; Secondes et al., 2014). Por lo tanto, en el presente trabajo se estudió el diseño de una columna de adsorción con CAP, en lecho fijo y flujo descendente, para evaluar la eficiencia de remoción dos fármacos recalcitrantes: carbamazepina y sildenafil, presentes en concentraciones traza en las aguas residuales. Además se evaluaron diferentes modelos matemáticos para determinar los parámetros de las curvas de rupturas obtenidas a partir de los resultados experimentales a escala de laboratorio y a escala piloto.

\subsection{Metodología}

\subsubsection{Determinación de la masa óptima de CAP}

Para determinar la masa óptima de carbón activado en polvo (CAP) a utilizar en la columna de adsorción a escala de laboratorio, se realizaron ensayos por triplicado en sistemas batch a $25^{\circ} \mathrm{C}$ y $90 \mathrm{rpm}$. Las masas de carbón evaluadas fueron $(5,10,25$, $50,100,200,500,1000$ y 1500) $\mathrm{mg}$, en contacto con $50 \mathrm{~mL}$ de agua declorinada y en concentraciones nominales para cada fármaco de $200 \mu \mathrm{g} / \mathrm{L}$, en su mezcla. Se tomaron muestras a los $30 \mathrm{~min}, 1 \mathrm{~h}$, y cada 2 horas, hasta alcanzar el equilibrio, el cual fue obtenido a las $8 \mathrm{~h}$ de contacto.

\subsubsection{Evaluación de la porosidad del lecho adsorbente}

El CAP es un material de difícil manipulación que no genera una porosidad adecuada para tratar soluciones acuosas en lecho fijo. Por lo tanto, se utilizó arena $(A R)$, de tamaño de partícula $\geq 150 \mu \mathrm{m}$, como material auxiliar para generar porosidad sobre el lecho. Las relaciones de CAP:AR evaluadas fueron: 1:0, 0:1, 1:1, 1:5, 1:15, 1:30 y 1:50. Las dos primeras se analizaron con el fin de evaluar el comportamiento individual de los materiales adsorbente y auxiliar, respectivamente. 


\subsubsection{Diseño y comportamiento hidráulico de la columna a escala de laboratorio}

La columna que contenía el material adsorbente, a escala de laboratorio, fue construida en polipropileno, con una altura de $20 \mathrm{~cm}$ y un diámetro de $3 \mathrm{~cm}$. Se utilizó $1 \mathrm{~cm}$ de gravas finas, $2 \mathrm{~cm}$ de gravilla y $2 \mathrm{~cm}$ de arena como soporte del lecho adsorbente. Para determinar el caudal de trabajo del sistema, se evaluaron diferentes configuraciones en las líneas de alimentación, manteniendo flujos volumétricos en sistemas continuos y discontinuos, y variando y manteniendo fijas las cargas hidráulicas. Además se evaluó el flujo por gravedad y a presión. Luego de encontrar la configuración adecuada, se determinó el comportamiento del sistema mediante la alimentación de diferentes soluciones acuosas, como: agua de red, agua declorinada y agua declorinada enriquecida con azida de sodio al $0,01 \%$, usada como agente antimicrobiano (Rossner et al., 2009).

\subsubsection{Comportamiento de los fármacos en matrices complejas}

Para determinar el comportamiento de la Cbz y el Sil en matrices complejas, primero se evaluó su comportamiento en agua nanopura, enriquecida con diferentes soluciones stock. Las soluciones stock evaluadas se prepararon en agua destilada (en concentraciones de $10 \mathrm{mg} / \mathrm{L}$ ) y en metanol (en concentraciones de $1000 \mathrm{mg} / \mathrm{L}$ ), en su formas puras y adicionadas con azida de sodio; frescas y en reposo a $4{ }^{\circ} \mathrm{C}$ y $-20{ }^{\circ} \mathrm{C}$ por $24 \mathrm{~h}$, además de ser filtrarlas en $0,45 \mu \mathrm{m}$. Esto último, para determinar si existían microcristales que pudieran afectar las diluciones. Luego, se estudió el comportamiento de los fármacos (en su mezcla) en diferentes matrices acuosas. Las soluciones evaluadas fueron: agua destilada, agua de red y agua declorinada, en sus formas puras y enriquecidas con azida de sodio y EDTA. La azida y el EDTA se utilizaron para evitar la biodegradación y/o reacciones de complejación de los fármacos. Las concentraciones nominales de trabajo fueron de $0,2 \mathrm{mg} / \mathrm{L}$ para cada compuesto, realizando cada experimento en condiciones batch. En cada caso se hicieron determinaciones por duplicado. Además, se evaluó la sensibilidad que presentan las diferentes técnicas analíticas para la detección de estos compuestos en matrices complejas. Las técnicas utilizadas fueron HPLC-MS y HPLC-UV. 


\subsubsection{Efecto de la concentración del cloro en la determinación de los fármacos}

Con el fin de evaluar el efecto del hipoclorito de sodio ( $\mathrm{NaClO}$ ) sobre las determinaciones analíticas de fármacos, se adicionaron concentraciones nominales de $0.5 \mathrm{mg} / \mathrm{L}$ de cada fármaco, en su mezcla, en agua declorinada, enriquecida con 0,3 ; 0,5; $1 ; 2$ y $4 \mathrm{mg} / \mathrm{L}$ de $\mathrm{NaClO}$. Estos experimentos se realizaron en batch, tomando muestras de las soluciones antes y 30 minutos después de haber adicionado el $\mathrm{NaClO}$ (EPA, 2011). Ensayos similares se llevaron a cabo para determinar la concentración del cloro residual en la solución acuosa, adicionando concentraciones iniciales del $\mathrm{NaClO}$ de 0,$3 ; 0,5 ; 1 \mathrm{mg} / \mathrm{L}$.

En la columna a escala de laboratorio se evaluó el efecto del cloro residual sobre la adsorción de los fármacos y sobre el desarrollo microbiano. Las concentraciones iniciales de $\mathrm{NaClO}$ en el tanque de alimentación del sistema fueron de $0,5 \mathrm{mg} / \mathrm{L}$ y $1 \mathrm{mg} / \mathrm{L}$. La concentración nominal inicial de cada fármaco fue de $0,5 \mathrm{mg} / \mathrm{L}$, adicionados en su mezcla. La solución de alimentación se preparó cada $24 \mathrm{~h}$, y se tomaron muestras afluentes y efluentes cada 24 h durante 25 días.

\subsubsection{Diseño de la columna a escala piloto y experiencias desarrolladas.}

La columna a escala piloto se construyó en acrílico, con un diámetro de $10 \mathrm{~cm}$ y una altura de $110 \mathrm{~cm}$. La línea de alimentación se ubicó en la pared lateral de la columna a $20 \mathrm{~cm}$ por debajo del tope. La altura del lecho adsorbente (CAP:AR) fue de $20 \mathrm{~cm}$, con un total de $40 \mathrm{~g}$ de CAP y $2 \mathrm{Kg}$ de arena. Como medio soporte y filtrante del material adsorbente se colocaron $6 \mathrm{~cm}$ de arenas medias, $5 \mathrm{~cm}$ de gravilla, $4 \mathrm{~cm}$ de grava fina y $4 \mathrm{~cm}$ de grava gruesa, utilizando una malla de acero inoxidable como base. Se completó el sistema con un prefiltro de polipropileno de $10 \mu \mathrm{m}$, una bomba peristáltica de caudales variables, y un tanque de alimentación de 200 L de capacidad.

Para evaluar el comportamiento operativo del lecho adsorbente, se alimentó el sistema con agua declorinada adicionada con los fármacos en concentraciones de 0,5 $\mathrm{mg} / \mathrm{L}$ para cada compuesto, en su mezcla. El agua declorinada fue enriquecida inicialmente con $0,5 \mathrm{mg} / \mathrm{L}$ de $\mathrm{NaClO}$, a la cual después de 30 min de contacto se le incorporaron los compuestos en estudio. El caudal de trabajo fue de $30 \mathrm{~mL} / \mathrm{min}$. La solución de alimentación se preparó cada tres días, tomando la muestra respectiva. En 
cambio, las de los efluentes se tomaron cada $24 \mathrm{~h}$, hasta completar 90 días de funcionamiento en continuo.

Los resultados obtenidos a escala piloto, así como a escala de laboratorio, se evaluaron mediante la simulación y análisis de las curvas de ruptura, utilizando diferentes modelos matemáticos. El modelo de Bohart-Adams, el modelo de Thomas, el modelo de Yoon-Nelson, y el modelo de dosis-respuesta modificado, se analizaron para predecir la capacidad y la velocidad de adsorción de la Cbz y el Sil, así como para calcular el tiempo de vida útil del lecho adsorbente.

\subsection{Resultados y discusión}

\subsubsection{Determinación de la masa óptima del CAP}

Con la finalidad de mejorar la velocidad de adsorción de los fármacos sobre el CAP y determinar la masa óptima del material adsorbente (para evitar el sobre agregado del mismo, lo cual puede elevar los costos de diseño de las columnas de adsorción; así como también evitar construir sistemas subdimensionados, que sean ineficientes en la remoción de los compuestos) se colocaron en contacto diferentes masas de CAP en $50 \mathrm{ml}$ de agua declorinada, conteniendo $200 \mu \mathrm{g} / \mathrm{L}$ de cada fármaco, en su mezcla. Las masas evaluadas del CAP fueron: 5, 10, 25, 50, 100, 200, 500, 1.000 y $1.500 \mathrm{mg}$. Se determinó una masa óptima de CAP de $1000 \mathrm{mg}$, con la que se obtuvo eficiencias de remoción superiores al 85\% tanto para Cbz como para Sil, en 30 min de contacto. Resultados similares fueron obtenidos para Sil, utilizando una masa de adsorbente de $500 \mathrm{mg}$, pero sin alcanzar la misma eficiencia para la Cbz (ver Figura 9.1). Por lo tanto, usar masas inferiores a $1.000 \mathrm{mg}$ puede resultar en un tiempo de vida útil bajo de la columna para la remoción de $\mathrm{Cbz}$, y emplear masas superiores a $1.000 \mathrm{mg}$ puede generar un sobredimensionamiento de la misma, ya que como se ve en la Figura 9.1, no hay diferencias significativas en la remoción de los fármacos con masas de CAP entre $1.000 \mathrm{mg}$ y $1.500 \mathrm{mg}$. La determinación de la masa óptima de CAP, la eficiencia de remoción y el tiempo de contacto, permitieron iniciar el diseño de la columna de adsorción a escala de laboratorio. 

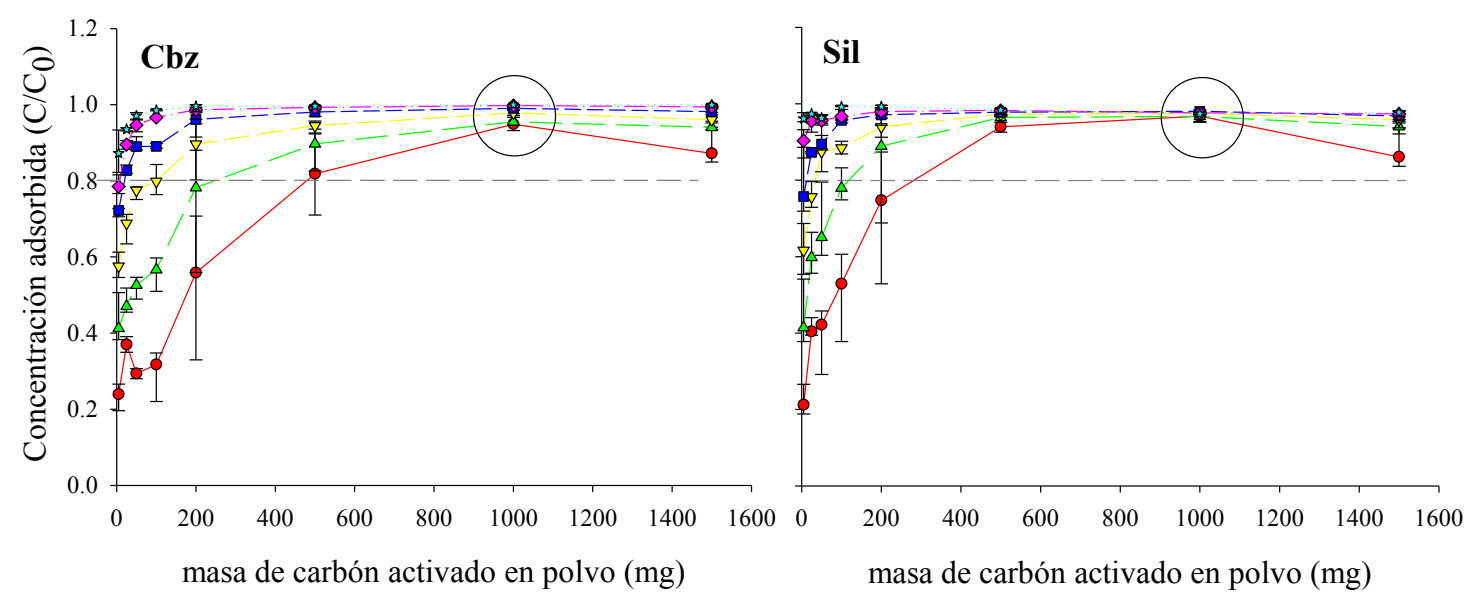

Figura 9.1. Determinación de la masa óptima de carbón activado en polvo, evaluada

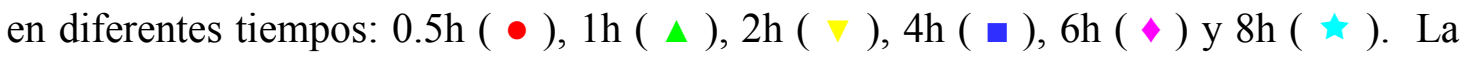
línea gris punteada indica un porcentaje de remoción del $80 \%$ y el círculo remarca la masa óptima de CAP.

\subsubsection{Evaluación de la porosidad del lecho adsorbente}

Debido a que el CAP es un material difícil de manipular, diferentes autores han reportado estudios en batch para la remoción de contaminantes emergentes (Kovalova et al., 2013; Mailler et al., 2016b; Meinel et al., 2016). Sin embargo, en el presente trabajo se evaluó su comportamiento en columnas de lecho fijo. En una primera experiencia se determinó una porosidad muy baja para tratar soluciones acuosas, con un caudal de escurrimiento inferior a $1 \mathrm{~mL} / \mathrm{min}$. Luego se lo mezcló con arenas medias (AR) para mejorar la velocidad de pasaje (el caudal de escurrimiento de estas arenas solas, fue de $45 \mathrm{~mL} / \mathrm{min})$. Las relaciones de CAP:AR evaluadas fueron 1:1, $1: 5,1: 15,1: 30,1: 50$, masa/masa. Con las tres primeras se obtuvieron flujos inferiores a $1 \mathrm{~mL} / \mathrm{min}$, por el contrario, con la relación 1:30 se alcanzaron caudales de 2,5 $\mathrm{mL} / \mathrm{min}$. Se determinó que la mezcla más favorable fue la de 1:50, la cual permitió obtener un caudal de $6,5 \mathrm{~mL} / \mathrm{min}$, y una velocidad superficial de $1,1 \mathrm{~cm}^{3} / \mathrm{cm}^{2} / \mathrm{min}$. En la Figura 9.2 se puede apreciar la homogeneidad de la mezcla CAP:AR (1:50), antes y después de mantener un flujo continuo en lecho fijo. 


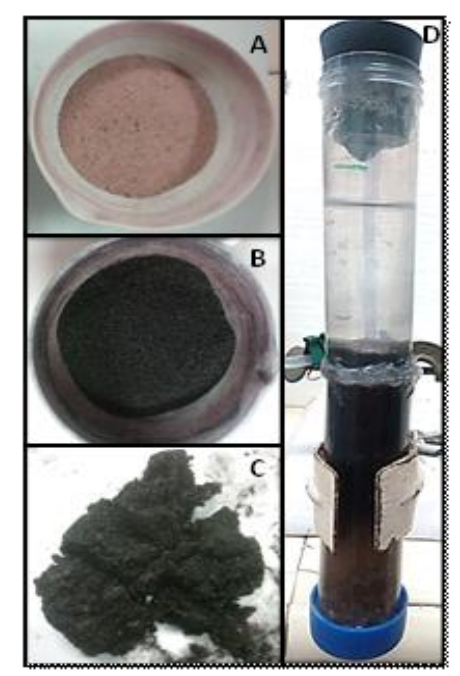

Figura 9.2. Apariencia de: (A) la arena sola, (B) la mezcla de CAP:AR en relación 1:50, antes de ser incorporado en la columna, y (C) homogeneidad de la mezcla después de mantener un flujo continuo en lecho. (D) diseño inicial de la columna de adsorción a escala de laboratorio.

\subsubsection{Diseño y comportamiento hidráulico de la columna a escala de laboratorio}

La columna a escala de laboratorio se diseñó en polipropileno, con caudal descendente de $6,5 \mathrm{~mL} / \mathrm{min}$ por escurrimiento. El diámetro de la columna fue de $3 \mathrm{~cm}$ y la altura de $20 \mathrm{~cm}$. La altura del lecho adsorbente, CAP:AR, fue de $6 \mathrm{~cm}$, soportando una columna de agua de la misma altura, y un borde libre de $3 \mathrm{~cm}$. En la parte inferior del lecho adsorbente se colocaron $2 \mathrm{~cm}$ de arenas medianas, las cuales evitaban la pérdida del CAP con el agua a tratar, seguido por $1 \mathrm{~cm}$ de gravas finas y por $2 \mathrm{~cm}$ de gravilla, formando un tamiz para retener los diferentes materiales. La base de la columna estaba compuesta por material plástico perforado para permitir el paso de la solución tratada, como se ve en la Figura 9.2 D.

El comportamiento hidráulico de la columna se evaluó inicialmente con un flujo discontinuo por gravedad, seguido de un flujo en continuo con cargas hidráulicas cada vez mayores, y luego se acoplaron válvulas reguladoras en la línea de alimentación como se muestra en la Figura 9.3 A, B y C, respectivamente. No se logró mantener un flujo constante en ninguno de los casos evaluados, debido a los cambios de presión, causados por la variabilidad de las cargas hidráulicas. Por lo tanto, se utilizó una bomba peristáltica de bajos caudales, para alimentar el sistema y mantener la presión y el caudal constantes, como se muestra en la Figura 9.3 D. Manteniendo este diseño, se alimentó la columna con agua declorinada. El sistema colapsó después de dos días de funcionamiento, debido al crecimiento bacteriano, como se muestra en la Figura 9.4 A. Consecuentemente, se adicionó azida de sodio en el tanque de 
alimentación, para evitar el desarrollo del biofilm (Rossner et al., 2009). Sin embargo, nuevamente la columna colapsó luego de cuatro días de funcionamiento en continuo, debido al depósito de sólidos suspendidos y coloidales en la superficie del lecho adsorbente, como se muestra en la Figura 9.4 B y C. Resultados similares fueron obtenidos al alimentar con agua de red. Este inconveniente se solucionó adaptando un filtro en polipropileno de $10 \mu \mathrm{m}$, antes de la bomba peristáltica, como se muestra en la Figura 9.3 E.

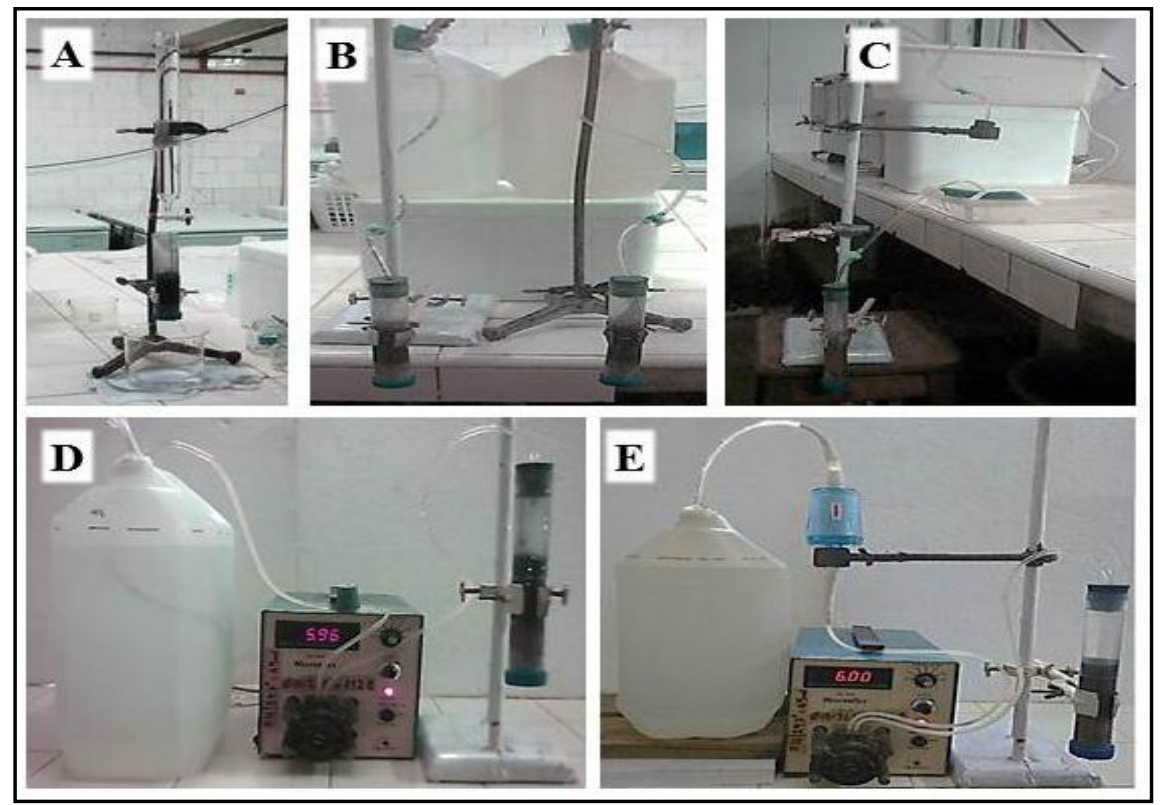

Figura 9.3. Evaluación del comportamiento hidráulico de la columna de adsorción a escala de laboratorio mediante: (A) funcionamiento discontinuo por gravedad, (B y C) manteniendo diferentes cargas hidráulicas y adaptando válvulas de cierre lento para regular el flujo, (D) acoplando una bomba peristáltica de bajos caudales y (E) instalando un prefiltro de polipropileno de $10 \mu \mathrm{m}$ para retener sólidos coloidales.

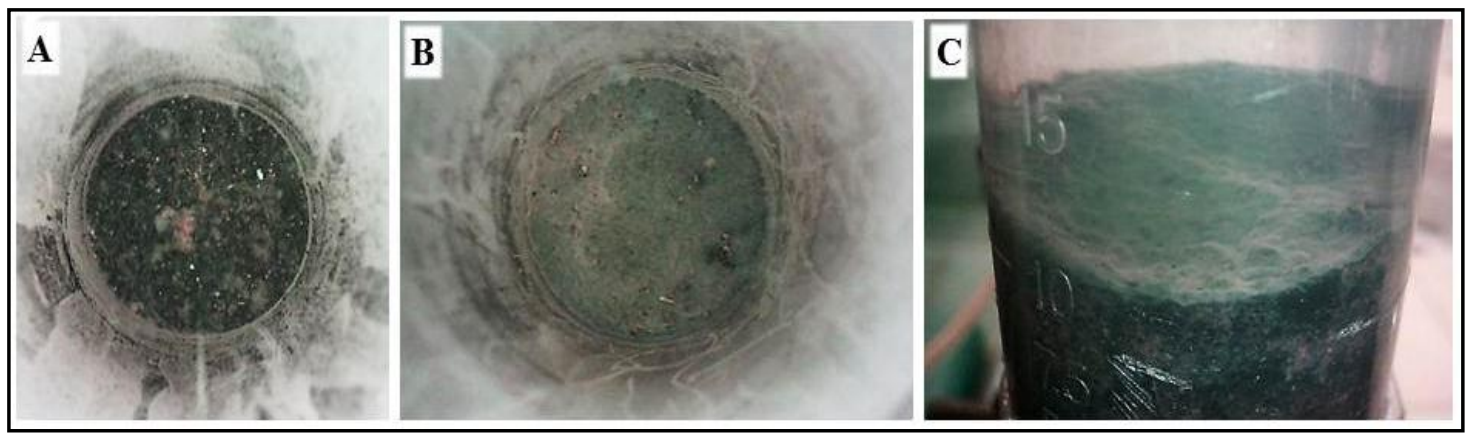

Figura 9.4. Vista superior del lecho con: (A) Crecimiento bacteriano y (B y C) depósito de sólidos coloidales sobre su superficie. 
Sin embargo, el principal inconveniente de este diseño fue el ingreso de aire en la columna, provocando secado del lecho y posterior compactación. Por lo tanto, se ubicó el prefiltro luego de la bomba peristáltica, con lo cual se mejoró el funcionamiento global del sistema. Además, se adaptaron válvulas en la línea de alimentación para facilitar su operación. Como se ve en la Figura 9.5, se incorporó una válvula principal $\left(\mathrm{V}_{1}\right)$ después del tanque de alimentación y antes de la bomba, con el fin de evitar perdida de la solución acuosa y consecuente introducción de aire, al realizar la limpieza del tanque. Una segunda válvula $\left(\mathrm{V}_{2}\right)$ se colocó después de la bomba y antes del prefiltro, la cual se utilizó únicamente para purgar el mismo. La válvula $\left(\mathrm{V}_{3}\right)$ funcionó como una trampa de aire. La válvula $\left(\mathrm{V}_{4}\right)$ se ubicó después del prefiltro, la cual se cerraba únicamente cuando se abría la válvula $\mathrm{V}_{3}$. La válvula $\left(\mathrm{V}_{5}\right)$ se utilizó para interrumpir las líneas de operación por mantenimiento en la columna. Con estos aditamentos se concluyó el diseño del sistema a escala de laboratorio, el cual al evaluarlo en continuo, con agua declorinada adicionada con azida de sodio, alcanzó un tiempo de funcionamiento de 30 días.

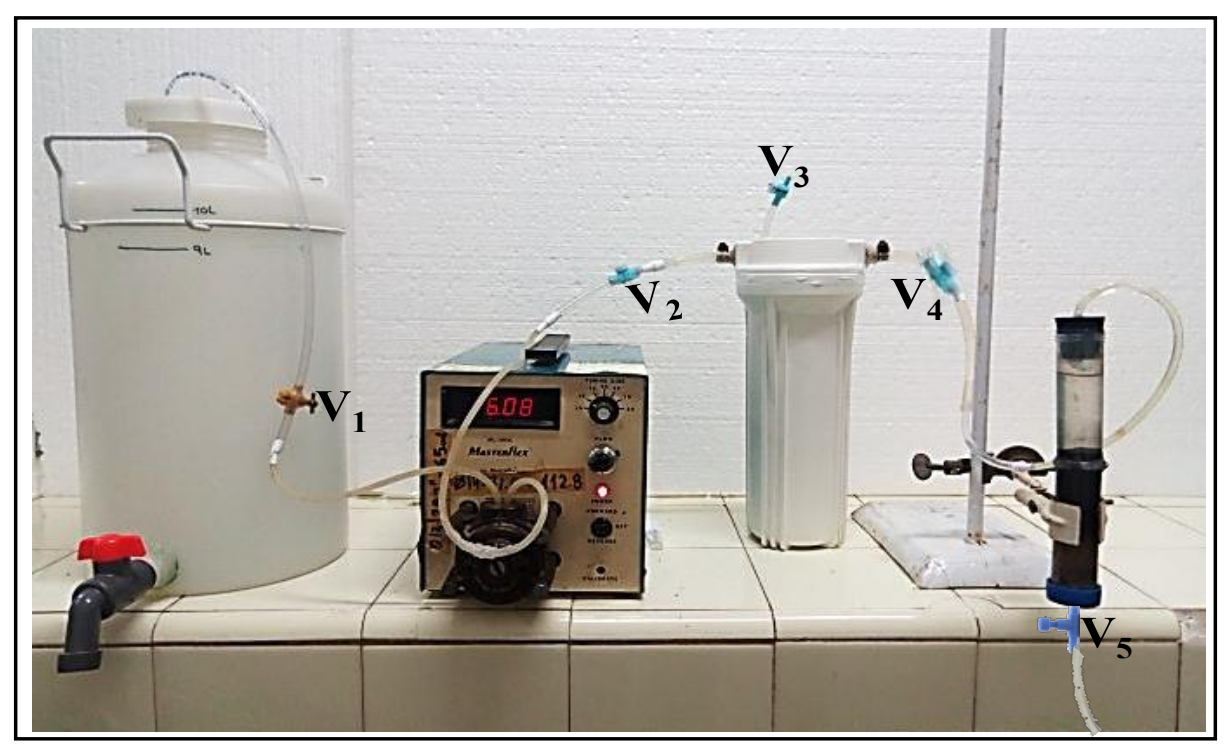

Figura 9.5. Diseño final de la columna de adsorción a escala de laboratorio. 


\subsubsection{Estudios preliminares para la remoción de los fármacos en la columna a escala de laboratorio}

Antes de evaluar la remoción de los fármacos en el lecho adsorbente, se estudió su adherencia sobre el material de trabajo, adicionando concentraciones de 0,2 mg/L de cada compuesto. Se determinó que en los tanque de alimentación de polietileno, se adhería aproximadamente un 10\% (ver Figura $9.3 \mathrm{E}$ ), mientras que no se detectó adherencia sobre los tanques de polipropileno (Ver Figura 9.5), los cuales se eligieron para el desarrollo del presente trabajo.

Para evaluar la eficiencia de adsorción de los fármacos sobre el lecho de CAP:AR se realizaron pruebas preliminares con agua declorinada y agua de red. La concentración para cada compuesto fue $0,2 \mathrm{mg} / \mathrm{L}$, adicionados en su mezcla. Como resultado más destacado, con el agua declorinada, se determinó que la columna diseñada resultó ser un tratamiento eficiente para la remoción de ambos fármacos, de manera simultánea, alcanzando eficiencias superiores al 90\%, desde el inicio de toma de muestras (15 min), hasta los cinco días de operación en flujo continuo (ver Figura $9.6 \mathrm{~A})$.

Por el contrario, aunque en las pruebas realizadas con agua de red se consiguió trabajar con un flujo continuo durante 22 días, no se pudo determinar claramente la concentración afluente de los compuestos, debido a la complejidad de la matriz acuosa (ver Figura 9.6 B y C). Por lo cual se evaluó su comportamiento en diferentes soluciones y utilizando diferentes técnicas analíticas, como se explica en el siguiente apartado.

Por su parte, en el efluente se detectaron concentraciones de Sil inferiores a 3

$\mu \mathrm{g} / \mathrm{L}$ durante el tiempo de estudio, mientras que para la $\mathrm{Cbz}$ se presentó un aumento gradual, hasta alcanzar una concentración máxima de $16 \mu \mathrm{g} / \mathrm{L}$. 

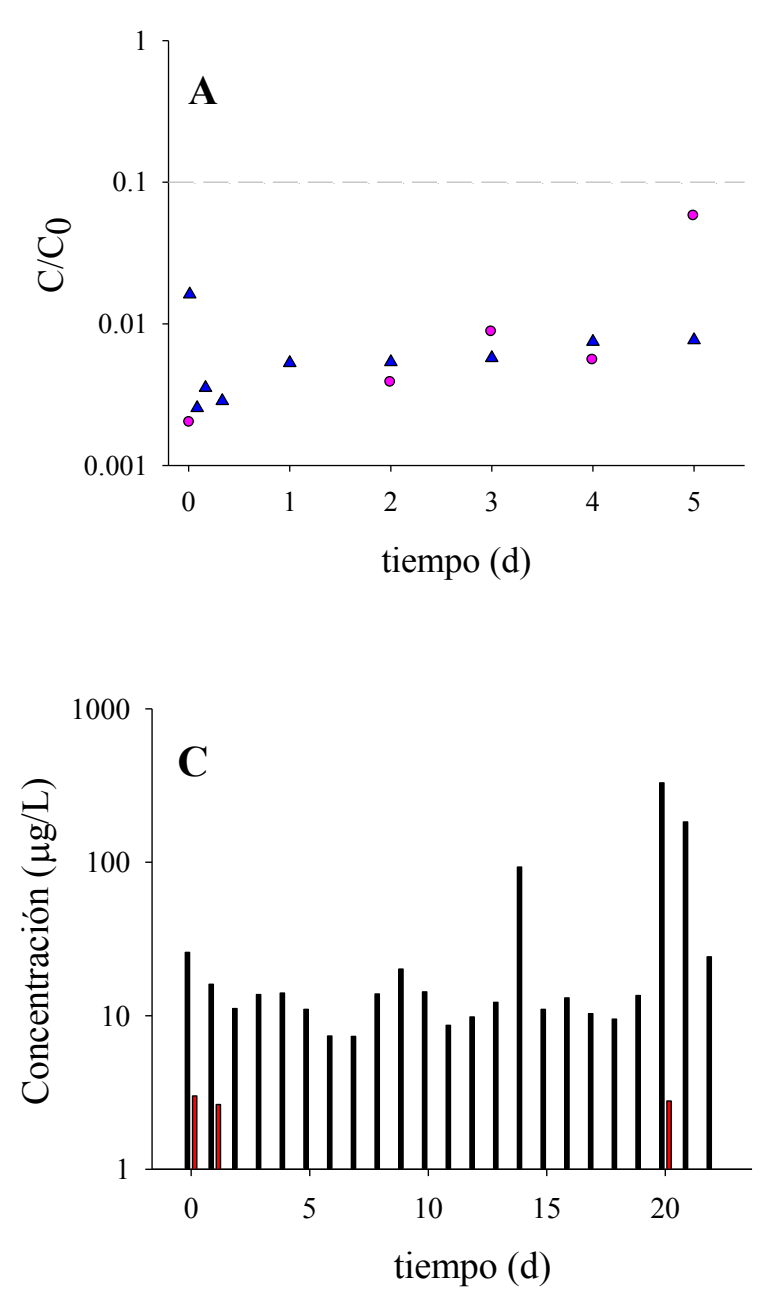

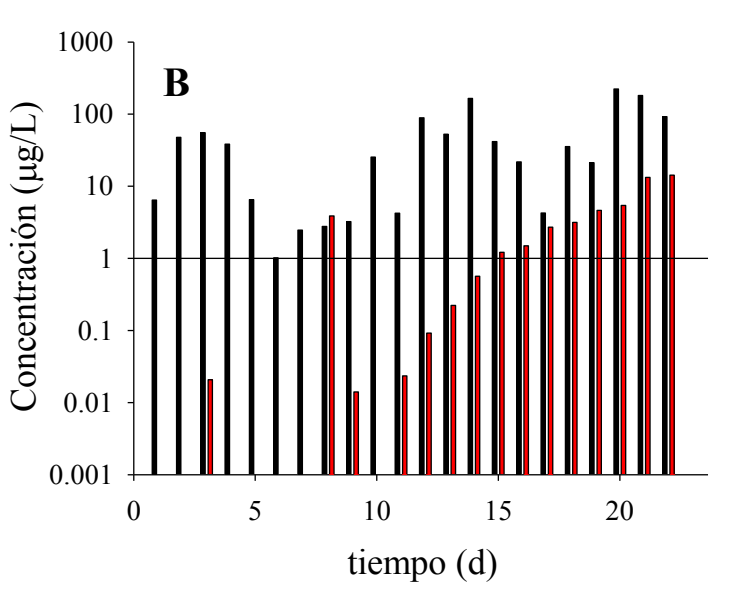

Figura 9.6. Remoción de fármacos en la columna a escala de laboratorio. (A) Concentraciones efluentes de $\mathrm{Cbz}(\bullet) \mathrm{y}$ Sil ( $\boldsymbol{\Delta}$ ), utilizando agua declorinada como solución de trabajo. Concentraciones (】) afluentes y ( ( ) efluentes de (B) Cbz y (C) Sil, en agua potable. Las concentraciones iniciales de los compuestos fueron de aproximadamente $0,2 \mathrm{mg} / \mathrm{L}$. La línea punteada en gris indica eficiencias de remoción superiores al $90 \%$.

\subsubsection{Comportamiento de los fármacos en matrices complejas}

Antes de alimentar la columna para evaluar la capacidad de adsorción de los fármacos, se analizó su comportamiento en diferentes soluciones stock, y en distintas matrices acuosas para su dilución. Las técnicas analíticas utilizadas fueron HPLC-MS y HPLC-UV.

No se observaron diferencias en ninguna de las diluciones en agua nanopura provenientes de las diferentes soluciones stock (preparadas en agua destilada y en metanol, en su formas puras y adicionadas con azida de sodio, frescas y en reposo a $4{ }^{\circ} \mathrm{C}$ y $-20{ }^{\circ} \mathrm{C}$ por $24 \mathrm{~h}$ o filtrarlas en $0,45 \mu \mathrm{m}$ ), determinadas mediante HPLC-MS. Con el fin de evitar cualquier interferencia por parte del metanol durante los experimentos de adsorción en la columna, se prepararon soluciones de los fármacos al límite de solubilidad en agua (ver Tabla 3.1). 
Las soluciones evaluadas para preparar el agua de alimentación fueron agua destilada, agua de red y agua declorinada, en sus formas puras y enriquecidas con azida de sodio y EDTA. Se evidenció una gran variabilidad en los resultados obtenidos por HPLC-MS, para todos los casos evaluados. Las concentraciones distaban entre valores inferiores al nivel de cuantificación de la técnica, hasta valores de aproximadamente $0.3 \mathrm{mg} / \mathrm{L}$. Concluyendo que la detección de los fármacos por este método, bajo las condiciones de estudio, no era la técnica más adecuada.

Las concentraciones de Cbz y Sil en las diferentes matrices acuosas fueron más uniformes mediante el uso del HPLC-UV, como se muestra en las Figuras 9.7 y 9.8, ya que esta técnica trabaja sobre el cromóforo, sin mucha influencia del entorno químico. La variabilidad por HPLC-MS tiene influencia en las determinaciones debido a que se mide el ion $\mathrm{M}+\mathrm{H}$ por enfoque $\mathrm{SIM}$, así al cambiar los entornos químicos, no es lo mismo medir una molécula en agua destilada ( $\sin$ iones), en agua potable o declorinada (con iones), o en agua enriquecida con azida de sodio. Por ejemplo, en las determinaciones de las matrices acuosas complejas, pueden formarse aductos del tipo $[\mathrm{M}+\mathrm{Na}]^{+}$o puede cambiar la distribución iónica, lo cual no permite realizar determinaciones claras, o directamente no se pueden detectar los compuestos en estudio. Este tipo de comportamientos fueron los responsables en la variabilidad de la concentración de los fármacos en las soluciones acuosas medidas anteriormente con el agua potable, resultados similares fueron encontrados por Taylor (2005).

Teniendo en cuenta que la mayoría de las soluciones presentan condiciones estables para ambos compuestos medidos por HPLC-UV, se eligió trabajar con el agua declorinada como solución de alimentación de la columna, ya que como se estudió en el Capítulo 8, los fármacos en ésta solución presentan un comportamiento de adsorción similar al del agua residual proveniente de un tratamiento secundario. 


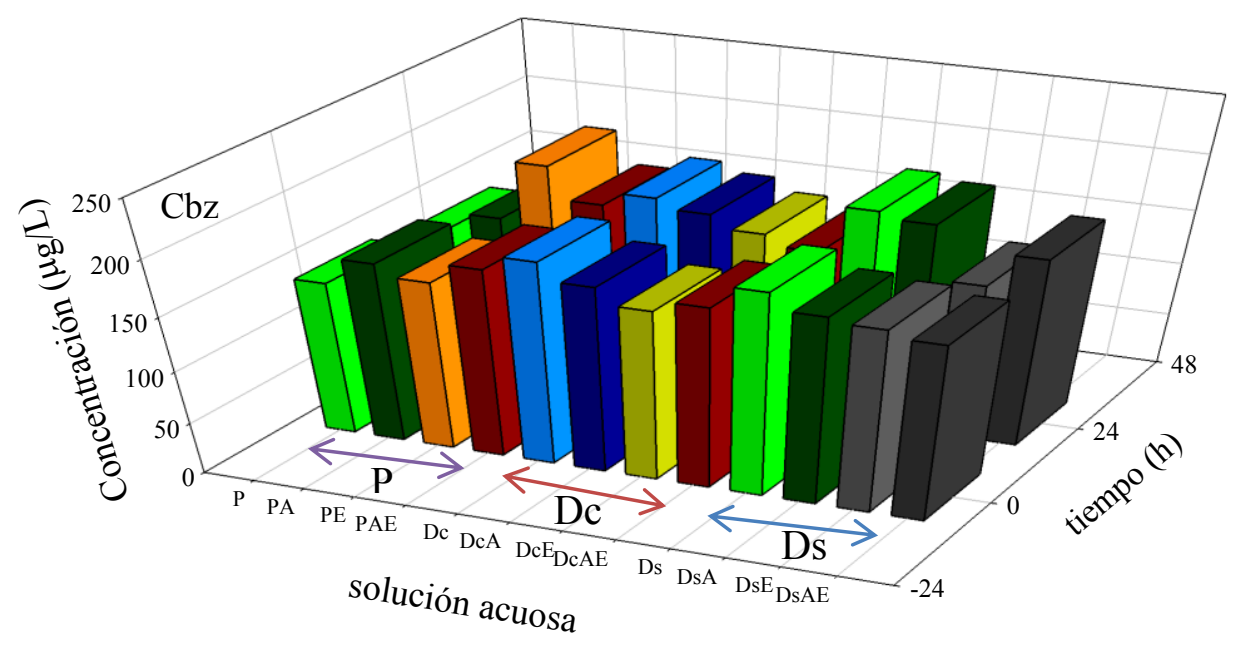

Figura 9.7. Determinación de la concentración de carbamazepina $(\mathrm{Cbz})$ por HPLC-UV, a las 0h y $24 \mathrm{~h}$. Las flechas agrupan los sistemas agua potable (P), agua declorinada (Dc) y agua destilada (Ds), en función de los tipos de solución pura y conteniendo azida (A) y EDTA (E). Por ejemplo: PA y PAE indican soluciones de agua potable con azida y agua potable conteniendo azida y EDTA, respectivamente. La misma nomenclatura vale para los demás sistemas estudiados.

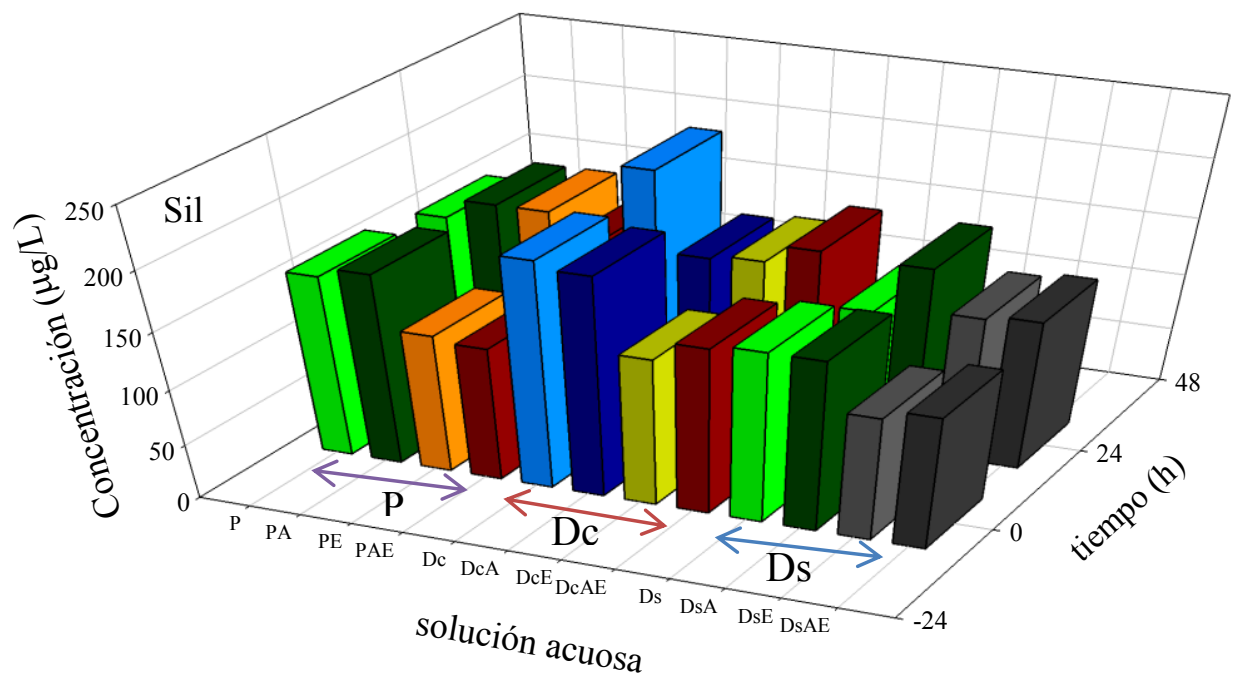

Figura 9.8. Determinación de la concentración de sildenafil (Sil) por HPLC-UV, a las 0 h y 24h. Las flechas agrupan los sistemas agua potable (P), agua declorinada (Dc) y agua destilada (Ds), en función de los tipos de solución pura y conteniendo azida (A) y EDTA (E). Por ejemplo: PA y PAE indican soluciones de agua potable con azida y agua potable conteniendo azida y EDTA, respectivamente. La misma nomenclatura vale para los demás sistemas estudiados. 


\subsubsection{Efecto de la concentración del cloro en la determinación de los fármacos}

Con el fin de mejorar la operabilidad del sistema y evitar el excesivo crecimiento de microorganismos, se evaluó el efecto del cloro sobre la determinación y la adsorción de los compuestos farmacéuticos. Cabe resaltar que la azida de sodio, se utilizó como bactericida únicamente en los estudios de laboratorio en batch, ya que no es un reactivo de uso a escala piloto o a escala real, debido a su costo y estabilidad en las soluciones acuosas. Por su parte el cloro es un bactericida económico y menos estable que la azida.

En las experiencias desarrolladas para evaluar el efecto de las diferentes concentraciones del $\mathrm{NaClO}(0,3 ; 0,5 ; 1 ; 2$ y $4 \mathrm{mg} / \mathrm{L})$ sobre las determinaciones de los fármacos (de $0.5 \mathrm{mg} / \mathrm{L}$ de cada compuesto, en su mezcla) por HPLC-UV, se observó que a medida que aumentaba la concentración del cloro disminuía la detección de los compuestos. Así, en concentraciones de $4 \mathrm{mg} / \mathrm{L}$ de cloro inicial, la concentración de los fármacos disminuía a la mitad, además de deformar los picos de los cromatogramas, aumentando el error de la técnica analítica. Resultados similares fueron obtenidos para $2 \mathrm{mg} / \mathrm{L}$ de cloro. Para las concentraciones iniciales de 0,3; $1 \mathrm{y}$ $0.5 \mathrm{mg} / \mathrm{L}$ no se observaron diferencias significativas en sus concentraciones respecto de los blancos, además no se vio afectado el pico del cromatograma.

Teniendo en cuenta que la concentración de cloro en la solución acuosa después de $30 \mathrm{~min}$ debe ser mayor o igual a $0,3 \mathrm{mg} / \mathrm{L}$, para asegurar la eliminación de las bacterias (EPA, 2011), se determinó el cloro residual en los tanque de alimentación. Las concentraciones iniciales evaluadas fueron 0,$3 ; 0,5$ y $1 \mathrm{mg} / \mathrm{L}$, determinándose concentraciones residuales de $0 ; 0,3$ y $0,5 \mathrm{mg} / \mathrm{L}$. Se concluyó que la concentración inicial en el tanque debía estar efectivamente entre 0,5 mg/L o $1 \mathrm{mg} / \mathrm{L}$, para mantener el cloro residual dentro de las concentraciones límites recomendadas.

De acuerdo a los resultados obtenidos anteriormente, se evaluó el efecto de estas dos concentraciones de cloro residual sobre la adsorción de los fármacos el en lecho de CAP:AR. Las concentraciones iniciales de la Cbz fueron $449 \pm 11 \mu \mathrm{g} / \mathrm{L}$ y $584 \pm 22 \mu \mathrm{g} / \mathrm{L}$ y las del Sil fueron $591 \pm 57 \mu \mathrm{g} / \mathrm{L}$ y $589 \pm 30 \mu \mathrm{g} / \mathrm{L}$, respectivamente, incorporándolos en su mezcla. El caudal de trabajo, fue de $6,5 \mathrm{~mL} / \mathrm{min}$, y la masa de CAP fue de $1 \mathrm{~g}$, mezclada con $50 \mathrm{~g}$ de arena. 
Se utilizó la prueba de suma de rangos de Mann-Whitney para evaluar su efecto sobre la adsorción de los compuestos. El nivel de significancia de la prueba fue de 0,05. El p-valor obtenido para comparar los resultados del Sil fue de 0,106 y el de la $\mathrm{Cbz}$ de 0,712. Se determinó que no existían diferencias estadísticamente significativas en las concentraciones efluentes de Cbz y Sil. Además, en la Figura 9.9 se puede observar que los valores efluentes de la $\mathrm{Cbz}$, la cual estuvo inicialmente en contacto con una concentración de $0,5 \mathrm{mg} / \mathrm{L}$ de cloro residual, se encuentran dentro del rango de error de la curva obtenida con $0,3 \mathrm{mg} / \mathrm{L}$ de cloro residual, evaluada para un intervalo de confianza del 95\%. Resultados similares se obtuvieron con el Sil. Por lo tanto, concertaciones de $0,3 \mathrm{mg} / \mathrm{L}$ de cloro residual son suficientes para mantener un buen funcionamiento del sistema.

Además, como resultados destacado de la presente experiencia, se determinó que la $\mathrm{Cbz}$ fue el reactivo limitante para determinar el tiempo de saturación del lecho de adsorción. Por el contrario, para el Sil se obtuvieron eficiencias de remoción superiores al $90 \%$ durante todo el tiempo de estudio, sin alcanzar la saturación del mismo.

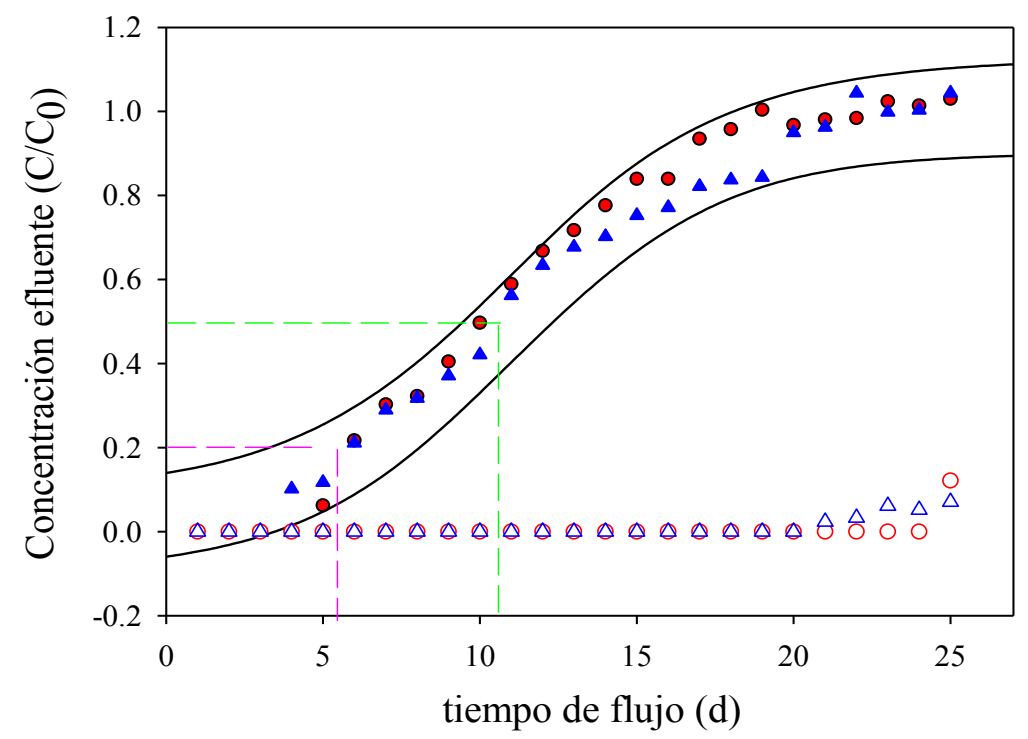

Figura 9.9. Efecto de la concentración del cloro residual, en concentraciones de $(\bullet \bullet)$ 0,5 mg/L y $(\boldsymbol{\Delta} \Delta)$ 0,3 mg/L, sobre la remoción de la carbamazepina $(\bullet \boldsymbol{\Delta})$ y el sildenafil $(\circ \Delta)$, en concentraciones iniciales de $500 \mu \mathrm{g} / \mathrm{L}$, evaluados en su mezcla en la columna a escala de laboratorio. (-) Intervalo de confianza del 95\% para la concentración efluente de Cbz que estuvo en contacto con $0.3 \mathrm{mg} / \mathrm{L}$ de cloro residual en el tanque de alimentación. Las líneas punteadas representan el tiempo en que se alcanza un porcentaje de remoción del (---) $50 \%$ y del (---) $80 \%$. 
En esta misma experiencia, luego de 20 días de funcionamiento en continuo se observó el crecimiento de una película fina de bacterias en la línea de alimentación, antes de llegar al prefiltro, tanto para los ensayos con $0,5 \mathrm{mg} / \mathrm{L}$ de cloro residual, como en los evaluados con $0,3 \mathrm{mg} / \mathrm{L}$. El crecimiento del biofilm fue muy lento durante los siguientes cinco días de funcionamiento, como se muestra en las Figuras 9.10 A y B. En el lecho adsorbente no se detectó desarrollo bacteriano para ninguna de las concentraciones de cloro evaluadas.

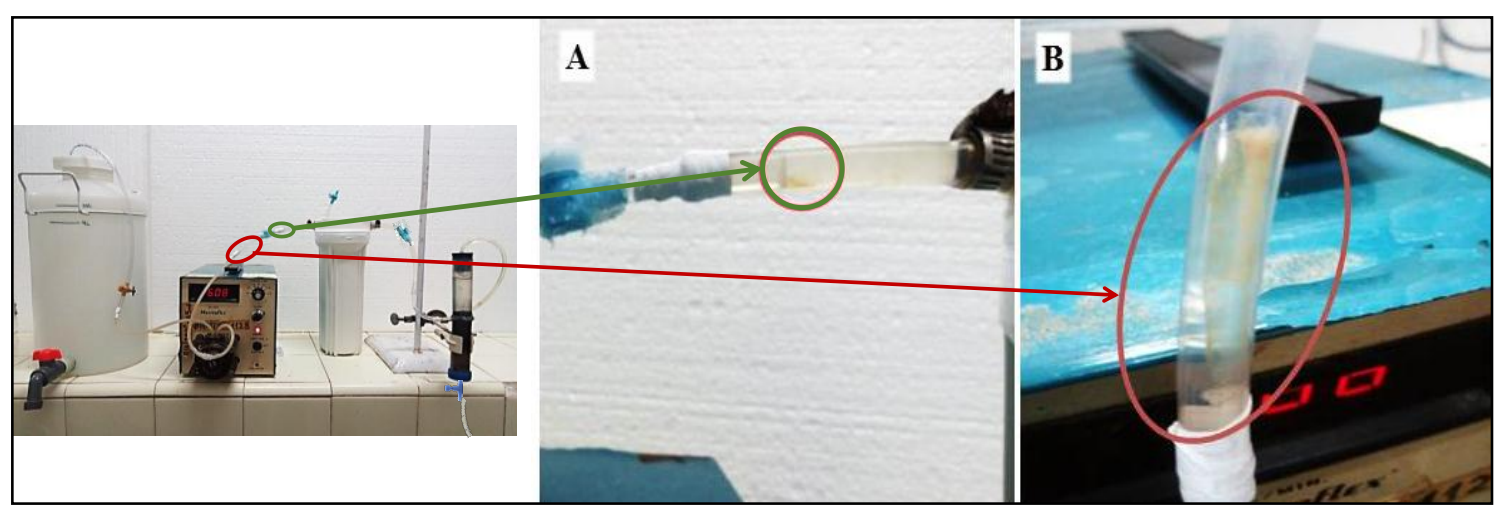

Figura 9.10. Crecimiento de biofilm en las líneas de alimentación de la columna de adsorción, después de los 25 días de funcionamiento, al adicionar $1 \mathrm{mg} / \mathrm{L}$ (A) y $0,5 \mathrm{mg} / \mathrm{L}$ (B) de cloro inicial en el tanque de alimentación.

\subsubsection{Diseño del sistema a escala piloto}

Luego de evaluar y verificar el correcto funcionamiento del sistema a escala de laboratorio, se realizó un diseño a escala piloto, como se muestra en la Figura 9.11. La columna fue construida en acrílico, con un diámetro de $10 \mathrm{~cm}$ y una altura de $110 \mathrm{~cm}$. El diámetro interno de la línea de alimentación se aumentó tres veces respecto de la línea del sistema a escala de laboratorio, con el fin de evitar pérdidas de carga excesivas por rozamiento. Ésta se ubicó en la pared lateral de la columna a $20 \mathrm{~cm}$ por debajo del tope, utilizando un tapón de goma de 2,5 cm de diámetro, para generar un sello hermético. Igualmente en la parte superior se colocó un tapón de goma de $14 \mathrm{~cm}$ de diámetro, que además funcionó como una válvula de seguridad. Se utilizaron arenas medias, gravilla, grava fina y grava gruesa como medio filtrante y soporte para el lecho adsorbente, el cual estaba compuesto por la mezcla de CAP:AR, en relación 1:50, con una altura de $20 \mathrm{~cm}$, siendo similar a la reportada en la literatura, teniendo en cuenta los rangos típicos para el tratamiento de aguas a gran escala (Worch, 2012). 
La masa total de CAP utilizada fue de 40 gramos. Como base soporte de se colocó una malla de acero inoxidable.

Teniendo en cuenta que la columna a escala de laboratorio funcionó correctamente desde el punto de vista hidráulico y operativo, con un caudal de 6,5 $\mathrm{ml} / \mathrm{min}$, se calculó el caudal de trabajo para la columna piloto mediante la ecuación: Q $=v^{*} \mathrm{~S}$, donde $\mathrm{Q}$ es el caudal, $v$ la velocidad superficial y $\mathrm{S}$ la sección transversal, manteniendo la misma velocidad superficial. El caudal obtenido fue de aproximadamente $80 \mathrm{~mL} / \mathrm{min}$. Sin embargo, al realizar la prueba hidráulica, se generó sobrepresión en el sistema, con apertura de la válvula de seguridad, y aumento gradual de la columna de agua hasta su desborde. Frente a este inconveniente se trabajó la columna por ciclos, el primero y segundo de llenado tardaron una hora, y el de drenaje 1,30 h. Se concluyó que este funcionamiento no era el más eficiente debido a su corta duración. Finalmente se determinó un caudal en continuo de aproximadamente 30 $\mathrm{mL} / \mathrm{min}$, siendo éste el que permitía el escurrimiento en el lecho adsorbente sin generar sobrepresiones. Su disminución comparada con el sistema a escala de laboratorio se generó por el aumento de la altura del lecho respecto de aquel, provocando una mayor presión sobre su base y su consecuente compactación. La velocidad superficial fue de $0,4 \mathrm{~cm}^{3} /\left(\mathrm{cm}^{2} \cdot \mathrm{min}\right)$, siendo inferior a la trabajada en el sistema de laboratorio $\left(1,1 \mathrm{~cm}^{3} / \mathrm{cm}^{2} . \mathrm{min}\right)$, garantizando mantener buenas eficiencias de remoción de los fármacos. La carga hidráulica fue $8 \mathrm{~cm}$.

Existen trabajos en los que se reportan velocidades superficiales entre 2-10 $\mathrm{cm}^{3} / \mathrm{cm}^{2}$.min en lechos fijos con CAG (Katsigiannis et al., 2015; Kim et al., 2010; Sotelo et al., 2013). Los mismos autores obtuvieron mejores eficiencias de remoción de los contaminantes emergentes utilizando CAP, pero en experimentos en batch. Velocidades de $10 \mathrm{~cm}^{3} / \mathrm{cm}^{2}$.min se obtuvieron para el CAP a escala piloto en lecho fluidizado, pero adicionando coagulantes y floculantes para evitar su pérdida con el agua tratada, necesitando reincorporaciones continuas del CAP para mantener buenas eficiencias de remoción (Mailler et al., 2015). No se encontraron trabajos que reporten velocidades superficiales para el CAP en columnas de lecho fijo, por lo tanto, este sería el primer estudió que reporta este funcionamiento, tanto a escala de laboratorio, como a escala piloto. 
El funcionamiento hidráulico de la columna en continuo se evaluó con agua declorinada enriquecida con $0,5 \mathrm{mg} / \mathrm{L}$ de cloro inicial y un caudal de $30 \mathrm{~mL} / \mathrm{min}$, preparando solución nueva cada tres días. Así, el cloro residual disminuyó de 0,3 mg/L (después de $30 \mathrm{~min}$ de contacto con el agua declorinada) a $0,1 \mathrm{mg} / \mathrm{L}$ después de $8 \mathrm{~h}$, sin detectarse luego de las $24 \mathrm{~h}$. El tiempo necesario para mantener en régimen el sistema fue de $72 \mathrm{~h}$. Después de 26 días de funcionamiento en continuo empezó a hacerse visible el crecimiento bacteriano en el lecho adsorbente, provocando su colapso después de 67 días (ver Figura 9.12 A y B). El caudal de escurrimiento en este momento disminuyó a $10 \mathrm{~mL} / \mathrm{min}$ y la carga hidráulica fue de $57 \mathrm{~cm}$. En el biofilm se detectaron principalmente microorganismos filamentosos y diatomeas (ver Figura 9.12 C, D y E), observados bajo la lupa 60x de un microscopio Olympus CH30. Esta película bacteriana se retiró manualmente, levantando además una capa del lecho adsorbente de aproximadamente $0,5 \mathrm{~cm}$. Luego de esta limpieza, el sistema retomó su funcionamiento normal, con el mismo caudal y carga hidráulica, hasta los 90 días de operación.

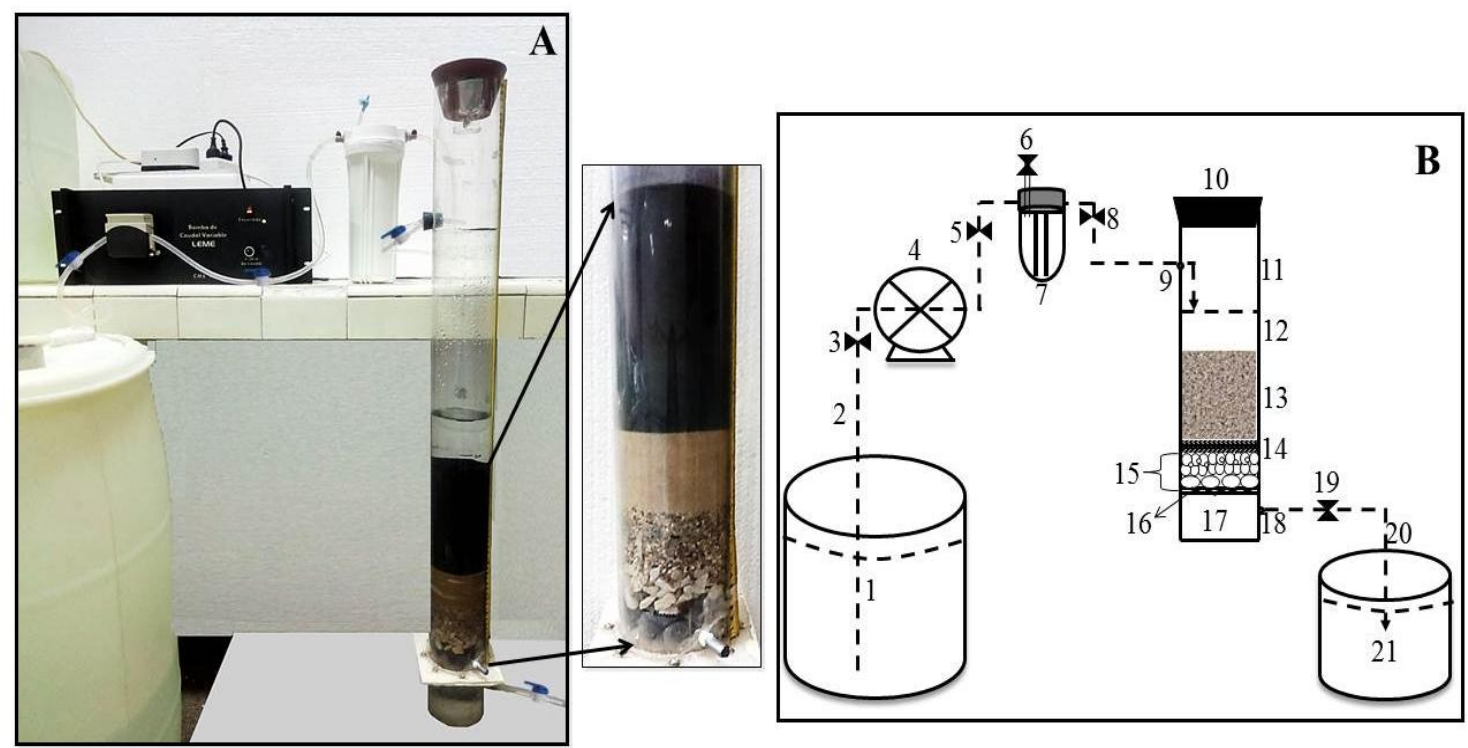

Figura 9.11. (A) Diseño y (B) esquema de la columna de adsorción a escala piloto: (1) tanque de alimentación y lugar de incorporación de los fármacos, (2) línea afluente, (3) válvula principal, (4) bomba peristáltica de bajos caudales, (5) válvula interruptora, (6) trampa de aire, (7) filtro de $10 \mu \mathrm{m}$, (8) válvula interruptora, (9) entrada de alimentación, (10) válvula de seguridad, (11) $50 \mathrm{~cm}$ de aire, (12) $8 \mathrm{~cm}$ de columna de agua a tratar, (13) $20 \mathrm{~cm}$ de lecho adsorbente CAP:AR. El material soporte estaba compuesto por: (14) $6 \mathrm{~cm}$ de arenas medianas, (15) $5 \mathrm{~cm}$ de gravilla, $4 \mathrm{~cm}$ de grava fina y $4 \mathrm{~cm}$ de grava media y (16) una base de acero inoxidable. (17) Colector del agua tratada de $7 \mathrm{~cm}$, (18) orificio de salida ubicado a $6 \mathrm{~cm}$ de la base, (19) válvula interruptora, (20) línea efluente y (21) tanque de efluente. 


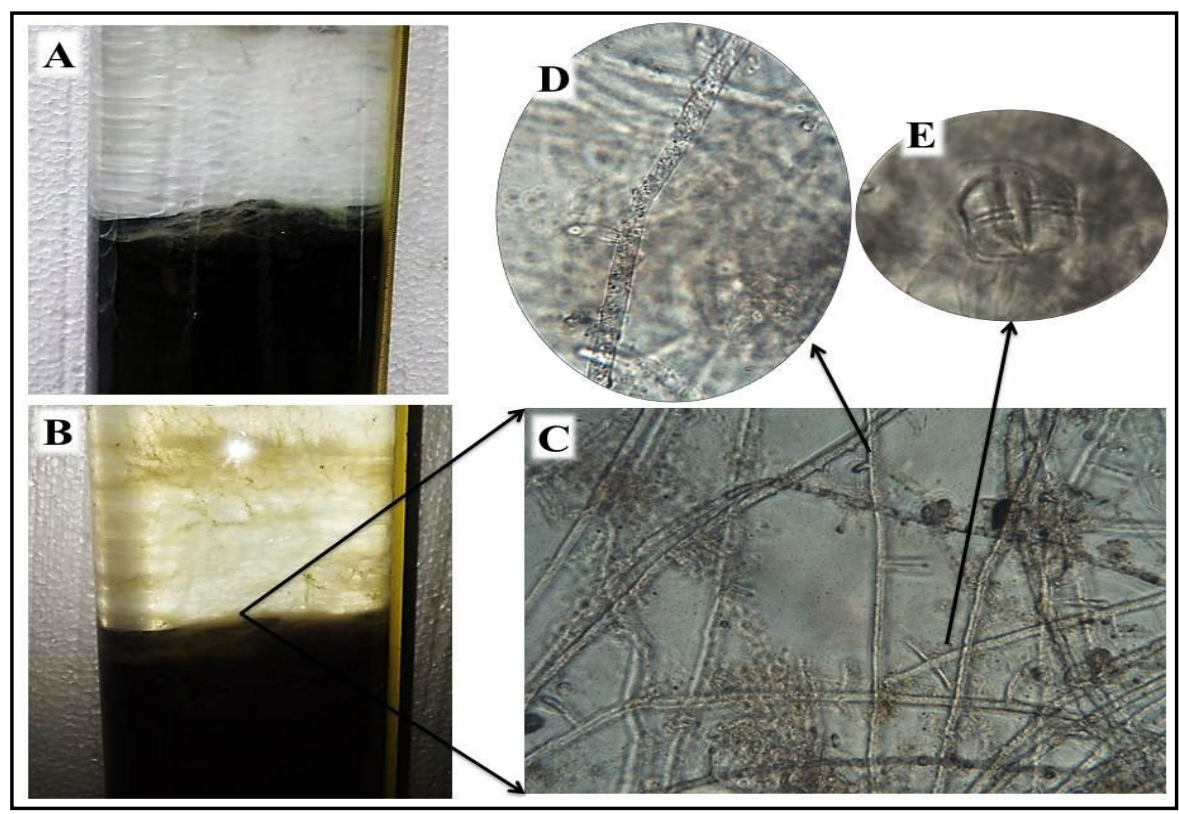

Figura 9.12. Crecimiento de biofilm sobre el lecho adsorbente de la columna piloto, (A) a los 26 días y luego de (B) 67 días de operación en continuo. (C) Vista específica de los microorganismos bajo la lupa 40x del microscopio, y determinación de: (D) microorganismos filamentosos y (E) diatomeas, bajo la lupa $60 \mathrm{x}$.

\subsubsection{Remoción de los fármacos en las columnas de lecho fijo con CAP}

Los experimentos desarrollados para determinar la capacidad de remoción de Cbz y Sil en las columnas de lecho fijo, a escala de laboratorio y piloto, se resumen en la Tabla 9.1.

Teniendo en cuenta que el agua a tratar en las columnas a escala laboratorio y piloto fueron similares, se midieron solamente los parámetros fisicoquímicos del afluente y efluente en la columna piloto, presentando una carga orgánica medida como DQO menor a $15 \mathrm{mg} / \mathrm{L}$ (límite de cuantificación de la técnica), siendo similar a las concentraciones reportadas para un efluente secundario de una PTAR a escala real, la que presentan en promedio concentraciones de DQO de $26 \pm 15 \mathrm{mg} / \mathrm{L}$ (Mailler et al., 2015), y en concentraciones similares a las reportadas anteriormente en los Capítulos 5 y 6 , mediante los tratamientos secundarios con biodiscos y humedales construidos $(\approx$ $18 \mathrm{mg} / \mathrm{L}$ ). Los valores obtenidos para el oxígeno disuelto, la temperatura, el $\mathrm{pH}$ y la conductividad en el afluente y el efluente fueron: $6,5 \pm 0,5 \mathrm{mg} / \mathrm{L}$ y $5,8 \pm 0,2 \mathrm{mg} / \mathrm{L} ; 22$ $\pm 2{ }^{\circ} \mathrm{C}$ y $21,5 \pm 0,9{ }^{\circ} \mathrm{C} ; 7,6 \pm 0,5$ y $7,6 \pm 0,4 ; 1,0 \pm 0,2 \mathrm{~ms} / \mathrm{cm}$ y $1,0 \pm 0,2 \mathrm{~ms} / \mathrm{cm}$, 
respectivamente. No se observaron diferencias estadísticamente significativas entre los valores de los parámetros fisicoquímicos medidos.

Tabla 9.1. Resumen de los parámetros de diseño de las columnas a escala piloto y laboratorio.

\begin{tabular}{lccc}
\hline & \multicolumn{3}{c}{ Escala de la columna de adsorción } \\
\cline { 2 - 4 } Parámetro de diseño de las columnas & & Laboratorio & Piloto \\
\cline { 2 - 4 } de adsorción & Unidad & Valor & Valor \\
\hline Altura total del lecho (CAP:AR) & $\mathrm{cm}$ & 6,5 & 20 \\
Masa de CAP & $\mathrm{g}$ & 1 & 40 \\
Altura efectiva del CAP & $\mathrm{cm}$ & 0,8 & 3 \\
Relación CAP:AR & $\mathrm{g} / \mathrm{g}$ & $1: 50$ & $1: 50$ \\
Tamaño del CAP & $\mu \mathrm{m}$ & $1-150$ & $1-150$ \\
Tamaño de la AR & $\mu \mathrm{m}$ & 150 & 150 \\
Densidad aparente CAP & $\mathrm{kg} / \mathrm{m}^{3}$ & 250 & 250 \\
Área superficial CAP & $\mathrm{m} / \mathrm{g}$ & 1328 & 1328 \\
Concentración afluente de Cbz & $\mu \mathrm{g} / \mathrm{L}$ & $584 \pm 22$ & $400 \pm 40$ \\
Concentración afluente de Sil & $\mu \mathrm{g} / \mathrm{L}$ & $589 \pm 30$ & $340 \pm 125$ \\
Concentración de cloro residual & $\mu \mathrm{g} / \mathrm{L}$ & 300 & 300 \\
Tiempo de contacto & $\mathrm{min}$ & 15 & 40 \\
Velocidad superficial & $\mathrm{cm} /\left(\mathrm{cm}{ }^{2} \cdot \mathrm{min}\right)$ & 1,1 & 0,4 \\
Caudal & $\mathrm{mL} / \mathrm{min}$ & 6,5 & 30 \\
Tiempo de recambio del agua a tratar & $\mathrm{h}$ & 24 & 72 \\
\hline
\end{tabular}

Como se puede ver en la Figura 9.9, se consiguieron eficiencias de remoción superiores al 80\% para el Sil durante los 25 días de operación en la columna de laboratorio, mientras que se alcanzó la saturación para la Cbz, con remociones superiores al 80\% durante los primeros seis días, y del $50 \%$ hasta los once días. Por el contrario, en la columna a escala piloto no se alcanzó la saturación para ninguno de los compuestos durante los 90 días de funcionamiento continuo, obteniéndose eficiencias de remoción superiores al 90\%. En este caso, la mayoría de las concentraciones efluentes de ambos fármacos se encontraron sobre el límite de cuantificación de la técnica analítica, con valores de $0,1 \mu \mathrm{g} / \mathrm{L}$ para $\mathrm{Cbz}$ y de $0,8 \mu \mathrm{g} / \mathrm{L}$ para el Sil (ver Figura 9.13), las cuales se evaluaron utilizando un cromatógrafo líquido de 
ultrapresión (UPLC-MS/MS), ya que esta técnica permite tener mayor sensibilidad de detección que el HPLC-UV, y presenta menor interferencia en la detección de los compuestos que el HPLC-MS. De acuerdo a estos resultados se puede concluir que el diseño de la columna de adsorción a escala piloto resulta ser muy eficiente para remover este tipo de contaminantes de las aguas residuales, el cual se propone como una etapa de tratamiento terciario, ya que es necesario remover la mayor cantidad de materia orgánica del agua residual, para evitar la proliferación de bacterias en el lecho, y mantener un buen funcionamiento operativo. Igualmente es un tratamiento que se puede incorporar en las plantas potabilizadoras, en las que aún no se ha logrado remover este tipo de contaminantes, como se demostró anteriormente en el Capítulo 4, y como se reportó en otros trabajos (Gavrilescu et al., 2015; Geissen et al., 2015; Rodriguez-Narvaez et al., 2017). En su aplicación en las PTAR, el objetivo final sería no solamente cuidar la salud humana, sino también el ambiente en general.

Además, esta tecnología resulta interesante ya que no requiere de procesos adicionales (como membranas o coagulación y floculación) para retirar el CAP, como se ha propuesto en otros trabajos (Kovalova et al., 2013; Mailler et al., 2015; Secondes et al., 2014), dado que la arena, además de generar porosidad en el lecho, funciona como un medio para retener el CAP.

Esta mezcla resulta interesante además porque luego de alcanzarse la saturación del lecho, una de las metodologías para ser reutilizada se puede enfocar en la industria de materiales y construcción, ya que en la última década se viene proponiendo la incorporación de cenizas volantes (son los residuos sólidos que se obtienen por precipitación electrostática o por captación mecánica de los polvos que acompañan a los gases de combustión de los quemadores de centrales termoeléctricas alimentadas por carbones pulverizados) como reemplazo parcial del cemento en el concreto, para mejorar su resistencia y durabilidad. Por lo tanto el CAP como un subproducto de un proceso industrial también abordar los desafíos de la construcción sostenible (Supit and Shaikh, 2015).

Otra posibilidad podría ser la regeneración por recirculación de vapor de agua a alta temperatura y baja presión (Worch, 2012). 


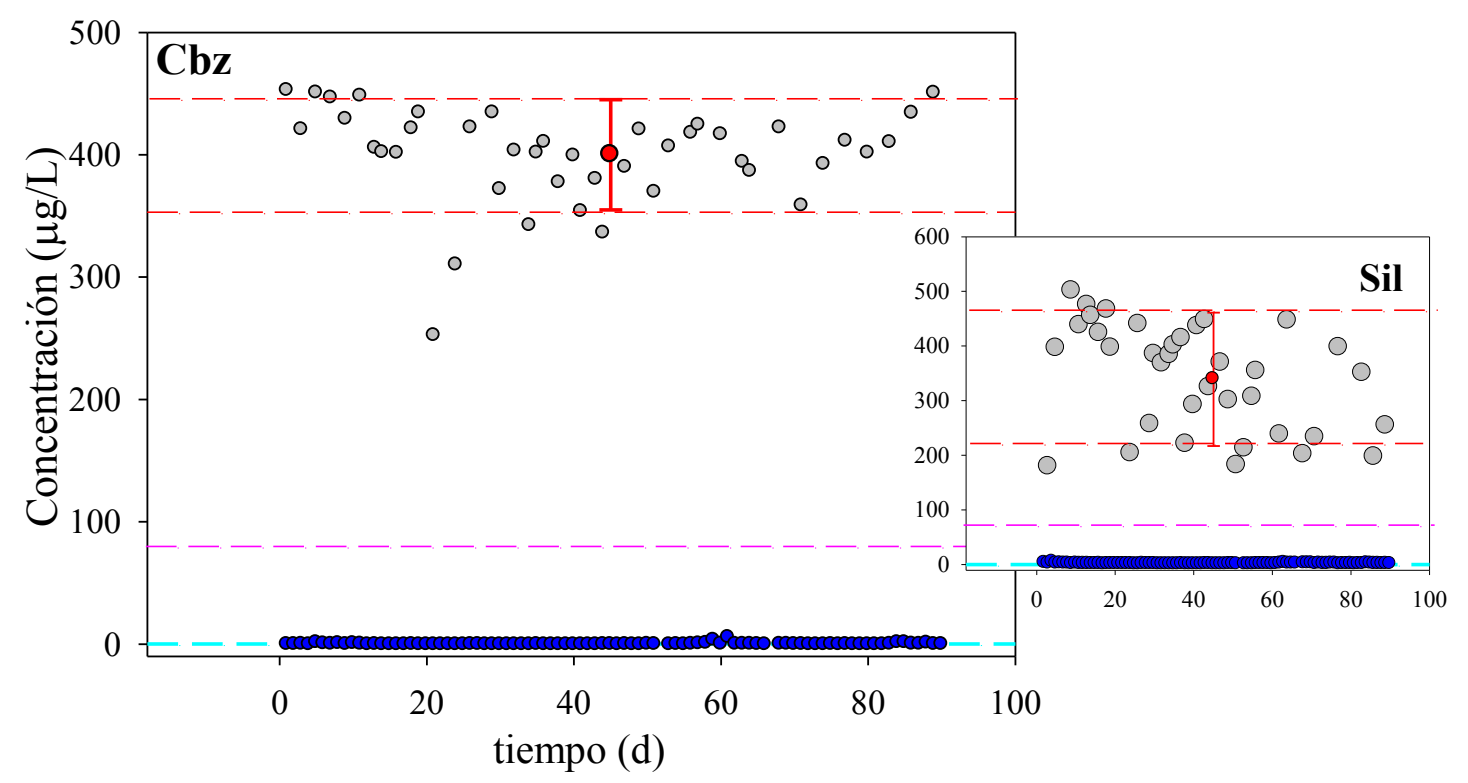

Figura 9.13. Figura comparativa del afluente (•) y el efluente (•) de Cbz y Sil, tratados en la columna con carbón activado en polvo a escala piloto. Se indican los valores de alimentación promedio $(\bullet)$ y su desviación estándar (---), una remoción teórica del $80 \%$ (---) y el límite de cuantificación de la técnica para ambos compuestos (---).

\subsubsection{Evaluación de las curvas de ruptura}

En la Figura 9.14 A se muestra el comportamiento de un contaminante tratado en un lecho fijo de adsorción, para una concentración inicial (Co) determinada. Teniendo en cuenta que en el presente trabajo se está evaluando una columna con flujo descendente, el adsorbente será retenido rápidamente en la parte superior del lecho, así que el efluente estará prácticamente libre del contaminante al inicio de la operación. Como la cantidad del líquido tratado va aumentando con el tiempo, la zona de transferencia de masa comienza a desplazarse y la concentración del adsorbato va aumentando en la salida. La concentración máxima permitida de adsorbato en el efluente de la columna se denomina punto de ruptura, y al tiempo empleado para alcanzar esta concentración específica se le llama tiempo de ruptura. La curva que resulta de graficar la relación C/Co en función del tiempo de operación, se conoce como curva de ruptura (Suzuki, 1993). 
El frente de onda de adsorción determina el tiempo de operabilidad de la columna, además se utiliza como criterio de diseño y escalado del proceso de separación (García-Mateos et al., 2015). Entre los modelos matemáticos utilizados para ajustar las curvas de ruptura a los datos experimentales y poder predecir los procesos de adsorción se encuentran: el modelo de Yoon- Nelson, el de BohartAdams, el de Thomas y el modelo modificado de dosis-respuesta.

Teniendo en cuenta que es necesario alcanzar la saturación del lecho para poder ajustar los modelos matemáticos a los datos experimentales, se utilizaron los resultados obtenidos para la $\mathrm{Cbz}$ en la columna a escala de laboratorio, ya que solamente en estas condiciones se alcanzó la saturación, como se puede ver en la Figura 9.9.

\subsubsection{Modelo de Yoon-Nelson}

El modelo Yoon-Nelson es uno de los más simples, ya que no requiere características del adsorbato, del adsorbente, ni de parámetros de la columna. El modelo asume que se produce un avance del $50 \%$ en el tiempo denominado $\tau$. Por lo tanto, debido a la naturaleza simétrica de las curvas de ruptura, el lecho estará completamente saturado en $\mathrm{t}=2 \tau(\mathrm{Xu}$ et al., 2013). La forma básica del modelo se muestra en la Ecuación (9.1)

$$
\frac{C}{C_{0}}=\frac{1}{1+\operatorname{Exp}\left(K_{Y N} \tau-K_{Y N} t\right)}
$$

donde $\mathrm{C}_{0}$ y $\mathrm{C}$ son las concentraciones de $\mathrm{Cbz}(\mu \mathrm{g} / \mathrm{L})$ inicial y en el tiempo t, respectivamente. $\tau$ es el momento en que se produce un avance del $50 \%$ y $\mathrm{K}_{\mathrm{YN}}$ es la constante de velocidad de Yoon-Nelson. Los parámetros $\tau(h)$ y $K_{Y N}(1 / h)$ se pueden calcular a partir de la regresión y la reorganización de una ecuación sigmoidea de 3 parámetros, graficando $\mathrm{C} / \mathrm{C}_{0}$ vs t, como se muestra en la Figura 9.14 B.

Se obtuvo un buen ajuste de los datos experimentales de la $\mathrm{Cbz}$ con este modelo, con un coeficiente de correlación de 0,9928 y un p-valor $<0,0001$ para la regresión no lineal. De acuerdo a los resultados conseguidos se determinó un valor $\tau$ de 268 h y una constante de velocidad $\left(\mathrm{K}_{\mathrm{YN}}\right)$ de $0,01 \mathrm{1} / \mathrm{h}$, como se muestra en la Tabla 9.2. 
En los estudios con columnas de CAG se ha reportado el "tiempo de ruptura" cuando la concentración del adsorbato en el efluente es del $20 \%$ de la concentración inicial, para luego regenerar el CAG (Taty-Costodes et al., 2005). Sin embargo, teniendo en cuenta que el CAP es un material difícil de regenerar, y que en los libros de dimensionado de columnas se deja este parámetro a criterio del diseñador (Worch, 2012), en el presente trabajo se estableció el tiempo de vida útil de la columna mediante el valor del parámetro $\tau$, ya que hasta este momento se alcanzarían eficiencias de remoción de la Cbz superiores al 50\%.

\subsubsection{Modelo de Bohart-Adams}

El modelo de Bohart-Adams es el modelo más utilizado para predecir la adsorción en una columna. El modelo se basa en la teoría de la velocidad de reacción superficial y asume que la velocidad de adsorción es proporcional tanto a la concentración del adsorbato como a la capacidad de adsorción del adsorbente (Trgo et al., 2011). La forma básica del modelo se muestra en la Ecuación (9.2)

$$
\frac{C}{C_{0}}=\frac{1}{1+\operatorname{Exp}\left(K_{B A} q_{m} \frac{H}{u}-K_{B A} C_{0} t\right)}
$$

donde $\mathrm{C}_{0}$ y $\mathrm{C}$ son las concentraciones de $\mathrm{Cbz}(\mu \mathrm{g} / \mathrm{L})$ inicial y en el tiempo t, respectivamente, $\mathrm{q}_{\mathrm{m}}$ es la capacidad máxima de adsorción expresada en $\mathrm{mg} / \mathrm{g}$ y $\mathrm{K}_{\mathrm{BA}}$ es la constante de velocidad en L/mg.h. Los parámetros " $\mathrm{H}$ ” y " $u$ " son la profundidad del lecho adsorbente y la velocidad superficial, respectivamente. $K_{\mathrm{BA}}$ y $\mathrm{q}_{\mathrm{m}}$ se pueden calcular a partir de las curvas de avance mediante la regresión no lineal y la reorganización de la ecuación sigmoidea de tres parámetros, graficando $\mathrm{C}_{2} \mathrm{C}_{0}$ vs $\mathrm{C}_{0} \mathrm{t}$, como se muestra en la Figura 9.14 C. Se obtuvo un buen ajuste de los datos experimentales con el modelo de Bohart-Adams, con un coeficiente de correlación de 0,9928 y un p-valor para la regresión no lineal de $<0,0001$. Los valores obtenidos para la $\mathrm{K}_{\mathrm{BA}} \mathrm{y} \mathrm{q}_{\mathrm{m}}$ fueron de $0,02 \mathrm{~L} / \mathrm{mg}$.h y $41 \mathrm{mg} / \mathrm{g}$, como se muestra en la Tabla 9.2.

\subsubsection{Modelo de Thomas}

El modelo Thomas es otro modelo ampliamente utilizado para predecir los parámetros de las curvas de ruptura. Este asume una cinética de reacción reversible de segundo orden combinado con la isoterma de Langmuir (Trgo et al., 2011). La forma básica del mismo se muestra en la Ecuación (9.3) 


$$
\frac{C}{C_{0}}=\frac{1}{1+\operatorname{Exp}\left(K_{T} q_{e} \frac{m}{Q}-K_{T} C_{0} t\right)}
$$

Los parámetros $\mathrm{C}_{0} \mathrm{y} \mathrm{C}$ tienen el mismo significado anterior. $\mathrm{q}_{\mathrm{e}}$ es la capacidad de adsorción en el equilibrio expresada en $\mathrm{mg} / \mathrm{g}, \mathrm{K}_{\mathrm{T}}$ es la constante de velocidad del modelo de Thomas en L/mg.h, m es la masa del adsorbente (g) y Q es el caudal (L/h). De manera similar al modelo de Bohart-Adams, $\mathrm{q}_{\mathrm{e}} \mathrm{y} \mathrm{K}_{\mathrm{T}}$ se pueden calcular a partir de las curvas de avance mediante regresión no lineal de $\mathrm{C} / \mathrm{C}_{0}$ vs $\mathrm{C}_{0} \mathrm{t}$, como se muestra en la Figura 9.14 C. Se determinó una capacidad de adsorción en el equilibrio $\left(\mathrm{q}_{\mathrm{e}}\right)$ de 61 $\mathrm{mg} / \mathrm{g}$. La constante de velocidad presenta el mismo valor a la obtenida con el modelo de Bohart-Adams (0,02 L/mg.h), debido a la similitud de las ecuaciones.

\subsubsection{Modelo modificado de Dosis-respuesta}

El modelo modificado de dosis-respuesta (también conocido como el modelo de Yan) fue desarrollado para estudios farmacológicos (Yan et al., 2001), y recientemente se ha empleado en el estudio de remoción de contaminantes emergentes sobre CAG (Katsigiannis et al., 2015). La forma básica del modelo se muestra en la Ecuación (9.4)

$$
\frac{C}{C_{0}}=\frac{1}{1+\left(\frac{q_{e} m}{C_{0} Q t}\right)^{\alpha}}
$$

donde $\mathrm{C}_{0}$ y $\mathrm{C}$ son las concentraciones de $\mathrm{Cbz}(\mu \mathrm{g} / \mathrm{L})$ inicial y en el tiempo t, respectivamente, $\mathrm{q}_{\mathrm{e}}$ es la capacidad de adsorción en el equilibrio expresada en $\mathrm{mg} / \mathrm{g}, \alpha$ es la constante adimensional del modelo, m es la masa del adsorbente ( $g$ ) y Q es el caudal (L/h). A diferencia de los modelos anteriores, se utilizó la ecuación logística de tres parámetros en su forma no lineal, para determinar $\mathrm{q}_{\mathrm{e}} \mathrm{y} \alpha$, mediante el reordenamiento de parámetros y graficando $\mathrm{C} / \mathrm{C}_{0}$ vs $1 / \mathrm{t}$, como se muestra en la Figura 9.14 D. Se determinó un buen ajuste del modelo para los datos experimentales, con un coeficiente de correlación de 0,9956 y un p-valor $<0,0001$. La capacidad de adsorción en el equilibrio fue similar a la encontrada con el modelo de Thomas, con un valor de $70 \mathrm{mg} / \mathrm{g}$ (ver Tabla 9.2). 

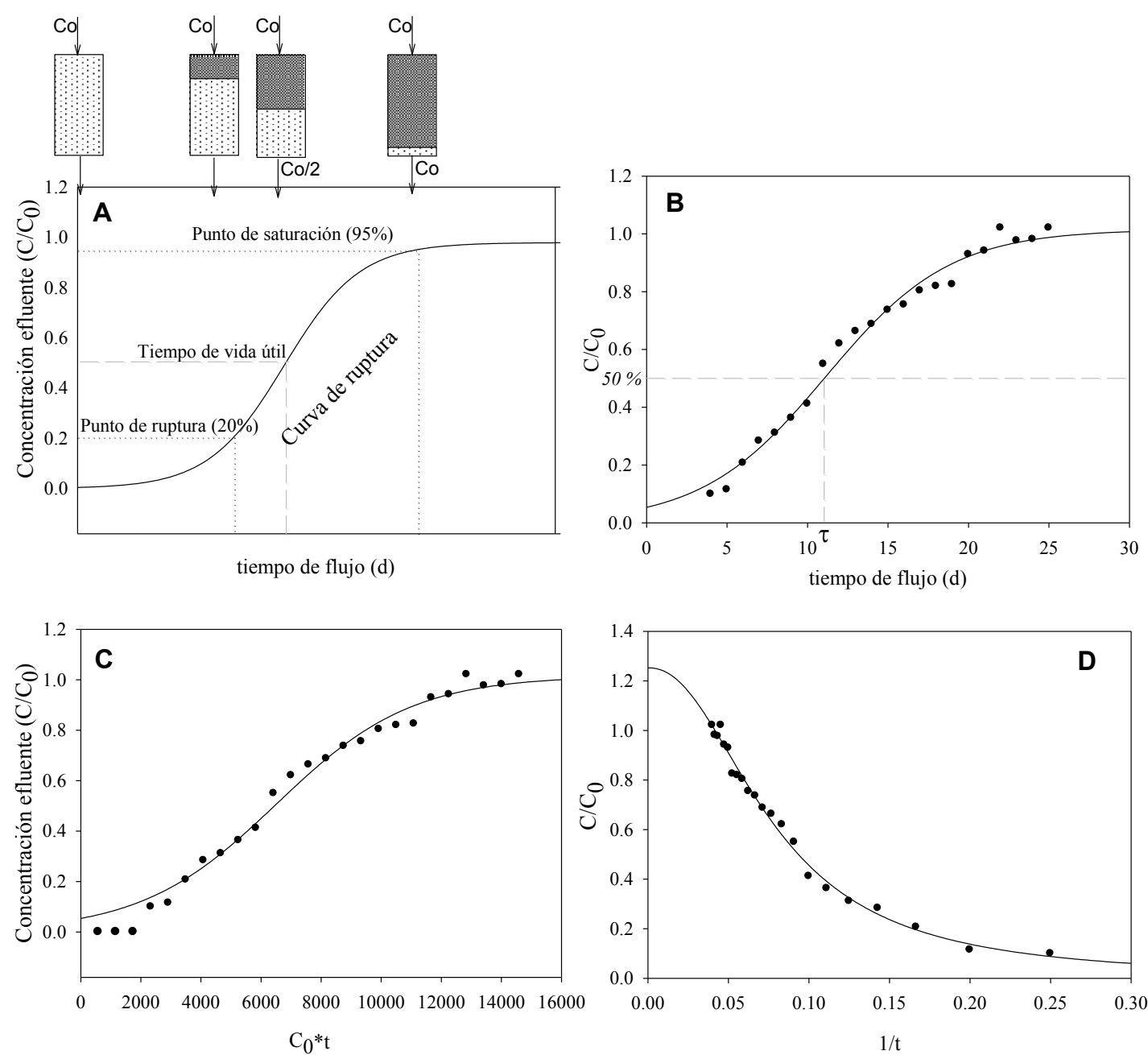

Figura 9.14. Comportamiento teórico de una curva de ruptura (A). Ajustes de los modelos de Yoon-Nelson (B), Bohart-Adamas y Thomas (C), y el modelo modificado dosis respuesta (D), para las concentraciones efluentes de Cbz, en la columna a escala de laboratorio. La concentración inicial nominal fue de $0,5 \mathrm{mg} / \mathrm{L}$.

Tabla 9.2. Parámetros obtenidos para predecir la adsorción de la Cbz en la columna a escala de laboratorio

\begin{tabular}{|c|c|c|c|c|c|c|c|}
\hline \multicolumn{4}{|c|}{ Modelo de Yoon-Nelson } & \multicolumn{4}{|c|}{ Modelo de Bohart-Adams } \\
\hline $\mathrm{K}_{\mathrm{YN}}(1 / \mathrm{h})$ & $\tau(\mathrm{h})$ & $\mathrm{R}$ & P-valor & $\mathrm{K}_{\mathrm{BA}}(\mathrm{L} / \mathrm{mg} \cdot \mathrm{h})$ & $\mathrm{q}_{\mathrm{m}}(\mathrm{mg} / \mathrm{g})^{*}$ & $\mathrm{R}$ & $\mathrm{P}$-valor \\
\hline 0.01 & 268 & 0,993 & $<0,0001$ & 0,02 & 41 & 0,993 & $<0,0001$ \\
\hline \multicolumn{4}{|c|}{ Modelo de Thomas } & \multicolumn{4}{|c|}{ Modelo modificado dosis-respuesta } \\
\hline $\mathrm{K}_{\mathrm{T}}(\mathrm{L} / \mathrm{mg} \cdot \mathrm{h})$ & $\mathrm{q}_{\mathrm{e}}(\mathrm{mg} / \mathrm{g})$ & $\mathrm{R}$ & P-valor & $\alpha$ & $\mathrm{q}_{\mathrm{e}}(\mathrm{mg} / \mathrm{g})$ & $\mathrm{R}$ & P-valor \\
\hline 0,02 & 61 & 0,993 & $<0,0001$ & 2,21 & 70 & 0,996 & $<0,0001$ \\
\hline
\end{tabular}


Según se vio se obtuvieron resultados satisfactorios en la predicción de la curva de ruptura para los cuatro modelos evaluados, con valores de los coeficientes de correlación superiores a 0,99. Cada uno de los mismos permitió obtener información valiosa del proceso de adsorción del fármaco sobre el CAP, como se puede ver en la Tabla 9.2. Los valores obtenidos para los parámetros con las diferentes ecuaciones resultaron muy similares, demostrando su pertinencia para la predicción de los mismos. Así por ejemplo, la velocidad de adsorción resultó similar, dentro del rango de error, para los modelos de Yoon-Nelson y el de Bhoart-Adams. Igualmente se obtuvieron valores equivalentes para la capacidad de adsorción en el equilibrio con los modelos de Thomas y el de dosis respuesta.

De acuerdo al comportamiento de la columna a escala de laboratorio, y sabiendo que la $\mathrm{Cbz}$ resultó ser el compuesto limitante en este proceso de adsorción, entonces se esperaría que la columna a escala piloto, que operó con 40 g de CAP, funcione aproximadamente durante 10 meses sin alcanzar la saturación, y con eficiencias de remoción superiores al 50\%, ya que con solamente $1 \mathrm{~g}$ de CAP se lograron remociones superiores al 50\% durante 268 h ( $\approx 11$ días); esto si se supone una relación proporcional entre los dos sistemas evaluados. Sin embargo, es necesario realizar estudios posteriores, con tiempos operativos mayores para corroborar la suposición que se está haciendo. Aunque es importante tener en cuenta que con la aproximación obtenida durante los 3 meses de funcionamiento, es posible un diseño que presente las condiciones necesarias para su extrapolación a escala real, satisfaciendo las necesidades de diferentes poblaciones.

En estudios anteriores con columnas de CAG en lecho fijo a escala de laboratorio se han reportado capacidades de adsorción en el equilibrio $\left(\mathrm{q}_{\mathrm{e}}\right)$ para la $\mathrm{Cbz}$ de $109 \mathrm{mg} / \mathrm{g}$ (Sotelo et al., 2013) y $170 \mathrm{mg} / \mathrm{g}$ (Torrellas et al., 2015a), siendo superiores a las obtenidas en el presente trabajo. Sin embargo esos estudios se realizaron en agua ultrapura, utilizando solamente $\mathrm{Cbz}$ en concentraciones mayores, mayor cantidad de CAG y caudales de trabajo menores respecto a los evaluados en esta experiencia. Por lo tanto bajo estas condiciones se tendrá mayor tiempo de contacto y mayor equilibrio de adsorción. Por el contrario, Katsigiannis et al. (2015), realizaron estudios bajo condiciones similares a las del presente trabajo, pero con $\mathrm{CAG}$, adicionando los compuestos en su mezcla en agua potable, y encontraron valores de $\mathrm{q}_{\mathrm{e}}$ de tan solo $0,055 \mathrm{mg} / \mathrm{g}$, para ibuprofeno, naproxeno y ketorpofeno. 


\subsection{Conclusiones parciales}

Teniendo en cuenta que en las últimas décadas, una gran cantidad de nuevos medicamentos están llegando al ambiente acuático a través del vertido de aguas residuales, y que no se cuenta con normativas que regulen su concentración, el desarrollo de tecnologías adecuadas, como las columnas de adsorción con carbón activado en polvo, resultan de gran interés ya que son capaces de obtener altas eficiencias de remoción para contaminantes modelos como la Cbz y el Sil. Además es importante tener en cuenta que esta problemática de incorporación de concentraciones trazas de contaminantes emergentes en las aguas superficiales, se ha visto agudizada últimamente por el rápido crecimiento poblacional.

El diseño desarrollado para la columna de adsorción con CAP a escala piloto, resultó ser muy eficaz para remover la carbamazepina y el sildenafil, en soluciones acuosas que presentan un comportamiento similar a las aguas residuales domésticas, alcanzando eficiencias de remoción superiores al $95 \%$ durante 3 meses de funcionamiento en continuo.

Este es el primer trabajo en el que se logró operar una columna con CAP en lecho fijo, sin necesidad de incorporar procedimientos adicionales para separar el CAP del agua tratada, ya que la arena además de generar porosidad en el medio, permite retenerlo.

El modelo modificado de dosis respuesta, el de Yoon-Nelson, Bohart-Adamas y el de Thomas, se ajustaron satisfactoriamente a los datos experimentales de la $\mathrm{Cbz}$, a escala de laboratorio, para predecir la curva de ruptura.

Mediante el empleo de columnas de adsorción con carbón activado en polvo, se podría reducir la magnitud de los efectos adversos que pueden producir los productos farmacéuticos sobre los recursos hídricos, la biota acuática y la salud humana. Implementar estas tecnologías contribuye al aseguramiento, la preservación y la mejora de la calidad de los cuerpos de agua, la salud pública y el ambiente, fomentando a la vez un desarrollo sostenible. 


\section{CAPÍTULO 10}

\section{CONCLUSIONES}

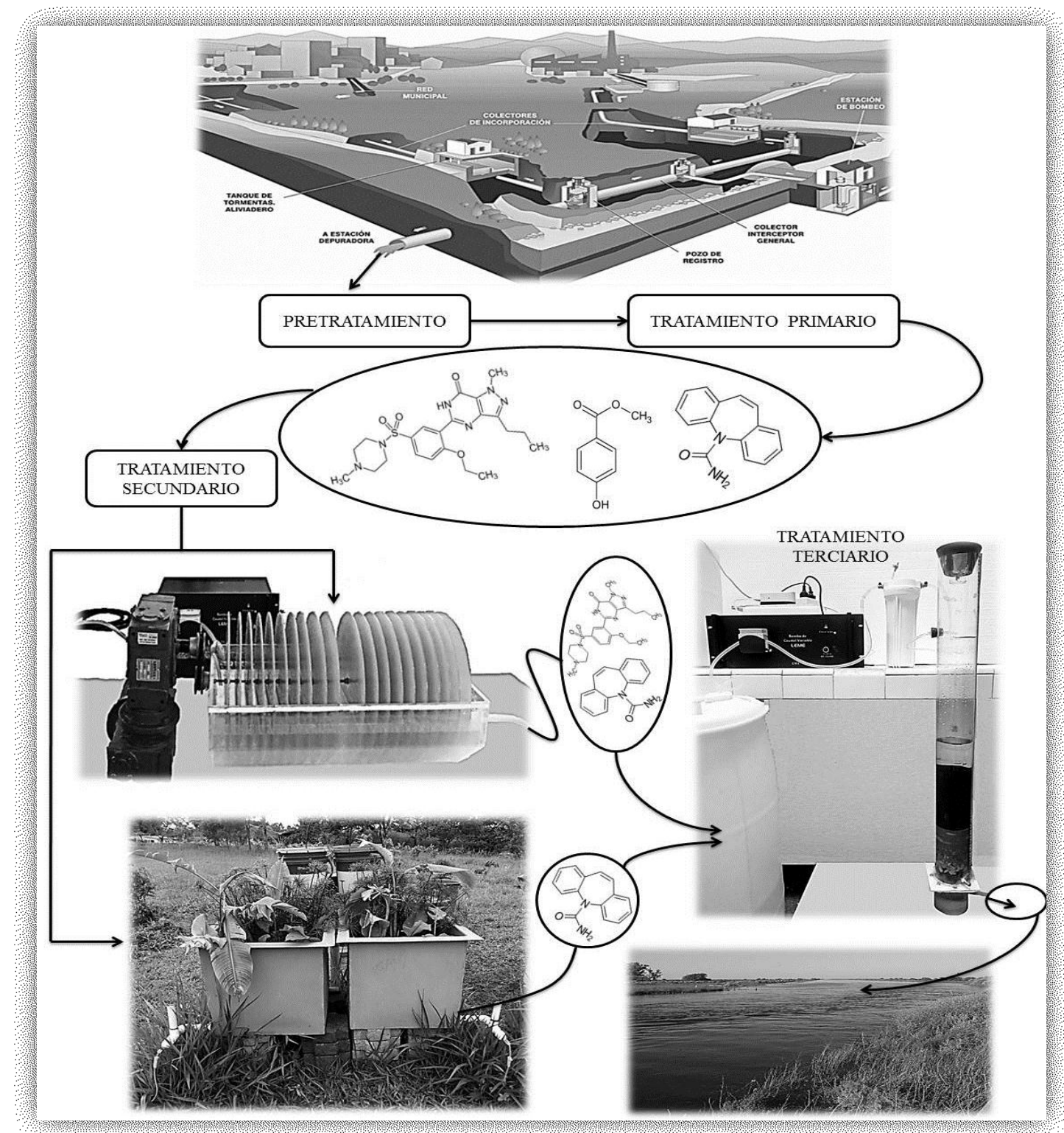


Aunque los productos farmacéuticos y de cuidado personal (PPCPs) han estado presentes en los cuerpos de agua durante décadas, sus niveles en el ambiente se han comenzado a cuantificar recientemente, reconociéndolos como potencialmente peligrosos para los ecosistemas y la salud humana. No existen concentraciones legalmente reguladas para su vertimiento, por lo que muchos de estos compuestos terminan en los cuerpos de agua debido a las descargas de aguas residuales sin tratamiento previo, o provenientes de las plantas de tratamiento convencionales (PTAR), que no los eliminan de manera efectiva. Por lo tanto, se requiere de procedimientos alternativos y específicos para reducir su impacto en los ecosistemas.

Teniendo en cuenta que en países como Argentina y Colombia son escasos los estudios de monitoreo de los PPCPs, en el presente trabajo se evaluaron tres contaminantes emergentes modelos: carbamazepina (Cbz), sildenafil (Sil), y metilparabeno (Mp), en diferentes sitios de muestreo. Todas las muestras analizadas, las cuales estaban vinculadas a actividades humanas, mostraron la presencia de estos contaminantes. En Argentina, el $\mathrm{Mp}$ fue el principal compuesto detectado y en mayores concentraciones, con valores de hasta $0,5 \mu \mathrm{g} / \mathrm{L}$; para la $\mathrm{Cbz}$ fueron inferiores a $0,1 \mu \mathrm{g} / \mathrm{L}$. Aclarando que no se presentan resultados del Sil. En Colombia la Cbz presentó valores de hasta $11 \mu \mathrm{g} / \mathrm{L}$, seguido del Mp y el Sil, con valores de 7,24 $\mu \mathrm{g} / \mathrm{L}$ y 2,64 $\mu \mathrm{g} / \mathrm{L}$, respectivamente. Las mayores concentraciones detectadas en este último caso se relacionaron con el mayor volumen de aguas residuales vertidas a ríos de bajos caudales. Es decir, en Popayán, cerca de 28.000 personas vierten sus aguas residuales al río Cauca, que tiene un caudal de aproximadamente $3.000 \mathrm{~m}^{3} / \mathrm{s}$; mientras que en La Plata se vierte casi la misma cantidad, pero en un río con un caudal de aproximadamente $22.000 \mathrm{~m}^{3} / \mathrm{s}$. Por otro lado, al comparar los resultados reportados por Peréz et al. (2018) para la Cbz y el Sil sobre el río Colastiné (Argentina), con los obtenidos en el río Cauca (Colombia), los que presentan condiciones similares de vertimientos y caudal de los ríos, se determinó que la aparición de los PPCPs es una problemática de igual magnitud en toda la región.

Resulta necesario entonces desarrollar tecnologías alternativas a las convencionales que permitan remover y mitigar los efectos negativos que estos compuestos puedan tener en el ambiente. A continuación se presentan los principales logros y desafíos que surgieron de haber evaluado los procesos estudiados a tal fin: 
contactores biológicos rotativos, humedales artificiales y procesos de adsorción con carbón activado.

Los biodiscos resultaron eficientes para remover compuestos de estructura molecular simple, como la del Mp, el cual tieneademás una estereoquímica favorable (molécula plana) para la adsorción sobre el biofilm, y una composición de elementos químicos esenciales $(\mathrm{C}, \mathrm{H}, \mathrm{O})$ que son fácilmente degradados por los microorganismos, obteniéndose remociones superiores al 95\%. De los resultados obtenidos para la Cbz y el Sil se plantea que es necesario aplicar procesos alternativos diferentes a éste. Esto es así dado que para ambos compuestos se obtuvieron eliminaciones inferiores al 10\%. En este trabajo se logró determinar que las bajas remociones de los fármacos se deben a la adsorción sobre el biofilm, mientras que para el Mp se confirmó su biodegradación, ya que no se detectó sobre la película bacteriana, ni en el agua tratada.

Esta técnica resulta además prometedora no solo por su eficiencia para remover el $\mathrm{Mp}$, sino que permite hacerlo manteniendo la calidad del efluente, como mostraron los estudios realizados para los parámetros fisicoquímicos. Se alcanzaron eficiencias de remoción para la materia orgánica de hasta un 95\%.

Otro aspecto a tener en cuenta para la viabilidad de esta técnica son los periodos de estabilización del sistema y la posibilidad de trabajar con la mezcla de los PPCPs. En este sentido se pudo determinar que luego de trabajar con los compuestos de forma individual, son necesario tiempos superiores a $100 \mathrm{~h}$ para alcanzar la estabilidad operativa para la $\mathrm{Cbz}$; mientras que para Sil y $\mathrm{Mp}$ fueron de aproximadamente $50 \mathrm{~h}$. Por otro lado, al adicionarlos en su mezcla, con cargas orgánicas típicas de un afluente secundario y terciario, solo se necesitaron $24 \mathrm{~h}$. Concluyendo que la mezcla de los compuestos, que corresponde a una situación más realista, permite trabajar en condiciones aceptables de acuerdo a lo esperado. En particular se sugiere que este último comportamiento se puede asociar a la transferencia de información horizontal por parte de las bacterias y/o a su selección, luego de haber estado en contacto con los compuestos agregados individualmente.

A fin de mejorar la remoción de la Cbz y el Sil, se estudiaron los humedales artificiales de flujo horizontal subsuperficial, como un tratamiento secundario, adicionando los PPCPs en su mezcla. Además se sembraron dos reactores en policultivo con macrófitas típicas de la zona de estudio (Cyperus Haspan y Heliconea 
Zingiberales), y se dejaron dos sin sembrar. Esta tecnología resultó satisfactoria para eliminar el Sil, obteniendo remociones de hasta un 97\% en los humedales plantados; en contraste para los no plantados se redujo en un 30\%. Además se alcanzaron eficiencias de eliminación superiores al 95\% para el Mp y la materia orgánica, en todos los reactores evaluados. Se concluyó que los sistemas plantados son capaces de remover eficientemente compuestos de estructura molecular simple, como el $\mathrm{Mp}$, y de estructura más compleja, como el Sil, a pesar de ser reportado como recalcitrante mediante el uso de tratamientos convencionales. Estos resultados sugieren que el Sil es susceptible al tipo de microorganismos presentes en los humedales; en consecuencia, el uso de estas macrófitas constituye un medio adecuado para eliminarlo.

Se determinaron tiempos de 20 días, 40 días y 60 días para alcanzar la estabilidad operativa del sistema respecto del Mp, la Cbz y el Sil, respectivamente; por lo que se recomienda considerar estos periodos de tiempo para estudios posteriores.

En los análisis de absorción de los PPCPs sobre las macrófitas, se determinó que la Cbz fue el compuesto mayormente detectado, seguido por el Sil y el Mp, principalmente en el Cyperus Haspan, la cual presentó menos síntomas de estrés que la Heliconea Zingiberales. En los de adsorción sobre el sustrato, la mayor concentración detectada fue de Sil, seguido de la $\mathrm{Cbz}$ y el $\mathrm{Mp}$. Estos resultados, no reflejaron en su mismo orden las mejores eficiencias de remoción de los PPCPs, dado que el $\mathrm{Mp}$, que fue el compuesto con menores concentraciones detectadas en ambos procesos, fue el más eficientemente removido, dando evidencias de su biodegradación. Para el Sil uno de los principales mecanismos que contribuyó en su eliminación se ve reflejado en la adsorción sobre el sustrato, que al parecer permite retenerlo el tiempo suficiente para que sea degradado por las plantas o por los microorganismos específicos desarrollados a partir de ellas.

Considerando que la $\mathrm{Cbz}$ se comportó como un contaminante recalcitrante frente a ambos tratamientos biológicos, y que el Sil no se logró remover en los biodiscos, se evaluó el carbón activado granular comercial (CAG) como proceso alternativo. El comportamiento de los tres PPCPs se evaluó de forma individual en experimentos de laboratorio en batch. Se determinaron capacidades máximas de adsorción de aproximadamente $200 \mathrm{mg} / \mathrm{g}$ para la Cbz y el Mp, y de $114 \mathrm{mg} / \mathrm{g}$ para el Sil, evaluados mediante la isoterma de Langmuir. Sin embargo, la cinética de adsorción fue demasiado lenta, con tiempos medios superiores a 168 h. Además, se 
observó que el tiempo necesario para que los compuestos alcancen el equilibrio aumenta progresivamente tras la reducción de su concentración inicial, este hecho dificultó el análisis de la cinética de adsorción, dado que las ecuaciones tradicionales requieren del conocimiento del valor de equilibrio de adsorción $\left(\mathrm{q}_{\mathrm{e}}\right)$.

Se desarrolló un nuevo análisis de velocidad que permitió obtener los parámetros cinéticos de adsorción, particularmente $\mathrm{q}_{\mathrm{e}} \mathrm{y} \mathrm{q}_{\mathrm{m}}$, sin suposiciones a priori $\mathrm{y}$ sin alcanzar el equilibrio. Sobre la base de este modelo se determinó que la adsorción sigue una reacción de seudo primer orden, con constantes de velocidad entre $0,003 \mathrm{1} / \mathrm{h}$ - 0,032 1/h para los tres PPCPs. La información obtenida fue valiosa para definir su interacción sobre el CAG, ya que se pudo establecer que el uso de este material como tecnología para la remoción de PPCPs del agua, debe contemplar la baja velocidad de adsorción al momento de diseñar un sistema a escala real.

Con el fin de mejorar la adsorción de los PPCPs, se estudió el carbón activado en polvo (CAP). En esta instancia, conociendo que el Mp es eficientemente removido en los tratamientos biológicos, y con el fin de desarrollar esta tecnología como un tratamiento terciario combinada a los mismos, solo se estudiaron los fármacos.

En estudios de laboratorio en modo batch se determinó que el CAP presenta mayor capacidad y velocidad de adsorción que el CAG. Así por ejemplo, para una concentración inicial de aproximadamente $10 \mathrm{mg} / \mathrm{L}$ de $\mathrm{Cbz}$ y Sil, la eficiencia de remoción fue superior al $80 \%$ sobre el CAP, en una ventana de tiempo de $8 \mathrm{~h}$, mientras que con el CAG fueron inferiores al 10\%. Además el tiempo medio de adsorción fue de $4 \mathrm{~h}$ horas para ambos compuestos sobre el CAP, mientras para el CAG fue superior a $80 \mathrm{~h}$. De acuerdo a estos resultados, se analizó la cinética y las isotermas de adsorción, logrando alcanzar el equilibrio, y determinando que el modelo que mejor se ajustó a los datos experimentales fue el de seudo primer orden, con constantes de velocidad entre $0,141 / \mathrm{h}$ y $0,231 / \mathrm{h}$, para ambos fármacos. La isoterma de Langmuir fue un buen enfoque para evaluar la capacidad de remoción de Cbz y Sil. Aunque, la isoterma de Redlich-Peterson también describió el comportamiento de la $\mathrm{Cbz}$, sugiriendo un mecanismo híbrido entre las isotermas de Langmuir y Freundlich. Se determinó una capacidad máxima de adsorción de $220 \mathrm{mg} / \mathrm{g}$ y $395 \mathrm{mg} / \mathrm{g}$ para la Cbz y el Sil, respectivamente, siendo superior a la obtenida con el CAG, al igual que la velocidad de adsorción. Así, el CAP surge como una tecnología prometedora para la eliminación de estos compuestos farmacéuticos presentes en los cuerpos de agua. 
Dada la alta eficiencia del CAP en la remoción de los fármacos, en el presente trabajo se inició, y se logró desarrollar el primer diseño de una columna en lecho fijo con CAP, tanto a escala de laboratorio como piloto. Se destaca su mezcla con la arena (AR), como una buena estrategia para generar porosidad en el medio adsorbente, y para su retención en la solución acuosa. La mejor relación obtenida de CAP:AR fue 1:50. De este modo se pudo optimizar el funcionamiento de la columna. Luego se corroboró que la misma debía funcionar como un tratamiento terciario, ya que es necesario retirar la mayor cantidad de materia orgánica, para evitar la proliferación de microorganismos que puedan causar obstrucción y disminución de área superficial del CAP. Este material no fue tenido en cuenta anteriormente en las PTAR debido a su dificultad para manipularlo, ya que se lo ha propuesto como un tratamiento en tanques agitados batch, debiendo utilizar membranas o productos químicos para separarlo del agua tratada, lo cual elevaba los costos de operación.

En el diseño a escala de laboratorio, en lecho fijo, se pudo determinar que el Sil se removía eficientemente, con porcentajes superiores al $90 \%$ durante 25 días de funcionamiento en continuo. Para la Cbz se alcanzó la saturación luego de 23 días. De acuerdo a estos resultados se determinó que la $\mathrm{Cbz}$ es el reactivo limitante para establecer el tiempo de operatividad del lecho adsorbente. A estos resultados se les ajustaron diferentes modelos matemáticos para predecir la curva de ruptura, la cual se utiliza como criterio de diseño y escalado de los procesos de separación. Todos los modelos evaluados (el modelo modificado de dosis respuesta, el de Yoon-Nelson, Bohart-Adamas y el de Thomas) se ajustaron satisfactoriamente a los datos experimentales, con coeficiente de correlación superiores a 0,99 y p-valores $<0,0001$. Se determinó un punto de ruptura de 11 días, una capacidad promedio de adsorción en el equilibrio de $65 \mathrm{mg} / \mathrm{g}$ y una constante de velocidad de adsorción promedio de 0,443 L/mg.d.

Habiendo determinado un buen funcionamiento operativo y de remoción de los fármacos se extrapoló este diseño a escala piloto. El cual resultó ser muy eficaz, alcanzando eficiencias de remoción superiores al 90\% para ambos compuestos, durante 3 meses de funcionamiento en continuo trabajando tan solo con $40 \mathrm{~g}$ de CAP. Por lo tanto se concluye que este diseño resulta prometedor para remover estos contaminantes emergentes de las aguas residuales. 
El utilizar tecnologías combinadas alternativas, ayuda a remover los PPCPs de las aguas residuales. Así por ejemplo, en regiones aisladas y pequeñas comunidades, que cuentan con pocas capacidades energéticas y económicas, se recomienda el uso de los humedales artificiales como tratamiento secundario; mientras que en las ciudades se recomienda la instalación de contactores biológicos rotativos, ya que estos permiten trabajar con grandes caudales en espacios más reducidos. En ambos casos es necesario un tratamiento terciario con columnas de carbón activado en polvo, para remover de manera eficiente contaminantes recalcitrantes, como la $\mathrm{Cbz}$, y concentraciones remanentes del Sil que puedan quedar de los tratamientos secundarios.

Además, mediante el empleo de estas tecnologías, se podría reducir la magnitud de los efectos adversos que pueden producir estos contaminantes sobre los cuerpos de agua, el ambiente acuático y la salud humana. Su implementación contribuye al aseguramiento, la preservación y la mejora de la calidad de los recursos de agua, la salud pública y el ambiente, fomentando a la vez un desarrollo sostenible. Conjuntamente es fundamental implementar regulaciones y medidas de gestión con respecto al uso y vertimiento de contaminantes emergentes en los cuerpos de agua, así como datos de monitoreo, para lograr un gestión eficiente de los recursos hídricos. Igualmente es importante generar conciencia en las personas, para evitar el uso indiscriminado de una gran cantidad de compuestos químicos que resultan dañinos para el ambiente. Como así también dejar de ver las aguas superficiales como un lugar de depósito de desechos. Las personas debemos aprender a convivir de forma más amigable con nuestro planeta, porque él nos brinda todo lo necesario para llevar una vida agradable y tranquila, y nosotros a cambio le estamos devolviendo destrucción. 
Ae

APC

AR

ARs

BET

Caf

CAG

CAP

CBR

$\mathrm{Cbz}$

Ce

CE

CH

CL

CS

$\mathrm{C}_{\mathrm{t}}$

$\mathrm{C}_{0}$

DQO

DTR

EDA

EDE

EDTA

H

$\mathrm{H}_{1}$ y $\mathrm{H}_{2}$

$\mathrm{H}_{3} \mathrm{y} \mathrm{H}_{4}$

HPLC-MS

HSJ

JL

K

$\mathbf{k}_{\mathrm{a}}$

$\mathbf{K}_{\mathrm{BA}}$

$\mathbf{k}_{\mathrm{d}}$

$\mathbf{K}_{\mathrm{F}}$

$\mathbf{K}_{\mathbf{L}}$

$\mathbf{K}_{\mathrm{LF}}$

$\mathbf{k}_{\mathbf{p}}$

$\mathbf{K}_{\mathrm{RP}}$

$\mathbf{K}_{\mathbf{T}}$

$K_{\mathbf{Y N}}$

$K_{1}$

$\mathbf{K}_{2}$

LC

LC-MS/MS
Aeronáutica civil

Agua potable con cloración

Arena

Agua residual sintética

Medidas Brunauer-Emmett-Teller

Cafeína

Carbón activado granular

Carbón activado en polvo

Contactor biológico rotativo

Carbamazepina

Concentración del adsorbato en el equilibrio

Contaminantes emergentes

Cordón hortícola Platense

Cloaca

Canal colector sur

Concentración en el tiempo $t$

Concentración inicial

Demanda química de oxígeno

Distribución del tiempo de residencia

Afluente de la PTAR

Efluente de la OTRA

Ácido etilendiaminotetraacético

Constante de Henry

Humedales construidos sin plantar

Humedales construidos plantados

Cromatografía líquida de alta eficiencia acoplada a espectrometría de masas

Hospital San José

José Ilario López (barrio)

Constante de velocidad global

constante de adsorción

Constante de velocidad de Bohart-Adams

Constante de desorción

Constante de adsorción en el equilibrio de Freundlich)

Constante de adsorción en el equilibrio de Langmuir

Constante de afinidad del modelo Langmuir-Freundlich

Constante de velocidad de difusión intrapartícula

Constante en la isoterma Redlich-Peterson

Constante de velocidad del modelo de Thomas

Constante de velocidad de Yoon-Nelson

Constantes de velocidad aparente de seudo primer orden

Constantes de velocidad aparente de seudo segundo orden

Límite de cuantificación

Cromatografía líquida acoplada a espectrometria de masas en tandem 


\begin{tabular}{|c|c|}
\hline LD & Límite de detección \\
\hline LECA & Arcilla expandida ligera \\
\hline L-F & Isoterma de Langmuir-Freundlich \\
\hline $\log K_{\text {ow }}$ & Coeficiente de reparto octanol-agua \\
\hline $\log K_{o c}$ & Coeficiente de reparto agua-carbono orgánico del suelo \\
\hline Lg & Lomas de Granada (Barrio) \\
\hline Мр & Metilparabeno \\
\hline МеОН & Metanol \\
\hline O.D & Oxígeno disuelto \\
\hline PA & Balneario Paso de Alonso \\
\hline PC & Puente paso del comercio \\
\hline $\mathbf{P H}$ & Puente Hormiguero \\
\hline pKa & logaritmo negativo de la constante de ionización de un ácido \\
\hline $\mathbf{P P}$ & Planta poptabilizadora \\
\hline PPA & Afluente de la planta potabilizadora \\
\hline PPCPs & Fármacos y productos de cuidado personal \\
\hline PT & Plantas de tratamiento de aguas residuales \\
\hline PTAR & Plantas de tratamiento de aguas residuales \\
\hline PTAP & Plantas de tratamiento de agua potable \\
\hline $\mathbf{Q}$ & Caudal \\
\hline $\mathbf{q}_{\mathrm{e}}$ & Concentración del adsorbato en el equilibrio \\
\hline $\mathbf{q}_{\mathbf{m}}$ & Máxima capacidad de adsorción \\
\hline $\mathbf{q}_{\mathbf{t}}$ & Cantidad adsorbida en el tiempo $t$ \\
\hline RDT & Rosario del Tala \\
\hline $\mathbf{S}$ & Sección transversal \\
\hline Sil & Sildenafil \\
\hline SPE & Extracción de fase sólida \\
\hline $\mathbf{t}$ & Tiempo \\
\hline TRH & Tiempo de retención hidráulico \\
\hline UPLC-MS/MS & Cromatógrafo líquido de ultrapresión \\
\hline $\mathbf{V}$ & Volumen de la solución \\
\hline $\mathbf{v}_{0}$ & Velocidad inicial de adsorción \\
\hline$v_{t}$ & Velocidad de adsorción en un tiempo t \\
\hline $\mathbf{W}$ & Peso del adsorbente \\
\hline Ws & Solubilidad en agua \\
\hline 2B & Balneario Dos Banderas \\
\hline
\end{tabular}




\section{BIBLIOGRAFÍA}

Abdel, A.M., 2013. Studying the efficiency of grey water treatment by using rotating biological contactors system. Journal of King Saud University - Engineering Sciences 25, 89-95.

Aksu, Z., Gönen, F., Demircan, Z., 2002. Biosorption of chromium(VI) ions by Mowital ${ }^{\circledR} \mathrm{B} 30 \mathrm{H}$ resin immobilized activated sludge in a packed bed: comparison with granular activated carbon. Process Biochemistry 38, 175-186.

Al-Othman, Z.A., Ali, R., Naushad, M., 2012. Hexavalent chromium removal from aqueous medium by activated carbon prepared from peanut shell: Adsorption kinetics, equilibrium and thermodynamic studies. Chemical Engineering Journal 184, 238-247.

Alemzadeh, I., Vossoughi, M., 2001. Biodegradation of toluene by an attached biofilm in a rotating biological contactor. Process Biochem 36, 707-711.

Aljeboree, A.M., Alshirifi, A.N., Alkaim, A.F., 2017. Kinetics and equilibrium study for the adsorption of textile dyes on coconut shell activated carbon. Arabian Journal of Chemistry 10, S3381-S3393.

Altmann, J., Ruhl, A.S., Zietzschmann, F., Jekel, M., 2014. Direct comparison of ozonation and adsorption onto powdered activated carbon for micropollutant removal in advanced wastewater treatment. Water Research 55, 185-193.

Altmann, J., Sperlich, A., Jekel, M., 2015. Integrating organic micropollutant removal into tertiary filtration: Combining PAC adsorption with advanced phosphorus removal. Water Research 84, 58-65.

Álvarez-Torrellas, S.O., Gabriel García Rodríguez, Juan, 2017. Eliminación de contaminantes emergentes de las aguas residuales, Investigación y Ciencia. Universidad Pompeu Fabra, Barcelona, p. 3.

Amin, A., Chauhan, S., Dare, M., Bansal, A.K., 2010. Degradation of parabens by Pseudomonas beteli and Burkholderia latens. Eur J Pharm Biopharm 75, 206212. 
Anjos, M.L., Isique, W.D., Albertin, L.L., Matsumoto, T., Henares, M.N.P., 2018. Parabens Removal from Domestic Sewage by Free-Floating Aquatic Macrophytes. Waste and Biomass Valorization.

APHA, 1998. Standard methods for the examination of water and wastewater. American Public Health Association, Washington, DC.

Archer, E., Petrie, B., Kasprzyk-Hordern, B., Wolfaardt, G.M., 2017a. The fate of pharmaceuticals and personal care products (PPCPs), endocrine disrupting contaminants (EDCs), metabolites and illicit drugs in a WWTW and environmental waters. Chemosphere 174, 437-446.

Archer, E., Wolfaardt, G.M., van Wyk, J.H., 2017b. Pharmaceutical and personal care products (PPCPs) as endocrine disrupting contaminants (EDCs) in South African surface waters. Water SA 43, 684-706.

Aristizabal , C., Botero Coy, A.M., López, F.J., Peñuela, G.A., 2017. Monitoring pharmaceuticals and personal care products in reservoir water used for drinking water supply. Environmental Science and Pollution Research 24, 7335-7347.

Arrubla, J.P., Cubillos, J.A., Ramírez, C.A., Arredondo, J.A., Arias, C.A., Paredes, D., 2016. Pharmaceutical and personal care products in domestic wastewater and their removal in anaerobic treatment systems: septic tank - up flow anaerobic filter. Ingeniería e Investigación 36, 70-78.

Asenjo, N. G., 2014. Una nueva generación de CA de altas prestaciones para aplicaciones medioambientales, Departamento de Ciencia y Tecnología de Materiales. Universidad de Oviedo, Oviedo, España, p. 217.

Ávila, C., Reyes, C., Bayona, J.M., García, J., 2013. Emerging organic contaminant removal depending on primary treatment and operational strategy in horizontal subsurface flow constructed wetlands: Influence of redox. Water Research 47, 315-325.

Azizian, S., 2004. Kinetic models of sorption: a theoretical analysis. Journal of Colloid and Interface Science 276, 47-52.

Azizian, S., Fallah, R.N., 2010. A new empirical rate equation for adsorption kinetics at solid/solution interface. Applied Surface Science 256, 5153-5156. 
Baccar, R., Sarrà, M., Bouzid, J., Feki, M., Blánquez, P., 2012. Removal of pharmaceutical compounds by activated carbon prepared from agricultural byproduct. Chemical Engineering Journal 211-212, 310-317.

Baker, D.R., Kasprzyk-Hordern, B., 2011. Multi-residue analysis of drugs of abuse in wastewater and surface water by solid-phase extraction and liquid chromatography-positive electrospray ionisation tandem mass spectrometry. Journal of Chromatography A 1218, 1620-1631.

Banerjee, D., Sarkar, U., Chakraborty, S., Roy, D., 2014. Removal of a cationic bisbiguanide using Functionalized Activated Carbons (FACs). Process Safety and Environmental Protection 92, 957-972.

Bellver, A., Fuentes, R., Hernández-Sancho, F., 2017. Shadow prices of emerging pollutants in wastewater treatment plants: Quantification of environmental externalities. Journal of Environmental Management 203, 439-447.

Benson, S.W., 1960. The foundations of chemical kinetics. McGraw-Hill, New York.

Bhide, J. V., Dhakephalkar, P. K., Paknikar, K. M., 1996. Microbiological process for the removal of $\mathrm{Cr}(\mathrm{VI})$ from chromate-bearing cooling tower effluent. Biotechnol Lett 18, 667-672.

Binelli, A., Pedriali, A., Riva, C., Parolini, M., 2012. Illicit drugs as new environmental pollutants: Cyto-genotoxic effects of cocaine on the biological model Dreissena polymorpha. Chemosphere 86, 906-911.

Bolong, N., Ismail, A.F., Salim, M.R., Matsuura, T., 2009. A review of the effects of emerging contaminants in wastewater and options for their removal. Desalination 239, 229-246.

Bondia, J.R., 2014. Eliminación de contaminantes emergentes mediante humedales artificiales como sistema alternativo o complementario a un tratamiento de aguas convencional, Ingeniería Hidráulica y Medio Ambiente. Universidad Politécnica de Valencia, Departamento de Ingeniería Hidráulica y Medio Ambiente p. 67.

Boyd, G.R., Reemtsma, H., Grimm, D.A., Mitra, S., 2003. Pharmaceuticals and personal care products (PPCPs) in surface and treated waters of Louisiana, USA and Ontario, Canada. Science of The Total Environment 311, 135-149. 
Bratkowska, D., Marcé, R.M., Cormack, P.A.G., Borrull, F., Fontanals, N., 2011. Development and application of a polar coating for stir bar sorptive extraction of emerging pollutants from environmental water samples. Analytica Chimica Acta $706,135-142$.

Bu, Q., Wang, B., Huang, J., Deng, S., Yu, G., 2013. Pharmaceuticals and personal care products in the aquatic environment in China: A review. Journal of Hazardous Materials 262, 189-211.

Cabije, A.H., Agapay, R.C., Tampus, M.V., 2009. Carbon-nitrogen-phosphorus removal and biofilm growth characteristics in an integrated wastewater treatment system involving a rotating biological contactor. Asia-Pacific Journal of Chemical Engineering 4, 735-743.

Cai, N., Larese, C., 2014. Sorption of carbamazepine by commercial graphene oxides: a comparative study with granular activated carbon and multiwalled carbon nanotubes. Journal of colloid and interface science 426, 152-161.

Calamari, D., 1993. Chemical exposure predictions. Lewis, Boca raton, pp. 256.

Çalışkan, E., Göktürk, S., 2010. Adsorption Characteristics of Sulfamethoxazole and Metronidazole on Activated Carbon. Separation Science and Technology 45, 244-255.

Casas, J.C., Ríos, K., Florville-Alejandre, T.R., Morató, J., Peñuela, G., 2013. Influence of chlorothalonil on the removal of organic matter in horizontal subsurface flow constructed wetlands. Journal of Environmental Science and Health, Part B 48, 122-132.

Česen, M., Ahel, M., Terzić, S., Heath, D.J., Heath, E., 2019. The occurrence of contaminants of emerging concern in Slovenian and Croatian wastewaters and receiving Sava river. Science of The Total Environment 650, 2446-2453.

Cizmas, L., Sharma, V.K., Gray, C.M., McDonald, T.J., 2015. Pharmaceuticals and personal care products in waters: occurrence, toxicity, and risk. Environmental Chemistry Letters 13, 381-394.

Clara, M., Strenn, B., Kreuzinger, N., 2004. Carbamazepine as a possible anthropogenic marker in the aquatic environment: investigations on the 
behaviour of Carbamazepine in wastewater treatment and during groundwater infiltration. Water Research 38, 947-954.

Cooper, P., 1999. A review of the design and performance of vertical-flow and hybrid reed bed treatment systems. Water Science and Technology 40, 1-9.

Cortez, S., Teixeira, P., Oliveira, R., Mota, M., 2008. Rotating biological contactors: a review on main factors affecting performance. Reviews in Environmental Science and Bio/Technology 7, 155-172.

Costley, S.C., Wallis, F.M., 2000. Effect of flow rate on heavy metal accumulation by rotating biological contactor (RBC) biofilms. J Ind Microbiol Biotechn 24, 244-250.

Costley, S.C., Wallis, F.M., 2001. Bioremediation of heavy metals in a synthetic wastewater using a rotating biological contactor. Water Res 35, 3715-3723.

Cruz, S.D., Barceló, D., 2015. Personal Care Products in the Aquatic Environment. Springer International Publishing.

Chang, E.E., Wan, J.-C., Kim, H., Liang, C.-H., Dai, Y.-D., Chiang, P.-C., 2015. Adsorption of Selected Pharmaceutical Compounds onto Activated Carbon in Dilute Aqueous Solutions Exemplified by Acetaminophen, Diclofenac, and Sulfamethoxazole. The Scientific World Journal 2015, 11.

Cheung, W.H., Szeto, Y.S., McKay, G., 2007. Intraparticle diffusion processes during acid dye adsorption onto chitosan. Bioresource Technology 98, 2897-2904.

De Felice, B., Argenziano, C., Guida, M., Trifuoggi, M., Russo, F., Condorelli, V., Inglese, M., 2008. Molecular Characterization of Microbial Population Dynamics during Sildenafil Citrate Degradation. Mol Biotechnol 41, 123-132.

Deblonde, T., Cossu-Leguille, C., Hartemann, P., 2011. Emerging pollutants in wastewater: A review of the literature. International Journal of Hygiene and Environmental Health 214, 442-448.

Delgado, N., Capparelli, A., Marino, D., Navarro, A., Peñuela, G., Ronco, A., 2016. Adsorption of Pharmaceuticals and Personal Care Products on Granular Activated Carbon. Journal of Surface Engineered Materials and Advanced Technology Vol.06No.04, 18. 
Delgado, N., Navarro, A., Marino, D., Peñuela, G.A., Ronco, A., 2018. Removal of pharmaceuticals and personal care products from domestic wastewater using rotating biological contactors. International Journal of Environmental Science and Technology.

Derylo-Marczewska, A., Marczewski, A.W., Winter, S., Sternik, D., 2010. Studies of adsorption equilibria and kinetics in the systems: Aqueous solution of dyesmesoporous carbons. Applied Surface Science 256, 5164-5170.

Desrosiers, S.S.a.M., 2014. A review of what is an emerging contaminant. Chemistry Central Journal 8, 15.

Dimpe, K.M., Nomngongo, P.N., 2016. Current sample preparation methodologies for analysis of emerging pollutants in different environmental matrices. TrAC Trends in Analytical Chemistry 82, 199-207.

Dordio, A., Carvalho, A.J.P., Teixeira, D.M., Dias, C.B., Pinto, A.P., 2010. Removal of pharmaceuticals in microcosm constructed wetlands using Typha spp. and LECA. Bioresource Technology 101, 886-892.

Dordio, A.V., Belo, M., Martins Teixeira, D., Palace Carvalho, A.J., Dias, C.M.B., Picó, Y., Pinto, A.P., 2011. Evaluation of carbamazepine uptake and metabolization by Typha spp., a plant with potential use in phytotreatment. Bioresource Technology 102, 7827-7834.

Duca, G., Boldescu, V., 2009. Pharmaceuticals and Personal Care Products in the Environment. Springer Netherlands, Dordrecht, pp. 27-35.

Duque, A.F., Bessa, V.S., Carvalho, M.F., Castro, P.M.L., 2011. Bioaugmentation of a rotating biological contactor for degradation of 2-fluorophenol. Bioresource Technol 102, 9300-9303.

Ebele, A.J., Abou-Elwafa Abdallah, M., Harrad, S., 2017. Pharmaceuticals and personal care products (PPCPs) in the freshwater aquatic environment. Emerging Contaminants 3, 1-16.

Elorriaga, Y., Marino, D., Carriquiriborde, P., Ronco, A., 2013a. Human Pharmaceuticals in Wastewaters from Urbanized Areas of Argentina. Bull Environ Contam Toxicol 90, 397-400. 
Elorriaga, Y., Marino, D.J., Carriquiriborde, P., Ronco, A.E., 2013b. Screening of pharmaceuticals in surface water bodies of the Pampas region of Argentina. International Journal of Environment and Health 6, 330-339.

EPA, 2011. Water Treatment Manual: Disinfection. Environmental protection Agency, Ireland, p. 200.

Eric Lichtfouse, J.S., Didier Robert, 2013. Green Materials for Energy, Products and Depollution. Springer, Netherlands.

Espinel, A., Valencia, J.L., 2007. Al río Cauca lo están matando las 500 toneladas de contaminantes que le caen cada día, El Tiempo. El Tiempo, Cali, p. 17.

Fan, C., Wang, H.-C., 2012. Degradation of Methyl Paraben by the Aerated Pebblebed Biofilm System. APCBEE Procedia 1, 299-303.

Farré, M.1., Pérez, S., Kantiani, L., Barceló, D., 2008. Fate and toxicity of emerging pollutants, their metabolites and transformation products in the aquatic environment. TrAC Trends in Analytical Chemistry 27, 991-1007.

Fent, K., Weston, A.A., Caminada, D., 2006. Ecotoxicology of human pharmaceuticals. Aquatic Toxicology 76, 122-159.

Ferrari, B.t., Paxéus, N., Giudice, R.L., Pollio, A., Garric, J., 2003. Ecotoxicological impact of pharmaceuticals found in treated wastewaters: study of carbamazepine, clofibric acid, and diclofenac. Ecotox Environ Safe 55, 359370.

Ferreira, L., Rosales, E., Danko, A.S., Sanromán, M.A., Pazos, M.M., 2016. Bacillus thuringiensis a promising bacterium for degrading emerging pollutants. Process Safety and Environmental Protection 101, 19-26.

Freundlich, H.M.F., 1906. Over the adsorption in solution. Journal of Physical Chemistry 57, 385-470.

García-Mateos, F.J., Ruiz-Rosas, R., Marqués, M.D., Cotoruelo, L.M., RodríguezMirasol, J., Cordero, T., 2015. Removal of paracetamol on biomass-derived activated carbon: Modeling the fixed bed breakthrough curves using batch adsorption experiments. Chemical Engineering Journal 279, 18-30. 
Gauthier, H., 2008. Biodegradation of pharmaceuticals by microorganisms, Department of Chemical Engineering McGill University, Montreal, p. 74.

Gavrilescu, M., Demnerová, K., Aamand, J., Agathos, S., Fava, F., 2015. Emerging pollutants in the environment: present and future challenges in biomonitoring, ecological risks and bioremediation. New Biotechnology 32, 147-156.

Geissen, V., Mol, H., Klumpp, E., Umlauf, G., Nadal, M., van der Ploeg, M., van de Zee, S.E.A.T.M., Ritsema, C.J., 2015. Emerging pollutants in the environment: A challenge for water resource management. International Soil and Water Conservation Research 3, 57-65.

Gil, M.J., Soto, A.M., Usma, J.I., Gutiérrez, O.D., 2012. Contaminantes emergentes en aguas, efectos y posibles tratamientos. Producción + Limpia 7, 52-73.

Gorito, A.M., Ribeiro, A.R., Almeida, C.M.R., Silva, A.M.T., 2017. A review on the application of constructed wetlands for the removal of priority substances and contaminants of emerging concern listed in recently launched EU legislation. Environmental Pollution 227, 428-443.

Gracia-Lor, E., Martínez, M., Sancho, J.V., Peñuela, G., Hernández, F., 2012. Multiclass determination of personal care products and pharmaceuticals in environmental and wastewater samples by ultra-high performance liquidchromatography-tandem mass spectrometry. Talanta 99, 1011-1023.

Grassi, M., Kaykioglu, G., Belgiorno, V., Lofrano, G., 2012. Removal of Emerging Contaminants from Water and Wastewater by Adsorption Process, in: Lofrano, G. (Ed.), Emerging Compounds Removal from Wastewater. Springer Netherlands, pp. 15-37.

Grossberger, A., Hadar, Y., Borch, T., Chefetz, B., 2014. Biodegradability of pharmaceutical compounds in agricultural soils irrigated with treated wastewater. Environmental Pollution 185, 168-177.

Haman, C., Dauchy, X., Rosin, C., Munoz, J.-F., 2015. Occurrence, fate and behavior of parabens in aquatic environments: A review. Water Research 68, 1-11.

Hassard, F., Biddle, J., Cartmell, E., Jefferson, B., Tyrrel, S., Stephenson, T., 2015. Rotating biological contactors for wastewater treatment - A review. Process Safety and Environmental Protection 94, 285-306. 
Heike Hoffmann, C.P., Martina Winker, Elisabeth von Muench, 2011. Technology review of constructed wetlands Subsurface flow constructed wetlands for greywater and domestic wastewater treatment. Deutsche Gesellschaft für, Eschborn, Alemania.

Hijosa-Valsero, M., Matamoros, V., Sidrach-Cardona, R., Martín-Villacorta, J., Bécares, E., Bayona, J.M., 2010. Comprehensive assessment of the design configuration of constructed wetlands for the removal of pharmaceuticals and personal care products from urban wastewaters. Water Research 44, 36693678 .

Hijosa-Valsero, M., Reyes-Contreras, C., Domínguez, C., Bécares, E., Bayona, J.M., 2016. Behaviour of pharmaceuticals and personal care products in constructed wetland compartments: Influent, effluent, pore water, substrate and plant roots. Chemosphere 145, 508-517.

Hijosa-Valsero, M., Sidrach-Cardona, R., Martín-Villacorta, J., Cruz Valsero-Blanco, M., Bayona, J.M., Bécares, E., 2011. Statistical modelling of organic matter and emerging pollutants removal in constructed wetlands. Bioresource Technology 102, 4981-4988.

Ho, J., Sung, S., 2010. Methanogenic activities in anaerobic membrane bioreactors (AnMBR) treating synthetic municipal wastewater. Bioresource Technology $101,2191-2196$.

Ho, Y.-S., 2004. Selection of optimum sorption isotherm. Carbon 42, 2113-2130

Ho, Y.-S., 2006. Review of second-order models for adsorption systems. Journal of Hazardous Materials 136, 681-689.

Ho, Y.S., McKay, G., 1998. Kinetic Models for the Sorption of Dye from Aqueous Solution by Wood. Process Safety and Environmental Protection 76, 183-191.

Ho, Y.S., Porter, J.F., McKay, G., 2002. Equilibrium Isotherm Studies for the Sorption of Divalent Metal Ions onto Peat: Copper, Nickel and Lead Single Component Systems. Water, Air, \& Soil Pollution 141, 1-33.

Hontela, A., Habibi, H.R., 2013. 8 - Personal Care Products in the Aquatic Environment: A Case Study on the Effects of Triclosan in Fish, in: Tierney, 
K.B., Farrell, A.P., Brauner, C.J. (Eds.), Fish Physiology. Academic Press, pp. 411-437.

Jones, O.A.H., Voulvoulis, N., Lester, J.N., 2007. The occurrence and removal of selected pharmaceutical compounds in a sewage treatment works utilising activated sludge treatment. Environmental Pollution 145, 738-744.

Jung, C., Son, A., Her, N., Zoh, K.-D., Cho, J., Yoon, Y., 2015. Removal of endocrine disrupting compounds, pharmaceuticals, and personal care products in water using carbon nanotubes: A review. Journal of Industrial and Engineering Chemistry 27, 1-11.

Kahl, S., Nivala, J., van Afferden, M., Müller, R.A., Reemtsma, T., 2017. Effect of design and operational conditions on the performance of subsurface flow treatment wetlands: Emerging organic contaminants as indicators. Water Research 125, 490-500.

Karunarathne, H.D.S.S., Amarasinghe, B.M.W.P.K., 2013. Fixed Bed Adsorption Column Studies for the Removal of Aqueous Phenol from Activated Carbon Prepared from Sugarcane Bagasse. Energy Procedia 34, 83-90.

Kasprzyk-Hordern, B., Dinsdale, R.M., Guwy, A.J., 2008. The occurrence of pharmaceuticals, personal care products, endocrine disruptors and illicit drugs in surface water in South Wales, UK. Water Research 42, 3498-3518.

Kasprzyk-Hordern, B., Dinsdale, R.M., Guwy, A.J., 2009. The removal of pharmaceuticals, personal care products, endocrine disruptors and illicit drugs during wastewater treatment and its impact on the quality of receiving waters. Water Research 43, 363-380.

Katsigiannis, A., Noutsopoulos, C., Mantziaras, J., Gioldasi, M., 2015. Removal of emerging pollutants through Granular Activated Carbon. Chemical Engineering Journal 280, 49-57.

Kim, S.H., Shon, H.K., Ngo, H.H., 2010. Adsorption characteristics of antibiotics trimethoprim on powdered and granular activated carbon. Journal of Industrial and Engineering Chemistry 16, 344-349.

Kolpin, D.W., Skopec, M., Meyer, M.T., Furlong, E.T., Zaugg, S.D., 2004. Urban contribution of pharmaceuticals and other organic wastewater contaminants to 
streams during differing flow conditions. Science of The Total Environment 328, 119-130.

Kovalova, L., Siegrist, H., von Gunten, U., Eugster, J., Hagenbuch, M., Wittmer, A., Moser, R., McArdell, C.S., 2013. Elimination of Micropollutants during PostTreatment of Hospital Wastewater with Powdered Activated Carbon, Ozone, and UV. Environmental Science \& Technology 47, 7899-7908.

Kruglova, A., Ahlgren, P., Korhonen, N., Rantanen, P., Mikola, A., Vahala, R., 2014. Biodegradation of ibuprofen, diclofenac and carbamazepine in nitrifying activated sludge under $12^{\circ} \mathrm{C}$ temperature conditions. Science of The Total Environment 499, 394-401.

Kümmerer, K., Al-Ahmad, A., 1997. Biodegradability of the Anti-tumour Agents 5Fluorouracil, Cytarabine, and Gemcitabine: Impact of the Chemical Structure and Synergistic Toxicity with Hospital Effluent. Acta Hydroch Hydrob 25, 166-172.

Lagergren, S., 1898. About the theory of so-called adsorption of soluble substances. Kun. Sven. Veten. HANDLINGAR 24, 1-39.

Langmuir, I., 1918. The adsorption of gases on plane surfaces of glass, mica and platinum. Journal of the American Chemical Society 40, 1361-1403.

Li, W., Shi, Y., Gao, L., Liu, J., Cai, Y., 2015a. Occurrence, fate and risk assessment of parabens and their chlorinated derivatives in an advanced wastewater treatment plant. Journal of Hazardous Materials 300, 29-38.

Li, X., Hai, F.I., Nghiem, L.D., 2011. Simultaneous activated carbon adsorption within a membrane bioreactor for an enhanced micropollutant removal. Bioresource Technology 102, 5319-5324.

Li, X., Xu, J., de Toledo, R.A., Shim, H., 2015b. Enhanced removal of naproxen and carbamazepine from wastewater using a novel countercurrent seepage bioreactor immobilized with Phanerochaete chrysosporium under non-sterile conditions. Bioresource Technol 197, 465-474. 
Li, Y., Zhu, G., Ng, W.J., Tan, S.K., 2014. A review on removing pharmaceutical contaminants from wastewater by constructed wetlands: Design, performance and mechanism. Science of The Total Environment 468-469, 908-932.

Li, Z.-H., Li, P., Randak, T., 2010. Ecotoxocological effects of short-term exposure to a human pharmaceutical Verapamil in juvenile rainbow trout (Oncorhynchus mykiss). Comparative Biochemistry and Physiology Part C: Toxicology \& Pharmacology 152, 385-391.

Li, Z., Xiang, X., Li, M., Ma, Y., Wang, J., Liu, X., 2015c. Occurrence and risk assessment of pharmaceuticals and personal care products and endocrine disrupting chemicals in reclaimed water and receiving groundwater in China. Ecotoxicology and Environmental Safety 119, 74-80.

Lide, D.R., 2004. Handbook of Chemistry and Physics, 85th ed. CRC Press, Florida.

Limousin, G., Gaudet, J.P., Charlet, L., Szenknect, S., Barthès, V., Krimissa, M., 2007. Sorption isotherms: A review on physical bases, modeling and measurement. Applied Geochemistry 22, 249-275.

Lin, Y.-L., Li, B.-K., 2016. Removal of pharmaceuticals and personal care products by Eichhornia crassipe and Pistia stratiotes. Journal of the Taiwan Institute of Chemical Engineers 58, 318-323.

López, O.J.B., 2014. Diseño de unidad piloto de humedales artificiales de flujo subsuperficial vertical para tratamiento de aguas residuales domesticas en el campus UMNG-CAJICÁ con fines de reusó, Facultad de Ciencias Naturales e Ingenieria. Universidad Jorge Tadeo Lozano, Facultad de Ciencias Naturales e Ingenieria, p. 79.

Ma, R., Wang, B., Yin, L., Zhang, Y., Deng, S., Huang, J., Wang, Y., Yu, G., 2017. Characterization of pharmaceutically active compounds in Beijing, China: Occurrence pattern, spatiotemporal distribution and its environmental implication. Journal of Hazardous Materials 323, 147-155.

Mailler, R., Gasperi, J., Coquet, Y., Buleté, A., Vulliet, E., Deshayes, S., Zedek, S., Mirande-Bret, C., Eudes, V., Bressy, A., Caupos, E., Moilleron, R., Chebbo, G., Rocher, V., 2016a. Removal of a wide range of emerging pollutants from wastewater treatment plant discharges by micro-grain activated carbon in 
fluidized bed as tertiary treatment at large pilot scale. Science of The Total Environment 542, 983-996.

Mailler, R., Gasperi, J., Coquet, Y., Derome, C., Buleté, A., Vulliet, E., Bressy, A., Varrault, G., Chebbo, G., Rocher, V., 2016b. Removal of emerging micropollutants from wastewater by activated carbon adsorption: Experimental study of different activated carbons and factors influencing the adsorption of micropollutants in wastewater. Journal of Environmental Chemical Engineering 4, 1102-1109.

Mailler, R., Gasperi, J., Coquet, Y., Deshayes, S., Zedek, S., Cren-Olivé, C., Cartiser, N., Eudes, V., Bressy, A., Caupos, E., Moilleron, R., Chebbo, G., Rocher, V., 2015. Study of a large scale powdered activated carbon pilot: Removals of a wide range of emerging and priority micropollutants from wastewater treatment plant effluents. Water Research 72, 315-330.

Majewsky, M., Gallé, T., Bayerle, M., Goel, R., Fischer, K., Vanrolleghem, P.A., 2011. Xenobiotic removal efficiencies in wastewater treatment plants: Residence time distributions as a guiding principle for sampling strategies. Water Res 45, 6152-6162.

Malachova, K., Rybkova, Z., Sezimova, H., Cerven, J., Novotny, C., 2013. Biodegradation and detoxification potential of rotating biological contactor (RBC) with Irpex lacteus for remediation of dye-containing wastewater. Water Res 47, 7143-7148.

Margot, J., Kienle, C., Magnet, A., Weil, M., Rossi, L., de Alencastro, L.F., Abegglen, C., Thonney, D., Chèvre, N., Schärer, M., Barry, D.A., 2013. Treatment of micropollutants in municipal wastewater: Ozone or powdered activated carbon? Science of The Total Environment 461-462, 480-498.

Mashayekh-Salehi, A., Moussavi, G., 2016. Removal of acetaminophen from the contaminated water using adsorption onto carbon activated with $\mathrm{NH} 4 \mathrm{Cl}$. Desalination and Water Treatment 57, 12861-12873.

Matamoros, V., Bayona, J.M., 2008. Behavior of Emerging Pollutants in Constructed Wetlands, in: Barceló, D., Petrovic, M. (Eds.), Emerging Contaminants from 
Industrial and Municipal Waste: Removal Technologies. Springer Berlin Heidelberg, Berlin, Heidelberg, 199-217.

Matamoros, V., García, J., Bayona, J.M., 2005. Behavior of Selected Pharmaceuticals in Subsurface Flow Constructed Wetlands: A Pilot-Scale Study. Environmental Science \& Technology 39, 5449-5454.

Matamoros, V., Gutiérrez, R., Ferrer, I., García, J., Bayona, J.M., 2015. Capability of microalgae-based wastewater treatment systems to remove emerging organic contaminants: A pilot-scale study. Journal of Hazardous Materials 288, 34-42.

Matamoros, V., Rodríguez, Y., Albaigés, J., 2016. A comparative assessment of intensive and extensive wastewater treatment technologies for removing emerging contaminants in small communities. Water Research 88, 777-785.

Matamoros, V., Rodríguez, Y., Bayona, J.M., 2017. Mitigation of emerging contaminants by full-scale horizontal flow constructed wetlands fed with secondary treated wastewater. Ecological Engineering 99, 222-227.

Matamoros, V., Salvadó, V., 2012. Evaluation of the seasonal performance of a water reclamation pond-constructed wetland system for removing emerging contaminants. Chemosphere 86, 111-117.

Mayorquín, C.M.R., 2011. Estudios de la contaminación de los recursos hídricos en la cuenca del Río San Pedro, previos a la construcción de una hidroeléctrica (P.H. Las Cruces) en Nayarit, México, Ciencias Biológicas y Ambientales. Universidad de Guadalajara, Centro Universitario de Ciencias Biológicas y Agropecuarias p. 170.

McCoy, M.A., Liapis, A.I., 1991. Evaluation of kinetic models for biospecific adsorption and its implications for finite bath and column performance. Journal of Chromatography A 548, 25-60.

Meinel, F., Sperlich, A., Jekel, M., 2016. Pilot-scale study of powdered activated carbon recirculation for micropollutant removal. Water Science and Technology 74, 927-934.

Mestre, A.S., Pires, J., Nogueira, J.M.F., Carvalho, A.P., 2007. Activated carbons for the adsorption of ibuprofen. Carbon 45, 1979-1988. 
Miège, C., Choubert, J.M., Ribeiro, L., Eusèbe, M., Coquery, M., 2009. Fate of pharmaceuticals and personal care products in wastewater treatment plants Conception of a database and first results. Environmental Pollution 157, 17211726.

Mohamed, M.O., Paleologos, E.K., 2018. Chapter 10 - Emerging Pollutants: Fate, Pathways, and Bioavailability, Fundamentals of Geoenvironmental Engineering. Butterworth-Heinemann, pp. 327-358.

Moldovan, Z., 2006. Occurrences of pharmaceutical and personal care products as micropollutants in rivers from Romania. Chemosphere 64, 1808-1817.

Montes-Grajales, D., Fennix-Agudelo, M., Miranda-Castro, W., 2017. Occurrence of personal care products as emerging chemicals of concern in water resources: A review. Science of The Total Environment 595, 601-614.

Mottaleb , M., Bellamy, M., Mottaleb, M., Islam, M., 2015. Use of LCMS and GCMS Methods to Measure Emerging Contaminants Pharmaceutical and Personal Care Products (PPCPs) in Fish. Journal of Chromatography \& Separation Techniques 6, 5-9.

Munz, G., Gori, R., Mori, G., Lubello, C., 2007. Powdered activated carbon and membrane bioreactors (MBRPAC) for tannery wastewater treatment: long term effect on biological and filtration process performances. Desalination 207, 349360.

Naipal, E., 2014. Critical design parameters of subsurface flow constructed wetlands for the removal of organic micro pollutants from wastewater. Wageningen Univerity, Wageningen.

Nielsen, L., Biggs, M.J., Skinner, W., Bandosz, T.J., 2014. The effects of activated carbon surface features on the reactive adsorption of carbamazepine and sulfamethoxazole. Carbon 80, 419-432.

Niemuth, N.J., Klaper, R.D., 2015. Emerging wastewater contaminant metformin causes intersex and reduced fecundity in fish. Chemosphere 135, 38-45.

Nieto, A., Peschka, M., Borrull, F., Pocurull, E., Marcé, R.M., Knepper, T.P., 2010. Phosphodiesterase type V inhibitors: Occurrence and fate in wastewater and sewage sludge. Water Research 44, 1607-1615. 
Onesios, K.M., Yu, J.T., Bouwer, E.J., 2009. Biodegradation and removal of pharmaceuticals and personal care products in treatment systems: a review. Biodegradation 20, 441-466.

Ortiz de García, S., Pinto Pinto, G., García Encina, P., Irusta Mata, R., 2013. Consumption and occurrence of pharmaceutical and personal care products in the aquatic environment in Spain. Science of The Total Environment 444, 451465.

Özengin, N., Elmaci, A., 2016. Removal of Pharmaceutical Products in a Constructed Wetland. Iranian Journal of Biotechnology 14, 221-229.

Pakshirajan, K., Kheria, S., 2012. Continuous treatment of coloured industry wastewater using immobilized Phanerochaete chrysosporium in a rotating biological contactor reactor. J Environ Manage 101, 118-123.

Patwardhan, A.W., 2003. Rotating Biological Contactors: A Review. Industrial \& Engineering Chemistry Research 42, 2035-2051.

Pearce, C.I., Lloyd, J.R., Guthrie, J.T., 2003. The removal of colour from textile wastewater using whole bacterial cells: a review. Dyes and Pigments 58, 179196.

Pérez, M.R., Rossi, A.S., Bacchetta, C., Elorriaga, Y., Carriquiriborde, P., Cazenave, J., 2018. In situ evaluation of the toxicological impact of a wastewater effluent on the fish Prochilodus lineatus: biochemical and histological assessment. Ecological Indicators 84, 345-353.

Petrie, B., Barden, R., Kasprzyk-Hordern, B., 2015. A review on emerging contaminants in wastewaters and the environment: Current knowledge, understudied areas and recommendations for future monitoring. Water Research 72, 3-27.

Petrie, B., Smith, B.D., Youdan, J., Barden, R., Kasprzyk-Hordern, B., 2017. Multiresidue determination of micropollutants in Phragmites australis from constructed wetlands using microwave assisted extraction and ultra-highperformance liquid chromatography tandem mass spectrometry. Analytica Chimica Acta 959, 91-101. 
Petrović, M., Gonzalez, S., Barceló, D., 2003. Analysis and removal of emerging contaminants in wastewater and drinking water. TrAC Trends in Analytical Chemistry 22, 685-696.

Plazinski, W., 2010. Applicability of the film-diffusion model for description of the adsorption kinetics at the solid/solution interfaces. Applied Surface Science $256,5157-5163$.

Pomati F., Castiglioni S., ZuccatoE., Fanelli R., Vigetti D., Rossetti C., 2006. Effects of a complex mixture of therapeutic drugs at environmental levels on human embryonic cells. Environmental Scince and Technology 40, 2442-2447.

Pope, R.L., 1978 Effect of cell residence time on nitrification with a rotating biological contactor system., Sanitary Engineering Georgia Institute of Technology Georgia p. 140.

Putra, E.K., Pranowo, R., Sunarso, J., Indraswati, N., Ismadji, S., 2009. Performance of activated carbon and bentonite for adsorption of amoxicillin from wastewater: Mechanisms, isotherms and kinetics. Water Research 43, 24192430 .

Ramos, M. 2018. Distribución ambiental de productos de cuidado personal en ambientes acuáticos. Tesis de grado para optar al título de Licenciada en Química y Tecnología Ambiental, Universidad Nacional de La Plata, Facultad de Ciencias Exactas, pp. 98.

Rashed, M.N., 2013. Adsorption Technique for the Removal of Organic Pollutants from Water and Wastewater.

Real, F.J., Benitez, F.J., Acero, J.L., Casas, F., 2017. Adsorption of selected emerging contaminants onto PAC and GAC: Equilibrium isotherms, kinetics, and effect of the water matrix. Journal of Environmental Science and Health, Part A 52, 727-734.

Reddy, K., DeLaune, R., 2008. Biogeochemistry of Wetlands. CRC Press, Boca Raton.

Reyes-Contreras, C., Hijosa-Valsero, M., Sidrach-Cardona, R., Bayona, J.M., Bécares, E., 2012. Temporal evolution in PPCP removal from urban wastewater by 
constructed wetlands of different configuration: A medium-term study. Chemosphere 88, 161-167.

Reyilla, J.A.B., 1993. Depuración de aguas residuales en un contactor biológico rotativo (rbc) con alternancia en el sentido del flujo, Departamento de Ciencias y Técnicas del Agua y del Medio Ambiente Universidad de Cantabria, Universidad de Cantabria Escuela Superior de la Marina Civil p. 47.

Richardson, S.D., 2010. Environmental Mass Spectrometry: Emerging Contaminants and Current Issues. Analytical Chemistry 82, 4742-4774.

Rivera-Utrilla, J., Sánchez-Polo, M., Ferro-García, M.Á., Prados-Joya, G., OcampoPérez, R., 2013. Pharmaceuticals as emerging contaminants and their removal from water. A review. Chemosphere 93, 1268-1287.

Roberts, J., Kumar, A., Du, J., Hepplewhite, C., Ellis, D.J., Christy, A.G., Beavis, S.G., 2016. Pharmaceuticals and personal care products (PPCPs) in Australia's largest inland sewage treatment plant, and its contribution to a major Australian river during high and low flow. Science of The Total Environment 541, 1625 1637.

Roca, R.a., 2016. Determination of emerging contaminants in environmental matrices, Química y Tecnología de Alimentos. Universidad Politécnica de Madrid, Escuela Técnica Superior de Ingenieros Agrónomos, p. 285.

Rodriguez-Narvaez, O.M., Peralta-Hernandez, J.M., Goonetilleke, A., Bandala, E.R., 2017. Treatment technologies for emerging contaminants in water: A review. Chemical Engineering Journal 323, 361-380.

Rodriguez, E., Campinas, M., Acero, J.L., Rosa, M.J., 2016. Investigating PPCP Removal from Wastewater by Powdered Activated Carbon/Ultrafiltration. Water, Air, \& Soil Pollution 227, 177.

Rojo, M.G., 2016. Estudios de residuos de compuestos farmacéuticos de uso humano en músculos de peces de interés comercial del Río Uruguay, Facultad de Ciencias Exactas. Universidad Nacional de la PLata, Centro de Invetigaciones del Medio Ambiente, p. 47. 
Rosal, R., Rodríguez, A., Perdigón-Melón, J.A., Petre, A., García-Calvo, E., Gómez, M.J., Agüera, A., Fernández-Alba, A.R., 2010. Occurrence of emerging pollutants in urban wastewater and their removal through biological treatment followed by ozonation. Water Research 44, 578-588.

Rossner, A., Snyder, S.A., Knappe, D.R.U., 2009. Removal of emerging contaminants of concern by alternative adsorbents. Water Research 43, 3787-3796.

Saeed, T., Sun, G., 2012. A review on nitrogen and organics removal mechanisms in subsurface flow constructed wetlands: Dependency on environmental parameters, operating conditions and supporting media. Journal of Environmental Management 112, 429-448.

SANTE 11945/2015. Guidance document on analytical quality control and method validation procedures for pesticides residues analysis in food and feed. European Commission Directorate - General for Health and Food Safety.

Sarkar, M., Acharya, P.K., Bhattacharya, B., 2003. Modeling the adsorption kinetics of some priority organic pollutants in water from diffusion and activation energy parameters. Journal of Colloid and Interface Science 266, 28-32.

Schäfer, A.I., Nghiem, L.D., Waite, T.D., 2003. Removal of the Natural Hormone Estrone from Aqueous Solutions Using Nanofiltration and Reverse Osmosis. Environmental Science \& Technology 37, 182-188.

Scholz, M., 2006. Chapter 17 - Rotating biological contactors, Wetland Systems to Control Urban Runoff. Elsevier, Amsterdam, pp. 111-113.

Scholz, M., Lee, B.h., 2005. Constructed wetlands: a review. International Journal of Environmental Studies 62, 421-447.

Schwertz, F.A., 1950. Rate-Indicating Mariotte Bottle. Analytical Chemistry 22, 12141216.

Secondes, F.N., Naddeo, V., Belgiorno, V., Ballesteros, F., 2014. Removal of emerging contaminants by simultaneous application of membrane ultrafiltration, activated carbon adsorption, and ultrasound irradiation. Journal of Hazardous Materials 264, 342-349. 
Shaver, D., 2011. Sources and Fate of Emerging Contaminants in Municipal Wastewater Treatment., Engineering. University of Guelph, Guelph, Ontario, Canada, p. 99.

Shrestha, S., Kazama, F., 2007. Assessment of surface water quality using multivariate statistical techniques: A case study of the Fuji river basin, Japan. Environ Modell Softw 22, 464-475.

Sing, K.S.W., 2008. Chapter One - Overview of Physical Adsorption by Carbons, in: Bottani, E.J., Tascón, J.M.D. (Eds.), Adsorption by Carbons. Elsevier, Amsterdam, pp. 3-14.

Singh, R., Paul, D., Jain, R.K., 2006. Biofilms: implications in bioremediation. Trends Microbiol 14, 389-397.

Snyder, S.A., Adham, S., Redding, A.M., Cannon, F.S., DeCarolis, J., Oppenheimer, J., Wert, E.C., Yoon, Y., 2007. Role of membranes and activated carbon in the removal of endocrine disruptors and pharmaceuticals. Desalination 202, 156181.

Sotelo, J.L., Ovejero, G., Rodríguez, A., Álvarez, S., García, J., 2013. Adsorption of Carbamazepine in Fixed Bed Columns: Experimental and Modeling Studies. Separation Science and Technology 48, 2626-2637.

Stackelberg, P.E., Furlong, E.T., Meyer, M.T., Zaugg, S.D., Henderson, A.K., Reissman, D.B., 2004. Persistence of pharmaceutical compounds and other organic wastewater contaminants in a conventional drinking-water-treatment plant. Science of The Total Environment 329, 99-113.

Stoykova, M., Koumanova, B., Mörl, L., 2013. Adsortive removal of carbamazepine fron wastewater by activated charcoals. Journal of Chemical Technology and Metallurgy 48, 469-474.

Streicher, J., Ruhl, A.S., Gnirß, R., Jekel, M., 2016. Where to dose powdered activated carbon in a wastewater treatment plant for organic micro-pollutant removal. Chemosphere 156, 88-94.

Stuart, M., Lapworth, D., Crane, E., Hart, A., 2012. Review of risk from potential emerging contaminants in UK groundwater. Sci total Environ 416, 1-21. 
Sui, Q., Cao, X., Lu, S., Zhao, W., Qiu, Z., Yu, G., 2015. Occurrence, sources and fate of pharmaceuticals and personal care products in the groundwater: A review. Emerg Contaminants 1, 14-24.

Sundaravadivel, M., Vigneswaran, S., 2001. Constructed Wetlands for Wastewater Treatment. Critical Reviews in Environmental Science and Technology 31, 351-409.

Supit, S.W.M., Shaikh, F.U.A., 2015. Durability properties of high volume fly ash concrete containing nano-silica. Materials and Structures 48, 2431-2445.

Suriyanon, N., Punyapalakul, P., Ngamcharussrivichai, C., 2013. Mechanistic study of diclofenac and carbamazepine adsorption on functionalized silica-based porous materials. Chemical Engineering Journal 214, 208-218.

Suzuki, M., 1993. Fundamentals of adsorption. Elsevier.

Taty-Costodes, V.C., Fauduet, H., Porte, C., Ho, Y.-S., 2005. Removal of lead (II) ions from synthetic and real effluents using immobilized Pinus sylvestris sawdust: Adsorption on a fixed-bed column. Journal of Hazardous Materials $123,135-144$.

Taylor P. J., 2005. Matrix effects: The Achilles heel of quantitative high-performance liquid chromatography-electrospray-tandem mass spectrometry. Clinical Biochemistry 38, 328-334.

Tejeda, A., Torres-Bojorges, Á.X., Zurita, F., 2017. Carbamazepine removal in three pilot-scale hybrid wetlands planted with ornamental species. Ecological Engineering 98, 410-417.

Ternes, T.A., 1998. Occurrence of drugs in German sewage treatment plants and rivers. Water Research 32, 3245-3260.

Torrellas, S.Á., García Lovera, R., Escalona, N., Sepúlveda, C., Sotelo, J.L., García, J., 2015a. Chemical-activated carbons from peach stones for the adsorption of emerging contaminants in aqueous solutions. Chemical Engineering Journal $279,788-798$.

Torrellas, S.A., Rodriguez, A.R., Escudero, G.O., Martín, J.M.G., Rodriguez, J.G., 2015b. Comparative evaluation of adsorption kinetics of diclofenac and 
isoproturon by activated carbon. Journal of Environmental Science and Health, Part A 50, 1241-1248.

Travaini, F., Sipaúba, L.H., 2012. Efficiency of a constructed wetland for wastewaters treatment. Acta Limnologica Brasiliensia 24, 255-265.

Trgo, M., Vukojevi, N., Medvidovi, Peri, J., 2011. Application of mathematical empirical models to dynamic removal of lead on natural zeolite clinoptilolite in a fixed bed column. Indian Journal of Chemical Technology 18, 123-131.

Valdés, M.E., Marino, D.J., Wunderlin, D.A., Somoza, G.M., Ronco, A.E., Carriquiriborde, P., 2015. Screening Concentration of E1, E2 and EE2 in Sewage Effluents and Surface Waters of the "Pampas" Region and the "Río de la Plata" Estuary (Argentina). Bulletin of Environmental Contamination and Toxicology 94, 29-33.

Vasiliadou, I.A., Molina, R., Martínez, F., Melero, J.A., 2014. Experimental and modeling study on removal of pharmaceutically active compounds in rotating biological contactors. Journal of Hazardous Materials 274, 473-482.

Verlicchi, P., Zambello, E., 2014. How efficient are constructed wetlands in removing pharmaceuticals from untreated and treated urban wastewaters? A review. Science of The Total Environment 470-471, 1281-1306.

Verlicchi, P., Zambello, E., Al Aukidy, M., 2015. Removal of Personal Care Products in Constructed Wetlands, in: Díaz-Cruz, M.S., Barceló, D. (Eds.), Personal Care Products in the Aquatic Environment. Springer International Publishing, Cham, pp. 319-353.

Vieira, C.E.D., Costa, P.G., Lunardelli, B., de Oliveira, L.F., da Costa Cabrera, L., Risso, W.E., Primel, E.G., Meletti, P.C., Fillmann, G., Bueno dos Reis Martinez, C., 2016. Multiple biomarker responses in Prochilodus lineatus subjected to short-term in situ exposure to streams from agricultural areas in Southern Brazil. Science of The Total Environment 542, 44-56.

Webb, S., Ternes, T., Gibert, M., Olejniczak, K., 2003. Indirect human exposure to pharmaceuticals via drinking water. Toxicology Letters 142, 157-167.

Westerhoff, P., F. Sharif, R. Halden, P. Herckes, AND R. Krajmalnik-Brown, 2014. Constructed Wetlands for Treatment of Organic and Engineered Nanomaterial 
Contaminants of Emerging Concerns (WaterRF Report 4334). Environmental Protection Agency, Denver, Co, p. 112.

Westerhoff, P., Yoon, Y., Snyder, S., Wert, E., 2005. Fate of Endocrine-Disruptor, Pharmaceutical, and Personal Care Product Chemicals during Simulated Drinking Water Treatment Processes. Environmental Science \& Technology 39, 6649-6663.

Williams, M., Kookana, R.S., Mehta, A., Yadav, S.K., Tailor, B.L., Maheshwari, B., 2019. Emerging contaminants in a river receiving untreated wastewater from an Indian urban centre. Science of The Total Environment 647, 1256-1265.

Worch, E., 2012. Adsorption Technology in Water Treatment: Fundamentals, Processes, and Modeling. Dresden University of Technology, Germany.

Wu, F.-C., Liu, B.-L., Wu, K.-T., Tseng, R.-L., 2010. A new linear form analysis of Redlich-Peterson isotherm equation for the adsorptions of dyes. Chemical Engineering Journal 162, 21-27.

Wu, F.-C., Tseng, R.-L., Juang, R.-S., 2001. Kinetic modeling of liquid-phase adsorption of reactive dyes and metal ions on chitosan. Water Research 35, 613-618.

Wu, F.-C., Tseng, R.-L., Juang, R.-S., 2009. Initial behavior of intraparticle diffusion model used in the description of adsorption kinetics. Chemical Engineering Journal 153, 1-8.

Xagoraraki, I., Kuo, D., 2008. Water Pollution: Emerging Contaminants Associated with Drinking Water A2 - Heggenhougen, Harald Kristian (Kris), International Encyclopedia of Public Health. Academic Press, Oxford, pp. 539-550.

Xu, J., Wang, L., Zhu, Y., 2012. Decontamination of Bisphenol A from Aqueous Solution by Graphene Adsorption. Langmuir 28, 8418-8425.

Xu, Z., Cai, J.-g., Pan, B.-c., 2013. Mathematically modeling fixed-bed adsorption in aqueous systems. Journal of Zhejiang University SCIENCE A 14, 155-176.

Yamaguchi, T., Ishida, M., Suzuki, T., 1999. Biodegradation of hydrocarbons by Prototheca zopfii in rotating biological contactors. Process Biochem 35, 403409. 
Yan, G., Viraraghavan, T., Chen, M., 2001. A New Model for Heavy Metal Removal in a Biosorption Column. Adsorption Science \& Technology 19, 25-43.

Yang, X., Flowers, R.C., Weinberg, H.S., Singer, P.C., 2011. Occurrence and removal of pharmaceuticals and personal care products (PPCPs) in an advanced wastewater reclamation plant. Water Research 45, 5218-5228.

Yang, Y.-Y., Liu, W.-R., Liu, Y.-S., Zhao, J.-L., Zhang, Q.-Q., Zhang, M., Zhang, J.N., Jiang, Y.-X., Zhang, L.-J., Ying, G.-G., 2017. Suitability of pharmaceuticals and personal care products (PPCPs) and artificial sweeteners (ASs) as wastewater indicators in the Pearl River Delta, South China. Science of The Total Environment 590-591, 611-619.

Yee-Batista, C., 2013. Un 70\% de las aguas residuales de Latinoamérica vuelven a los ríos sin ser tratadas, Un 70\% de las aguas residuales de Latinoamérica vuelven a los ríos sin ser tratadas. Banco Mundial, Buenos Aires.

Yu, Z., Peldszus, S., Huck, P., Anderson, W., 2009. Removal of Selected Pharmaceuticals and Endocrine Disrupting Substances Using Granular Activated Carbon Isotherm and Kinetic Studies. Dept. of Civil Engineering, University of Waterloo, Canada.

Yu, Z., Peldszus, S., Huck, P.M., 2008. Adsorption characteristics of selected pharmaceuticals and an endocrine disrupting compound-Naproxen, carbamazepine and nonylphenol—on activated carbon. Water Research 42, 2873-2882.

Zenobio, J.E., Sanchez, B.C., Leet, J.K., Archuleta, L.C., Sepúlveda, M.S., 2015. Presence and effects of pharmaceutical and personal care products on the Baca National Wildlife Refuge, Colorado. Chemosphere 120, 750-755.

Zhang, D.Q., Gersberg, R.M., Hua, T., Zhu, J., Tuan, N.A., Tan, S.K., 2012. Pharmaceutical removal in tropical subsurface flow constructed wetlands at varying hydraulic loading rates. Chemosphere 87, 273-277.

Zhang, D.Q., Hua, T., Gersberg, R.M., Zhu, J., Ng, W.J., Tan, S.K., 2013. Carbamazepine and naproxen: Fate in wetland mesocosms planted with Scirpus validus. Chemosphere 91, 14-21. 
Zhang, Y., Geiben, S.U., 2010. Prediction of carbamazepine in sewage treatment plant effluents and its implications for control strategies of pharmaceutical aquatic contamination. Chemosphere 80, 1345-1352.

Zhang, Y., Geiben, S.U., Gal, C., 2008. Carbamazepine and diclofenac: Removal in wastewater treatment plants and occurrence in water bodies. Chemosphere 73, 1151-1161.

Zhao, C., Xie, H., Mu, Y., Xu, X., Zhang, J., Liu, C., Liang, S., Ngo, H.H., Guo, W., Xu, J., Wang, Q., 2014. Bioremediation of endosulfan in laboratory-scale constructed wetlands: effect of bioaugmentation and biostimulation. Environmental Science and Pollution Research 21, 12827-12835.

Zhao, D., Zhang, J., Duan, E., Wang, J., 2008. Adsorption equilibrium and kinetics of dibenzothiophene from n-octane on bamboo charcoal. Applied Surface Science $254,3242-3247$. 